Trabajo de Tesis para optar al título de Doctor en Comunicación

RECUPERACIÓN DE MEMORIAS, IMAGINACIONES POÉTICAS, INTERPELACIONES EDUCATIVAS Y HORIZONTES DE EMANCIPACIÓN

Una articulación entre prácticas de comunicación/educación y museología social latinoamericana en espacios museales

Mg. Darío Gastón Artiguenave

Facultad de Periodismo y Comunicación Social - Universidad Nacional de La Plata 



\section{RECUPERACIÓN DE MEMORIAS, IMAGINACIONES POÉTICAS, INTERPELACIONES EDUCATIVAS Y HORIZONTES DE EMANCIPACIÓN}

Una articulación entre prácticas de comunicación/educación y museología social latinoamericana en espacios museales

Postulante:

Mg. Darío Gastón Artiguenave

Doctorado en Comunicación

Director:

Dr. Darío Gabriel Martínez

Codirectora:

Prof. María Belén Fernández 
ARTIGUENAVE, Darío Gastón (2018)

RECUPERACIÓN DE MEMORIAS, IMAGINACIONES POÉTICAS, INTERPELACIONES EDUCATIVAS Y HORIZONTES

DE EMANCIPACIÓN. Una articulación entre prácticas de comunicación/educación y museología social latinoamericana en espacios museales

Trabajo de Tesis para optar al título de Doctor en Comunicación

Director: Dr. Darío Gabriel Martínez - Codirectora: Prof. María Belén Fernández

Facultad de Periodismo y Comunicación Social

Universidad Nacional de La Plata

La Plata, Argentina

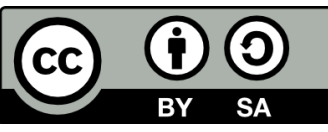

Esta obra está sujeta a la licencia Reconocimiento-Compartir Igual 4.0 Internacional de Creative Commons Para ver una copia de esta licencia, visite http://creativecommons.org/licenses/by-sa/4.0/ 


\section{INDICE}

\section{Introducción}

Objetivos iniciales y contexto de producción

pág. 11

\section{Capítulo 1}

Algunos posicionamientos antes de empezar
-Institucionalización del campo comunicación/educación en la FPYCS UNLP
- Creación del Centro de Comunicación y Educación
-Implementación del Profesorado en Comunicación Social
- Aportes de Jorge Huergo y la cátedra de Comunicación/Educación
- Congreso CoMEDU 2012
-Maestría en Comunicación y Educación
-Reforma Curricular del Profesorado
-La interpelación de las memorias del campo comunicación/educación
-Comunicación/educación popular
-El horizonte del "buen vivir"
-Descolonizar la mirada
-Comunicación/educación popular como matriz transversal

pág. 17

pág. 17

pág. 17

pág. 18

pág. 19

pág. 21

pág. 22

pág. $\quad 23$

pág. 26

pág. 30

pág. $\quad 32$

pág. $\quad 33$

pág. 36

\section{Capítulo 2}

Estudios culturales, interpelaciones y memorias populares

pág. $\quad 39$

-El poder y la lucha como problema

pág. 40

-En busca de la complejidad perdida

pág. 42

-La interpelación de lo popular

pág. 44 
-Lo popular y las tradiciones

pág. 46

- La cultura popular o lo otro excluido

pág. $\quad 49$

-Los estudios culturales y el proyecto decolonial

pág. $\quad 50$

- Historia popular y memoria colectiva

pág. $\quad 52$

-Recuperación de la experiencia

pág. 55

-Experiencia

pág. 56

-Experiencia social

pág. 56

-Sistematización de experiencias

pág. $\quad 58$

-Sistematización de experiencias: camino de conocimiento de

los procesos latinoamericanos

pág. 59

-Sistematización de experiencias educativas

pág. 62

-Sistematización de experiencias educativas y sujetos de conocimiento

pág. $\quad 64$

-Recuperación de la experiencia y construcción subjetiva

pág. 66

-Biografía y reflexividad

pág. $\quad 67$

-La gravitación del giro hermenéutico

pág. 68

-La narración biográfica y el conocimiento biográfico

pág. 69

-Sinuosos caminos de frontera

pág. $\quad 70$

- ¿De qué hablamos cuando nos biografiamos?

pág. $\quad 71$

-Potencialidad reflexiva del ejercicio biográfico

pág. $\quad 72$

\section{Capítulo 3}

Voces, experiencias y tramas que protagonizaron la investigación

$\begin{array}{ll}\text { pág. } & 73 \\ \text { pág. } & 74 \\ \text { pág. } & 76 \\ \text { pág. } & 77 \\ \text { pág. } & 78 \\ \text { pág. } & 79 \\ \text { pág. } & 79 \\ \text { pág. } & 80 \\ \text { pág. } & 81 \\ \text { pág. } & 83 \\ \text { pág. } & 84 \\ \text { pág. } & 84 \\ \text { pág. } & 85 \\ \text { pág. } & 86 \\ \text { pág. } & 86 \\ \text { pág. } & 87\end{array}$

-Algunas precisiones sobre el objeto de investigación

-Sobre la entrevista en profundidad

-La trama de acceso a las fuentes

-Analía Bernardi

-Leonardo Casado

-Participación en el encuentro de MINOM en Córdoba

-Sujetos clave que es necesario nombrar

- Participación en instancias de encuentro

- Olga Bartolomé

-Julieta Rausch

- Verónica Stáffora

-Anabelle Castaño

-Carlos Molina

- Verónica Jeria

pág. 


\section{Capítulo 4}

\section{Los museos, la construcción de la historia y la memoria}

- Historización de los modos de hacer museo

-El coleccionismo

-El patrimonio como objeto de transmisión cultural

-El inicio de las exposiciones masivas

-Otros espacios de exhibición en el Río de la Plata

-La República de los Niños

-Feria de América (1954)

-Tecnópolis

-La ampliación del acceso al museo como horizonte político

-Los museos de historia y las configuraciones del tiempo histórico

-Dejar el pasado y mirar al futuro

-En busca de un nuevo pasado

-Revisionismo histórico

-Memoria, Verdad, Justicia

-Los festejos del Bicentenario (2010)

-Los festejos del Bicentenario de la Independencia (2016)

-La producción museográfica en contexto histórico pág. 91

pág. 91

pág. 91

pág. 93

pág. 95

pág. 96

pág. 98

pág. 102

pág. 104

pág. 107

pág. 108

pág. 109

pág. 110

pág. 112

pág. 118

pág. 120

pág. 123

pág. 124

\section{Capítulo 5}

Algunas especificaciones en el campo de la museología

pág. $\quad 127$

-Recuperación de diversas perspectivas en el campo de la museología

pág. $\quad 127$

-El museo como lugar para los cuerpos

pág. $\quad 130$

-La educación EN los museos

pág. $\quad 130$

-Museos hacia la comunidad y el representante del

público (perspectiva anglosajona)

pág. $\quad 131$

-Los museos para niños y los museos de ciencia

pág. 132

-La nueva museología (perspectiva francesa y española)

pág. $\quad 133$

-Museología crítica

pág. 134

-La perspectiva latinoamericana desde la "Mesa de Santiago" (1972)

pág. $\quad 137$ 
-Cambios de eje y propuestas de diálogo

pág. 139

-Lectura crítica de los museos y su relación con el entorno

pág. 141

-Algunos detalles de la declaración de la Mesa de Santiago

pág. 143

-Legados conceptuales de la Mesa de Santiago

pág. 145

-Los museos comunitarios a la mexicana

pág. 147

-El museo Ambrosetti en la Universidad Nacional y Popular de Buenos Aires (1973)

pág. 152

-Continuidad de la museología latinoamericana

pág. 156

-La conferencia de MINOM en Córdoba (2017)

pág. 159

-"Hay una gota de sangre en cada museo"

pág. 161

\section{Capítulo 6}

\section{Desarrollo de la recuperación de sentidos y experiencias}

\begin{tabular}{|c|c|}
\hline a partir de las entrevistas & pág. \\
\hline -Matriz de interpretación de los sentidos producidos en las entrevistas & pág. \\
\hline -La configuración de los sentidos del proyecto en el marco de un museo & pág. \\
\hline -Algunos datos de contexto & pág. \\
\hline -Epistemología crítica y la pregunta por el sentido & pág. \\
\hline -Reconocimiento de conflictos y resistencias & pág. \\
\hline -La importancia del horizonte político de intervención & pág. \\
\hline -Deconstrucción decolonial del museo & pág. \\
\hline -Deconstrucción decolonial del patrimonio & pág. \\
\hline -Abriendo a las comunidades, nuevos roles, nuevas miradas & pág. \\
\hline -Ampliar el acceso de las comunidades & pág. \\
\hline -El acceso a partir de actividades culturales & pág. \\
\hline -Garantizar derechos desde lo público & pág. \\
\hline -Espacios de gestión y solidaridad colectiva & pág. \\
\hline -Intervenciones para la memoria desde los lenguajes & pág. \\
\hline -El doble filo & pág. \\
\hline -La pregunta para abrir el juego y no responsabilizar al otro por lo que no sabe & pág. \\
\hline -Mirada desde lo cotidiano & pág. \\
\hline -Las imaginaciones poéticas & pág. \\
\hline -El presente como tiempo privilegiado para pensar & pá \\
\hline -Interpelaciones subjetivas y su dimensión formativa & pág. \\
\hline -Una mirada integral de las interpelaciones formativas & pág. \\
\hline -Ver más allá de lo evidente y descubrir lo que negamos & pág. \\
\hline - ¿Y las manzanas verdes? & pág. \\
\hline
\end{tabular}


-Los procesos también van por dentro

pág. 215

-Una trama para potenciar horizontes políticos

pág. 216

-Referencias compartidas

pág. 217

-Redes de formación profesional

pág. 218

- Romper el cerco (Asociación de Trabajadores de Museos - ATM)

pág. 221

-Encuentro de Educadores de Museos (Córdoba)

pág. 224

- Hacia la construcción de una conciencia colectiva

pág. 226

-Articulaciones con el sistema de formación

pág.

227

\section{Capítulo 7}

Abrir para no cerrar. Dimensión política de los espacios sociales de formación

pág. $\quad 231$

Bibliografía

pág. $\quad 241$ 


\section{Agradecimientos}

A Manuela, mi compañera, por aguantarme en todas, por los proyectos, por seguir aprendiendo juntos.

A mi familia.

A Silvia Durá y Santiago Pagura con quienes compartí la primer aventura de Museo, y de algún modo también marcaron parte de este camino.

A Analía Bernardi, Leonardo Casado, Olga Bartolomé, Julieta Rausch, Verónica Stáffora, Anabelle Castaño, Carlos Molina, Verónica Jeria y Susana Maresca, quienes se prestaron a participar de esta investigación.

A María Belén Fernández y a Darío Martínez por su generosidad en el acompañamiento paciente, meticuloso y amoroso.

A la comunidad de la Facultad de Periodismo y Comunicación Social por construir y sostener de manera cotidiana un proyecto profundamente colectivo que se demuestra en acciones.

A los equipos de la Secretaría de Posgrado y la Secretaría de Investigaciones Científicas que aportan a que estos procesos sean mucho más disfrutables.

A profesores, profesoras y compañeres del Doctorado en Comunicación y de la Maestría en Comunicación y Educación, con quienes seguimos sosteniendo intercambios profundos.

A los compañeros y compañeras de la Secretaría de Extensión, en especial Agustín Martinuzzi y Federico Araneta, con quienes he compartido experiencias formativas fundamentales.

A los compañeros y compañeras de las cátedras Taller de Análisis de la Comunicación en las Instituciones Educativas, y del Taller de Técnicas de Animación Sociocultural.

A Jorge Huergo y su camino lleno de vitalidad y alegría que nos sigue marcando horizontes posibles. 


\section{Introducción OBJETIVOS INICIALES Y CONTEXTO DE PRODUCCIÓN}

El presente trabajo de tesis se propone producir una articulación entre los campos de la museología social latinoamericana y el campo comunicación/educación, considerando que puede tratarse de un aporte que colabore, desde la discusión y la vinculación crítica, con la apertura -o el ensanchamiento- y actualización de los márgenes y relaciones de ambos campos.

Si bien creo que no se han establecido diálogos explícitos, ambos campos comparten una historia común. Ambos parten del reconocimiento de los sujetos de sus territorios y se construyen conceptualmente como configurados a partir de las interpelaciones de diversos problemas y experiencias de luchas -de orden político- que se han desarrollado en el continente: a partir de los efectos de la colonización, las luchas por la emancipación popular de mediados de Siglo XX, los efectos de las políticas producidas por el desarrollismo bajo la denominada Alianza para el Progreso en los '60, los movimientos revolucionarios de los '60 y '70, las dictaduras de los '70/'80, los movimientos de alfabetización, los movimientos sociales de base, las peleas por la posesión de la tierra, los movimientos de recuperación popular indígena, el acompañamiento a colectivos migrantes, a aquellos que luchan por el reconocimiento de las identidades diversas, así como a las acciones vinculadas a políticas públicas socioeducativas propiciadas por los gobiernos de corte popular que se dieron en diversos países de la región en los primeros años de este siglo, y a la resistencia a las políticas discriminatorias y de deshistorización de estos últimos años, entre otros.

Dentro de esa historia común, se dan diversos puntos de contacto en los que comparten referentes teóricos y culturales, trabajan con experiencias territoriales similares -principalmente de sectores populares-, y sobre todo comparten la vocación de intervenir en la construcción política asociada a las diversas luchas por la emancipación latinoamericana.

En ese sentido, la presente investigación buscó construir una cartografía que articule ámbitos, prácticas, problemas y matrices conceptuales de ambos campos a partir del intercambio con referentes empíricos que se inscriben en el campo de la museología social latinoamericana y que se desempeñan en espacios museales diversos. 
Es necesario también explicitar que este producción se realiza en el marco de una Beca Tipo B de la Universidad Nacional de La Plata y que se constituye como una derivación del trabajo de Tesis aprobado a principios de 2017 para obtener la Maestría en Comunicación y Educación de la Facultad de Periodismo y Comunicación Social (UNLP). Dicho trabajo consistió en la sistematización de mi experiencia de intervención como comunicador/educador en la Red de Museos de Quilmes'. Allí aparecieron los primeros esbozos de esta articulación entre la museología social y el campo comunicación/educación. Fueron esos primeros trazos, algo intuitivos, los que me dieron lugar a transformar ese punto de interés insinuado en una pregunta de investigación que direccionó y dio sentido al desarrollo de este trabajo.

Este documento final es el emergente material de un proceso formativo que excede largamente a las páginas de esta tesis, en el que se incluyen infinitas horas de lecturas, el trabajo de campo, la preparación y realización de entrevistas, los intercambios con especialistas, las reuniones con los directores, y los sucesivas y sucesivas versiones de borradores, para dar lugar a este resultado. Pero además de todo eso, a la vez, como le suele ocurrir a la mayoría de los becarios del sistema universitario público argentino, la tarea no estuvo solo circunscripta al estudio de la carrera de posgrado y la escritura de la tesis, sino que al mismo tiempo desarrollé otro tipo de actividades académicas, de extensión y transferencia realizadas desde varios ámbitos de intervención. Los que se configuraron como potentes espacios formativos desde la inserción institucional y el intercambio con muchos otros tipos de sujetos formadores que interpelaron nuevas miradas y preguntas, y que de algún modo u otro alimentaron este texto.

Por citar y describir algunas de estas tareas, puedo nombrar por un lado, que desde el Centro de Comunicación y Educación "Jorge Huergo" que se encuentra enmarcado en el Laboratorio de investigación de Comunicación, Medios, Educación y Discurso COMEDI ${ }^{2}$ de la Facultad, desde donde hemos planificado y desarrollado encuentros de formación, coordinado proyectos de extensión y acompañado -o evaluando- a tesistas de grado y posgrado, realizado diversas tareas de investigación en el marco de los programas de I+D de la Universidad, así como hemos comunicado avances a partir de publicaciones científicas y participación en encuentros y congresos.

Desde la docencia de grado en dos cátedras: el "Taller de Análisis de la Comunicación en las Instituciones Educativas" (TACIE) del Profesorado en Comunicación Social; y el "Taller de Técnicas de Animación Sociocultural" de la Tecnicatura en Comunicación Popular. Y en posgrado con dos

1 Dicho trabajo de tesis se tituló "Construcción comunicacional de un espacio público educativo de memoria colectiva. Experiencia de intervención museográfica desde el campo comunicación/educación en el Museo Histórico Regional "Almirante Brown" de Bernal, Quilmes (julio 2014-diciembre 2015)". Contó con la dirección de María Belén Fernández quien es además directora del proyecto de beca. La tesis se encuentra disponible en el repositorio público SEDICI de la UNLP http://hdl.handle.net/10915/60467

2 http://multisitio.sedici.unlp.edu.ar/comedi-laboratorio-de-investigacion-de-comunicacion-medios-educacion-ydiscurso/ 
seminarios: el de "Matrices Latinoamericanas de Comunicación/Educación" para la Maestría en Comunicación y Educación; y el de "Formación de Formadores en Comunicación/Educación" ofrecido para la Especialización en Comunicación Digital y la Especialización en Prácticas, Medios y Ámbitos Educativos Comunicacionales.

Así como también con tareas de gestión en la Secretaría de Extensión de la Facultad donde durante el último tiempo he realizado el seguimiento de diversas actividades, asesorado en la elaboración de proyectos y especialmente en el seguimiento de proyectos socioeducativos, como el Programa Territorial de Inclusión a la Educación Universitaria que impulsa la creación de sedes barriales de la Facultad para aumentar la accesibilidad y permanencia de estudiantes que de otro modo no lo logran.

Sumado a todas estas prácticas que se encuadran dentro de las tareas del entorno académico, me interesa sumar también muchas otras tantísimas actividades que en estos últimos tres años hemos tenido que realizar. Ante las profundas transformaciones en las políticas económicas y también en las educativas, entre otras tantas, hemos tenido que dedicar mucho tiempo de nuestras vidas para poner el cuerpo en organizarnos de manera colectiva, para salir a la calle, para manifestar nuestros desacuerdos ante estas políticas de ajuste. En definitiva una infinidad de acciones que también las considero parte del proceso, desarrolladas en el marco de la defensa de la educación pública en nuestro país.

Enuncio todas estas cuestiones, entre tantas, porque son constitutivas de la tesis, forman parte del contexto de producción en que se realiza este trabajo ${ }^{3}$, desde la matriz de la universidad pública argentina, en la que en función de todo lo descripto no puede producirse de manera aislada. Por ello esta tesis también está embebida de todas estas experiencias, es parte de una trama de prácticas que seguramente integran lo construido, y que de algún modo han aportado a su peculiar configuración.

Este contexto también se hizo presente en la perspectiva de los sujetos de investigación durante el trabajo de campo, dado que la totalidad de las personas que entrevisté participaron y participan de museos públicos, en los que actúan desde el Estado y desde lo público, y desde sus lugares se expresan desde ciertos grados de tensión y resistencia, ocupando el espacio público y estatal que les toca gestionar desde una perspectiva de derechos, lo que no necesariamente se corresponde con el actual proyecto nacional gobernante, haciendo allí uso de cierta autonomía para dar lugar a sus posicionamientos.

3 En este sentido, resulta interesante traer a cuento la definición que desde los estudios culturales angloajones propone Lawrence Grossberg sobre el contexto: "propongo conceptualizar el contexto como una singularidad que también es una multiplicidad, un ensamblaje activo organizado y organizador de racionalidades que condicionan y modifican la distribución, la función y los efectos -el ser mismo y la identidad- de los acontecimientos que, a su vez, están activamente implicados en la producción del contexto mismo. Los contextos se producen aún cuando "articulan" los "hechos" o las individualidades y relaciones que los conforman; se encuentran siempre en relación y conexiones multidimensionales" (Grossberg, 2012:47-48). 
Volviendo al objeto de investigación, y si bien ya fue enunciado, me resulta importante explicitar de manera clara el objetivo general propuesto para orientar esta indagación:

Producir una articulación entre los campos de comunicación/educación y museología social latinoamericana, a partir del trazado de una cartografía de matrices (compuesta por ámbitos, prácticas y conceptos) construida en una investigación participativa con referentes de museos que adscriben a la museología social.

Obviamente al igual que ocurre con cualquier proyecto de investigación, por más planificado y ajustado que esté en su planificación, luego en su implementación se ve siempre transformado por el proceso de producción de conocimiento, a partir de la experiencia de encuentro con otros, los que siempre deparan sorpresas.

Para lograr el objetivo propuesto, el presente documento está organizado en una serie de siete capítulos que pretenden dar sustento a la argumentación de esta articulación entre los campos descriptos.

En el capítulo 1 presento los posicionamientos que corresponden de manera más específica a describir el surgimiento e institucionalización del campo comunicación/educación en nuestra Facultad y a la articulación con las matrices latinoamericanas y populares en ese contexto, las que constituyen en un punto de partida, mi domicilio dentro de la cartografía planteada.

En el capítulo 2 me dedico a producir una lectura desde los estudios culturales, también desde una matriz situada para retomar las preguntas por lo popular, las luchas de poder, las experiencias sociales y su relación con las configuraciones de las biografías de los sujetos.

En el capítulo 3 presento la experiencia de acceso a los sujetos informantes y describo las peculiaridades que tuvo el proceso de inserción al campo, así como durante ese camino se fueron desarrollando algunos puntos de interés para anclar la particular configuración de la trama de la investigación.

En el capítulo 4 propongo una historización de los modos de hacer museos que se dieron en el mundo y especialmente algunos antecedentes en nuestro país, los que me interesa sumar a esa genealogía. Al mismo tiempo dedico un apartado especial a trabajar diversas perspectivas y acontecimiento que resultan antecedentes que provocan configuraciones singulares del tiempo histórico.

En el capítulo 5 recupero otra historización, en ese caso de diversas perspectivas dentro del campo de la museología para luego especificar sobre la perspectiva latinoamericana a partir del 
antecedente de la Mesa Redonda ocurrida en Santiago de Chile en 1972 y de las posteriores recuperaciones, derivaciones y experiencias.

El capítulo 6 condensa el núcleo analítico de la tesis, en el que voy desarrollando una serie de nudos problemáticos articulando de manera reflexiva con los sentidos de los entrevistados y entrevistadas. Recuperando sentidos de intervención, roles y miradas, modos de producción de memorias, interpelaciones subjetivas y estrategias de formación y organización.

Finalmente el capítulo 7, en el que propongo algunas ideas a modo de conclusiones provisorias sobre los alcances de la investigación, y sobre algunas proyecciones del trabajo.

Si bien no se encuentran directamente relacionados tanto desde las perspectivas trabajadas como desde las preguntas de investigación, de todos modos me interesa vincular mi trabajo con otros dos investigaciones realizadas en el marco del Doctorado en Comunicación de la Facultad de Periodismo y Comunicación Social dado que también integran a los museos como parte de sus objetos de estudio. Una que fue aprobado en 2013, realizada por Carlos González Pérez en la que produce un análisis de procesos de comunicación interna del Museo de Ciencias Naturales de Universidad Nacional de La Plata desde la semiótica peirceana. Y otro trabajo aún en proceso de producción dedicado a estudiar los procesos de virtualización de los museos, en tanto forma de mediatizar la experiencia museal y de producir otras formas de acceso.

Para cerrar este apartado, me gustaría decir que además de intentar cumplir con los objetivos de investigación propuestos para aportar a la academia en términos de los requisitos que la producción de conocimientos sistemática requiere, en el marco de una de las funciones sociales del sistema universitario público, esta tesis también se propone aportar a algunos de los objetivos manifestados en la Declaración de Córdoba ${ }^{4}$ del Movimiento Internacional para una Nueva Museología (MINOM) firmado en 2017.

Alli se planteaba la necesidad de concretar mingas para la redistribución y circulación de recursos, saberes y experiencias, así como se invitaba a generar y propiciar encuentros y espacios trans e interdisciplinarios para continuar los debates. Esos entre otros puntos de dicha declaración son de algún modo cumplidos en este trabajo en el que se reúne a una decena de trabajadores y trabajadoras de museos que participan de las entrevistas, pero en el que además se recuperan muchos otros aportes reflexivos producidos en intercambios en el propio encuentro de Córdoba, como también en espacios del Observatorio de Museos Universitarios de la Universidad de La Plata, así como otras interacciones más informales con profesionales que intervienen en espacios museales de La Plata, Ciudad Autónoma de Buenos Aires, Tucumán y Córdoba.

4 http://www.minom-icom.net/noticias/minom-cordoba-declaration-2017-es-pt-fr-en 
Por todo ello me interesa ofrendar esta tesis como un humilde aporte, a partir de una investigación que sistematiza y pretende dar visibilidad en otros ámbitos a algunas de las prácticas, sentidos y horizontes de acción de un grupo de referentes de ese enorme colectivo que trabaja desde la museología social, en esa potente red de vínculos que han establecido y en la que se van fortaleciendo a medida que avanzan construyendo su propia politicidad tejida sobre lazos de solidaridad y afecto. 


\section{Capítulo 1}

\section{ALGUNOS POSICIONAMIENTOS ANTES DE EMPEZAR}

\section{Institucionalización del campo comunicación/educación en la FPyCS UNLP}

Desde la consolidación del campo de la comunicación en América Latina (décadas '80/'90) y sus diversas reconfiguraciones descritas por referentes teóricos como Raúl Fuentes Navarro y Jesús Martín Barbero, entre otros, se plantearon debates sobre la formación académica de los comunicadores. En ese marco, nuestra facultad aportó el primer estudio sistemático para trazar la topografía del campo comunicación/educación, a partir de la investigación de un equipo encabezado por Jorge Huergo (FPyCS-UNLP, 1997) a la que luego se le sumaron una serie de acciones institucionales que le fueron confiriendo densidad y estatus académico a dichas formulaciones ${ }^{5}$.

\section{Creación del Centro de Comunicación y Educación}

Entre los aspectos institucionales, uno de los primeros antecedente, sin duda lo configura la creación del Centro de Comunicación y Educación en 1995.

En sus inicios se proponía como objetivos generales ${ }^{6}$ : formar graduados y estudiantes de Periodismo y Comunicación Social en la especificidad del problema de la relación comunicación/educación; programar y coordinar actividades académicas relacionadas con el área en cuestión: seminarios, cursos, talleres de capacitación; y coordinar y diseñar prácticas en el área de comunicación y educación, destinadas a la comunidad, instituciones educativas y organizaciones sociales.

En cuanto a sus programas de investigación se proponía: un primer núcleo dedicado a las indagaciones acerca de lo educativo y lo comunicacional en espacios institucionales educativos, en

5 Si bien se trata de un trabajo aún en proceso, es importante también señalar que Paula Morabes se encuentra desarrollando su tesis de doctorado estudiando la institucionalización de la investigación en el campo académico de comunicación/educación. Avances de dicho problema de investigación han sido presentados en artículos y ponencias.

6 Extraídos del Documento "Unidades de Investigación de la UNLP" (sin datar) producido por la Secretaría de Ciencia y Técnica de la Universidad Nacional de La Plata. Disponible en http://unlp.edu.ar/uploads/docs/unidades de investigacion de la unlp.pdf

7 Ver nota al pie anterior. 
ámbitos socio-comunitarios y en dispositivos mediático-tecnológicos; un segundo núcleo vinculado a estudiar la relación entre dos formas de organizar la transmisión de saberes y la socialización, como lo son la escolar y la mediática, con el agregado de la complejidad creada por el desarrollo de las telecomunicaciones; el tercer núcleo surge de la necesidad de intervenir en el contexto social latinoamericano para desnaturalizar la cultura del silencio en sectores oprimidos y para promover, junto con ellos, instancias de toma de la palabra. Esta última preocupación es particularmente notable en la historia de las acciones del Centro de Comunicación y Educación que se caracterizó por proponer actividades, y acciones estratégicas para trabajar e intervenir en los territorios, más que dedicarse a las discusiones meramente teóricas, aunque sin por ello abandonar la construcción conceptual, sobre todo en el caso de la producción de Jorge Huergo, cuyo peso específico en esta dimensión es innegable.

En este mismo sentido, no puede soslayarse como una de las estrategias de construcción del Centro, en el año 2002 el lanzamiento de la Revista "Nodos de Comunicación/Educación"8 que contó en sus cuatro números con los aportes de destacados referentes teóricos del campo de todo el continente, investigadores de universidades nacionales, educadores de diversos espacios, integrantes de organizaciones políticas, sociales y culturales, y estudiantes de nuestra Facultad quienes aportaron investigaciones, artículos, ensayos, entrevistas, relatos de experiencias, crónicas, que fueron componiendo los primeros trazados del campo.

En la actualidad, y a partir de las transformaciones organizadas desde el ámbito de Ciencia y Técnica de la Universidad para la conformación de Institutos y Laboratorios de Investigación y Desarrollo, el Centro de Comunicación y Educación pasó a formar parte del Laboratorio de investigación de Comunicación, Medios, Educación y Discurso (COMEDI) que es dirigido por Paula Morabes y que se encuentra reconocido dentro de la nómina de unidades de I+D de la UNLP.

\section{Implementación del Profesorado en Comunicación Social}

Sosteniendo estos esbozos iniciales en el campo, en 1998 se estableció un antecedente que sería de alcance masivo cuando la Facultad de Periodismo y Comunicación Social (UNLP) implementó el Profesorado en Comunicación Social.

La carrera se gestó en el año 1997 en el contexto de reforma del Plan de Estudios 1989, a partir de dos hechos relacionados: por un lado un importante desarrollo institucional previo de reflexiones y prácticas que dieron forma al campo de Comunicación/Educación, sintetizados en el Plan de Estudios de la Licenciatura a través de un espacio curricular específico que lo abordara (la asignatura Comunicación y Educación del Ciclo Superior de la Licenciatura), así como la experiencia

8 La revista puede consultarse en http://perio.unlp.edu.ar/nodos/. Contó con 4 números editados en septiembre de 2002, noviembre de 2003, junio de 2004 y noviembre de 2004. 
antes citada del Centro de Comunicación y Educación; y de Programas de Investigación que articulaba este espacio de producción de conocimiento.

Según consta en el Plan Curricular, la propuesta del profesorado implicó un doble desafío: formar a un profesional de la comunicación con formación docente, habilitado a desempeñarse en el sistema educativo, a la vez que contener otras prácticas profesionales del campo de la comunicación/ educación que excedan la docencia formal (Huergo-Fernández, 2000).

La formulación de ese profesorado tiene una marca diferencial con respecto a los profesorados desarrollados en otras carreras de esta y otras universidades donde por lo general el título de profesor se alcanza cursando un "bloque pedagógico" compuesto por 4 o 5 materias y la realización de prácticas áulicas que suelen ser las mismas para todos los estudiantes más allá de la orientación disciplinar del profesorado en el que estén cursando. En este caso, la propuesta hacía hincapié en la interpelación del campo de comunicación/educación en la definición general de los contenidos tanto para el campo de formación pedagógica como en la específica comunicacional y en la práctica. De esta forma, en vez de incorporar ese "bloque pedagógico", se generaba una formación integral en la que los contenidos y las prácticas estaban atravesados por comunicación y educación de manera transversal.

Desde su implementación en 1998, ocurrieron una serie de transformaciones en los ámbitos educativos en los que los graduados se insertaron, lo cual implicó interpelaciones diversas a los planteos de la carrera, a su vez que variaciones en el campo de posibilidades del desarrollo profesional.

Entre esas transformaciones de diversas escalas a nivel global, debemos incluir de manera central, los contextos socio políticos de nuestro país, que desde 1998 en adelante han transitado por momentos históricos complejos que también implicaron transformaciones profundas. Las más evidentes se pueden marcar en dos etapas que de modo esquemático podrían caracterizarse como: los años de las políticas de matriz neoliberal de los '90, y en paralelo los movimientos de resistencia desde la subalternatividad; y las desarrolladas post crisis de 2001, profundizadas con posterioridad a 2003, basadas en las políticas públicas de restitución y ampliación de derechos, recuperación de las memorias históricas, la reconstrucción de la justicia social, y una voluntad de recuperación de la integración latinoamericana y de los sectores populares, por las que muchos de los movimientos que habían estado en la resistencia en los '90 se incorporan a las políticas de Estado.

\section{Aportes de Jorge Huergo y la cátedra de Comunicación/Educación}

Mucho le debe el campo de comunicación/educación a Jorge Huergo, quien sin dudas fue uno de los principales tejedores de las complejas tramas que lo componen. Tal como plantea María Belén Fernández (2014) su contribución debe ser considerada en una doble dimensión, por un lado desde 
sus aportes epistemológicos, y por otro, por sus acciones estratégicas concretas, tanto en la materialidad de sus acciones en la Facultad (con las prácticas de la cátedra de Comunicación y Educación y a partir de diversos proyectos de extensión), como en organizaciones del territorio, así como su intervención desde la política pública.

Dentro de sus planteos epistemológicos, según afirma Fernández, el posicionamiento de Jorge Huergo siempre estuvo centrado en "construir conocimiento desde una perspectiva crítica que articule interpretación y transformación" (2014: 17). En este marco, la perspectiva epistemológica crítica permite articular dos dimensiones transversales en la construcción del campo comunicación/educación como campo académico y estratégico:

la dimensión hermenéutica participativa, cuyo objeto es la comprensión o interpretación y su interés es el de la copertenencia dialógica de los sujetos de la investigación y el conocimiento, en un horizonte común; y la dimensión praxeológica, cuyo objeto es el reconocimiento de las articulaciones entre teoría y práctica, la reflexión y la acción, y su interés es el de la transformación de determinadas prácticas sociales y culturales o acciones políticas (2014: 17).

En la misma clave epistemológica otro hito clave lo representa su tesis de Maestría PLANGESCO9 "Hacía una genealogía de comunicación/educación. Rastreos de algunos anclajes político culturales" dirigida por María Cristina Mata, publicada luego por la Editorial de la FPyCS en 2005. En la que se ocupa de hacer un minucioso tejido conceptual para el campo comunicación/educación que incluye articulaciones y/o críticas trazando un tejido genealógico de tradiciones hegemónicas y emergentes, las que consideró como "memorias constitutivas del campo". Entre ellas vinculó dialógicamente a comunicación/educación con las trayectorias y pensamientos de Simón Rodríguez, Domingo F. Sarmiento, los movimientos anarquistas en Argentina, Saúl Taborda, el peronismo, la Alianza para el progreso y el desarrollismo, los movimientos insurgentes de Latinoamérica, la Teología de la Liberación, Paulo Freire, Francisco Gutiérrez, entre otros. Todos como nodos constitutivos que interpelaron al campo en momentos particularmente significativos de nuestro continente.

Aunque la muerte lo encontró en enero de 2014, seguramente aún con mucho para dar, una última producción suya fue publicada de manera póstuma en 2015, "La educación y la vida: un libro para maestros de escuela y educadores populares"10 en el que había estado trabajando en años anteriores. Allí realiza un trazado en dos ejes, uno denominado "La educación para la vida", y el otro, "La vida en la educación". En ellos realiza un extenso desarrollo que comienza con Comenio y llega hasta nuestros días, pasando por diversas corrientes y referentes, en un estilo de escritura muy accesible en el que sin embargo se sostiene su característico virtuosismo conceptual.

9 Maestría en Planificación y Gestión de Procesos Comunicacionales que forma parte de la oferta de posgrado de nuestra Facultad. Ver http://perio.unlp.edu.ar/taxonomy/term/30

10 El libro fue publicado por la Ediciones de Periodismo y Comunicación (EPC) en formato Ebook en 2015. Disponible en http://perio.unlp.edu.ar/sites/default/files/la educacion y la vida ebook.pdf. Luego fue publicado en formato libro físico en 2017 por la misma editorial 
Como parte de los merecidos homenajes tras su partida, en reconocimiento de su trayectoria académica, profesional y militante fue propuesto su nombre para el Centro de Comunicación y Educación del que es sin dudas uno de sus pilares fundamentales. En los considerandos del Consejo Directivo de la FPyCS -que fue aprobado por unanimidad- decía

se impone al Centro de Comunicación y Educación el nombre de 'Profesor Jorge Huergo' por enseñar con la fuerza de su ejemplo, por su compromiso político, por su honestidad intelectual, por su intensidad en el acto de conocer, por su alegría y por su militancia en el sueño de la transformación social ${ }^{11}$.

\section{Congreso COMEDU 2012}

Otro momento de especial importancia en la institucionalización del campo ocurrió en 2012, con la realización del primer congreso COMEDU "Desafíos de comunicación/educación en tiempos de restitución de lo público" que marcó un importante antecedente dentro de los encuentros del campo en el marco de los congresos. Realizado desde el 12 al 14 de septiembre de ese año, este evento académico tuvo la voluntad de consolidar el sentido político estratégico del campo comunicación/educación en el escenario nacional y latinoamericano de ese momento, por lo que contó no solo con conferencias y mesas de ponencias como en la mayoría de los congresos, sino que además se complementó con otra serie de actividades ${ }^{12}$ en espacios y dispositivos de encuentro y discusión destinados a ampliar la convocatoria trascendiendo el público académico hacia educadores y comunicadores de instituciones, medios, organizaciones sociales, etc. Para ello se realizaron ateneos, conversatorios, actividades destinadas a jóvenes estudiantes de escuelas secundarias de la región, e incluso un espacio de formación ${ }^{13}$ para docentes del distrito.

Como una interpelación concreta para reforzar el sentido político estratégico del campo, en el programa del congreso se reconocía que

a partir del año 2003 comienza en la Argentina un período con luces y sombras, con logros y desafíos, que abre un lento pero firme proceso de restitución del Estado argentino, basado en gran medida en la recuperación de las memorias históricas, en la reconstrucción de la justicia social, en la voluntad de integración latinoamericana, en la iniciativa de las políticas públicas populares.

También decía que

11 Ver en http://unlp.edu.ar/articulo/2014/4/21/homenaje al profesor jorge huergo en periodismo, también en http://www.cile.perio.unlp.edu.ar/node/4112

12 Una más detallada recuperación de lo ocurrido en el Congreso COMEDU de 2012 es sistematizado en el artículo "Debates, interrogantes y proyecciones del campo Comunicación/Educación" (Fernández, Sanguino, Artiguenave, 2013) publicado en la Revista Trampas 75. Disponible en http:/www.revistatrampas.com.ar/2013/12/debates-interrogantesy-proyecciones.html

13 El curso de formación docente se denominó al igual que el congreso "Desafíos de comunicación/educación en tiempos de restitución de lo público". Constaba de una carga horaria de 25 horas reloj, las que se realizaron en instancias presenciales durante los días del congreso y se complementaron con una instancia virtual entre los meses de septiembre y octubre de 2012. El curso fue acreditado por la Dirección General de Cultura y Educación de la Provincia de Buenos Aires para otorgar puntaje bajo la resolución N. ${ }^{\circ} 4730$ de 2012, dictamen N. 8991. 
en este escenario se vuelve fundamental repensar el campo de las ciencias sociales en general, pero sobre todo, aquellas que se han cimentado en el concepto de lo público y que han visto, a lo largo de la última década del Siglo pasado, desmantelar y vaciar de sentido a muchos objetos de estudio de su área. Por lo tanto, retomar los debates que definieron los objetos, los sujetos y los ámbitos de Comunicación/Educación en un escenario de restitución de lo público, implica recuperar los discursos de la pérdida para reformularlos, pero también indagar acerca de los nuevos modos en que estas dimensiones aparecen en un escenario de reparación ${ }^{14}$.

La alta convocatoria que tuvo el congreso COMEDU, provocó un espacio de encuentro de diversos actores para discutir, poner (y reponer) en común experiencias, trayectorias de trabajo, formas de participación que alentaron la visibilidad del campo de comunicación/educación. La participación de estudiantes, educadores, investigadores, referentes sociales, culturales y políticos vinculados a la comunicación y la educación fue entonces una reconfirmación del sentido político estratégico del campo comunicación/educación, que a través de su convocatoria representó una interpelación a la actualización de los debates, reflexiones y desafíos estratégicos de comunicación/ educación, en que nuestra unidad académica se reconocía pionera y referente en la conformación del campo, tanto por sus estudios e investigaciones, como por el desarrollo de prácticas estratégicas articuladas con la educación popular, las políticas públicas y la formación de comunicadores. El congreso contó a su vez con un dispositivo de registro realizado por un equipo de docentes y estudiantes de la Facultad, que sistematizó las discusiones y aportes, los que fueron presentados al cierre del encuentro, a las vez que fueron publicados en un artículo ${ }^{15}$ en la edición especial que la revista "Tram(p)as de la Comunicación y la Cultura" le dedicó al COMEDU en su número $75^{16}$.

\section{Maestría en Comunicación y Educación}

Otro punto clave se marca en 2013 con la implementación de la Maestría en Comunicación y Educación en el marco de la FPyCS acreditada por CONEAU ${ }^{17}$ que desde entonces ha convocado a estudiantes de posgrado de universidades de nuestro país y a una significativa cantidad de estudiantes provenientes de Uruguay, Chile, Perú, Colombia y Ecuador.

A la actualidad la maestría cuenta con cuatro cohortes, con 4 graduados y graduadas, 2 tesis en proceso de evaluación y una decena de tesistas en diversos grados de avance y desarrollo, algunos comenzando sus trabajos de indagación y otros a punto de entregar sus producciones escritas. Aún

14 Extraído de los fundamentos del Congreso COMEDU que podía leerse en el programa, en las circulares de convocatoria y en la web. Disponible en http://perio.unlp.edu.ar/congresos/node/65

15 Fernández, M.B., Sanguino, S., Artiguenave, D. (2013) “Debates, interrogantes y proyecciones del campo comunicación/ educación" en Revista Tram(p)as de la comunicación y la cultura N. ${ }^{\circ}$ 75, La Plata, Facultad de Periodismo y Comunicación Social UNLP. Disponible en http://www.revistatrampas.com.ar/2013/12/debates-interrogantes-yproyecciones.html

16 Disponible en http://www.revistatrampas.com.ar/2013/12/trampas-75-mayojunio-2013 19.html

17 La Maestría en Comunicación y Educación de la FPyCS-UNLP fue acreditada por la Comisión Nacional de Evaluación y Acreditación Universitaria (CONEAU) en su acta N 414 del año 2015. 
así, es difícil dimensionar los alcances que la formación de la Maestría ha tenido. Sin embargo, por lo experimentado hasta el momento, sabemos que se ha constituido en un ámbito ideal para la profundización y actualización de los debates conceptuales del campo, tanto por los aportes del destacado cuerpo de referentes que integran el cuerpo de docentes ${ }^{18}$, sino también la amplia y variada experiencia de los y las cursantes de la carrera, para quienes se torna en un espacio de diálogo de saberes donde se propicia la posibilidad de relecturas en otras direcciones de los referentes teóricos ${ }^{19}$ a partir de las articulaciones con la práctica, a partir de los aportes y experiencias de docentes y cursantes de las cohortes de la maestría, para la aparición de nuevas líneas de investigación, para el trazado de nuevas tramas dentro del campo.

\section{$\underline{\text { Reforma Curricular del Profesorado }}$}

Acercándonos a la segunda década de la implementación de la carrera del profesorado en la FPyCS, se propuso y aprobó en 2014 una reforma de la propuesta curricular en función de contener algunas de las prácticas, experiencias y recorridos que fueron reconfigurando las prácticas de desempeño de los y las profesores en comunicación social, a la vez que actualizó la topografía del campo profesional de comunicación/educación ampliando su campo de acción a partir de las experiencias de sus egresados.

Es este marco de reconceptualización de los ámbitos y prácticas de comunicación interpelados por las transformaciones impulsadas por el Estado los que llevan al colectivo de la Facultad a promover la discusión de los planes de estudio que fueron aprobados en 2014, luego de un largo período de diagnóstico, discusiones y evaluaciones. Desde allí, es necesario destacar que la actualización del plan de estudios, posee como rasgo central la intensión de ensanchar el horizonte reflexivo, pero sobre todo también el campo de acción de los y las profesores en comunicación social a nuevos y estratégicos espacios.

Es por ello que se requirió una reconfiguración de los saberes y las prácticas alrededor de la enseñanza áulica, de la gestión de procesos comunicacionales educativos, del abordaje integral de los medios y los materiales educativos, y la incorporación de las tecnologías de la información y la comunicación como elementos clave en los diferentes ámbitos de trabajo.

Del documento curricular aprobado en la reforma se puede leer que

las distintas revisiones y discusiones destacaron la necesidad de reflexionar sobre la formación de comunicadores educadores reconociendo la necesidad de ensanchar las

18 Entre los que podemos nombrar además del mismo Jorge Huergo (quien dirigió la maestría hasta su muerte), se encuentran Silvia Delfino, Carlos Cullen, María Belén Fernández (quien es la actual directora de la carrera), Cecilia Ceraso, Claudia Villamayor, Rodolfo luliano, Patricia Vargas, Darío Martínez, Verónica Piovani, Kevin Morawiki, Eva Da Porta, Paula Morabes, y docentes invitados como Adriana Puiggros, Carla Wainzstok, Carlos Casalli, Verónica Bonelli, Cintia Rogovsky, entre otros y otras.

19 Entre ellos nos debemos sin duda la tarea de seguir leyendo y releyendo el complejo y vital legado de Jorge Huergo, del que todavía tenemos mucho por seguir entendiendo y aprendiendo. Con el que todavía podemos seguir dialogando desde sus escritos y prácticas concretas. 
posibilidades de intervención. De esta forma, se identificó su posición interpelada por la realidad con un horizonte ético, en tanto profesional que facilita procesos de enseñanza y aprendizaje mediados por el uso de tecnologías, protagonista en el proceso de generar contenidos educativos en distintos lenguajes, mediador de materiales educativos, generador de procesos de producción de sentidos con saberes para intervenir en el espacio de las políticas de inclusión social y con capacidad para recuperar la historia del sujeto, con predisposición a la escucha y al reconocimiento cultural. Además se pretende un comunicador educador sensible a las transformaciones sociales, políticas y culturales que atraviesan el campo de la comunicación y de la educación, por los avances normativos, por la emergencia de nuevos actores y por la presencia de tecnologías para potenciar la dimensión educativa en los procesos y proyectos de distinta índole.

Los tiempos académicos casi nunca se corresponden con las coyunturas nacionales o globales. Esto se hizo evidente una vez más al poco tiempo de manifestada la reforma curricular. En diciembre de 2015 la matriz política de la gestión del Estado cambió drásticamente, a partir de la asunción de Mauricio Macri a la Presidencia de la Nación, volviendo a tener una conducción política que retorna a una marcada matriz neoconservadora y neoliberal.

Por ejemplo el documento curricular 2014 afirma ser discutido "al calor de la implementación de la Ley 26522 de Servicios de Comunicación Audiovisual" aprobada en octubre de 2009, la que fue derogada durante el primer mes de la presidencia macrista mediante el Decreto de Necesidad y Urgencia 267/16 en el que se crea el ENACOM (Ente Nacional de Comunicación) y se modifican la mayoría de los artículos sustanciales de la LSCA, así como la AFSCA, su órgano de aplicación.

Este es un ejemplo, entre tantos, de que el plan 2014 fue pensado en un contexto que ya no existe como tal ${ }^{20}$. Aunque a la vez, las experiencias de estos 12 años, se configuran como un marco de posibilidades, como un umbral de conquistas sociales y derechos conseguidos a los que se hace difícil renunciar, y que por ende se transforman en desafíos y horizontes políticos que obligan a sostener la lucha.

Sostener la discusión sobre lo público desde una matriz popular, no abandonar la disputa por los derechos y por la producción colectiva desde lo popular son enormes desafíos que nos interpelan como campo. Sobre todo en este marco histórico en el que el actual gobierno, plantea una vuelta a la idea de la individualización y propicia una tendencia a la privatización del espacio público, aun cuando lo que se propongan sean actividades de acceso libre y gratuito pero que sin embargo están siendo

20 En el contexto de aprobación del plan, en 2014, implicaba pensar en políticas públicas como: Programa Conectar Igualdad, Plan FinEs, PROGRESAR, las nuevas estructuras mediáticas como la Televisión Digital Abierta, los canales educativos como Encuentro y PAKA PAKA, o los cambios que genera la Ley de Servicios de Comunicación Audiovisual, los que permitían repensar el perfil de un profesional que no sólo debiera formarse con el mandato de la intervención áulica, sino que lograse comprender e intervenir en este nuevo y dinámico escenario. En el actual contexto, muchos de estos programas ya no existen, o fueron desfinanciados y desmantelados. Sin embargo esas y otras tantas políticas impulsadas desde el Estado fueron un ejemplo de acciones posibles de ser gestionadas desde otras agencias de lo público, aunque claro será muy difícil lograr el impacto masivo que se podía lograr con el impulso del Estado como promotor de esas acciones. 
gestionadas desde la lógica de lo individual, de lo privado, y sobre todo traccionadas por los intereses del mercado. Por lo que quienes participan son interpelados principalmente como consumidores y por ende a partir de ese tipo de vínculo, el poder adquisitivo modifica sustancialmente las posibilidades de acceso a la experiencia. Del mismo modo como también se evidencian modificaciones radicales en las variables de las ofertas propuestas, en las que son cada vez más visibles y marcadas las presencias de las grandes empresas a través del sistema de franquicias en cada evento público, en desmedro de las propuestas de otro tipo de sectores, como los de la economía social y solidaria, y menos aún de los sujetos de las economías informales, quienes generalmente son desplazados de maneras violentas con el uso de la fuerza pública, cuando intentan instalarse en eventos donde podrían asegurarse mayor circulación y eventuales diferencias en sus posibilidades de generar estrategias de sustento.

En este marco de destrucción de lo público, en un pasaje del rol del Estado como garante de derechos a un Estado de gerentes, es que vuelve a ser pertinente la recuperación como bandera de la matriz política ligada a los movimientos populares de emancipación latinoamericana. Movimientos que son considerados "memorias fundantes" del campo en el que nos inscribimos y que como horizontes ético-políticos nuestra Facultad ayudó a consolidar y densificar.

En el marco de la tradición y el horizonte ético político de formación propuesto por la matriz comunicación/educación la carrera propone toda una diversidad de ámbitos y prácticas donde la preocupación se encuentra en la posibilidad de incorporar lógicas de interpelación desde la comunicación y la educación popular más allá de si se trata de un espacio en una organización barrial o si se trata de una institución con alto grado de formalidad o institucionalidad. Es decir, buscar un abordaje integral que implique considerar al hecho educativo en un sentido amplio que comprende las diversas agencias educativas y los múltiples polos de interpelación de los sujetos (Buenfil Burgos, 1993).

Más allá de haber sido aprobado en 2014, las transformaciones curriculares de dicha carrera se comenzaron a implementar de manera gradual, año por año, a partir de la cohorte que ingresó a cursar en la Facultad en 2017.

Es interesante historizar los momentos que fueron marcando las distintas propuestas que acabo de enunciar, en tanto, a pesar de estar mediados por un lapso de tiempo relativamente breve, son años en los que se hacen visibles momentos muy distintos de nuestro país y del mundo, en los que han ocurrido profundas transformaciones de diversos órdenes en las que se configuran matrices contrapuestas, a modo de acción, reacción y restauración. 


\section{La interpelación de las memorias del campo comunicación/educación}

Según nos planteaba Jorge Huergo en la apertura del Congreso COMEDU²1 de 2012 hay una memoria del campo de comunicación/educación que nos conduce a las escenas fundacionales del campo, las que "tienen más del fragor de pugnas continentales, que de la apacible reflexión del escritorio" (Huergo, 2013: 19). Esa marca de nacimiento ligada a las luchas de emancipación popular en América Latina permite asumir el reto de pensar, hablar y re-crear este campo con el compromiso de sostenerlo como un campo político-estratégico.

Si tuviéramos que referirnos a la metáfora del "nacimiento" del campo, decía Huergo, tenemos que reconocer todo un movimiento político-cultural vinculado a las radios populares y también educativas que necesitamos rescatar para comprender nuestro posicionamiento presente. Experiencias como Radio Sutatenza en Colombia (desde 1947) o las radios mineras en Bolivia (fines de los 40), trazan las primeras vinculaciones entre alfabetización, educación formal y la educación popular. Pero estas experiencias no se quedaron solo en la emisión de mensajes, sino que estas primeras radios populares de la región se caracterizaron por construir lazos comunitarios, y en el caso de las radios mineras, generaron tejido colectivo, motorizaron la convocatoria a las asambleas populares, fueron parte de la lucha social. No aplicaron un mensaje cerrado, sino que fueron un espacio para dar voz a los que no tenían dónde expresarse públicamente, ubicándose como medios al servicio de la liberación popular. El campo de comunicación/educación en América Latina nace con esa misma convicción: inscribir las prácticas, los medios, los procesos, como experiencias encarnadas dentro de las luchas por la liberación.

Por ello resulta inadmisible esta altura -al menos desde el punto de vista de la cultura académica de nuestra Facultad- proponer una adscripción del campo a un proceso academicista y despolitizado dado que el campo siempre ha estado vinculado a la articulación entre producción académica y a la acción dentro del campo político-cultural.

En ese marco es que se encuadra este trabajo de investigación que no pretende ser un soliloquio de erudición académica, sino la recuperación reflexiva y crítica de diversas experiencias concretas, de trabajos de intervención en el espacio público, en espacios de políticas públicas educativas que puedan ser recuperados desde la mirada del campo comunicación/educación, como un aporte a la reflexión desde el sentido crítico, para proponer y sostener en praxis, las matrices populares del campo.

21 El congreso COMEDU "Desafíos de comunicación/educación en tiempos de restitución de lo público" fue realizado en la Facultad de Periodismo y Comunicación Social UNLP del 12 al 14 de septiembre de 2012. La conferencia inaugural realizada por Jorge Huergo fue publicada completa en formato de artículo en el número 75 (mayo-junio 2013) de la revista "Tram(p)as de la comunicación y la cultura". Disponible en http://www.revistatrampas.com.ar/2013/12/trampas75-mayojunio-2013 19.html 
Y así como esas primeras experiencias mencionadas son las primeras puntadas de la trama del campo, la historia se va densificando con diversos procesos de luchas, y sobre todo de resistencias en la segunda mitad del Siglo XX. Del mismo modo la historia reciente también ha interpelado fuertemente al campo a partir de experiencias de comunicación/educación popular impulsadas desde las políticas públicas en el marco de las experiencias de varios Estados latinoamericanos que se posicionaron desde una matriz popular como promotores de derechos.

Estas experiencias de protagonismo de lo popular tuvieron un espacio central en la discusión de lo público a partir de los distintos gobiernos de orientación nacional y popular que llegaron democráticamente a dirigir los gobiernos de Argentina, Uruguay, Paraguay, Brasil, Bolivia, Ecuador y Venezuela, lo que Álvaro García Linera (2016) caracteriza como la "década virtuosa" en América Latina. Gobiernos que no solo tuvieron en cuenta a los sectores populares sino que fueron configurados desde una matriz popular interpelando los distintos espacios de la esfera pública.

Gobiernos a los que se los calificó de "populistas", usando el término desde su acepción hegemónicamente peyorativa. Aunque tal como dice Eduardo Rinesi

la palabra populismo no sólo no es una cosa diferente que lo que en la gran tradición occidental se llama republicanismo, sino que es, ni más ni menos, una de sus formas. Los rasgos que se destacan siempre como característicos de las formas populistas de organización del lazo político, a saber, su carácter con frecuencia tumultuoso y siempre conflictivo, son los mismos que, como ya vimos, caracterizan a la república que pensaron los grandes teóricos de una de las dos grandes tradiciones republicanas que transitan la historia de la civilización occidental: la del republicanismo popular (2016: 15).

Esto puede observarse en nuestro país durante los gobiernos del kirchnerismo (2003-2015), en los que muchos de los referentes y organizaciones sociales del campo popular fueron incluidos en la promoción y gestión de políticas públicas que tenían en su mayoría esa matriz popular y que además se proponían desde una gestión integral, sin partimentaciones estamentarias, articulando y vinculando diversos organismos, agencias y ministerios. Políticas públicas y líneas de acción que muchas veces surgieron desde las organizaciones y fueron universalizadas logrando el impacto masivo que solo puede lograr el Estado. A lo que se sumó en el proceso la producción de una serie de marcos normativos ${ }^{22}$ que en muchos casos fueron por delante de las demandas, promoviendo e impulsando macro transformaciones sociales y culturales desde esa matriz popular.

22 Algunas de las que interpelan al campo pueden ser: Ley 26.075 de Financiamiento Educativo; Ley 26.058 de Educación Técnico Profesional; Ley 26.606 de Educación Nacional; Ley 26.522 de Servicios de Comunicación Audiovisual; Ley 26.618 de Matrimonio Igualitario; Ley 26.743 de Identidad de Género; Ley 26.150 de Educación Sexual Integral. Las que al mismo tiempo fueron operativizadas con líneas de acción en políticas públicas como la Asignación Universal por Hijo/ a, el Programa Conectar Igualdad, la promoción de la AFSCA y de producción de contenidos locales en la Televisión Pública, Canal Encuentro y Paka Paka, la Ley 27.208 de Desarrollo de la Industria Satelital, el Plan FinEs, PROGRESAR, las políticas socioeducativas como CAJ, CAl, orquestas escuelas, la ampliación del calendario de vacunación, la recuperación de la administración pública de los fondos jubilatorios previsionales y la mayoría accionaria de YPF, y tantísimas otras más. 
Se trata entonces de una época en la que las experiencias de comunicación/educación popular tomaron este impulso para salir de las zonas marginales y artesanales y formar parte de las políticas públicas desde los más diversos espacios del Estado. Una época en la que lo popular se vio ensanchado y densificado en las organizaciones que empezaron a participar de las pugnas de lo público en escenarios mayores. Reconocidas en desarrollos que fueron dando lugar a las demandas populares, que fueron siendo cada vez más parte de lo público, en esa visibilidad fueron ganando en demandas que en muchos casos se transformaron en nuevas políticas públicas o en reformas normativas que resultaron en nuevas ampliaciones de derechos.

Hoy, después de esos años, podemos afirmar que esos sectores populares recuperaron muchos espacios en la esfera pública; no obstante, la reincorporación a la vida social de esos otros no fue vista con buenos ojos por otra parte de la población, lo que se expresó en el viraje que dio lugar a la actual coyuntura, la que se hizo evidente a partir del resultado de las elecciones de 2015. Esa incorporación de lo popular a la arena pública ha generado resistencias e incluso ha propiciado la visibilización de nuevas conflictividades (hasta entonces negadas) a partir justamente de la diversificación cultural, de la aparición de una multitud de actores que no jugaron (ni juegan) con las reglas del pretendido consenso universalista de la clase media. Colectivos que hoy son el cuerpo de los movimientos de resistencia, a la vez que impulsores de acciones y políticas que podemos considerar de tremenda potencia y originalidad, motorizados en la mayoría de los casos por la articulación de los sectores populares, los movimientos del feminismo y la diversidad sexual, y fundamentalmente los protagonizados por los y las jóvenes.

Esto es particularmente visible en los espacios de educación, los que fueron profundamente modificados fundamentalmente a partir de la Ley 26.206 de Educación Nacional de 2006, la que supuso ampliar la obligatoriedad escolar hasta sexto año de secundaria; pero además por otra cantidad de políticas de acceso socio educativo como el Programa Conectar Igualdad, que distribuyó más de 5 millones de netbooks a estudiantes y docentes secundarios de todo el país; el Plan FinEs para la finalización de estudios primarios y secundarios, que devolvió a muchísimos sujetos a escuelas y a instituciones educativas que se establecieron en clubes, organizaciones e instituciones barriales; la creación de nuevas universidades nacionales públicas y gratuitas, en territorios donde antes hubiese sido impensable; la modificación de la Ley de Educación Superior ${ }^{23}$ (en octubre de 2015) en la que se asegura por ley la gratuidad y el ingreso irrestricto (eliminando los cursos de ingreso eliminatorios); o las acciones de las políticas socioeducativas que permitieron el reingreso de niños, niñas y jóvenes desligados de este sistema, nuevamente a las escuelas en horarios

23 A partir de la Ley 27.204 de Implementación Efectiva de la Responsabilidad del Estado en el nivel de Educación Superior sancionada el 28 de octubre en el Congreso de la Nación.

Disponible en http://servicios.infoleg.gob.ar/infolegInternet/anexos/250000-254999/254825/norma.htm y publicada el 11 de noviembre de 2015 en el Boletín Oficial a partir de su ratificación por el Decreto 2358/2015 del Poder Ejecutivo Nacional.

Disponible en http://servicios.infoleg.gob.ar/infolegInternet/anexos/250000-254999/254826/norma.htm 
extracurriculares a través de los Centros de Actividades Infantiles (CAI), Centros de Actividades Juveniles (CAJ), o los Coros y Orquestas Escolares ${ }^{24}$.

Todas estas acciones incorporaron una enorme cantidad de sujetos de los sectores populares que en otros momentos de la historia habían sido expulsados (y por ende negados) con total naturalidad ante la menor conflictividad. Y que en ese marco debían quedarse, o reincorporarse, porque el marco político pedagógico así lo asumía. Esto generó una infinidad de procesos conflictivos que podríamos englobar sobre todo dentro del campo de la cultura, la que se expresa con fuerza en los ámbitos de la comunicación/educación.

Por ello, desde esta perspectiva, esta propuesta se constituye como un desafío fundamental: el de procurar siempre un espacio de encuentro de culturas, considerando a la vez que cada vez que se produce ese encuentro, no puede esperarse que sea armonioso, sino que tienda a ser complejo, confuso y conflictivo.

Considerar ese encuentro conlleva la necesidad de plantear un criterio de base: el del reconocimiento del mundo cultural del otro. Desde el punto de vista comunicacional "necesito saber y reconocer, quién es el otro con el que voy a comunicarme, cuáles son sus sueños y expectativas, cuáles sus labores cotidianas, sus lenguajes, sus dudas, sus limitaciones, sus creencias" (Huergo, 2004). Por ello, producir espacios de encuentro no significa solamente buscar información sobre los otros, sobre sus modos de vida, de sus formas de trabajo, las historias de su vida cotidiana y sus saberes, sino de algo mucho más complejo, "reconocer que el otro, desde su cultura, puede jugar el mismo juego que yo, por así decirlo, sin necesidad de adoptar mi cultura para jugarlo. Se trata de reconocer su dignidad" (Huergo, 2004).

Así dicha, la propuesta de Huergo plantea la posibilidad de generar un espacio para habilitar la palabra y construir subjetividad. Hacer referencia al reconocimiento del mundo cultural del otro significa considerar que las prácticas socioculturales son desarrolladas por sujetos. En ellas, los sujetos sociales se encuentran inmersos en una cultura, en la que invierten permanentemente esfuerzo, creatividad y trabajo de producción, y a pesar de los condicionamientos, conservan cierta capacidad para actuar por lo que podemos considerar en esos sujetos a los artífices de la transformación del mundo (entendido desde este contexto y caracterizado por su complejidad).

Con este convencimiento se construye el horizonte político de nuestras intervenciones de comunicación/educación, que intentan contribuir a la transformación de las prácticas, saberes, relaciones, modos de producción y de relación en un sentido emancipador. Pero para ello es necesario que nuestros interlocutores reconozcan su mundo cultural como algo dinámico, pasible de ser transformado.

24 A riesgo de resultar reiterativo es importante remarcar que la mayoría de estas políticas y normativas fueron desarticuladas y/o modificadas con Decretos y resoluciones desde diciembre de 2015. Y aún aquellas que siguen normativamente vigentes, han sido desfinanciadas en sus organismos de ejecución por lo que resultan solo letra legal pero que no es ejecutada en acciones concretas. 


\section{Comunicación/educación popular}

Desde esa perspectiva, preguntarse por el pensamiento popular implica romper con la autodefinición tecnicista del pensamiento calculador, utilitarista, impuesto desde la universalidad cultural para descubrir un pensamiento propio. Por ello recurrimos a Rodolfo Kusch, quien identifica en el sujeto popular americano una capacidad de inteligir de manera simbólica el mundo para establecer "conexiones entre este pensamiento profundamente americano y diferentes tradiciones que, desde contextos culturales diversos, desarrollaron una conciencia simbólica capaz de perforar la superficie del discurso solucionista" (2007c: 323).

Pero incluso va más allá, a los fines de encontrar la posibilidad de incorporar el gesto en primera persona,

decir cultura popular implica utilizar por un lado, un concepto que es cultura y que responde a un objeto llamado tal, y por el otro un calificativo que es popular y que indica un nivel determinado. Entonces cuando se dice cultura popular se marca una distancia entre nosotros y ella. En cierto modo es verla por fuera, pero no por dentro. Se crea entonces un abismo (Kusch, 1976: 145).

Un abismo de negación que tiene un origen concreto en el pensamiento occidental según lo plantea Boaventura de Sousa Santos (2010). Para quien el pensamiento occidental es un "pensamiento abismal" en el que existen "líneas radicales que dividen la realidad social en dos universos, el universo de este lado de la línea y el universo del otro lado de la línea". La división es tal que ese "otro lado de la línea" desaparece como realidad, se convierte en no existente, y de hecho es producido como un no existente.

El mayor efecto de este pensamiento abismal es que configura una "imposibilidad de la copresencia de los dos lados de la línea". Este lado de la línea prevalece "en la medida en que angosta el campo de la realidad relevante. Más allá de esto, sólo está la no existencia, la invisibilidad, la ausencia no dialéctica" (De Sousa Santos: 12).

El carácter abismal de las líneas se manifiesta por sí mismo en el elaborado trabajo cartográfico invertido para su definición. En su constitución moderna, lo colonial representa, no lo legal o lo ilegal, sino "lo sin ley". De Sousa Santos recupera una máxima popular de la época que resulta elocuente para entender hasta qué punto se configura este umbral. La máxima dice: "más allá del ecuador no hay pecados" (De Sousa Santos: 16). Es decir, lo colonial es el estado de naturaleza donde las instituciones de la sociedad civil moderna no tienen lugar.

La misma cartografía abismal es constitutiva del conocimiento moderno. La zona colonial es el reino de las creencias y comportamientos incomprensibles, los cuales de ningún modo pueden ser considerados conocimientos. El otro lado de la línea sólo contiene prácticas mágicas indescifrables. La extrañeza de dichas prácticas llevó a la negación de la naturaleza humana de los agentes de las mismas. 
La cartografía moderna es dual: el otro lado de la línea abismal es el reino de más allá de la legalidad (sin ley) y del más allá de la verdad (lo mágico, lo incomprensible). Juntas, estas formas de negación radical resultan en una ausencia radical de humanidad. Exclusión. Inexistencia. Así configurados como sub-humanos no somos candidatos para la inclusión social. Y por lo mismo somos candidatos ideales para la apropiación y la violencia hegemónica.

A todo esto De Sousa Santos agrega otro matiz en la contemporánea vuelta de lo colonial, donde lo abismal se manifiesta ya no solo en los territorios coloniales, sino que también se hace presente en las sociedades de las metrópolis. En el mundo actual la barbarie ya no está del otro lado de la frontera, sino que se hace presente dentro, habitando sus mismas ciudades, en el corazón mismo del denominado "primer mundo".

Ante este abismo trazado, ante esta mirada única del mundo y de las cosas planteada por el pensamiento neocolonial, negador de la diversidad, de Sousa Santos propone trabajar en la recuperación de una ecología de saberes:

la ecología de saberes es la dimensión epistemológica de una solidaridad de tipo nuevo entre actores o grupos sociales. Es una solidaridad internamente diversa en que cada grupo solo se moviliza por razones propias y autónomas de movilización, pero, por otro lado, entiende que las acciones colectivas que pueden transformar esas razones en resultados prácticos sobrepasan lo que es posible llevar a cabo por un solo actor o grupo social (De Sousa Santos: 71).

La ecología de saberes señala el paso de una política de movimientos sociales a una política de "intermovimientos sociales".

En este sentido, los procesos ocurridos en Latinoamérica en la primera década del Siglo XXI, vuelven a interpelar al campo de la comunicación/educación popular. Las transformaciones políticas, culturales, comunicacionales y sociales en el continente transformaron el mapa político y comunicacional, sumando nuevos actores y escenarios. Sin embargo con ello también interpelaron a la construcción de reacciones neoconservadoras y neocoloniales, las que hoy se encuentran nuevamente instaladas en las gestiones de los gobiernos de nuestro país, en Brasil, en Paraguay, así como pugnan por conseguirlo en Bolivia, Venezuela y Ecuador. Y con el agravante de que además en este momento las dirigencias políticas están conformadas por los sectores financieros trasnacionales, ya no solo por el patriciado, por los dueños de los latifundios, como había sido en los momentos de los Estados-Nación de nuestro continente, sino que ahora son los mismísimos CEOs ${ }^{25}$ (gerentes) representantes de las multinacionales y sectores financieros internacionales timoneando las decisiones políticas de nuestro país.

25 CEO es la sigla en inglés para Chief Executive Officer que se utiliza para designar al director ejecutivo de una compañía. Término que se ha extendido y naturalizado en nuestro país para nombrar a los gerentes de las corporaciones. 


\section{El horizonte del "buen vivir"}

Dentro de esa ecología de saberes, uno de los conceptos que se recuperaron durante esta "década virtuosa" en términos de García Linera, y que aporta a nuestra construcción es la del "Buen Vivir", recuperado como emergente milenario de las culturas indígenas andinas. Un concepto complejo, que debe reconocerse con matices, como plural y polisémico, en el que se congregan una diversidad de cosmovisiones que hoy se pueden encontrar coincidiendo en la defensa de una ética propia recuperada de sus propias memorias, en compromiso con la transformación y la defensa del continente desde sus propios marcos.

El "Buen Vivir" (o "Vivir Bien" desde otras acepciones) aparece como una corriente de reflexión que retoma las cosmovisiones de los pueblos latinoamericanos y los movimientos de resistencia que operan desde hace siglos en estos pueblos.

En el "Buen Vivir" no se trata de encontrar una definición acabada, aplicable a todo tipo de comunidad, porque ello implicaría entrar en contradicción con uno de los postulados principales de esta construcción, que es el de no universalizar, no colonizar, no generar una mirada esquemática, la de no suponer que existe una sola manera de que los pueblos pueden ser felices. El "Sumak Kawsay" (el vivir bien, la vida plena), o el "Suma Qamaña" (vivir bien), expresan esa búsqueda constante de los pueblos andinos por alcanzar la vida plena en armonía con la comunidad y el cosmos.

Como aclara Fernando Huanacuni Mamani (2010) los territorios no son solo un espacio geográfico, tal como se piensan los Estados de las constituciones liberales modernas. Para los pueblos indígenas no son solo recursos naturales, son más que la frontera, más que una delimitación, es la estructura, es la organización, es mucho más, porque todo es integral. "Ahí se vive y se convive. En nuestros territorios tenemos organización política, autoridad propia, idioma propio y todo un conjunto de saberes legados de nuestros pueblos" (Huanacuni Mamani, 2010: 7).

Los pueblos indígenas viven de acuerdo a principios éticos construidos en relación con la naturaleza. Son pueblos que viven en comunidad, y de acuerdo a los principios de reciprocidad, dualidad, y complementariedad. Según Huanacuni Mamani

Nosotros tenemos conocimiento y sabiduría, lo que ocurre es que nosotros no escribimos, no acumulamos en computadores y en papeles, acumulamos y transmitimos de generación en generación. Es por eso que nuestros conocimientos están acumulados en el propio pueblo y ahí los ejercemos (Huanacuni Mamani: 9).

Por eso los derechos territoriales, los conocimientos y la justicia son ejercidos de manera colectiva, en conjunto: en este sistema todos crecen o pierden en conjunto. Se trata de una economía distributiva

En nuestros pueblos no acumulamos, por eso no hay mendigos, convivimos entre nosotros y distribuimos la riqueza. Nosotros tenemos autoridad propia, idioma, territorio y en todos los espacios nos desenvolvemos con ética, respeto por todos los seres, principalmente por la 
Pachamama, por eso hablamos de la naturaleza como un sujeto de derecho y no como una mercancía (Huanacuni Mamani: 9).

\section{Descolonizar la mirada}

Aquí resulta pertinente una aclaración. Recuperar estos conocimientos culturales, en la recuperación de las culturas populares no implica encontrar recetas lógicas, algoritmos de la felicidad, ni fórmulas de éxito. Sino tratar de encontrar y comprender los términos dentro de las complejidades y contradicciones que se dan en el fondo de nuestras comunidades que fueron largamente silenciadas y negadas. Tampoco se trata de una vuelta ilusoria a los orígenes, no es una búsqueda esencialista, porque eso sería negar la coexistencia (en términos de contemporaneidad) tanto de los pueblos indígenas como de las culturas populares que existen y existieron siempre negadas delante de nuestras narices.

En términos de Kusch no se trataría de encontrar

la verdad o la falsedad rotunda que no le hace al hecho de vivir, sino el verdadero peso del vivir que nunca es totalmente falso ni totalmente verdadero en sí mismo, sino que es totalmente verdadero en la cultura propia. Es lo que hace a la cultura (1976: 99).

Desde este posicionamiento, la pregunta por la cultura en términos políticos es una pregunta por la ampliación de la autonomía. Y la pregunta de la cultura en relación a la tecnología -y sobre todo la pregunta por las culturas populares y su relación con las tecnologías para vivir- debe orientarse a ampliar las posibilidades de los sectores populares para lograr mayores márgenes de autonomía, y a la constitución de esos grupos como comunidades organizadas.

En esa dirección Kusch propone la recuperación de "una praxis americana", soslayar la pregunta por una cultura popular y "ensayar una decisión cultural", una puesta en acción de nuestra cultura, aclarando que no habla de una cultura argentina sino una "cultura local" (con lo que tenemos entre manos).

Toda decisión exige una fuente, y ésta está en la cotidianeidad. De ahí arranca nuestra autenticidad cultural. $Y$ en tanto recobramos nuestra autenticidad, habremos abordado realmente la liberación popular. Va en esto la paradoja de la actitud científica. Si objetivamos científicamente la cultura popular, borramos nuestro compromiso con ella aún cuando hablemos de liberarla. Cabe entonces ser pre-científicos y asumir nuestra condición real (1976: 146).

Se trata de un esfuerzo por no colonizar lo popular. Tal como dice Silvia Rivera Cusicanqui (2010):

La posibilidad de una reforma cultural profunda en nuestra sociedad depende de la descolonización de nuestros gestos, de nuestros actos, y de la lengua con que nombramos el mundo. El retomar el bilingüismo como una práctica descolonizadora permitirá crear un 'nosotros' de interlocutores/as y productores/as de conocimiento, que puede posteriormente 
dialogar, de igual a igual, con otros focos de pensamiento y corrientes en la academia de nuestra región y del mundo (...) A través de la liberación de nuestra mitad india ancestral y el desarrollo de formas dialogales de construcción de conocimientos (Rivera Cusicanqui, 2010: 71).

El pensamiento descolonizador que nos permitirá construir un continente genuinamente multicultural y descolonizado parte de la afirmación de ese nosotros bilingüe, abigarrado y mestizo, que se proyecta como cultura, teoría, epistemología, política de Estado y también como definición nueva del bien-estar y el "desarrollo". Según insiste Rivera Cusicanqui, "el desafío de esta nueva autonomía reside en construir lazos sur-sur que nos permitan romper los triángulos sin base de la política y la academia del norte" (Rivera Cusicanqui: 73). La propuesta nos invoca a construir nuestra ciencia propia, en un diálogo entre nosotros mismos y dialogando con las ciencias de los países vecinos, para poder a la vez afirmar -o tal vez hasta descubrir o fundar- nuestros lazos con las corrientes teóricas de los países de Asia y África, y enfrentar así "los proyectos hegemónicos del norte con la renovada fuerza de nuestras convicciones ancestrales" (Rivera Cusicanqui: 73).

En la perspectiva de Rodolfo Kusch, el suelo implica el arraigo que toda cultura debe tener en un sentido geopolítico y por ello reniega de aquellos intelectuales que piensan desde un sentido universal. Para Kusch el único modo posible de lograr el pensamiento propio es desde el aquí y ahora, que proporciona el suelo que habitamos, donde echar raíces a las que acudir en los momentos de crisis: "cultura supone un suelo en el que obligadamente se habita. Y habitar un lugar significa que no se puede ser indiferente ante lo que aquí ocurre" (1976: 115).

Esta percepción es fundamental en los procesos de comunicación/educación donde resulta necesario ese reconocimiento del otro y su circunstancia. Poder comprender desde dónde nos están hablando, desde qué sentidos, y a la vez, encontrar la posibilidad de producir desde ese aquí y ahora.

Ésta será la manera para que la cultura logre su sentido propio, allí donde la cultura puede ser partícipe, puede encontrar en ella una especial significación.

Kusch insiste en buscar en la cultura popular. Según afirma, el sentido profundo de la cultura "está en que ésta puebla de signos y símbolos el mundo. Y que este poblamiento es para lograr un domicilio en el mundo a los efectos de no estar demasiado desnudo y desvalido en él" (1976: 117).

El suelo para Kusch es "como un fundamento", es el punto de gravedad que lo rige todo. Estar en el suelo es no caer más, es "estar de pie" (del latín stare), y "estar parado es un estar dispuesto ante la circunstancia a fin de poder instalar la existencia" (1978: 18). Implica no atarse a identidades cristalizadas, sino comprender el carácter contingente y las complejidades con las que estamos conformados y habitados.

Para Kusch el suelo simboliza la "dimensión tópica de una experiencia", el lugar donde "acontece" lo humano, en medio de un paisaje, de un tiempo, de símbolos y, principalmente, "en medio de lo absoluto que presiona" (1978: 95). El punto radica en que el pensamiento de una 
comunidad no puede desprenderse de su "topos". No se trata sólo de la presencia de las cosas (materiales) que están en el mundo por una cuestión de gravidez, sino que se trata de comprender la gravidez del pensamiento que no puede desarraigarse de todo lo que el estarallí instaló.

Kusch plantea así una descolonización de la cultura. En sus términos de lo que se trata es de "americanizar la cultura". Kusch reconoce que ambas posturas funcionan como obstáculos de una americanización de la cultura, pero además insiste en que la clave es la cuestión de reconocer a la cultura como decisión, como gesto, reconocer su rasgo político. Por ello afirma que para americanizar la cultura no alcanza con preguntarle a un indígena cómo es América, ni tampoco alcanza con acudir al repetido recurso del folklorismo: asegura que esto no sería más que "cubrir con máscaras la propia y desnuda cara", sería como elaborar una cultura americana "por el lado de afuera", sin comprometerse. Lo americano no puede ser una cosa, es "la consecuencia de una profunda decisión por lo americano entendido como un despiadado aquí y ahora y, por ende, como un enfrentamiento absoluto consigo mismo. La cultura americana es ante todo un modo: el modo de sacrificarse por América" (1976: 71). Implica darle lugar a aquello que desde la llegada de los colonizadores a América fue desplazado. Darle lugar a lo que toda la cultura occidental moderna ha tratado de borrar, de ocultar, de sanar o evangelizar: el lugar del "hedor" en términos de Kusch (1962). Se trata en definitiva de una mácula que nos impusieron, una especie de vergüenza originaria, que se traduce en una inquietud inconfesable. Dice Kusch, "el hedor es un signo que no logramos entender, pero que expresa, de nuestra parte, un sentimiento especial, un estado emocional de aversión irremediable, que en vano tratamos de disimular" (2007b: 12).

A tal punto está presente este "hedor" que generalmente asociamos a todo lo americano con un rostro sucio y pies descalzos que deberían ser lavados. Y esa ha sido quizá una de las premisa que ha justificado y permitido las repetidas exterminaciones de las que nuestro continente es testigo.

Siempre la solución de los impulsos civilizatorios ha sido remediar esa suciedad, para proponer pulcritud.

En la Argentina eran los hijos de inmigrantes que desbocaban las aspiraciones frustradas de sus padres. Contra ellos luchaban los de abajo, siempre en esa oposición irremediable de hedientos contra pulcros, sin encontrar nunca el término medio. Así se sucedieron Túpac Amaru, Pumacahua, Rosas, Peñaloza, Perón como signos salvajes. Todos ellos fueron la destrucción y la anarquía, porque eran la revolución en su versión maldita y hedienta: eran en suma el hedor de América. Esta es la dimensión política del hedor, que pone a éste en evidencia y lo convierte en un antagonista inquietante (2007b: 14-15).

Ambos son como los dos extremos de una antigua experiencia del ser humano. Uno está comprometido con el hedor y lleva encima el miedo al exterminio y el otro, en cambio, es triunfante y pulcro, y apunta hacia un triunfo ilimitado aunque imposible. 
Oposición de eso "otro" que se manifiesta en el "hedor" según Rodolfo Kusch, o en los "desarrapados" (aquellos indígenas, negros y criollos ineducables y por ende desechables) a los que Simón Rodríguez recibía en su proyecto pedagógico, "el sujeto latinoamericano revolucionario y plural" de José Mariátegui, o la matriz de "lo facúndico" según Saúl Taborda, los "descamisados" de Eva Perón, las "masas mudas" para Freire.

Para Kusch

esta misma oposición, en vez de parecer trágica, tiene una salida y es la que posibilita una interacción dramática, como una especie de dialéctica, que llamaremos más adelante fagocitación. Se trata de la absorción de las pulcras cosas de Occidente por las cosas de América, como a modo de equilibrio o reintegración de lo humano en estas tierras. La fagocitación se da por el hecho mismo de haber calificado como hedientas las cosas de América (2007b: 18-19).

\section{Comunicación/educación popular como matriz transversal}

En tiempos en los que se discute sobre la eficacia del dispositivo escolar y por extensión de las instituciones educativas, en que se escuchan repetidas quejas que refieren a que "la gente ya no va a los museos", o se reflexiona desde las más diversas disciplinas sobre la caída de la capacidad de marcar subjetividad de las instituciones. En ese contexto, la intención por recuperar una serie de experiencias en museos desde la mirada de comunicación/educación apunta a preguntarse si tal vez en los espacios educativos la cuestión no sea tanto discutir una cuestión de formas, pensando el balance entre si lo que vale es la educación formal, o no formal, o informal; o sobre qué objeto del acervo puede interesar más a los niños en el museo; o sobre si la cuestión es lograr "elevar" el nivel de las propuestas, o si hay que hacerlas más accesibles, o si se trata de mejorar la tan nombrada "calidad educativa"; o si la selección de los contenidos enseñados son los adecuados para el espacio, o de qué modo hacemos dialogar a la muestra con los contenidos mínimos de la escuela. Sino que tal vez la discusión necesaria, la que deberíamos darnos, sería la de encontrar los modos para asegurarnos de incorporar la cultura cotidiana, la que está ocurriendo en los territorios producida por sus sujetos, la que está ocurriendo aquí y ahora delante de nuestras narices, en los espacios educativos en los que intervenimos.

Pero para esto no estoy pensando en la idea de incluir contenidos populares, no estoy intentando curricularizar lo popular. No hablo de una cuestión temática, ni folklórica, lo que sería colonizar, construir una cultura "por afuera" en términos de Kusch. Sino que lo que busco es articular una incorporación integral de los modos de enseñar y aprender, los modos de relacionarse, de trabajar, de reunirse, de hacer comunidad, de hablar y escuchar, de sentarse, de andar, de comer, de evaluar, de juzgar, de celebrar, de cantar o leer, de vestirse o adornar un espacio. Es decir, la incorporación del gesto cultural, en tanto decisión, en sus propios términos, que implica por supuesto 
la habilitación de los sujetos del territorio a habitar esos espacios, a ocuparlos y apropiarlos, a ofrecer espacios para decidir. Esa me resulta una necesidad de estos tiempos. Tomar la decisión, la de una incorporación compleja de los modos y de los sentidos de la cultura latinoamericana tensionando los procesos educativos, desde nuestro aquí y ahora.

Y para ese aquí y ahora paradójicamente también necesitamos mirar hacia el pasado. Pero no hacia el pasado en sentido de la historia lineal, sino en un sentido dialéctico, mirando la historia desde un presente continuo que nos permita discutir lo que nos pasa y proponer perspectivas de futuro. En ese sentido adherimos a la propuesta que enuncia Jorge Huergo en su tesis de Maestría:

Las transformaciones necesitan de las raíces; de hecho la memoria representa la fuente y raíz creadora de las transformaciones. La tradición, entonces, es una memoria de valores para la recreación permanente de la cultura; lo cual no supone cristalizar una consigna inerte para un recorrido previsto, sino estimular el movimiento de la fantasía creadora (2001: 107).

Recuperando a su vez la idea de Saúl Taborda (1951) de que "nada se crea ex-nihilo" aludiendo a un "movimiento continuo", una espiral dialéctica que se mueve entre tradición y transformación, convirtiendo a los polos en indisociables entre sí. La capacidad de articulación de algo que se trae del pasado con algo que se crea en el presente, convirtiéndose o actualizándose como problema. Recuperando la ya citada frase de Huergo: "comunicación significa la capacidad «táctica» desde las prácticas culturales de apropiarse y resignificar, desde marcos político-culturales, las acciones estratégicas" (2001: 110).

En este mismo sentido impulsar procesos de descolonización en todos los ámbitos no sólo hace a una actitud crítica o a un acto de justicia ante los atropellos coloniales (sobre todo si lo pensamos en ámbitos como los museos y las escuelas), también habilita y activa una memoria de liberación que da nuevos sentidos a la educación pública, común y popular. Tiempos y espacios de posibilidad que pueden abrirse a memorias y procesos que instalan, no una novedad inédita, sino historias olvidadas en nuestras memorias y nuestros sueños sociales, tantas veces negados o avasallados.

Desde este posicionamiento que se instala como horizonte político, ligado desde el campo comunicación/educación a las luchas por la emancipación. Desde ese posicionamiento es que hoy resulta necesario actualizar esos debates, hacerlos parte de las discusiones cotidianas dentro del campo comunicación/educación, pero también en otros espacios (académicos o no académicos). Ya no para ser pensadas para el armado de experiencias desde la alternatividad, desde el sentido de alguna micro experiencia, desde algún espacio de educación "no formal" en una organización, sino como una matriz que se debe instalar cruzando todos los espacios, tensando, disputando e interpelando ya no solo a esas experiencias originarias, las de las organizaciones, las radios populares, los espacios de alfabetización, sino también en los espacios más institucionalizados, como los de la educación primaria, secundaria y por supuesto en la educación universitaria, la que ha estado 
demasiado habitada por pensamientos eurocéntricos. Implica el esfuerzo de descolonizar el pensamiento, descolonizar la academia y por ende nuestro modo de comprender el mundo. Aunque para esto no alcanza con citar a autores latinoamericanos, emancipar nuestros pensamientos implica también abordar de manera diferente nuestras acciones de producción.

Descolonizar tanto la universidad como los museos implica encontrar otros modos de abordar lo popular donde no sea sólo un objeto de conocimiento, sino que busquemos los modos de hacerlos parte de los procesos de construcción de conocimiento, incluyéndolos, trabajando "con" y no "para", dejando que la matriz popular, sus marcos de inteligibilidad y prácticas sean parte integral en cada uno de los procesos.

Lo popular más que un concepto, tiene que ser una matriz de producción, y eso implica darle lugar a los sujetos populares como sujetos dignos, sujetos "a la altura del juego" en términos de Jorge Huergo cuando habla del reconocimiento del otro. Poder producir conocimiento en diálogo, incluyéndolos en las propuestas, dejándonos interpelar con sus acciones, experiencias y pensamientos. 


\section{Capítulo 2}

\section{ESTUDIOS CULTURALES, INTERPELACIONES Y MEMORIAS POPULARES}

El campo de los estudios culturales es una topografía amplia y compleja, que desde hace un buen tiempo a esta parte cuenta con una influencia importantísima y hasta decisiva en las matrices de producción y acción de diversos sectores, entre los que se incluye nuestra comunidad académica al igual que muchos otros espacios de producción e intervención dedicados a la comunicación o las ciencias sociales, y en especial los colectivos que forman parte del campo comunicación/educación tal lo descrito en el capítulo anterior. Dicho campo está atravesado por una diversidad de referentes y construcciones de los denominados estudios culturales, que atendiendo a la propuesta de aquellos que nos interesa repasar, debe comprenderse considerando sus intervenciones en su contexto de producción, en su historicidad, y en este sentido, teniendo muy en cuenta -y de manera situada-, la conflictividad de esos contextos y momentos históricos. Por lo que de ningún modo podríamos considerar a los estudios culturales como un campo homogéneo, y menos aún como un espacio exento de luchas y contradicciones.

Según lo planteado por el colombiano Eduardo Restrepo (2012) hay dos formas de abordar el modo en que se caracterizan los estudios culturales: uno que tiene que ver con su especificidad programática, y otra que él llama etnográfica, que apunta a observar prácticas concretas, tópicos estudiados, publicaciones realizadas, intervenciones políticas desarrolladas por quienes sostienen estos estudios culturales.

En este sentido no podemos dejar de tener en cuenta la enorme influencia que tuvieron y tienen las enunciaciones y publicaciones construidas desde el Centro de Estudios Culturales Contemporáneos de la Universidad de Birmingham, con los reconocidos aportes conceptuales y políticos de Richard Hoggart, Raymond Williams y Edward Palmer Thompson (entre fines de los '50 y los '60), o Stuart Hall (hacia los '70 y '80), entre otros referentes de los Cultural Studies (según su enunciación original), los que por su masiva circulación (y tal vez por cierto colonialismo intelectual, aspecto sobre el que más adelante ahondaremos) han sido convertidos un poco en la metonimia representativa de los estudios culturales. Pero que en función de la especificación y a la vez para dar 
lugar a otras construcciones, a nuestro criterio no menos relevantes y a la vez más situadas en nuestro contexto, deberíamos Ilamar como estudios culturales ingleses.

Para aportar a reconocer esos otros aportes Restrepo insiste en una multiplicidad de genealogías reconociendo que "lo que en un lugar determinado se practica con ese nombre, responde a sus trayectorias y tradiciones intelectuales en relación no sólo con específicos establecimientos académicos y articulaciones políticas locales, sino también con la geopolítica del conocimiento global" (Restrepo, 2012: 123) como justificación para la preminencia de los aportes ingleses por sobre los producidos desde nuestro continente por ejemplo por Jesús Martín Barbero, Anibal Ford, o tantos otros, quienes habían realizado estudios que podríamos considerar dentro del campo de los estudios culturales, aún cuando fueran escritos sin necesariamente pretender adscribir a dicha etiqueta.

Construir una cartografía otra, más amplia, no implica aplacar los disensos o las contradicciones, sino al menos provocar algunas especificaciones de corte situado, justamente para demarcar la pluralidad de las diversas vertientes de esas disputas, con el afán de continuar las discusiones políticas que esos mismos estudios culturales aportaron como campo, y que también es necesario sostener sobre su propio terreno (o mejor dicho, sobre nuestro propio terreno). Sobre todo porque justamente la potencialidad de los estudios culturales no está tanto en esos "estudios", o en esos aportes conceptuales, sino más bien en su vocación política. Es decir, no se pretenden como una acción exclusivamente del campo académico, sino que se plantean como una práctica intelectual con deseos de intervenir en el campo de lo concreto, para impulsar transformaciones.

\section{El poder y la lucha como problema}

El interés de este campo por la cultura como objeto de atención, no es por la cultura en sí misma, sino por su articulación constitutiva con el poder. Encontrando allí una propuesta política que resulta central como aporte a las ciencias sociales, de la mano de la mirada gramsciana, dando cuenta de los marcos de acción y relación de lo sujetos. Reconociéndoles su capacidad de agencia, a partir de observar en la cultura tanto las estructuras de dominación, como las prácticas de resistencia. Las que son consideradas de enorme relevancia para el campo, dado que se trata del lugar donde puede intervenirse para la transformación del presente.

En este marco son centrales los aportes (desde Birmingham) de Raymond Williams o Edward P. Thompson quienes con sus trabajos abonan al concepto de experiencia. Para mirar a la cultura como algo vital, observándola no como una abstracción, sino a través de la vida de los sujetos sociales, y además proponiendo un gesto disruptivo para las ciencias sociales de la época, al darle protagonismo y entidad analítica a la experiencia de los sujetos de las clases populares. Los que en estas producciones de los estudios culturales ingleses dejan de ser vistos como sujetos pasivos, meros alienados, o como representantes de un segmento económico que los determina, para ser 
reconocidos como agentes activos de la cultura, a partir de su experiencia de la existencia social, y sobre todo en la observación de sus diversas prácticas de resistencia.

Esta apuesta, que como ya advertimos no es solamente metodológica, sino además política, por intentar prestar atención al modo en que se producen las relaciones de poder para tratar de desanudarlas y modificarlas.

En este punto es en el que observar, y sobre todo tratar de comprender en sus propios términos, la vida de los sectores populares se vuelve relevante, dado que es en sus prácticas donde aparecen expresadas las relaciones de poder. Según afirmaba el jamaiquino Stuart Hall, la cultura es "un campo de batalla donde no se obtienen victorias definitivas, pero donde siempre hay posiciones estratégicas que se conquistan y se pierden" (1984:05). Lo que se busca es propiciar una mirada más compleja y dinámica, sin esencialismos y sobre todo se separa de las miradas homogeneizadoras de lo social, para pensar en cambio en permanentes luchas y tensiones, resistencias y aceptaciones, rechazos y apropiaciones.

Es importante a la vez aclarar que poner atención en las resistencias de los sectores populares no implica una mirada que los romantice, y les suponga poderes supremos en sus acciones de oposición. Tal como afirma el mismo Stuart Hall:

hay una lucha continua y necesariamente irregular y desigual, por parte de la cultura dominante, cuyo propósito es desorganizar y reorganizar constantemente la cultura popular; encerrar y confinar sus definiciones y formas dentro de una gama más completa de formas dominantes. Hay puntos de resistencia; hay también momentos de inhibición. Ésta es la dialéctica de la lucha cultural (1984:5).

Por eso justamente la necesidad de prestar atención a los contextos situados, a atender a las particularidades de las acciones en momentos específicos. Siguiendo a Hall, Restrepo afirma que "los estudios culturales se plantearían como un contextualismo radical, como una teorización de lo concreto, como una teoría sin garantías" (2012:133). Esto implica según el mismo autor, no pensar a los contextos como escenario o telón de fondo, sino como una densa red de relaciones que son constituyentes de las representaciones, prácticas y acciones. Desde esta mirada entonces, los contextos dejan de ser fondo para pasar a ser trama, para ser configurados pues como condición de posibilidad.

Esto del contextualismo es también importante por algo en lo que insiste el colombiano Jesús Martín Barbero, quien dice que en nuestro continente (tal vez por ese mismo colonialismo intelectual que ya mencionamos) muchas veces fueron más importantes las seguridades teóricas que las "verdades culturales", por ello es que en eso de una teoría "sin garantías" ya Martín Barbero había aportado en consonancia la interesante idea de los denominados "mapas nocturnos". La idea de dejar de lado las nociones prefiguradas, las fórmulas metodológicas y teóricas que obturan la investigación para en cambio avanzar "a tientas" buscando nuevas topografías. No para cambiar de tema, sino para 
seguir indagando en torno a la dominación, el trabajo y la producción "pero desde el otro lado: el de las brechas, el consumo y el placer. Un mapa no para la fuga, sino para el reconocimiento de la situación desde las mediaciones y los sujetos" (1991:229). De este modo, Martín Barbero aporta tanto en el sentido político como en el metodológico. A partir de una apuesta a la salida a la intemperie en términos disciplinares y teóricos ${ }^{26}$, para salir a buscar el objeto y encontrarse con otros que también lo estuviesen buscando (sean o no intelectuales). Para a partir de allí construir una nueva agenda basada en lo que pasaba allí afuera.

A partir de esa búsqueda en su caso también aparecerá un énfasis por indagar en torno a lo popular:

el valor de lo popular no reside en su autenticidad o su belleza, sino en su representatividad sociocultural, en su capacidad de materializar y de expresar el modo de vivir y pensar de las clases subalternas, las maneras como sobreviven y las estratagemas a través de las cuales filtran, reorganizan lo que viene de la cultura hegemónica, y lo integran y funden con lo que viene de su memoria histórica (Martín Barbero, 1991: 85).

por ello es que el mismo autor plantea la necesidad de "prestar atención a la trama" para poder encontrar (y encontrarse) en la cultura, a través de las prácticas, acciones y representaciones, en las que se expresan las complejidades y contradicciones. En este sentido insiste con la idea de que

no toda asunción de lo hegemónico por lo subalterno es signo de sumisión como el mero rechazo no lo es de resistencia, y que no todo lo que viene "de arriba" son valores de la clase dominante, pues hay cosas que viniendo de allá responden a otras lógicas que no son las de la dominación (1991:87).

No obstante insistiendo con Stuart Hall es necesario volver a afirmar que "no hay ninguna «cultura popular» autónoma, auténtica y completa que esté fuera del campo de fuerza de las relaciones de poder cultural y dominación" (1984:5), para no subestimar las acciones del poder y su capacidad de producción desigual sobre los sujetos.

\section{En busca de la complejidad perdida}

Siguiendo en la lógica del contextualismo "sin garantías" es importantísimo revisar en esos contextos la situación histórica y topográfica en que ocurren las prácticas observadas para no forzar una cristalización de facto de las prácticas o los sentidos, para no homogeneizar, para no imponer representaciones, y sobre todo para no aportar a seguir violentando a esos sujetos y sus circunstancias. Según afirma Eduardo Restrepo lo político es siempre contextualmente específico "las

26 Dice Martín Barbero: "algo se movió tan fuertemente en la realidad que se produjo un emborronamiento, un derrumbe de las fronteras que delimitaban geográficamente el campo y nos aseguraban psicológicamente. Desdibujado el "objeto propio" nos encontramos a la intemperie de la situación. Pero ahora ya no estábamos solos, por el camino había otras gentes que sin hablar de "comunicación" la estaban indagando, trabajando, produciendo: gentes del arte y la política, la arquitectura y la antropología. Habíamos necesitado que se nos perdiera el "objeto" para encontrar el camino al movimiento de lo social en la comunicación, a la comunicación en proceso" (1991:220). 
implicaciones políticas no están inscritas indisolublemente, de una vez y para siempre, en la "naturaleza" de una posición o planteo. Lo que en un contexto puede ser políticamente progresista, en otro momento o contexto puede ser abiertamente reaccionario" (2012:131).

Para la comprensión de estas complejidades resulta muy operativa la propuesta de Raymond Williams quien en "Marxismo y Literatura" (2001) presenta tres capas o momentos dialécticos que se superponen y tensan dinámicamente entre sí en las formaciones culturales: lo arcaico, lo residual, y lo emergente.

Lo arcaico como aquello que sobrevive del pasado, pero que de algún modo ya es considerado un recuerdo, un objeto de estudio.

Lo residual es aquello que proviene del pasado pero que tensa en el presente, pero no de manera uniforme, sino que implica elementos incorporados, pero también aquellos que negados en su momento son recuperados, o tal vez pueden ser aquellos elementos que desde el pasado propongan tensiones u oposiciones, resistencias conservadoras. Y lo interesante en esta mirada propuesta por Williams es que esas resistencias conservadoras, tal vez consideradas a priori como reaccionarias, pueden ser en ciertos contextos también estrategias de oposición o impugnación a la dominación.

Por último el estrato de lo emergente, lo nuevo, las innovaciones en prácticas y significados, las apropiaciones o reapropiaciones, las que tampoco son homogéneas, y obviamente al igual que como mencionábamos en el párrafo anterior, tampoco son necesariamente resistencias a la dominación, ni salidas emancipatorias. Lo emergente también puede ser, en muchos casos, innovaciones desde las estrategias de lo hegemónico, refuerzos para sostener las desigualdades.

Esto puede leerse de manera más o menos evidente en estos últimos años en los que las fuerzas hegemónicas han demostrado tener una enorme capacidad de innovación y de creación de sentidos y prácticas que se han puesto en funcionamiento para operar en el campo cultural y les han servido para reforzar su posición de poder. Así como también estos mismos grupos han sabido recuperar (o re-crear) y revitalizar sentidos residuales que parecían dormidos, pero que se encontraban profundamente instalados en las raíces de diversos colectivos y que han sido base de sustentación para la construcción de importantes rupturas en nuestra región.

Esa es la complejidad, lo emergente también puede aparecer reforzado con disfraces históricos, no siempre señalando la novedad. 0 incluso puede aparecer disfrazada de futuro y 
contener enormes fuerzas reaccionarias, residuales ${ }^{27}$. Por eso es siempre necesario observar en contexto situado, en el marco del proceso histórico.

Aludiendo a la necesidad de prestar atención a la dinámica de los cambios, Stuart Hall (1994) refiere que no podemos esperar nunca los "comienzos absolutos", o al menos no podemos considerarlos una lectura seria. Así como tampoco será posible encontrar transformaciones sin fracturas. Lo importante para Hall serán las fracturas significativas, los espacios en los que las líneas de pensamiento son desarticuladas, donde aparecen los desplazamientos y reagrupamientos. Allí reside la clave, y la responsabilidad política de quienes investigan, en su posibilidad de sostener una dialéctica entre "conocimiento" y "poder", en la articulación entre el pensamiento y la realidad histórica "los cambios en una problemática transforman significativamente la naturaleza de los interrogantes que son formuladas, las formas en que ellas son planteadas y la manera en que pueden ser adecuadamente respondidas" (1994:1).

\section{La interpelación de lo popular}

Por lo antes expuesto, es que resulta tan importante el rol y el espacio asignado a los sectores populares en estos estudios por parte de estos sectores intelectuales que se han sentido interpelados por las desigualdades evidenciadas en la lectura histórica situada. Tal como dice Jesús Martín Barbero "no son únicamente los límites del modelo hegemónico los que nos han exigido cambiar de paradigma. Fueron los tercos hechos, los procesos sociales de América Latina, los que nos están cambiando el 'objeto' de estudio a los investigadores de comunicación" (1991:224). Y en este sentido la búsqueda no es por una ampliación representativa, es decir, no se trata de darle mayor definición al instrumento metodológico, ni de ampliar el campo de visión. Se trata de un desplazamiento para reubicar el "lugar" de lo popular, para de ese modo "asumirlo como parte de la memoria constituyente del proceso histórico, presencia de un sujeto-otro hasta hace poco negado por una historia para la que el pueblo sólo podía ser pensado 'bajo el epígrafe del número y el anonimato"' (1991:72)28. En los mismos términos Hall propone que

el estudio de la cultura popular es como el estudio de la historia del movimiento obrero y sus instituciones. Declarar que se tiene un interés en ello es corregir un desequilibrio importante, señalar una omisión significativa. Pero, a la postre, cuando más rinde es cuando la vemos en relación con una historia más general, más amplia (1994:3).

27 Para ejemplo es interesante observar como la coalición política formada por el PRO (Propuesta Republicana), la UCR (Unión Cívica Radical), y la Coalición Cívica para la Afirmación de una República Igualitaria (CC-ARI), eligió el nombre "Cambiemos" para su fuerza política, y construyó su plataforma sobre los significantes de "cambio" y "futuro", una propuesta que -a esta altura está las claras- buscaba un cambio, que implicaba una diversidad de acciones y propuestas de intervención en pos de producir una reforma de restauración conservadora. Propuestas que desarrollaron de manera sistemática y profunda durante su gestión de gobierno, tanto a nivel nacional, como provincial y municipal, apelando de manera constante a estos mismos significantes.

28 En el entrecomillado final de la cita Martín Barbero está citando a Ginzburg, C. (1982), El queso y los gusanos. El cosmos según un molinero del siglo XVI. Barcelona, Muchnik. p.22. 
En función de este énfasis Hall (1984) a la vez propone prestar atención a una serie de matices sobre el uso del adjetivo "popular" en diversos estudios, a los que caracteriza a partir de tres tipos de miradas.

Una definición que denomina "de mercado" que define como populares a las cosas que son consumidas por masas de personas. Ésta según dice es "la definición que pone malos a los socialistas. Se la asocia acertadamente con la manipulación y el envilecimiento de la cultura del pueblo" (1984:4). Pero a la vez aclara que hay algo en esta mirada que implica que

si las formas y relaciones de las que depende la participación en esta clase de «cultura» suministrada comercialmente, son puramente manipulatorias y envilecidas, entonces las personas que las consumen y disfrutan están ellas mismas envilecidas por estas actividades o viven en un estado permanente de «falsa conciencia». Deben de ser «tontos culturales» incapaces de ver que lo que les están dando es una forma actualizada del opio del pueblo (...) no sé si este parecer puede sobrevivir mucho tiempo como explicación suficiente de las relaciones culturales; y aún menos como perspectiva socialista de la cultura y la naturaleza de la clase obrera. En última instancia, el concepto del pueblo como fuerza puramente pasiva es una perspectiva profundamente no socialista (1984:4).

Esta última frase, profundamente provocadora, será luego también retomada por diversos autores como por ejemplo Anibal Ford ${ }^{29}$, llamando la atención sobre las miradas maniqueas y sobre todo mesiánicas de algunos sectores, tratando de otorgar interés sobre las acciones de los sectores populares, para en este movimiento poner el acento en tanto la recuperación de la capacidad de agencia de todos los sujetos sociales, más allá de su posición de poder. En este sentido aprovechando la formulación de Ford podemos decir que "hay momentos 'receptores' en la cultura. Negarlos es como pensar que el hombre solo se estructura sobre el 'hablar' y no también sobre el 'ver' o el 'escuchar'" (1994a:154).

Hall continua con una segunda posición para lo popular que denomina como "antropológica" y que descarta de plano por sospechar de su amplitud descriptiva. En ella entrarían, sin distinciones, todas aquellas cosas que el pueblo a hecho.

El jamaiquino prefiere una tercer definición, que supone como "insegura" pero que considera con mayor potencia. Está compuesta por "aquellas formas y actividades cuyas raíces estén en las condiciones sociales y materiales de determinadas clases; que hayan quedado incorporadas a tradiciones y prácticas populares" (1984:6). Este modo contiene de algún modo la función descriptiva de la segunda pero a la vez se centra en las relaciones constitutivas de la cultura popular, poniendo énfasis en la continua tensión (relación, influencia y antagonismo) con la cultura dominante. Según el mismo afirma, se trata de "un concepto de la cultura que está polarizado alrededor de esta dialéctica cultural. Trata el dominio de las formas y actividades culturales como un campo que cambia

29 Dice Anibal Ford "se podría decir, siguiendo a Stuart Hall, que pensar que las clases populares consumen medios porque son idiotas es muy poco socialista" (1994a:152). 
constantemente" (1984:6). Aquí lo interesante es la idea de proceso, la comprensión de estas relaciones siempre dinámicas, siempre en tensión entre la dominación y la subordinación. A la vez, se corre de la preocupación por la autenticidad de las prácticas para centrarse más bien en las contradicciones que allí se observan, en la continua presencia de elementos antagónicos e inestables

El significado de un símbolo cultural lo da en parte el campo social en el que se le incorpore, las prácticas con las que se articule y se le hace resonar. Lo que importa no son los objetos intrínsecos o fijados históricamente de la cultura, sino el estado de juego en las relaciones culturales: hablando francamente y con un exceso de simplificación: lo que cuenta es la lucha de clases en la cultura y por la cultura. Casi todos los inventarios fijos nos traicionarán (1994:7).

En diálogo con esta propuesta resulta pertinente traer de nuevo a Martín Barbero quien analizando y especificando la idea de cultura popular de Michel de Certau plantea que de lo que el francés en realidad habla es de la "impura y conflictiva cultura popular urbana" (1991:94), y que en tal caso, popular sería "el nombre" que se le da a una serie de prácticas insertas en la modalidad industrial, o que incluso más bien sería "el lugar" desde el que deben ser miradas para desentrañar sus prácticas:

cultura popular habla entonces no de algo extraño, sino de un resto y un estilo. Un resto: memoria de la experiencia sin discurso, que resiste al discurso y se deja decir sólo en el relato. Resto hecho de saberes inservibles a la colonización tecnológica, que así marginados cargan simbólicamente la cotidianidad y la convierten en espacio de una creación muda y colectiva. Y un estilo, esquema de operaciones, manera de caminar la ciudad, de habitar la casa, de ver la televisión, un estilo de intercambio social, de inventiva técnica y de resistencia moral (1991:94).

Esta mirada aporta una vez más a la idea de lo popular como una experiencia. Más cercana a una posición política que a una posición de pertenencia, de consumo, o de acceso a ciertos bienes culturales.

\section{Lo popular y las tradiciones}

Pensar lo popular como experiencia, o como costumbre en común (en términos de Thompson, 1995), resulta interesante también para interpelar en nuestro continente la mirada que se ha tenido sobre lo indígena, sobre los pueblos que lo habitaron desde antes de la violenta irrupción de los colonizadores. Muchas miradas romantizan y esencializan a estos pueblos y los congelan con el mote de "originarios", clavándolos con alfileres en una vitrina, marcándoles como artículos de un inventario, exigiéndoles el sostenimiento de la pureza de su cultura e historia primitiva, desconociendo su vitalidad y actualidad, dado que se trata de culturas que se siguen insertando y entramando en las vidas y culturas urbanas actuales. 
Si no se sostiene una mirada de dinámica histórica, en la que reconocer momentos diversos, tensiones, contradicciones, luchas, avances y retrocesos, asunciones, presencias, complicidades o reivindicaciones, solo veremos en ellos pérdida de identidad, contaminación de su pureza. Sin poder reconocer todo lo que han afectado y afectan en la vida cotidiana, en el paisaje, en las prácticas, en los sentidos. En definitiva en todo lo que implica la cultura.

Asumiendo a lo indígena como espacio de lo popular, vuelve a ser pertinente no imaginar ni pretender suponer una total autonomía por fuera de las estructuras del capitalismo y del mercado. El que muchas veces los toman y utilizan como pieza de museo, como motivo autóctono, como diseño orgánico. Pero a la vez pudiendo reconocer que esa es una manera de persistencia y de acceso, como una estrategia de reconocimiento, en su multideterminación de etnia y clase. En palabras de Martín Barbero, "se configura así un mapa nuevo: las culturas indígenas como parte integrada a la estructura productiva del capitalismo pero sin que su verdad se agote ahí" (1991:206).

Dice también Martín Barbero que la cultura popular, permanentemente asediada por la cultura hegemónica, vive una continua contradicción "amenazada de desaparición va a ser al mismo tiempo tradicional y rebelde. Mirada desde la racionalidad ilustrada esa cultura aparece conformada únicamente por mitos y prejuicios, ignorancia y superstición" (1991:108).

Obviamente la vinculación de la tradición y lo popular no está solamente vinculado a lo indígena, sino también a su continuidad en la mistura y tensión con lo colonial, y los procesos de lo criollo como cultura donde se empiezan a confundir en esa intersección, a la vez que en la construcción concentrada, porteñocéntrica, de la mirada cultural hegemónica de nuestro país, también puede leerse y posicionarse a todo lo que se denomina como "el interior", asociado habitualmente con lo tradicional en términos de atraso, de resistencia a los avances a la modernidad. Mirada que fue instalada con éxito en la historia oficializada por la denominada generación del $80^{30}$ y que ha persistido desde entonces instalada, un siglo y medio después, siempre en su afán modernista, proyectado con aires de superioridad por sobre el resto de la geografía. A la vez que puede leerse de modo similar en las grandes ciudades en su relación con sus barrios externos, con sus zonas periféricas. 0 también con los asentamientos y villas que se instalan dentro mismo de las capitales.

Esta mirada tiene mucho que ver con lo que la llegada de lo que este "proyecto nacional" propuso y propone en la cultura popular de las diversas regiones del país. La llegada de la modernidad se ofrece como conjunto con la instalación en nuestro país de los capitales extranjeros y sus modos de producción intensivo. En tal caso la llegada del capital propone no solo otro modo (por cierto

30 Aquel grupo político de ideales liberales positivistas, integrado por Bartolomé Mitre, Domingo Sarmiento, Julio A. Roca, entre otros. Este grupo disputó el poder en nuestro país y logró conducir los gobiernos nacionales en el momento en que se estaba conformando la identidad nacional, históricamente suele caracterizarse el período 1880-1916, aunque este grupo logró su dominio a partir de la denominada Batalla de Pavón (1861), produciendo un bloque ideológico que resultó hegemónico, aún a pesar de haber sido luego desplazados por sectores más progresistas. 
desmesurado para producir y extraer beneficios de la tierra y para explotar la fuerza de trabajo de sus habitantes) sino sobre todo un profundo cambio en el modo de vida impulsado por las exigencias de los productores por surtir a los mercados internacionales ${ }^{31}$.

A la vez, como parte del proyecto de instalación de modernización masiva la generación del '80 fomentó la llegada de contingentes migratorios europeos, con la esperanza de que influyeran culturalmente con su estilo de vida (que por ser europeo suponían civilizado por definición) sobre la población local. Lo que ciertamente hicieron. Solo que en esos contingentes apenas llegó la imaginada "alta cultura europea", y en cambio sobre todo trajeron a las culturas populares de los pueblos más empobrecidos de aquel continente. $Y$ con ellos también una serie de prácticas y significantes contrahegemónicos, como los de la organización obrera, los idearios anarquistas y socialistas, junto con otros tantísimos "malos ejemplos" de la época, los que trashumando hasta los más recónditos rincones del territorio se fueron mestizando con las culturas locales. Es que con los migrantes que provenían de sectores desplazados, también viajaron sus culturas desplazadas, o desclasadas, las culturas de los sujetos excluidos que se vieron obligados a desarraigarse en busca de otro tipo de subsistencia.

En este sentido es posible considerar a la tradición como parte necesaria y hasta vital de la cultura, pero esto no implica como antes decíamos, la persistencia momificada de formas originales, sino que lo interesante es el modo en que las tradiciones se articulan con otros significantes más actuales, aún con aquellos que podrían leerse como contradictorias a simple vista. Tal como afirma Stuart Hall

es frecuente que la lucha cultural se manifieste de la forma más aguda justamente en el punto donde se encuentran, se cruzan, tradiciones distintas, opuestas. Tratan de despegar una forma cultural de su implantación en una tradición y de darle una nueva resonancia o acento cultural. Las tradiciones no son fijas para siempre: ciertamente no lo son en ninguna posición universal en relación con una sola clase. Las culturas, concebidas no como «formas de vida» separadas, sino como «formas de lucha» se cruzan constantemente: las luchas culturales pertinentes surgen en los puntos de cruzamiento (1984:8).

Como ya dijimos antes la recuperación de lo residual o lo emergente puede ser utilizado tanto para la resistencia como para reforzar la posición de poder. En este sentido también se puede pensar lo que ocurre con la tradición, que puede ser usada como estrategia de resistencia de los sectores populares, pero que en nuestra historia también ha sido utilizada por la cultura hegemónica. En el sentido de lo que hoy podríamos llamar el "tradicionalismo", una cultura que debe en parte a la invención de la gauchesca propuesta por escritores como José Hernández en la construcción nacional de la generación del '80, o en la invención del criollismo impulsado por la recuperación conservadora de la denominada década infame (caracterización del período 1930-1943), en la folklorización

31 Algo que con sus matices aún hoy en día sigue ocurriendo de modo similar. 
mediatizada de la cultura nacional, o en la recuperación más actual de "todos somos el campo"32 impulsada por los sectores agrícolas de la explotación sojera intensiva, quienes apoyados por el sistema de medios hegemónicos (quienes también participan con intereses económicos en la siembra extensiva de soja) lograron profundizar la utilización e instalación de la idea de que el campo de la pampa húmeda es la metonimia de la totalidad del país, mito porteñocéntrico que desde una mirada miope del territorio nacional se adjudica la centralidad en la provisión de riquezas para instalar en la opinión pública significantes y símbolos de la cultura rural de manera cristalizada, ya desprovista de todos los rasgos populares conflictivos, y en la que a la pasada, y en el mismo movimiento, se niega, se invisibiliza la diferencia, la enorme diversidad geográfica y cultural del territorio argentino, en la que hay mucho más que pampa, y en la que incluso hay un enorme terreno marítimo aún más invisibilizado.

\section{La cultura popular o lo otro excluido}

En esta trama muchas veces contradictoria de sumisiones y resistencias, incorporaciones y oposiciones, hay una cuestión que Hall resalta: la idea de lo popular como una relación "un tanto desplazada" entre la cultura y las clases,

esa alianza de clases y fuerzas que constituyen las «clases populares». La cultura de los oprimidos, las clases excluidas: este es el campo a que nos remite el término «popular». Y el lado opuesto a éste —el lado que dispone del poder cultural para decidir lo que corresponde y lo que no corresponde- es, por definición, no otra clase «entera», sino esa otra alianza de clases, estratos y fuerzas sociales que constituye lo que no es «el pueblo» y tampoco las «clases populares»: la cultura del bloque de poder (1984:9).

En esta postura se configura lo que podríamos considerar como una contradicción principal, la de lo popular, el pueblo, como un bloque en contra del bloque de poder, las fuerzas populares contra aquel bloque que permanentemente le impugna su posibilidad (y hasta su derecho) a participar en el campo cultural.

Y en el mismo sentido, sin homogeneizar, ni alizar el campo popular, es interesante recuperar otra idea planteada por el mismo autor,

la cultura popular es uno de los escenarios de esta lucha a favor y en contra de una cultura de los poderosos: es también lo que puede ganarse o perderse en esa lucha. Es el ruedo del consentimiento y la resistencia. Es en parte el sitio donde la hegemonía surge y se afianza (1984:10).

la de la necesaria pugna política por aportar a la construcción de la cultura popular. En tanto, en términos de esta contradicción principal, si no se apoya la cultura popular se estará apoyando la

32 Significante que se convirtió en slogan a partir de la disputa por "la 125" generada entre el gobierno y los sectores agroexportadores, en referencia a la resolución 125 del Ministerio de Economía y Producción, publicada en marzo de 2008 que fijaba una modificación en la política arancelaria de exportación de granos.

Disponible en http://servicios.infoleg.gob.ar/infolegInternet/anexos/135000-139999/138567/norma.htm 
cultura del poder y al reforzamiento de las desigualdades. Como en el mismo movimiento se puede favorecer a esa exclusión que se produce desde el momento mismo en que se marca la diferencia.

\section{Los estudios culturales y el proyecto decolonial}

Si hablamos de exclusión y de diferencia, y si retomamos esa idea del "interior" como "atrasado", es necesario considerar que se trata de significantes que se configuran en función de una idea de cultura que proviene de un sentido único instalado, y por oposición de un ideario de lo que se considera lo "adelantado" o al menos un horizonte cultural, que en nuestra historia siempre ha estado marcado de manera hegemónica por Europa, por una Europa obviamente idealizada en la que también están invisibilizadas las diferencias y las desigualdades.

Ese ideario que fue clavado en nuestro continente con la llegada de los colonizadores, pero además luego fue reactualizado en sucesivas oportunidades y de diversas maneras. Ya sea mediante las conveniencias de la clase criolla local, o por la llegada de capitales extranjeros de otras colonias, o por las construcciones de los proyectos nacionales y sus acciones económicas, o por la instalación de tratados internacionales, o por las acciones de las geopolíticas internacionales en el marco de la guerra fría y del desarrollismo, o por las más actuales definiciones de democracia liberal y la irrupción de los gobiernos de los gerentes en la región.

Un paradigma de racionalidad acumulativa, de cierto orden pulcro que impulsa una estética unificada (y por cierto mercantilizada), que por lo general se mueve y construye en un tiempo ahistórico, que anula las diferencias y sus contextos. Para a la vez producir así un otro por fuera del esquema, la diferencia excluida, el atrasado, lo que está por fuera de LA cultura.

Esta sea tal vez una de las cuestiones más intrigantes de comprender de este orden colonial que aún sigue siendo, que aún sigue operando de manera compleja, pero que al mismo tiempo aún en su poder, no logra aplacar lo que ese fondo desplazado sigue pugnando. Tal como dice Martín Barbero comprender tanto lo que en la diferencia histórica ha puesto el atraso, pero no un tiempo detenido, sino un atraso que ha sido históricamente producido — niños que mueren diariamente por desnutrición o disentería, millones de analfabetos, déficit de calorías básicas en la alimentación de las mayorías, baja en las expectativas de vida de la población, etcétera - , como lo que a pesar del atraso hay de diferencia, de heterogeneidad cultural, en la multiplicidad de temporalidades del indio, del negro, del blanco y del tiempo que hace emerger su mestizaje (1991:165)

33 También resulta interesante este otro fragmento que amplía aún más esta misma idea, y le otorga otras nociones contextuales: "Sólo desde esa tensión es pensable una modernidad que no se reduzca a imitación y una diferencia que no se agote en el atraso. Ahí apuntaba la difícil lucha de Bolivar por adecuarlas doctrinas políticas de su época a la "gramática déla diversidad"racial, geográfica, climática y cultural de estos países, por adecuar el liberalismo a las exigencias de una sociedad en formación, en la que a nombre de la igualdad el liberalismo acababa haciendo de la libertad un principio de los fuertes2.

Bolivar proponía un tipo de Nación que no se recortaba sobre el calco de la Nación europea, y un tipo de Estado que, abatiendo el poder absoluto, fuera sin embargo suficientemente fuerte para defender a los débiles contra las clases ricas. linea de pensamiento y lucha que continúa Martí colocando el obstáculo fundamental a la construcción de estas 
Desde estas particulares características, desde esa tensión siempre latente se construyen los nacionalismos de nuestra región, en las que de algún modo se incorpora algo de lo criollo como una especie de ingrediente típico para sazonar la cultura hegemónica. Una síntesis cultural que tendrá sus particularidades regionales, pero que siempre serán expropiadas de manera recurre para el sentido de la bandera y siempre referidas desde la metrópoli. Se trata de un movimiento de adaptación económica que recurre a acciones políticas que pueden leerse también y tal vez sobre todo en políticas culturales.

En la articulación entre cultura y poder la lectura de los estudios culturales resulta pertinente, y en ese movimiento de atención a las particularidades deben reconocer su espacio situado, la topografía desde la que se enuncian. En todo lo antedicho se configuran nuestras subjetividades. Y en particular en el caso de nuestras posiciones como investigadores, en algún punto como intelectuales, también se hacen presentes estas mismas tensiones. Las academias, las universidades, han construido sus propias acciones culturales, acciones políticas de adaptación en las que también pueden leerse las presencias de la colonialidad. Una colonialidad intelectual que muchas veces ha elegido sesgar los cristales con los que mira, ya sea por eso de acudir a "las seguridades teóricas" enunciadas por Martín Barbero, o ya sea por cierto desprecio a lo propio o lo local, en el marco de un "colonialismo intelectual". En tal caso hay una enorme tradición académica que en el caso de nuestras universidades está mirando siempre a Europa y sobre todo parece tener, al menos en Argentina, una especial atención -o atracción- hacia la producción de la intelectualidad de Francia.

En ésto es donde se hace necesario prestar atención a los proyectos decoloniales, los que nos permitan al menos prestar atención a esta tendencia, para ponerla en tensión, para propiciar su deconstrucción, y para de a poco empezar a trazar vínculos con otro polos. Sobre todo con los pares, poniendo énfasis en lo que se construye en nuestro continente en este sentido, y para empezar a prestar atención a lo que se construye en otros continentes que no necesariamente sean la metrópoli Europea. En lo que diversos intelectuales de esta perspectiva denominan como el eje sur-sur.

Eduardo Restrepo (2012), citando a Walter Mignolo (2003) advierte que los estudios culturales latinoamericanos deben poder diferenciarse de los provenientes de Inglaterra y Norteamérica, y a la vez poder establecer grises entre los proyectos institucionales y los intelectuales. Según Restrepo esta diferencia deba establecerse por lo que ha producido el proyecto de la Universidad Simón Bolívar de Quito Ecuador donde los Estudios Culturales Latinoamericanos tienen un alto grado de institucionalización. Pero que también podríamos complejizar con los aportes ya

naciones en la no comprensión "de cuáles desordenados elementos* se habían forjado las nuevas naciones con tanta prisa"3. Y la de Mariátegui insistiendo denodadamente en que la tarea de estos países no es alcanzar a Europa, redescubriendo el valor y el sentido del mito y proclamando que en América Latina "había que soltar la fantasía, libertar la ficción de todas sus viejas amarras para descubrir la realidad" 4. (Martín Barbero, 1991:165166). 
citados de Jesús Martín Barbero en Colombia, o los de Anibal Ford en Argentina, a la vez que tantos otros.

Restrepo insiste en la idea de que incorporar las ideas, conceptos y proyectos de los estudios culturales ingleses (por ejemplo) no quiere decir asumir necesariamente sus proyectos intelectuales. Del mismo modo plantea generar algunas precisiones con respecto a los estudios sobre subalternidad y sobre los estudios poscoloniales.

Con respecto a los estudios de la subalternidad, que pueden referenciarse con las formulaciones desde la India en los años ochenta por Ranajit Guha o Gayatri Spivak, por citar dos ejemplos, quienes critican las construcciones de la historiografía elitista sobre su país y desde allí recuperan las capacidades de agencia de los sectores subalternos. Sectores de los que los estudios culturales también se ocupan, pero que aclara no necesariamente implica confundirlos.

Del mismo modo argumenta matices con respecto a la teoría poscolonial, sobre todo la presentada por el palestino Edward Said, en su referencia a la experiencia colonial como una relación estructurante tanto para el colonizador como para el colonizado, en su obra Orientalismo (1978). O la propuesta del martinico Frantz Fanon con su elaboración en torno a Los condenados de la tierra (1961), ambos son releídos y de algún modo redescubiertos en este contexto de crisis y si bien el colonialismo continúa teniendo presencia configuradora sobre subjetividades, corporalidades, espacialidades y prácticas, según aclara Restrepo "no se puede confundir estudios culturales con teoría poscolonial, aunque esta última haya sido inspiradora y sea apropiada por los primeros" (2012:144).

\section{Historia popular y memoria colectiva}

Aquellos mitos y significantes que fueron configurados por los colonizadores y que son asumidos e incorporados por los pueblos dominados, han sido tema de discusión y estudio en las relecturas de la historia y en los programas de construcción de memorias. Los que a partir de los aportes historiográficos de los estudios culturales ingleses, o de las propuestas latinoamericanas de la comunicación vinculadas a la cultura como las de Jesús Martín Barbero, han permitido otorgar mayor lugar y atención a las experiencias de las vidas cotidianas de los sectores populares.

En De los medios a las mediaciones (1991), Martín Barbero, justamente apunta a la idea de romper con el desencuentro entre "método y situación". Buscando reconsiderar los caminos de las disciplinas y sobre todo revisando el sentido de las preguntas que han guiado sus caminos.

Las razones del desencuentro apuntan más allá de la teoría, a un des-conocimiento que, en lugar de más conocimiento en la lógica pura de la acumulación, reclama el re-conocimiento, según la lógica de la diferencia, de verdades culturales y sujetos sociales (1991:204).

Interpelando en ese reconocimiento de los sujetos sociales de los sectores populares, al reconocimiento de un mestizaje que en nuestro continente no es cosa del pasado, de lo originario, 
sino parte constitutiva de lo que somos, aclarando una complejidad extra, que "no es sólo hecho racial, sino razón de ser, trama de tiempos y de espacios, de memorias e imaginarios que hasta ahora únicamente la literatura había logrado decir" (1991:204). Se trata de una propuesta para que ese "mestizaje", esa cultura de los sectores populares, deje de ser tema, deje de ser objeto de investigación, para pasar a ser sujeto, y además un sujeto con capacidad de habla, con una lengua propia, con un modo de vivir, con un modo de experimentar y narrar propio.

A diferencia de la memoria instrumental, la memoria cultural no trabaja con "información pura" ni por lineariedad acumulativa, sino que se halla articulada sobre experiencias y acontecimientos, y en lugar de acumular, filtra y carga. No es la memoria que podemos usar, sino aquella otra de la que estamos hechos. Y que no tiene nada que ver con la nostalgia, pues su "función" en la vida de una colectividad no es hablar, del pasado, sino dar continuidad al proceso de construcción permanente de la identidad colectiva (1991:200).

En este sentido el reconocimiento de estas memorias desplazadas, ignoradas, se plantean desde una sensibilidad política, en oposición a una "razón instrumental", en busca de recuperar identidades, de construcción de lazos de saberes otros, en la promoción de solidaridades que recuperen sentidos presentes pero ignorados. Para poder intervenir sobre las desigualdades, sobre las negaciones, y reivindicar las acciones y memorias propias.

Recorriendo los sentidos sobre el reconocimiento del que está hablando, Martín Barbero establece una especificación, posicionando dos perspectivas. Una situada en el plano del conocer, en la que re-conocer es una pérdida de tiempo, y si además por isotopía se le suma el sentido ideológico en el que se considera territorio de la alienación, implicaría aún más, sería un des-conocimiento. Pero aclara que hay un otro sentido que resulta interesante, desde la matriz en la que re-conocer significa interpelar

cuestión acerca de los sujetos, de su modo específico de constituirse. Y no sólo los individuales, también los colectivos, los sociales, incluidos los sujetos políticos. Todos se hacen y rehacen en la trama simbólica de las interpelaciones, de los reconocimientos. Todo sujeto está sujeto a otro y es a la vez sujeto para alguien (1991:243-244).

En este mismo sentido, y en el marco de culturas en las que las narrativas tienen importancia considerable, es también importante poder reconocer los modos en que producen sus memorias y relatos, y como muchas veces las disciplinas y metodologías de las ciencias sociales se han ocupado de aplastar la riqueza de sus manifestaciones que no siempre se pueden contener en la palabra escrita. Muchas veces en sus lógicas de relato popular, de memoria cultural, por fuera de la lógica del saber acumulativo, racionalizado, no cuenta con la información prolijamente ordenada, ni tal vez aparezca presentada de un modo eficiente para los estándares de la historia. También es importante cuidarse de no terminar en el otro extremo y fetichizar esas memorias. De lo que se trata es de producir el esfuerzo por reconocer los modos propios de producción de esos relatos. 
Aquí resulta pertinente recuperar un trabajo de Aníbal Ford (1994b), quien para discutir la hegemonía de la palabra escrita en su uso instrumental, para la narración, para la argumentación, pone como ejemplo los procesos de modernización y constitución del Estado Nacional Argentino y como las incursiones militares al sur del territorio, que darían lugar al enorme genocidio que la historia oficial a llamado "La Campaña del Desierto", serían escenario de enormes batallas no solo en términos militares, sino también violentos choques culturales, entre la cultura modernizadora y letrada -en sus propios términos "civilizadora"- que colisionaba contra las culturas de las comunidades indígenas. Así Aníbal Ford recupera los siguientes testimonios para reivindicar la oralidad, la narratividad y la comunicación no verbal de dichos pueblos:

«A mí me parece que las palabras escritas pierden el valor que la boca les ha dado» (Tralamán). «Cómo se hace perdurar para siempre una tradición mapuche, ¿escrita o contada?: Solamente una nütran (narración de sucesos reales) o una epeu (narración de ficciones, cuentos, fábulas) no se va a perder. Las cosas escritas se pierden, la palabra escuchada queda para siempre» (Kinchauala). «El uinka (blanco) no sabe leer ni en la cara ni en el alma de nosotros. Para nosotros todo habla; un movimiento de la cara, de las manos, es una enseñanza, un aviso para cuidarnos...» (Uenchu Küdel) (Ford, 1994b:4).

Poder reconocer estos sentidos otros, estas variantes en los modos de producir, reproducir o gestionar las memorias es importante para no violentar esas memorias, para no producir modos que supongan que en lo escrito, que en la palabra impresa, se resguarda la totalidad de los sentidos que la cultura produce. En definitiva, no dejar de reconocer en la escritura una tecnología, una herramienta del poder, con la que obviamente nosotros también podemos producir y con la que hemos logrado modificar nuestras posiciones en el campo, pero que en el fondo siempre esconde la racionalidad del poder moderno. Uno de los modos con los que la hegemonía sigue actuando desde adentro y por lo que es necesario comprender y reconocer otras racionalidades, otras matrices de producción.

Si llevamos esta misma pregunta a los espacios de museo deberíamos sumarle la doble precaución, dado el poder instituido que el dispositivo tiene en cuanto espacio de saber, como espacio de recorte habilitado de la cultura. Un espacio que el museólogo francés Hugues de Varine (1979), y diciéndolo además desde Francia, denomina como "un fenómeno puramente colonialista". Según afirma

han sido los países europeos los que han impuesto a los países no europeos su método de análisis del fenómeno y patrimonio culturales: han obligado a las élites de estos países y a los pueblos a ver su propia cultura con ojos europeos (1979:12-13).

En este caso, pensando esta pregunta es que tal vez haya que pensar hasta qué punto el dispositivo mismo es una herramienta del poder, hasta qué punto podemos buscar justicia para los sectores desplazados, olvidados o ignorados, si será eso posible desde semejante espacio de poder institucionalizado. $Y$ una posible respuesta tal vez tenga que ver con activar por un lado la posibilidad 
de mostrar los hilos del dispositivo, por exponer los engranajes de la maquinaria, por explicitar las estrategias y los supuestos teóricos que lo sustentan. Pero a la vez, tal vez otra respuesta tenga que ver con habilitar otro tipo de lenguajes, otro tipo de diseños, o hasta experimentar con el antidiseño, o el antilenguaje, a tal punto de que si no puede cambiarse el dispositivo, al menos pueda cambiarse el para qué, su función. Que el dispositivo se abra a jugar e inventar en el marco de lenguajes diversos, de poéticas que eviten la negación y la crueldad, que promuevan otro tipo de participación, que habiliten a la escucha, que interpelen a la pregunta, que estén abiertos al reconocimiento de otras perspectivas y de otras matrices de producción.

\section{Recuperación de la experiencia}

La idea de reponer una serie experiencias de trabajo concreta no surge espontáneamente. Es el resultado de una decisión, implica el reconocimiento de que esos espacios y esas prácticas cargan con el suficiente valor para considerarlos como objetos de nuestra atención y a la vez implica recuperar un modo particular de investigación social, al considerarlos fuentes de conocimientos. Implica una oportunidad para recuperar acciones, decisiones, estrategias, para reflexionar críticamente sobre las experiencias, haciendo un recorrido intenso sobre ellas. Requiere de una voluntad de trabajo con otros, ya que nadie puede recuperarle a otro la propia experiencia. Lo que se puede es propiciar marcos de aproximación, se pueden compartir aportes metodológicos, facilitar instancias de diálogo y reflexión para que la recuperación se produzca de la manera más compleja posible, pero el resto es potestad, es territorio, de cada sujeto. Esta decisión implica la voluntad de reconocernos como sujetos del hacer, pero también como sujetos de saber.

En este caso además se trata de recuperar las experiencias de trabajo en museos a través del relato de sus trabajadores y trabajadoras. Espacios que fácilmente podríamos encasillar dentro de aquellas instituciones de mayor formalidad (si se tiene en mente el arquetipo de los museos decimonónicos), pero que justamente desde la selección de referentes empíricos de este trabajo, se puede identificar que se trata de espacios en los que muchos de estos trabajadores y trabajadoras adscriben a la museología social, y por tanto se trata de espacios ocupados por sujetos con cierta voluntad crítica, que dan cuenta en sus relatos de buscar que los espacios donde se desarrollan trabajen por la producción de memoria, desde diversos tipo de prácticas y estrategias. Esto obviamente no les exime de contener cierta institucionalidad y sistematicidad, una direccionalidad conceptual, metodologías propias, o un programa con propuestas pedagógicas. 


\section{Experiencia}

La categoría de experiencia constituye un debate central en las ciencias sociales que adquirió relevancia en términos epistemológicos a partir del llamado giro hermenéutico. El cual provocó el ascenso de la comprensión de los procesos y los sentidos desde los sujetos, las instituciones y la historia, en lugar de la tradición explicativa causal del racionalismo moderno. En este trabajo la misma opera como articuladora entre el sentido político educativo y la intervención situada. Recuperando como matriz fundacional el sentido freireano de praxis, en tanto productor de la articulación del saber/palabra con la acción política propia de la práctica del educador, "hablar la palabra y transformar la realidad" (Freire,2005).

En el mismo sentido, la perspectiva del canadiense Peter McLaren (1995), define a la experiencia como acontecimientos que se dan en las formaciones sociales, los que mediados por el lenguaje son constitutivos de la subjetividad. El proceso dialógico textualiza la vivencia, le otorga sentido, convirtiéndola en experiencias y praxis transformadoras (Fernández, Felli, 2012).

En la misma línea es pertinente el principio de alteridad y reflexividad que aportan LarrosaSkliar (2009) para el análisis de la experiencia en educación. Jorge Larrosa, al igual que otros varios autores, reconoce que existe una multitud de sentidos y usos diversos en torno a la categoría, por lo que propone que es necesario "dignificar" y "reivindicar" a la experiencia, lo que "supone dignificar y reivindicar todo aquello que tanto la filosofía como la ciencia tradicionalmente menosprecian y rechazan: la subjetividad, la incertidumbre, la provisionalidad, el cuerpo, la fugacidad, la finitud, la vida" (Larrosa, 2006: 4).

En función de buscar una especificación, para Larrosa la experiencia puede explicarse mediante la frase "eso que me pasa" (Larrosa, Skliar, 2007: 14). Según el filósofo español en el desglose de esa oración reside el sentido complejo de la categoría. "Eso" implica que la experiencia es un acontecimiento que está por fuera del sujeto, "algo que no soy yo", y por ende "algo que no depende de mí", allí propone el principio de exterioridad y de alteridad de la experiencia. Pero a la vez es eso que "me" pasa, y por ende sucede "en mi" no es algo que esta frente o que pasa cerca, por lo que el sujeto es su domicilio, "el lugar de la experiencia soy yo". A esto lo llama el principio de subjetividad de la experiencia. Y por último se detiene en eso que me "pasa", planteando la idea del tránsito, del pasaje, algo que adviene, que deja una huella, que "me transforma". La experiencia requiere de un sujeto activo, que pone el cuerpo: "la experiencia no se hace, se padece", lo que denomina como el principio de pasión.

\section{Experiencia social}

Al igual que en Larrosa, en la construcción conceptual de Jorge Huergo, también hay una búsqueda por especificar algo de la imprecisión y vaguedad que flota sobre el uso del concepto de 
experiencia. En el caso de Huergo y Morawicki (2008), direccionando su atención sobre la dimensión del sentido social de la experiencia desde la mirada de comunicación/educación.

Para ello recupera las miradas de pedagogos de diversos tiempos históricos y geografías. Por un lado, la experiencia del viaje de Simón Rodríguez (junto a Simón Bolívar) en la que las diversas aventuras de la travesía advienen en proceso educativo, a partir de la que Huergo dirá que "el pedagogo es el viaje". También la vida social como experiencia educativa en la producción del norteamericano John Dewey, que resalta la experiencia práctica social como fuente de aprendizajes significativos, por lo que sugerirá que la única manera de preparar al niño para la vida social es sumergiéndolo en la vida social. Asimismo retoma de Célestin Freinet quien desarrolla en Francia una experiencia en la que los niños salen a investigar a la comunidad y luego publican lo aprendido en un periódico escolar que es distribuido en la comunidad. De la que se pueden retomar dos ideas centrales: por un lado una búsqueda expresiva, al decir que a los niños no hay que hacerlos producir solo para la práctica escolar, sino que "deben escribir para ser leídos" y al igual que Dewey, reclama la confianza en la vida social como espacio de aprendizaje, asegurando que a los niños no hace falta darles contenidos de la cultura para la vida sino que éstos adquieren la cultura en la experiencia de vida social cotidiana. En la misma tónica Saúl Taborda -en Argentina- pone énfasis en la recuperación de la experiencia histórica popular, y en la vivencia y experiencia juvenil, a quienes incentiva en su predisposición a participar de la vida de los espacios comunales como fuente formativa, asegurando que estos espacios cuentan con con una didáctica propia (que según describe sería herética desde el punto de vista de la didáctica oficial).

Más allá de estos recorridos, que complementa con otras visiones y definiciones sobre la experiencia a lo largo de la historia, Huergo y Morawicki invitan a no reducir la experiencia a una cuestión de forma, a no reducirla a una cosa, a no privilegiar la racionalización calculadora, sino a comprometerse con una búsqueda de encuentro con lo desconocido que se asegura imprevisible y que resulta intransferible, "no se trata ya de privilegiar el dispositivo, sino de animarnos a la incontrolable vivencia del encuentro con otros, (...) nunca sabemos dónde va a parar, cuál será el destino de una experiencia de encuentro, incluso puede ser el fracaso" (Huergo, Morawicki, 2008).

Más allá de la recuperación de las experiencias que son objeto de este trabajo de investigación, es necesario resaltar que en la práctica cotidiana de los museos que trabajan en la perspectiva de la museología social, también se dedican de manera cotidiana junto con quienes visitan sus espacios, y sobre todo con las comunidades inmediatas, de hacer un trabajo de recuperación de experiencias, con el objetivo permanente de recuperar historias de esas comunidades. Tal como afirma Oscar Jara "Las experiencias, son esencialmente procesos vitales que están en permanente movimiento y combinan un conjunto de dimensiones objetivas y subjetivas de la realidad histórico-social" (2006: 7). A la vez que esas experiencias nunca son aisladas, por más que 
esa sea la percepción del sujeto. Para Antonio Ghiso "el sujeto de la práctica social no es un sujeto solitario, es una persona que se ubica 'en relación' a una situación, a unos problemas, a unos grupos o instituciones, a unos saberes y conocimientos, a unas opciones políticas, económicas culturales. El sujeto que sistematiza es un sujeto en relación, su práctica social o educativa la construye en relación y cobra sentido en ésta" (Ghiso, 2006: 41).

\section{Sistematización de experiencias}

En la complejidad del día a día, de las acciones cotidianas, es muy fácil que las experiencias se nos escapen de entre los dedos, que se nos vayan de la memoria si no nos ocupamos de enmarcarlas en algún momento, mediándolas a partir de diversas estrategias y dispositivos.

Con previsión metodológica es posible lograr que la sistematización de conocimientos se transforme en un proceso permanente, acumulativo, que permita construir conocimientos sobre nuestras acciones y decisiones, sobre nuestra realidad social. Tal vez una oportunidad única de aprender de lo que hicimos, de nuestros aciertos y errores, de recuperar nuestras ocurrencias, y transformarlas en parte de nuestros repertorios de prácticas.

Según José Hleap, el sentido de la recuperación de experiencias es una producción, una actividad constructiva a través de la cual los distintos actores le dan intencionalidad, dirección, y sentimiento a lo vivido. Esta producción del sentido de la experiencia se hace en y por el lenguaje, donde este no es un instrumento transparente y neutro, un intermediario a través del cual asumimos la realidad, es el mediador que funda la relación entre el sujeto y el mundo (su pertenencia cultural), de modo que vincula y construye, transforma y le da forma a la experiencia (Hleap, 1999: 3).

La sistematización de la experiencia nos permite dar respuesta a nuestras preguntas a través de encontrar juegos de sentido, dinámicas, reconstruyendo desde alli las relaciones que se dan entre actores, saberes y procesos de legitimación, recuperando así desde un trabajo etnográficohermenéutico. Lo que Hleap considera como la posibilidad de hacer legible "la densidad cultural de la experiencia" (Hleap, 1999: 3).

Para Jara, la sistematización de experiencias relaciona los procesos inmediatos con su contexto, "confronta el quehacer práctico con los supuestos teóricos que lo inspiran" (1999: 57). Se crean así nuevos conocimientos a partir de la experiencia concreta, pero, "en especial -en la medida en que su objeto de conocimiento son los procesos sociales y su dinámica- permite aportar a la teoría algo que le es propio: explicaciones sobre el cambio en los procesos" (Jara, 1999: 57).

En este movimiento interpretativo se construye conocimiento a la vez se genera una nueva experiencia, otro punto de partida para el proceso. Según Lola Cendales

toda sistematización, como modalidad colectiva de producción de sentidos, es siempre una experiencia inédita, dado que lo que se ponen en juego no son un conjunto de procedimientos 
y técnicas estandarizadas, sino las vivencias, sueños, visiones y opciones de individuos y grupos que la asumen como posibilidad de auto comprensión y transformación (en Jara,2006: 29).

Por ello durante este trabajo aparecerán, mediadas por el relato, las reflexiones que se originan a partir de las decisiones, de los marcos de comprensión, los desafíos propios y colectivos, los diálogos y discusiones, las memorias y las ganas o deseos puestas en juego, como parte de un proceso formativo. Para Ana Bickel (en Jara,2006), la importancia de la resignificación de lo que hacemos potencia los cambios producidos por la experiencia, en el sentido de que la sistematización no solo descubre elementos relacionales a la práctica pasada, sino que además permite que esta praxis trascienda al presente y cobre dimensión de futuro, es decir que la misma sistematización permite fortalecer el proceso de transformación de la realidad. En el mismo sentido considera que existe allí una dimensión política al aportar a un modo de construcción de conocimientos que otorga autonomía a los sujetos para buscar caminos de transformación de los espacios y contextos en los que interactúan.

En este mismo sentido desde un enfoque histórico dialéctico, para Alfredo Ghiso, las experiencias hacen parte de una práctica social e histórica general -igualmente, dinámica, compleja y contradictoria- que pueden ser leídas y comprendidas de manera dialéctica. Dado que estas prácticas están en relación con otras similares en contextos que permiten comprenderlas,

las experiencias son entendidas como espacios de interacción, comunicación y de relación: pudiendo ser leídas desde el lenguaje que se habla y en las relaciones sociales que se establecen en estos contextos (...) expresadas en los procesos conversacionales que se dan en toda práctica social. Las claves son: reconocer toda acción como un espacio dialógico, relacionar diálogo y contexto, o sea introducir el problema del poder y de los dispositivos comunicativos de control, reconociendo en las diferentes situaciones los elementos que organizan, coordinan y condicionan la interacción (1999: 9).

\section{Sistematización de experiencias: camino de conocimiento de los procesos latinoamericanos}

De acuerdo a la recuperación realizada por Oscar Jara existen diversas acepciones para definir a la sistematización. La más utilizada (y no por eso menos válida) es la que en diversas disciplinas refiere a la tarea de catalogar, ordenar datos, a "ponerlos en sistema". En cambio, dice que desde los proyectos sociales y desde la educación popular en Latinoamérica se aplica no solo a la recuperación de datos o informaciones, sino a experiencias, y que por ello se habla de "sistematización de experiencias" (2006:7).

Según afirma, esto no tiene que ver con un capricho, o con una "aventura conceptual", sino que responde justamente a experiencias históricas, políticas y sociales concretas de nuestro continente, las que fueron de tal densidad que requirieron de otros métodos de producción de 
conocimiento. A la vez que al ser muchas de éstas experiencias de tipo revolucionario animaron justamente a cuestionar los modos y saberes establecidos.

A partir de experiencias como la de la Revolución Cubana en 1959, se ponía de manifiesto que en nuestro continente era posible imaginar y realizar proyectos de sociedad distintos a los impulsados por los países centrales, proyectos en los que pudiésemos buscar nuestros propios caminos para encontrar la justicia social y la autodeterminación, que era posible construir marcos propios de interpretación y de producción teórica que surgieran de nuestras particularidades. La respuesta hegemónica a ese momento histórico, propiciada principalmente por las acciones continentales de la "Alianza para el Progreso" no hicieron más que confirmar esta misma lectura, dado que lo que proponían -en reacción- eran diversos proyectos destinados a traer "modernización" o "cultura" -en sus términos- a los pueblos de América, en acciones estandarizadas, al modo de recetas que se aplicaban indistintamente, sin importar los lugares, las culturas, costumbres, ideas, 0 necesidades de los pueblos en los que intervenían.

En la misma línea de los proyectos latinoamericanos durante esos años se siguieron produciendo otros ejemplos notables, como el del gobierno de la Unidad Popular en los '70 (con el liderazgo de Salvador Allende, quien fue elegido en elecciones democráticas como presidente de Chile), en el que se desarrollaron acciones de transformación social y políticas de Estado inéditas, que también requirieron de otros modos de producción.

Lo que ocurría en esas décadas en nuestro continente, según Alfonso Torres Carrillo, es que se trataba de producir un conocimiento

diferente al modo de investigar predominante en el mundo académico, impregnado de positivismo, colonialismo intelectual y desconocimiento del saber de los sectores populares. Se procuraba que las metodologías utilizadas fueran consecuentes y coherentes con los criterios pedagógicos de las prácticas educativas populares: generación colectiva de conocimiento, valoración de los saberes populares y diálogo de saberes, partir de la realidad para volver a ella, reflexión crítica frente a las ideologías dominantes, participación activa de los sujetos involucrados, etc. (Torres Carrillo, 2008: 33).

Según Jara (2011), son Leticia Cáceres y María Rosario Ayllón quienes comienzan a construir los antecedentes de la sistematización, apoyando sus bases en el campo del trabajo social de los '50 y '60. Momento en que existe una búsqueda de profesionalización de lo que se conocía como "asistencia social" y que estaba fuertemente influenciado por concepciones norteamericanas que impulsaban el "metodologicismo aséptico".

El sentido inicial del término estuvo por la idea de recuperar, ordenar y clasificar información de los servicios sociales, aunque más cerca de los '70 encuentran la denominada "reconceptualización del Trabajo Social" desde un enfoque anclado en la realidad latinoamericana y en confrontación con la pretendida neutralidad metodológica norteamericana. 
La principal conquista del Movimiento de Reconceptualización fue el rechazo de los asistentes sociales a caracterizarse exclusivamente como agentes técnicos ejecutores de las políticas sociales. A través del proceso de recalificación, principalmente con el ingreso de estos profesionales en el ámbito de la investigación académica, fue posible romper con la división establecida de trabajo entre científicos sociales (los teóricos) y asistentes sociales (los profesionales de la práctica) (Netto, 2005: 12) ${ }^{34}$.

Se atribuye así a la sistematización "la misión de recuperar y reflexionar sobre las experiencias como fuente de conocimiento de lo social para la transformación de la realidad, (...) buscando extraer conocimientos de situaciones particulares con el fin de generalizarlas para fundamentar la intervención profesional" (Jara, 2011: 4). La sistematización se procura así como una posibilidad de superar la pretendida separación entre práctica y teoría.

Siguiendo con la recuperación de Jara, ubica dentro de la producción conceptual de la sistematización al trabajo "Sistematización de las prácticas como fuente de teoría" de Ana María Quiroga y Leila Lima, aparecido en 1971, como uno de los primeros artículos publicados sobre la temática desde esta mirada. En paralelo Quiroz y Palma desarrollan su reflexión y propuesta teóricopráctica en función de los desafíos que viven en el Chile de la Unidad Popular, en el que a su vez retomaban los antecedentes del trabajo realizado por Paulo Freire en la Escuela de Trabajo Social (en los años de Frei, 1964-1970), la que caracterizan como una epistemología "que ligaba el conocimiento corriente con el conocimiento científico, que iba en contra del positivismo y del marxismo ortodoxo; que le dio mucha importancia a la práctica e hizo un esfuerzo sistemático por ordenar lo que se iba encontrando" (Jara, 2011: 6).

En todo este período, quienes estaban produciendo este particular modo de sistematización de experiencias intentaban demostrar que los problemas y las necesidades de este lado del mundo tenían características particulares propias de nuestros contextos y que por ello requerían de respuestas y conceptos propios. Estos abordajes se pueden establecer sobre cuatro pilares: a) la referencia a la particularidad del contexto latinoamericano y por tanto, a las perspectivas de transformación social predominantes en el contexto teórico de ese período; b) la negación de una metodología neutra influenciada por las corrientes norteamericanas dominantes; c) la centralidad de la práctica cotidiana y del trabajo de campo profesional como fuente de conocimiento; d) el interés por construir un pensamiento y una acción orientados con rigurosidad científica (Jara, 2006: 10).

Aunque luego este camino de construcción colectiva de conocimientos abierto desde estas experiencias fue violentamente interrumpido por los movimientos de reacción contrainsurgente, propiciados por las doctrinas de seguridad del Departamento de Estado norteamericano, que desembocaron en la instalación de sangrientas dictaduras cívico-militares en la mayoría de los países del continente.

34 Citado en Jara, 2011: 4. 


\section{Sistematización de experiencias educativas}

En los '80 y '90, la sistematización se abrirá otros caminos además del que se desarrollaba desde el trabajo social, impulsándose con fuerza en los procesos de educación de adultos y de educación popular o no formal, que venían produciéndose desde los ' 60 principalmente en los países de Centroamérica ${ }^{35}$. Con estas múltiples experiencias que comienzan a cuestionar los paradigmas de la pedagogía, desde las experiencias de educación en comunidades rurales, movimientos de educación popular que buscan una relación más horizontal, en la que se impulsa la autonomía de los sujetos, por lo que el lenguaje de estos espacios se puebla de "autos": autoaprendizaje, autogestión, autodisciplina, autoevaluación. A la vez que la producción de conocimiento se asocia cada vez más a la acción, a la praxis.

Surge un interés por conocer este movimiento, en tanto fenómeno social y en tanto propuesta formativa. Entonces comienzan a desarrollarse dos líneas en paralelo: por un lado las que desarrollan los investigadores de la educación; y por otro, los propios educadores y educadoras populares que generan sus instancias de reflexión sobre la práctica a partir de la sistematización.

La sistematización de experiencias desde la educación popular "va a significar uno de los instrumentos privilegiados de cuestionamiento y de búsqueda alternativa a esos 'métodos ortodoxos', en general positivistas, que dominaban el campo de la investigación y evaluación educativa. En el segundo ámbito, el de la práctica y la reflexión de educadores y educadoras populares, se destacan las afirmaciones que sustentan una postura teórica sobre lo que se concibe como Educación Popular; sobre su rol de cara a los desafíos políticos, éticos y organizativos; sobre el

35 Entre ellos sin duda el ejemplo más reconocible es el de la experiencia del Movimiento de Educación de Base y los Centros Populares de Cultura donde Paulo Freire construye e impulsa su pedagogía liberadora, una propuesta que hoy sigue siendo referencia de la educación popular. Sin embargo no por ello deben de reconocerse otras tantas experiencias: "Es en los años sesenta y setenta del Siglo XX en los cuales la Educación no formal de Adultos tiene en América Latina su desarrollo más importante y significativo, orientado por la perspectiva del llamado Desarrollo de la Comunidad y otras corrientes de promoción social existentes en ese período. Surgen así una gran diversidad y riqueza de experiencias, lo que motiva a realizar esfuerzos de investigación del campo de la educación de adultos, debido a la necesidad de identificación e intercambio de lo que ocurría con dichas experiencias y sus innovaciones. Estos esfuerzos de investigación se centrarán en recopilar, clasificar, catalogar y organizar repertorios de experiencias, tarea que recibirá el nombre de "sistematización". En esta dirección, algunos de los esfuerzos más conocidos fueron, por ejemplo: la recopilación de experiencias realizada con ocasión del Simposio Mundial de Cartagena, Colombia, sobre Crítica y Política en las Ciencias Sociales, en 1977, promovido por Orlando Fals Borda. El proyecto de consolidación metodológica, sistematización y apoyos a la educación no-formal de adultos rurales, coordinado por el Centro de Estudios del Tercer Mundo, CEESTEM, de México, dirigido por Félix Cadena, en 1979; la sistematización de proyectos en varios países centroamericanos realizados por el Instituto Latinoamericano de Pedagogía de la Comunicación, ILPEC, de Costa Rica, coordinados por Francisco Gutiérrez y Edgar Céspedes en 1981; la recopilación realizada por el proyecto de Investigación y evaluación de experiencias de innovación en educación de adultos, del Centro de Estudios Educativos, CEE, de México en 1982, coordinado por Humberto Barquera; el importante trabajo de recopilación y establecimiento de una tipología, hecho por Pablo Latapí en torno a las principales tendencias de la Educación de Adultos en América Latina, publicado por el CREFAL en 1984; asimismo, el trabajo pionero en el mapeo, identificación y análisis de experiencias de Educación de Adultos (incorporando ya experiencias de Educación Popular), de Patricio Cariola, Juan Eduardo García Huidobro y Sergio Martinic del Centro de Investigación y Desarrollo de la Educación, CIDE, de Chile, entre 1980 y 1983" (Jara, 2011: 10-11). "En ese mismo período, Mercedes Gagneten va a desarrollar toda una propuesta políticometodológica de sistematización basada en una larga experiencia de trabajo social antes y después de la dictadura militar en Argentina" (Jara, 2011: 9). En el contexto de nuestra casa de estudios, el trabajo de Darío G. Martínez para su tesis de doctorado titulado "Saberes, experiencias y subjetividades de la educación de jóvenes y adultos en la ciudad de La Plata. Un abordaje desde la perspectiva de comunicación/educación" también retoma el desarrollo de la educación de jóvenes y adultos en nuestro país desde una lectura del campo. 
sentido y carácter de su metodología y de las técnicas y procedimientos que utiliza, entre otros temas. La gran mayoría de dichas afirmaciones surgieron, de alguna manera, de sistematizaciones de experiencias, producto de reflexiones colectivas e individuales realizadas en eventos de encuentro entre educadores y educadoras populares, sea en sus ámbitos nacionales o a escala continental" (Jara, 2011:14). Se invierten así los términos propiciando una vinculación otra entre teoría y práctica: en lugar de aplicar en la práctica lo que se había formulado antes en la teoría, se construyen aproximaciones teóricas teniendo como punto de partida la sistematización de las prácticas educativas.

De manera similar durante los '70 y '80 se producen una serie de diálogos entre disciplinas y colectivos sociales en interacciones que producen una potente retroalimentación en torno a esta mirada latinoamericana. De este modo, según Jara (2011) la sistematización se vincula en la interacción con: el Trabajo Social reconceptualizado; la Educación de Adultos; la Educación Popular; la Comunicación Popular, el Teatro del Oprimido, la Teología de la Liberación, la Teoría de la Dependencia y la Investigación Acción Participativa ${ }^{36}$. A su vez, estas corrientes se estimulan, retroalimentan y convergen entre sí, al punto que muchas veces algunas se entrecruzan y hasta confunden. Por ello, "al ser la sistematización de experiencias un concepto y una propuesta tan profundamente enraizada en nuestra historia, no podemos entenderla ni asumirla sino dentro de este marco común y sus desafíos" (Jara, 2011: 17). Marco común que justamente es fruto de la historia, de la recuperación en sentido crítico de la experiencia continental, de los procesos revolucionarios, del diálogo entre los diversos procesos sociales, políticos y culturales que no hubiesen sido posibles sin poner en crisis los marcos conceptuales hegemónicos.

Este movimiento continental tiene, a partir de la Revolución Sandinista (Nicaragua, 19791990) un nuevo rol, que congrega y dinamiza una serie de intercambios que potenciaron una multiplicidad de prácticas (así como producciones teóricas) desde estas perspectivas políticas sobre la producción de conocimiento y las propuestas pedagógicas que se proyectaron sobre todo el continente $^{37}$. Así desde mediados de los '80 surge la Red ALFORJA, "la cual incorpora la sistematización de experiencias como componente esencial de su propia constitución como red" (Jara,

36 En el ámbito de las ciencias sociales a partir de la producción de "Ciencia Propia y Colonialismo intelectual" (1970) y otros documentos como "Ciencia Popular, Causa Popular" (1972) del colombiano Orlando Fals Borda se da base a la aparición de una nueva corriente en la investigación social: la Investigación-Acción-Participativa. Esta propuesta juega en total consonancia con este movimiento latinoamericano, en tanto una perspectiva de investigación que busca la participación activa de los sujetos sociales de los sectores populares en la lectura crítica de su propia realidad.

37 Según Jara, entre los primeros materiales de reflexión teórico-metodológica sobre Educación Popular, vinculados a la sistematización y producidos a partir de la experiencia sandinista y centroamericana, se encuentran: Ministerio de Educación de Nicaragua(1989): Elementos Fundamentales de la Concepción de Educación Popular Nicaragüense, Ministerio de Educación, Nicaragua; Núñez, C, (1984): Educar para Transformar, Transformar para Educar, Guadalajara. IMDEC; Leis, R. (1986): El Arco y la Flecha, San José. Alforja; Jara, Oscar (1981): Educación Popular, la dimensión educativa de la acción política, Panamá. CEASPA - ALFORJA; (1984): Los desafíos de la educación popular, San José. Alforja; (1986:) Aprender desde la práctica, San José. Alforja. Ver también: Fals Borda, O.(1982): Conocimiento y Poder, México. Siglo XXI; Brandão, Carlos Rodrigues (1984): Lições da Nicaragua, Rio de Janeiro. Vozes; Torres, R.M (1982): Los Cep: Educación Popular y Democracia Participativa en Nicaragua, Managua. CRIES (en nota al pie 31 en Jara, 2011: 18). 
2011: 18). En esa misma época se consolida el Consejo de Educación de Adultos de América Latina (CEAAL), organización en la que se afiliarían muchísimas instituciones y organizaciones que trabajaban en Educación Popular en el continente:

nunca antes se había generado tal nivel de intercambio, reflexión y búsqueda de aprendizajes conjuntos como en este período en el que se suceden importantes e inolvidables encuentros latinoamericanos que dan lugar a la conformación de importantes redes de educadores y educadoras que trabajan en todos los rincones de nuestra región (Jara, 2011: 19).

A la salida de las dictaduras militares de los distintos países se van conformando también otras redes y grupos de trabajo vinculados al trabajo desde la defensa de los Derechos Humanos, la Comunicación Popular, la promoción de la Salud Comunitaria, la Investigación Participativa, el trabajo con Pueblo Indígenas, la formación de educadores y educadoras. En ese marco, en los '90 la CEAAL le encarga al especialista chileno Diego Palma la realización de un estudio que permitiera establecer un mapa de este creciente campo de trabajo, el que fue luego publicado bajo el título "La sistematización como estrategia de conocimiento en la educación popular. El estado de la cuestión en América Latina"38 (Jara, 2011). Otra fuente de actualización en este campo se encuentra en la Biblioteca Virtual del Programa Latinoamericano de Apoyo a la Sistematización del CEAAL ${ }^{39}$ (CEPAL-FORJA), donde se pueden consultar una multitud de producciones sobre experiencias de todo el continente.

En los últimos años, si bien la sistematización de experiencias se ha extendido por una diversidad de ámbitos, incluyéndose de manera intensa también en la investigación académica y las políticas públicas, tal vez un caso significativo se da en la Venezuela de la revolución Bolivariana, donde la Universidad Bolivariana transformó su dirección de investigación en una dirección de "creación y recreación de saberes" que impulsa proyectos de sistematización de experiencias de trabajo comunitario como parte fundamental de su currículo académico (Jara, 2011: 25).

\section{Sistematización de experiencias educativas y sujetos de conocimiento}

La clave mas interesante al tomar a la sistematización de experiencias como perspectiva es que permite desdibujar algunas barreras que la ciencia moderna ha convertido casi en infranqueables. Retomar las memorias de la educación y la comunicación popular en este sentido para reconocer los espacios y prácticas culturales donde interactúan sujetos, prácticas y saberes populares, con otros provenientes de los medios, de los saberes teóricos, entre otros, propiciando formas otras de acción, de adecuación, de resistencia, o de supervivencia. Lo que implica, según Hleap, "asumir en serio al otro, renunciar al privilegio del ojo observante del investigador para cruzar nuestras miradas sobre lo sucedido, dialogar" (Hleap, 1999: 2).

38 Palma, Diego (1992), publicado en Papeles de CEAAL N³, Santiago de Chile, CEAAL.

39 Se puede acceder a la biblioteca virtual desde http://www.cepalforja.org/sistematizacion 
En este sentido, proponer una investigación interpretativa, implica recuperar las experiencias no como hechos objetivos, o como cosas, sino que implica un conjunto de interpretaciones de los sujetos intervinientes, implica producir a partir de la construcción de sentido sobre la acción, las que son constitutivas de la realidad socio-cultural.

Esto a su vez lleva a reconocer que todo sujeto es un sujeto de conocimiento y posee una percepción y un saber sobre lo que hace:

El sujeto que sistematiza es un sujeto contextuado, ubicado en una situación en la que se plantea y se exige, o le plantean y es exigido a actuar sobre esa realidad en la que él se constituye y a la que él, con su hacer, aporta elementos configuradores. En este punto, destacamos la condición histórica y contextuada del sujeto que hace que también su quehacer y saber sean históricos, contextuados e inacabados. Por otro lado, en esa condición el sujeto se enfrenta -o lo enfrentan- a asumir un reto desde la perspectiva que él construye con otros o desde la opción que otros determinan para él. La práctica y el saber sobre la práctica implican acciones y reflexiones en y sobre la realidad social y éstas se originan y son ocasionadas por situaciones concretas, en las que no sólo se pone en juego la capacidad o la incapacidad para resolver un problema, sino que ante todo, la habilitación o inhabilitación social, política y cultural para definir en qué consiste y sobre qué aspectos actuar (Ghiso, 2006: 40).

Esto implica que todo proceso de sistematización es un proceso de interlocución entre sujetos, en el que se cruzan (en un sentido conflictivo) discursos, teorías y construcciones culturales. Múltiples miradas que al hacerse visibles se confrontan para construir un objeto de reflexión y aprendizaje. Tal como afirma Ghiso

la sistematización, como proceso de construcción de conocimiento sobre una práctica social, no es neutro; por el contrario el interés que lo direcciona y los principios éticos que lo enmarcan son eminentemente emancipadores y transformadores. La sistematización hace parte de las propuestas socio-críticas de construcción de conocimiento (1999: 8).

En el mismo sentido agrega que "el proceso vincula múltiples componentes, uno de ellos es el pedagógico; nos formamos para sistematizar y sistematizando nos formamos. Estamos hablando aquí de aprendizajes altamente significativos para los que participan" (1999: 8).

Este ida y vuelta entre la acción, la reflexión y el aprendizaje, en la medida en que van y vuelven desde y hacia sus sujetos propician el autoreconocimiento como sujetos de conocimientos, experiencias y posibilidades de ser actores de transformación:

la sistematización busca penetrar en el interior de la dinámica de las experiencias, algo así como 'adentrarse' en los procesos sociales vivos y complejos, para circular entre sus elementos, palpar sus relaciones, recorrer sus etapas, localizar sus contradicciones, tensiones, marchas y contramarchas, para llegar a entenderlos desde su propia lógica (Granados, 2005: 25). 
Sistematizar es también un ejercicio en el que se puede comprender cómo es que la teoría se encuentra implícita en nuestras prácticas, cómo es que se va haciendo carne en la medida que nos vamos apropiando de nuestros aprendizajes y conocimientos. En el desarrollo de la recuperación de las experiencias, de las acciones, de las estrategias, y tal vez particularmente en los textos producidos en ese contexto será posible encontrar los rastros de las matrices epistemológicas, teóricas, metodológicas, de los discursos propios del campo puestos en práctica en relación con los discursos sociales.

En esos diálogos entre teoría y práctica, es importante no subestimar o sobrestimar a ninguna de las dos, así como tampoco tratar de reducir una a la otra, evitar reducciones forzadas. Sino que lo que necesitamos es encontrar cómo se sostienen y se tensionan en una relación dialéctica, que por ende será compleja y hasta contradictoria.

De alguna manera, aunque no de modo conclusivo, la sistematización también es una forma de evaluación, no en un sentido auditor (de si se cumplió o no con los objetivos), sino más bien como mirada de integración, y por ende puede aprovecharse como un hecho educativo, en la medida en que vuelven densificados los significados y saberes a los sujetos de la experiencia para potenciarla y transformarla. Para ello según Cendales,

el nuevo orden de significado no es necesariamente conceptual, aunque es deseable que además de la reconstrucción narrativa se realice algún grado de conceptualización sobre algunos ejes problemáticos de la práctica (...) una autorreflexión que hacen los sujetos que impulsan una experiencia de acción social o educativa, a partir del reconocimiento de los saberes que ya poseen sobre ella y de un esfuerzo colectivo e intencionado por reconstruirla, de comprender los contextos, factores y elementos que la configuran, para transformarla (2006: 36).

\section{$\underline{\text { Recuperación de la experiencia y construcción subjetiva }}$}

La construcción de conocimiento a partir del relato es también la posibilidad de expresar una experiencia que es única e irrepetible. "El relato es una totalidad significante, su especificidad comunicativa obliga a una coherencia, una legibilidad, un orden en la exposición, que le da a la vez un orden, un sentido a lo vivido (generalmente de manera caótica) en la experiencia" (Hleap, 1999: 4). Es la posibilidad que tenemos como sujetos de construir nuestra realidad, de lanzarla al mundo, a la vez que configuramos así nuestra propia identidad.

En este entramado vivo, complejo, multidimensional y pluridireccional de factores objetivos y subjetivos que constituye lo que llamamos 'experiencia', no hay simplemente hechos y cosas que suceden; hay personas que pensamos, que sentimos, que vivimos; personas que hacemos que esos hechos acontezcan en contextos y situaciones determinadas y que al hacerlo construyen nuevos contextos, situaciones y relaciones (Jara, 2006: 8). 
Es una realidad construida desde la densidad del intérprete, que muestra en acto sus propias contradicciones, sus temores y deseos, en donde el lenguaje opera como mediador entre lo interno y lo externo, lo macro y lo micro, lo subjetivo y lo objetivo (Hleap, 1999: 4).

Siendo personal la experiencia es también intersubjetiva, se nutre del relato colectivo. En este sentido, los relatos no solo expresan la experiencia, sino que la configuran. Son una oportunidad de construcción de memoria colectiva en tiempo presente, en tanto según afirma Cendales

la memoria humana, tanto individual como colectiva, no es almacenamiento y recuperación de información sobre el pasado, sino un proceso de construcción activa de significado sobre el pasado construido social y culturalmente, el cual opera a través de una dialéctica de recuerdo y el olvido; por tanto, la memoria es creativa y selectiva, más que informar sobre el pasado lo interpreta desde las lógicas culturales y los requerimientos de los sujetos del presente. Por eso, la memoria no dice tanto sobre los acontecimientos y experiencias pasados como sí del significado que tuvo para sus protagonistas y del sentido y utilidad que le otorgan los sujetos en el presente (2006: 37).

Lo cual posibilita la construcción colectiva de realidades y la posibilidad de imaginar futuros posibles, y por qué no de formular utopías. Es una oportunidad para incluir a los otros en las memorias, las resistencias y los procesos de transformación. Propósitos, que también se busca potenciar desde la sistematización de experiencias en este trabajo en particular.

\section{Biografía y reflexividad}

La investigación biográfico-narrativa se ha constituido como una perspectiva o enfoque que en los últimos años ha ganado aceptación académica, con especial pregnancia en el campo de la investigación educacional ${ }^{40}$, aunque muchas veces se la tiene en cuenta sólo como una metodología cualitativa, sin considerar su dimensión epistemológica, la que altera considerablemente los modos de lo que habitualmente se entiende por conocimiento en ciencias sociales y de lo que importa

40 En nuestro país se han generado algunos interesantes movimientos de maestros y profesores que se han dedicado a la investigación-acción a partir del intercambio de relatos autobiográficos y las autobiografías profesionales como punto de partida para la reflexión sobre las prácticas profesionales de docentes. Entre ellos se pueden destacar el proyecto iniciado por el Laboratorio de Políticas Públicas de la Ciudad de Buenos Aires coordinado por Daniel Suárez, que luego fue desarrollado de manera extensa durante la gestión de Daniel Filmus en el Ministerio de Educación de la Nación bajo el "Programa de Documentación Pedagógica y Memoria Docente" coordinado por Daniel Suarez y Cecilia Tanoni, el que fue continuado en varias de las gestiones del kirchnerismo.

http://portal.educ.ar/debates/educacionytic/super-sitios/memoria-docente-y-documentacion-pedagogica.php

Este trabajo luego se ramificó en otros trabajos por provincias y regiones y desde los que se produjeron diversos materiales y bibliografías.

http://www.memoriapedagogica.com.ar/publicaciones/publicaciones.HTML

En particular en nuestra Facultad, es necesario recuperar el antecedente del Seminario-Taller "Producción de relatos en ámbitos educativos" realizado en 4 encuentros entre octubre y noviembre de 2013 con graduados y graduadas del Profesorado de Comunicación Social FPyCS-UNLP en el marco del proyecto de investigación "Procesos de inserción del profesor en comunicación social en las instituciones educativas" (P225 FPYCS UNLP 2013-2014) dirigido por María Belén Fernández. Y que luego tuvo posteriores desarrollos en la misma unidad académica con talleres y seminarios de narrativas de experiencias pedagógicas destinados a docentes del sistema público de la región. 
conocer. A su vez, su utilización no siempre está justificada claramente, por ello intentaré exponer algunas potencialidades y limitaciones de este enfoque $y$, en todo caso, los problemas epistemológicos que involucra.

En este mismo sentido, me interesa presentar brevemente la relación entre investigación biográfica y reflexividad, trabajados como antecedente en los rastreos de experiencias de profesores en comunicación egresados de la FPyCS que se han desarrollado en función de la investigación en clave biográfica ${ }^{41}$.

\section{La gravitación del giro hermenéutico}

Si bien el denominado giro hermenéutico y narrativo de las ciencias sociales -impulsado por las teorías de Paul Ricoeur entre otros- está presente desde hace tiempo y ha ganado terreno paulatinamente, no siempre es aceptado en tanto estatuto epistemológico para las ciencias humanas.

Este cambio de eje propuesto por la hermenéutica que pone al significado de los actores investigados en el centro de la escena, sigue siendo resistido en algunos campos académicos, que desconfían de la perspectiva interpretativa y relativizan la relevancia de los datos que ésta proporciona a la ciencia.

Para Paul Ricoeur (1995) la acción significativa es un texto a interpretar, y se articula de modo narrativo. Para él, la subjetividad es, más bien, una condición necesaria del conocimiento social, y por ende, la narrativa no sólo expresa dimensiones de la experiencia vivida, sino que, además, media la propia experiencia y configura la construcción social de la realidad.

En el mismo sentido, el enfoque narrativo comprende que la construcción de ese yo, de ese sí mismo en términos de Ricoeur, no es individual, interno, sino un yo dialógico, que se construye de manera relacional y comunitaria, para producir una subjetividad que es construcción social, intersubjetivamente conformada por el discurso comunicativo. En ese juego de subjetividades, ese proceso dialógico se convierte en un modo de construir conocimiento.

En la lectura que Francois Dosse (2007) hace de Sí mismo como otro de Ricoeur, retoma la cuestión de la identidad narrativa. Rescata la productividad de la distinción entre mismidade ipseidad que propone Ricoeur, la mismidad evoca el carácter del sujeto en lo que tiene de inmutable, como sus huellas digitales, mientras que la ipseidad remite a la temporalidad, a la promesa, a la voluntad de una identidad conservada a pesar del cambio: "es la identidad en una trayectoria de pruebas del tiempo y del mal. (...) la ipseidad no se construye en una relación analógica de exterioridad al otro, sino en una implicación, una verdadera fusión con el otro" (Dosse, 2007:355-356). Esta lectura permite

41 Algunos de estos desarrollos fueron trabajados en referencia a las producciones de mi Plan de Beca UNLP Tipo $A$ (2013-2016) "El profesor en comunicación social en las instituciones educativas. Estudio de experiencias significativas de una profesión emergente", y comunicadas en diversas publicaciones en encuentros académicos en esos años. 
trabajar en la tensión entre lo que podríamos entender como lo intangible del sujeto y los cambios que lo intervienen a lo largo de su historia.

Para acceder a ese discurso requerimos de la narración, donde la experiencia se produce en relato, a la vez que permite conocer los sentidos que los sujetos le otorgan a su experiencia vital. Un proceso reflexivo en el que los sujetos dan coherencia y significado a lo que vivieron (Ricoeur, 1995) reuniendo los elementos dispersos de una vida personal para agruparlos en un esquema de conjunto (Gusdorf, 1991). Según Gustave Gusdorf hay que renunciar al "prejuicio de objetividad", dado que la verdad de los hechos se subordina a la verdad del hombre, pues es sobre todo el hombre lo que está en cuestión. La narración nos aporta el testimonio de un hombre sobre sí mismo, el debate de una existencia que dialoga con ella misma, a la búsqueda de su fidelidad más íntima (Gusdorf, 1991:12).

\section{La narración biográfica y el conocimiento biográfico}

El relato biográfico es un modo de comprensión y expresión de la vida en el que no se puede desconocer la voz -como presencia- del autor. Debido a que la actividad educativa es una acción práctica que acontece en situaciones específicas, guiada por determinadas intenciones, parece como lo ponen de manifiesto los sujetos de la investigación cuando nos hablan de sus experienciasque los relatos y el modo narrativo es una forma, más que válida de comprender y expresar la enseñanza (y particulares aprendizajes). Dado que allí aparecen elementos a conocer que no serían tan identificables desde otros enfoques.

En este sentido resulta pertinente recuperar lo que Christine Delory-Momberger (2009) aporta a la relación entre aprendizaje y biografización social, cuando señala que todo aprendizaje, intencionado o no, es un acto socialmente situado y socialmente construido. No hay aprendizaje que no esté inserto en la singularidad de una biografía. La biografía educativa amplía el alcance de la noción de escritura, en tanto acción cognitiva mediante la cual se delinea, antes que nada, la figura de sí.

Frente a un modo de construcción lógico, de generalización, propuesto por el paradigma positivista, el modo narrativo parte del carácter único e irrepetible de las acciones humanas, por lo que se centra en sus particularidades como un espacio de conocimiento y comprensión de esos matices que no pueden ser encerrados en proposiciones universalizantes. Son esos pequeños detalles, esos relatos los que permiten acceder a la comprensión de los sentidos que los sujetos le dan a sus acciones. Su singularidad en el dato de valor y no tanto lo generalizable, considerando que además esa particularidad se construye dialógicamente con el conjunto de la sociedad y su momento histórico que configuran su experiencia. Como identifica María Da Conceiçao Passeggi "la biografización resulta de ese modo una acción permanente de figuración de sí, que se actualiza en la 
acción del sujeto al narrar su historia, a tal punto que él mismo se confunde con ella" (en DeloryMomberger, 2009:20).

El desafío es entonces encontrarse con ese entramado intermedio, evitando las generalizaciones, pero cuidando a la vez de no romantizar los discursos. Tal como afirma Leonor Arfuch esto es

lo que lleva una y otra vez a recomenzar el relato de una vida -minucioso, fragmentarios, caótico, poco importa su modo- ante el propio desdoblamiento especular: el relato de todos.

Lo que hace al orden del relato -de la vida- y a su creación narrativa, ese 'pasar en limpio' la propia historia que nunca se termina de contar (2002:18).

Dado que los propios relatos de los sujetos son construcciones sociales que dan un determinado significado a los hechos y, como tales, deben ser analizados por la investigación en los propios términos de esos sujetos y considerando sus contexto de interacción.

\section{Sinuosos caminos de frontera}

La investigación narrativa se propone no violentar ni expropiar las voces de los sujetos investigados, al no imponer categorías alejadas de sus palabras. Pero a la vez, si se respeta "en exceso" el discurso de los sujetos, la interpretación quedará encerrada dentro de los horizontes de los interpretados, imposibilitando toda explicación comparativa, generalizable o teórica; lo que le quitaría el sentido en tanto investigación científica que pretenda aportar conocimientos sobre el espacio investigado.

El desafío como investigador implica superar el mero remix de fragmentos e intentar adentrar en la complejidad de sentidos que los sujetos usan para darle significado a su mundo y a su vida, situando a los relatos en sentidos más amplios. Allí es donde la investigación narrativa puede aportar desde lo particular con sentimientos, deseos, propósitos, anhelos, que la investigación formal dejaría de lado -o desconocería- y que permiten dar cuenta de aspectos que resultan relevantes.

Esto no implica dejar de situar las experiencias narradas dentro de un conjunto de regularidades y pautas explicables socio-históricamente, pensando que el relato de vida responde a una realidad socialmente construida. Sin embargo, no se puede desdeñar que es completamente único y singular. Se trata de trabajar en el diálogo entre el punto de vista nativo y el del investigador. Teniendo en cuenta que además hay muchos casos en los que el objeto de investigación hace que los roles de cognoscente y conocido dejan de diferenciarse para entrar en una relación indivisible, traspasando una barrera que ha sido un principio intocable de la objetividad científica positivista.

Esto es particularmente evidente en esta tesis, teniendo en cuenta que que trabajaremos en la construcción de conocimientos de manera participativa con los sujetos que forman parte de las experiencias que son objeto de esta investigación. Por eso mismo y por el interés de que este trabajo permita aportar a la reflexión de prácticas propias de manera crítica, nos animaremos a trabajar en 
estas zonas intermedias, en estos bordes no del todo claros. Pero con el horizonte de que desde la narración biográfica y la investigación participativa se puedan generar otro tipo de reflexividades de las prácticas y que esas narraciones que se produzcan, puedan ser leídas como construcciones sociales. Estos relatos son por un lado productos hechos desde el presente, por ende contingentes y situados, pero a la vez son configurados en función de marcos históricos y sociales que los hicieron posibles.

\section{¿De qué hablamos cuando nos biografiamos?}

Volviendo a la discusión biográfica, insistimos en que lo que da forma a lo vivido y a la experiencia de los sujetos son las narrativas que ellos hacen de sí mismos. La narración no es sólo el instrumento de la formación, el idioma en que ésta se expresaría: la narración es el lugar en el que el individuo se concreta, donde se elabora y experimenta la historia de su vida: lo que Arfuch (2002) denomina el espacio biográfico, como un espacio dinámico, no siempre cartografiable, espacio de mediación dialógica, e históricamente situado, entre las esferas de lo público y lo privado. Plantea así un enfoque no disociativo que intenta evitar las visiones antinómicas que suelen cargar de negatividad a alguna de estas esferas.

Tal como propone Gusdorf,

toda autobiografía es una obra de arte, y, al mismo tiempo, una obra de edificación; no nos presenta al personaje visto desde fuera, en su comportamiento visible, sino la persona en su intimidad, no tal como fue, o tal como es, sino como cree y quiere ser y haber sido. Se trata de una especie de recomposición realzada del destino personal; el autor, quien es al mismo tiempo el héroe de la historia, quiere elucidar su pasado a fin de discernir la estructura de su ser en el tiempo (Gusdorf:14).

Esa dimensión de la historia que nos escribe cuando relatamos nuestra historia es una dimensión importante a tener en cuenta, porque es el punto de intersección entre la dimensión contingente y la dimensión histórica, el espacio donde leer lo generalizable. Delory-Momberger propone, como matiz, la categoría de heterobiografía a la forma de escritura de sí que practicamos cuando nos confrontamos con la narrativa de otro. Para describir que, así como nos apropiamos de una canción o de un poema, lo hacemos también con la narrativa de otro, construyendo a partir del universo de expectativas, proyectos e intereses de quien los recibe.

Según Delory-Momberger, la historia de vida, no es la historia de vida (entendida en el sentido de confrontarla con las acciones tal y como fueron vividas), pero es una ficción apropiada por la cual el sujeto se produce como sujeto de sí mismo. Solo puede haber sujeto de una historia a ser realizada, esto es, la emergencia de ese sujeto, que intenta su historia y que se experimenta como proyecto, que responde al movimiento de biografización. Allí es donde reside otro interesante punto de esta perspectiva: en su provocación a la reflexividad de los sujetos. 


\section{Potencialidad reflexiva del ejercicio biográfico}

En el marco de sociedades con alta descentralización y con instituciones que pierden su capacidad de generar referencias estables, con roles de los sujetos sociales que se ven desdibujados, los sujetos llegan a la necesidad de construirse por sí mismos, a ser ellos mismos quienes le den sentido a su actividad social. En este marco, el individuo ya no es el representante fijo de un grupo estable, sino que es producto de una multiplicidad de experiencias socializadoras. En este mundo complejo se puede ser a la vez padre, hijo, profesor, investigador, compañero, pareja, músico, amigo de alguien, o amigo de facebook, youtuber, prolífico generador de twitts bajo un alias, o un insistente relator de momentos cotidianos a través de "historias" de Instagram y muchísimas otras cosas más. Las maneras de experimentar lo social son cada vez más amplias, heterogéneas, y multideterminadas por lo que exigen un ejercicio de reflexividad que colabore con la producción de un orden biográfico. Al construir la narrativa de mí, me distancio de mí mismo, buscando subjetivar mi experiencia social.

Para Gusdorf, el valor de la autobiografía y su privilegio antropológico reside en que, es uno de los medios del conocimiento de uno mismo, gracias a la reconstitución y al desciframiento de una vida en su conjunto. Un examen de conciencia limitado al momento presente no me dará más que un trozo fragmentario de mi ser personal. Al contar mi historia, tomo el camino más largo, pero ese camino que constituye la ruta de mi vida me lleva con más seguridad a mí mismo. La recapitulación de las etapas de la existencia, de los paisajes y de los encuentros, me obliga a situar lo que yo soy en la perspectiva de lo que he sido (Gusdorf: 8).

Lo que denomina como una "expresión coherente y total de su destino" (Gusdorf: 6). Así la autobiografía es una segunda lectura de la experiencia, y según Gusdorf,

más verdadera que la primera, puesto que es toma de conciencia: en la inmediatez de lo vivido, me envuelve generalmente el dinamismo de la situación, impidiéndome ver el todo. La memoria me concede perspectiva y me permite tomar en consideración las complejidades de una situación, en el tiempo y en el espacio (Gusdorf: 8-9).

Si bien esta búsqueda, al igual que en la comunicación, nunca garantizará acceder a la totalidad acabada del otro, al menos proponemos que esta reflexividad narrativa puede empoderar al sujeto y sus aprendizajes. Aprender y apropiarse de los saberes, sea cual sea su naturaleza, es en diversos grados, retocar, revisar, modificar y transformar un modo de ser y estar en el mundo, replantear un conjunto de relaciones con los otros y consigo mismo, y de manera más o menos sensible, provocar nuevas ojeadas sobre su pasado y sobre sus orígenes, para proyectar deseos de otro modo, para repensar sus acciones a futuro, y por ende biografiarse de otro modo. 


\section{Capítulo 3}

\section{VOCES, EXPERIENCIAS Y TRAMAS QUE PROTAGONIZARON LA INVESTIGACIÓN}

Como ya enuncié en las primeras páginas, esta investigación es una derivación de mi anterior trabajo de tesis realizado para la Maestría en Comunicación y Educación de la Facultad de Periodismo y Comunicación Social (UNLP). En esa oportunidad me dediqué, desde el relato autobiográfico y la reflexión, a sistematizar mi experiencia de intervención como comunicador/educador en el Museo Histórico Regional "Alte. Brown" de Bernal, perteneciente a la Red de Museos de Quilmes ${ }^{42}$. En aquella producción comencé a visualizar una posible articulación entre las perspectivas del campo comunicación/educación y las de la museología social latinoamericana. Tarea que pretendo trenzar con la presente investigación, por eso para esta ocasión decidí abrir a otras experiencias a partir de las expresiones de trabajadores y trabajadoras de museos de nuestro país, desde una investigación cualitativa que respete las voces de los actores sociales.

La decisión metodológica desde la sistematización implicó por un lado el rastreo de las matrices conceptuales que se sostienen en ambos campos y por otro la realización de una serie de entrevistas en profundidad con referentes de museos en los que se identifica la museología social como una matriz significativa, para encontrar allí sentidos, experiencias, ideas, memorias de formación, referentes teóricos, deseos y expectativas. El objetivo general es producir una articulación desde el trazado de una cartografía que identifique ámbitos, prácticas y conceptos que sistematicen el recorrido en vinculación con los y las referentes del campo empírico.

El criterio inicial de selección de los sujetos a entrevistar tuvo que ver con la búsqueda de aquellas personas y museos que conocía por mi experiencia previa en los museos de Quilmes y que consideraba importantes en mi rastreo, para a partir del diálogo con ellos y de sus vinculaciones y recomendaciones poder avanzar a modo de "bola de nieve" hacia otros referentes que fuesen significativos en sus propios términos, lo que permite por un lado romper el cerco de proximidad

42 El trabajo fue dirigido por María Belén Fernández y se titula "Construcción comunicacional de un espacio público educativo de memoria colectiva. Experiencia de intervención museográfica desde el campo comunicación/educación en el Museo Histórico Regional "Almirante Brown" de Bernal, Quilmes (julio 2014-diciembre 2015)". Está disponible en http://hdl.handle.net/10915/60467 
personal, pero además encontrar apoyo en los criterios y conocimientos propios de los sujetos de la investigación.

De ese modo la investigación inicial que comenzó con dos personas, terminó derivando en la realización de 10 entrevistas, a partir de la selección de actores clave en articulación con lo que se iba desplegando en las intercambios, de personas que resultaban significativas dentro del entramado de una enorme red de referentes, de personas que adscriben a la perspectiva de la museología social y que la practican de diversas maneras en sus respectivos espacios museales. La selección de esas y esos 10 entrevistados respondió a un criterio de recorte y a la selección de algunas características que me parecía le darían cierta diversidad teniendo en cuenta las características y el tipo de ámbitos en los que se desempeñan, sumado a un criterio de accesibilidad (en términos logísticos y materiales) para la realización del trabajo de campo. Pero es necesario aclarar que este trabajo podría haberse hecho del mismo modo seleccionando a otras 10 o 20 personas totalmente distintas. Si hay algo que puedo afirmar después de realizar el rastreo para esta investigación es que el campo de la museología social latinoamericana en nuestro país conforma una potente red que tiene una gran variedad de referentes en museos y sitios de memoria de las más diversas latitudes de nuestro territorio, y que en la mayoría de los casos se trata de personas que se encuentran cargados y cargadas de vitalidad, creatividad y energía suficientes como para seguir alimentando y expandiendo las fronteras del campo en vinculación con una enorme diversidad de perspectivas y disciplinas. Y que justamente una de sus principales fortalezas se encuentra en su ánimo por seguir alimentando esa red que conforman, a partir del intercambio y el encuentro, no solo en relación con personas de nuestro país, sino también con referentes de Brasil, Chile, Uruguay, Colombia, México y Portugal, entre otros.

\section{Algunas precisiones sobre el objeto de investigación}

Otra cuestión en términos metodológicos que es necesario aclarar es algo que surgió como idea inicial, tal vez a modo casi intuitivo, pero que fui configurando y ajustando cada vez más a medida que avanzaba con la realización de las entrevistas: que el objeto de estudio de este trabajo no son los museos en sí, o sus museografías, sino las experiencias de las personas que trabajan en esos espacios, quienes mediante sus prácticas lo producen y gestionan en el hacer cotidiano.

En este sentido propongo como objeto de investigación no a los museos como instituciones, o sus muestras -cosas que obviamente son material observable-, sino que propongo que el centro de interés esté puesto más en el museo como una práctica social que se actualiza permanentemente, y que es ejercida de manera cotidiana por sus sujetos, sus ideas y sus deseos, sus horizontes y posicionamientos políticos (explícitos o no, pero que siempre existen). Lo propongo teniendo en cuenta que lo que analizo es un momento dentro de la historia de esos museos. Se trata de un 
proyecto de gestión, que en algunos casos cuenta con mayor desarrollo o continuidad en su línea, y otros en los que están más sujetos a los cambios, a merced de las mareas coyunturales (en términos políticos o económicos, por cambios de gestión de gobierno, por tendencias organizacionales o movimientos culturales), que en algunos casos les desvían de su camino, y en otros directamente pueden significar enormes virajes en su rumbo como proyecto institucional. 0 incluso hay casos en los que son los propios sujetos investigados los que se salen del rumbo pasando a intervenir en otros espacios, ya sea por propia decisión o por elecciones de terceros.

Pensar a los museos desde sus sujetos intervinientes también les da más vitalidad, los hace más dinámicos, más mutables. Sobre todo teniendo en cuenta que esos sujetos que forman parte de esas instituciones muchas veces actúan respondiendo orgánicamente a las instituciones a las que pertenecen, pero también en otras ocasiones -sobre todo en aquellas instituciones más grandes en términos de la cantidad de sujetos que los gestionan, con más historia, o con mayores discontinuidades en sus rumbos-, a veces ocupan posiciones más laterales o de resistencia, posiciones disidentes al proyecto institucional, en función de accionar desde sus perspectivas, posicionamientos y deseos ya sean en una posición personal o en nombre de un colectivo sin importar el tamaño o el peso institucional que este grupo tenga.

En este sentido, y a partir de la experiencia del rastreo, a priori podemos dar cuenta de que los museos como toda institución, sin importar el grado de institucionalidad que posean, son espacios polisémicos, e incluso a la inversa, suele ser "museo" el concepto englobador y tal vez por eso en un punto invisibilizador de las diferencias, para una enorme diversidad de espacios con intereses y objetivos muy diversos. Y a su vez dentro de cada espacio cohabitan una enorme diversidad de sentidos sobre sus trayectorias, sus objetivos y sus acciones prioritarias.

Los museos son procesos accionados por las prácticas cotidianas de los sujetos que los gestionan en el marco de la cultura, y en el marco de esos procesos cargan con diversos grados de fragilidad, cierto grado de contingencia, tienen una temporalidad, una finitud, y los sujetos que allí actúan también pueden cambiar de acuerdo a diversas circunstancias, pueden cambiar tanto de perspectiva como de museo. Todas esas complejidades son parte de este estudio, y trataré -en la medida de lo posible- de sostenerlas visibles durante todo el trabajo. En ese sentido, los museos, como instituciones con sus paredes, se pueden sostener, aunque en el momento actual, ni siquiera eso puede ser una certeza. La totalidad de las personas que entrevisté participaron y participan de museos públicos, que actúan desde el Estado y desde lo público, y desde sus lugares se expresan desde cierto grado de tensión y resistencia, ocupando el espacio público y estatal que les toca gestionar desde una perspectiva de derechos, en una actitud que no necesariamente se corresponde con el proyecto nacional gobernante, haciendo uso de cierta autonomía que les otorgan los espacios que ocupan y los proyectos museales que representan. 
A la vez es necesario aclarar que en términos de la investigación, cada uno de los sentidos recuperados de las entrevistas son tomados como sentidos producidos por esos sujetos. Los que si bien se encuentran inmersos e inmersas en esas instituciones, que por supuesto de algún modo les configuran su discurso, pero en los que de todos modos conservan su capacidad de agencia. Por todo ello esos sentidos, esas respuestas, son tomadas por mí y para esta investigación como respuestas de esos sujetos, como respuestas a nivel personal y no en nombre de las instituciones en las que intervienen y se desempeñan.

\section{Sobre la entrevista en profundidad}

En cuanto a la perspectiva metodológica, dentro del marco de una investigación de carácter cualitativo, las entrevistas se plantearon en el formato de entrevistas abiertas o no estructuradas, las que podemos definir como

una forma especial de conversación entre dos personas (...) dirigida y registrada por el investigador con el propósito de favorecer la producción de un discurso conversacional continuo y con cierta línea argumental por parte del entrevistado, acerca de un tema de interés definido en el marco de la investigación (Marradi, Archenti, Piovani, 2007:216).

es decir, se trata de un formato de entrevista en la que si bien el investigador busca conocer sobre determinadas áreas, dimensiones o categorías, éstas no son buscadas de manera coercitiva por el investigador, sino que lo que se busca es generar una conversación guiada por esos intereses de investigación, pero también abierta a los sentidos que el entrevistado o entrevistado desee aportar. Según Rosana Guber

vamos en busca de temas y conceptos que la población expresa por asociación libre; esto significa que los informantes introducen sus prioridades, en forma de temas de conversación y prácticas atestiguadas por el investigador, en modos de recibir preguntas y de responder, donde revelan los nudos problemáticos de su realidad social tal como la perciben desde su universo cultural (2012:82).

la riqueza justamente de este método de producción de datos es que permite que el investigador pueda conocer de otro modo al sujeto entrevistado, sus intereses, valores y sentidos.

Según Marradi, Archenti y Piovani no existe aún en la metodología de las ciencias sociales una sola manera de designar a este tipo de entrevistas, por lo que dependiendo de las fuentes podría encuadrarse este tipo de prácticas investigas dentro de lo que algunos autores denominan como: entrevista abierta o no directiva (Rogers 1942); no estandarizada (Denzin 1970); intensiva (Brenner et al 1984); cualitativa (Valles 1997); hermenéutica (Monsteperelli 1998) (en Marradi, Archenti, Piovani, 2007) o en lo que Guber (2012) denomina como entrevista antropológica.

Lo que me interesa de este método de investigación es algo que es claramente enunciado por Rosana Guber, que en este tipo de entrevista de lo que se trata es del desarrollo de "una relación 
social a través de la cual se obtienen enunciados y verbalizaciones en una instancia de observación directa y de participación". Por eso mismo, para la antropóloga se trata de un instrumento de producción de datos que

cabe plenamente en el marco interpretativo de la observación participante, pues su valor no reside en su carácter referencial -informar sobre las cosas- sino performativo. La entrevista es una situación cara-a-cara donde se encuentran distintas reflexividades pero, también, donde se produce una nueva reflexividad (2012:75).

En este sentido, afirma que este tipo de entrevistas son ideales en dos grandes momentos de la investigación: el de la apertura y el de la focalización. Lo que en nuestro caso fue de ese modo, dado que sirvieron tanto para abrir el campo a la identificación de los primeros sentidos y las primeras categorías, para la prueba de la estructura de la guía de preguntas, así como luego fueron el instrumento ideal para la profundización de las dimensiones y categorías que se fueron construyendo a medida que avanzaba con la realización de cada una de las entrevistas.

Volviendo al criterio de reflexividad, y siguiendo con Guber es interesante decir que el investigador puede predefinir un "campo" según sus intereses teóricos o su sentido común, (...) pero el sentido último del "campo" lo dará la reflexividad de los nativos. Esta lógica se aplica incluso cuando el investigador pertenece al mismo grupo o sector que sus informantes, porque sus intereses como investigador difieren de los intereses prácticos de sus interlocutores (2012:47).

esta afirmación resulta un enunciado interesante en esta investigación dado que se realiza en interacción con sujetos que no son legos, que no hablan desde el sentido común, sino que las entrevistas se realizaron con personas que tienen un saber experto sobre lo que estamos investigando, se trata de hombres y mujeres con una larga experiencia de trabajo, estudio y reflexión específicas sobre su propia práctica y sobre los desafíos que la museología social propone.

Es necesario insistir desde el criterio de reflexividad teniendo en cuenta que los sentidos aportados por las y los entrevistados no se producen en el vacío, sino que se configuran y actualizan en cada interacción social, donde estos sentidos en su circunstancia son mediados por el lenguaje hablado principalmente, pero también acompañado por otros diversos lenguajes. El sentido expresado es inseparable de las circunstancias en que fueron pronunciados, del mismo modo que son inseparables de los sujetos que los pronunciaron.

\section{La trama de acceso a las fuentes}

Como parte de esta reflexividad resulta necesario explicitar el modo en que se fue desenvolviendo la producción de conocimientos para esta investigación, resulta pertinente recuperar y reflexionar sobre la secuencia que permitió la operacionalización de las entrevistas y el modo en que fui contactando a cada uno de los sujetos de investigación. Sin entrar en detalles sobre el contenido 
de las entrevistas (lo que será objeto del capítulo 6), sí es importante describir el proceso de aproximación, dado que la trama de acceso a las fuentes resulta tan elocuente como los dichos de cada una de las personas entrevistadas. En esa trama de relaciones pude empezar a identificar esa enorme red de trabajadores y trabajadoras de museos que inscriptos en la matriz de la museología social intervienen y desarrollan tareas cotidianas en espacios de museos y sitios de memoria. Una red que sostienen mediante diversas estrategias para realizar encuentros interpersonales, o a veces institucionales, con los que se sostienen, desarrollan intercambios y también producen lazos de afecto.

\section{Analía Bernardi}

La primer persona elegida como entrevistada fue Analía Bernardi, a quien conocía personalmente primero por una relación de parentesco político y que luego derivara en conocer su tarea en el Museo Ferrowhite ${ }^{43}$ de Ingeniero White. Todo esto fue varios años antes incluso de que yo comenzara a trabajar en los museos de Quilmes, pero ya en ese entonces, sin tener aún conocimiento específico sobre museología, ya podía percibir la peculiaridad del trabajo que allí realizaban.

Este particular museo que según la construcción que el propio equipo realiza del espacio lo denominan como un "Museo-Taller" está ubicado en una localidad portuaria del partido de Bahía Blanca, provincia de Buenos Aires y se encuentra instalado en lo que fuera el taller de la usina General San Martín. El museo resguarda herramientas y útiles recuperados tras la privatización y el "desguace parcial" de los ferrocarriles en la década de 1990. Un dato interesante de la muestra permanente es que exhibe lo que no está en el taller, dando cuenta de ese desguace, para ésto por ejemplo señalan una silueta de color amarillo donde tendría que estar atornillada la bancada de una fresadora o un torno mecánico, dando cuenta del faltante. En el museo se les da una importante participación a los ex empleados ferroviarios y sus relatos, quienes muchas veces incluso guían a los y las visitantes por el espacio.

La charla con Analía, que fue registrada como la primer entrevista abierta de la investigación, se pautó para ser realizada vía Skype, pero finalmente por problemas con la conexión de Internet se realizó vía telefónica. De ese primer intercambio surgieron una enorme cantidad de ideas y categorías, así como toda una tanda de nuevas preguntas para sumar a la guía de entrevista ${ }^{44}$. Del mismo modo hablar con ella sirvió para confirmar que Leonardo Casado, a quien había elegido como mi segundo entrevistado, era un referente significativo, así como me recomendó entablar diálogos con Verónica Jeria y Verónica Stáffora de Buenos Aires, a quienes referenció en su trabajo museológico, pero también por su militancia en la Asociación de Trabajadores de Museos, también me

43 http://museotaller.blogspot.com.ar/

44 La guía de entrevistas puede leerse en la sección anexo, junto con cada una de las transcripciones de las entrevistas, donde esa guía tomó distinto tipo de identidad según las interacciones con las personas entrevistadas. 
refirió con Olga Bartolomé del Museo de Alta Gracia en Córdoba, quien además era integrante de un espacio de educadores de museos de aquella provincia.

\section{Leonardo Casado}

El segundo entrevistado era también un contacto previo aunque no de tan larga data. A Leonardo lo había conocido en mi experiencia de trabajo en los Museos de Quilmes. En ese entonces él estaba a cargo en el puesto de director, de la Dirección de Museos Municipales de Berazategui, territorio lindante con Quilmes, por lo que conocía personalmente de su tarea y de su predicamento en el campo de la museología.

En el momento de esa primer entrevista continuaba a cargo de la dirección del área compuesta por tres museos ${ }^{45}$ instalados en antiguas casas recuperadas: el Museo Histórico y Natural ubicado en un barrio muy cercano a la zona céntrica, a pocas cuadras de la estación de trenes, lugar al que fui a realizar el intercambio de modo presencial, y donde pude recorrer sus muestras en un recorrido guiado por el propio Leonardo; el Museo Taller "César Bustillo", ubicado en la localidad de Plátanos; y el Museo del Golf "Roberto De Vicenzo" ubicado en un solar de la localidad de Ranelagh.

Con él apliqué las primeras modificaciones a la guía de entrevista a partir de la experiencia con Analía. En la interacción me sugirió a las tres mismas personas que había recomendado Analía, a la vez que me nombró la experiencia del Museo del Juguete de San Isidro, en una gestión de unos años atrás, y a la vez me abrió la puerta a una experiencia que fue muy importante para el desarrollo de esta investigación. Me comentó que como parte de la Asociación de Trabajadores de Museos ${ }^{46}$ en la que él también participaba, estaban organizando la XVIII Conferencia Internacional de MINOM-ICOM ${ }^{47}$ que se realizaría a los pocos meses en la ciudad de Córdoba. Este encuentro se co organizaba junto con el Encuentro de Educadores de Museos ${ }^{48}$ de Córdoba, del que también ya me había hablado Analía.

\section{Participación en el encuentro de MINOM en Córdoba}

A partir de los datos aportados por Analía y Leonardo, sabiendo que era organizado por dos colectivos que ya identificaba como espacios con los que sería importante establecer contacto y tratar de conocer para la investigación, y motivado también por la certeza de la importancia ${ }^{49}$ que el Movimiento Internacional para la Nueva Museología (MINOM) ha tenido a nivel histórico y que aún tiene en el ámbito de la museología social, me decidí a inscribirme para participar de dicho encuentro.

45 http://www.berazategui.gob.ar/cultura/espacios-culturales/museos/institucional

46 http://trabajadoresdemuseos.blogspot.com/

47 http://www.minom-icom.net/about-us

48 https://educadoresdemuseos.wordpress.com/

49 Sobre esta cuestión me explayo largamente en el Capítulo 5 de este trabajo de tesis cuando describo los desarrollos de las perspectivas de la "nueva museología", la "museología crítica" y la "museología social latinoamericana", sobre la aparición del MINOM, así como también describo las actividades que se desarrollaron durante esa semana en Córdoba. 
Alli efectivamente conocí a las personas anteriormente referenciadas, pero además de ellas, me puse en contacto con otra enorme cantidad de profesionales de museos de todo el país, así como de países vecinos, dado que había presentes personalidades destacadas de Brasil como Mario de Souza Chagas y Marcelle Pereira quienes estuvieron a cargo del curso de los primeros tres días, y que además asistían como presidente y vicepresidenta del MINOM; Pedro Pereira Leite investigador de la Universidade de Coimbra y de la Universidade Lusófona de Lisboa y miembro del comité del MINON en representación de Portugal; Leonardo Mellado del área educativa del Museo Histórico Nacional de Santiago y representante de ICOM Chile, Favio López Suárez del Museo Nacional de Colombia, entre otros.

En los 5 días que conformaron el encuentro, en el que hubo cursos, visitas a espacios de museos y sitios de memoria, talleres, conferencias, actividades recreativas, exposiciones y sobre todo muchas oportunidades para desarrollar profundas discusiones, encuentros e intercambios de experiencias diversas, pude transformar la visión que tenía del campo, la que a partir de esos días se amplió de manera exponencial con el reconocimiento de la enorme diversidad de referentes y experiencias que existían en el país, a la vez que pude entablar lazos de confianza a partir de los cuales luego pude avanzar en los posteriores contactos con las fuentes para esta investigación. En esos espacios de interacción pude hablar con Olga Bartolomé, Verónica Jeria, Verónica Stáffora, Julieta Rausch, Anabelle Castaño y Susana Maresca, pude contarles de mi preocupación de investigación, establecer unos primeros intercambios de ideas y pensar posibles encuentros posteriores para la realización de las entrevistas.

\section{Sujetos clave que es necesario nombrar}

Más allá de que luego no serían entrevistados de manera formal en el marco de este trabajo, en los días y noches del encuentro de MINOM charlé con muchos y muchas más, a quienes dada su importancia y experiencia me gustaría poder nombrar. Ellos y ellas son: Cristina Agüed del área pedagógica del Museo Genaro Pérez ${ }^{50}$, Marcela Fernández del Museo Provincial de Ciencias Naturales $^{51}$, Ana García Armesto y Mariela Zabala del área educativa del Museo de Antropología ${ }^{52}$ de la Universidad Nacional de Córdoba, Celina Hafford del Museo de Arte Religioso Juan Tejada ${ }^{53}$, Gloria Palacio del Museo Histórico ${ }^{54}$ de la Universidad Nacional de Córdoba, Claudia Rivarola del área educativa del Museo Genaro Pérez y del Centro Cultural Casa de Pepino ${ }^{55}$, Mariana del Val del Museo Superior de Bellas Artes Evita ${ }^{56}$ (donde se realizó la mayor parte del encuentro de MINOM), todas

50 https://museogenaroperez.wordpress.com/

51 https://cultura.cba.gov.ar/institucional/museos/museo-provincial-de-ciencias-naturales/

52 http://museoantropologia.unc.edu.ar/

53 http://www.museotejeda.com/\#!/-institucional/

54 http://www.museohistorico.unc.edu.ar/

55 https://casadepepino.wordpress.com/

56 https://www.cordobaturismo.gov.ar/experiencia/palacio-ferreyra/ 
ellas además integrantes del Encuentro de Educadores de Museos ${ }^{57}$ de Córdoba; Belén Moliniego y Germán Giordano del Museo Provincial de Ciencias Naturales ${ }^{58}$ de Santa Fe; Sabine Dupuy y Daniel Delfino del Museo Integral de la Reserva de Biósfera Laguna Blanca ${ }^{59}$ de la Universidad Nacional de Catamarca; Eduardo Ribotta y Lilian Prebisch de la Maestría en Museología ${ }^{60}$ de la Universidad Nacional de Tucumán, Ana Carolina Oliva del Museo Casa Histórica de la Independencia ${ }^{61}$, Ignacio Fernández del Amo del Museo Histórico Nicolás Avellaneda62, Claudia Esperguín del Museo de la Universidad Nacional de Tucumán ${ }^{63}$; Germán Paley y Ayelén Rodríguez del área de comunidades ${ }^{64}$ del Museo de Arte Moderno de Buenos Aires, Mariana Silva del Museo de la Historia del Traje ${ }^{65}$, Clara Sarsale del Museo Nacional del Cabildo de Buenos Aires y de la Revolución de Mayo ${ }^{66}$, así como también estaban Silvia Durá mi ex compañera de la Red de Museos de Quilmes ${ }^{67}$, Alicia Sarno y Florencia Lloret trabajadoras del Archivo Histórico Provincial y docentes de la carrera de Museología 68 en el Instituto de Formación Docente y Técnica N. ${ }^{\circ} 8$ de La Plata.

A todas estas personas nombradas también les conté sobre mi indagación e intercambiamos ideas, criterios, bibliografías, espacios significativos, que de algún modo forman parte y fueron necesarios puntos de apoyo para la construcción de esta investigación tal como ahora se presenta. Todas estas personas serían dignos entrevistados para la investigación. No fueron incluidos por una cuestión de acotar las dimensiones del trabajo y permitir su concreción en el mediano tiempo, pero me tomo el trabajo de nombrarles ${ }^{69}$ porque les considero personas importantes, por sus experiencias y saberes que se inscriben desde sus posicionamiento y prácticas en la museología social.

Les nombro también para compartir y dar visibilidad a otros tantos puntos de esta enorme red, como un dato significativo de la investigación, y como actores clave con quienes se pueden entablar diálogos para realizar futuras aproximaciones al tema.

\section{Participación en instancias de encuentro}

En función de esos nuevos contactos construidos durante el encuentro de Córdoba, me surgieron una serie de invitaciones para participar de otros espacios de intercambio. En los que si bien

57 https://educadoresdemuseos.wordpress.com/

58 http://www.museogallardo.gob.ar/

59 http://unca.edu.ar/pagina-44-museos-99.html

60 https://info.csnat.unt.edu.ar/secretarias/posgrado/maestria/museologia

61 https://casadelaindependencia.cultura.gob.ar/

62 https://enteculturaltucuman.gob.ar/museo-historico-de-la-provincia-pte-nicolas-avellaneda/

63 https://www.unt.edu.ar/Extension/MUNT.php

64 https://www.museomoderno.org/es/comunidades

65 https://museodeltraje.cultura.gob.ar/

66 https://cabildonacional.cultura.gob.ar/

67 https://museosquilmes.wordpress.com/

68 http://is8.com.ar/webis8/?page id $=154$

69 Estoy seguro de que aún tratando de hacer el mayor esfuerzo y de tener el mayor de los cuidados, en esta enumeración, como en cualquier enumeración estoy cometiendo alguna falta, estoy dejando afuera de manera injusta a otras tantas personas que forman parte importante de este campo. Se trata de una lista confeccionada a partir de la experiencia y los vínculos que logré desarrollar, pero siendo consciente de que solo se trata de una fracción de ese territorio. 
no realicé entrevistas, sí pude realizar observaciones participantes, escuchar a los y las participantes, registrara sentidos e incluso proponer los sentidos propios desde mi mirada de comunicación/educación. Fueron también espacios en los que volví a encontrar a varios y varias de las personas conocidas en esas jornadas.

Entre esos espacios es interesante nombrar dos experiencias que fueron significativas en cuanto permitieron establecer continuidades en la visualización de la red de referentes y contactos:

- La jornada de Encuentro de Educadores de Museos organizada por la Red de Educadores de Museos de Ciencias Sociales que se realizó en el patio del Museo Nacional del Cabildo. Donde me reencontré con Verónica Stáffora y Anabelle Castaño del Museo Etnográfico de la UBA, con Susana Maresca del Museo Malvinas e Islas del Atlántico Sur, y con Clara Sarsale del Museo del Cabildo, quienes junto con otros integrantes de sus espacios y con trabajadores y trabajadoras del Museo Histórico Nacional ${ }^{70}$ y del Museo Imaginario ${ }^{71}$ de la Universidad Nacional General Sarmiento desarrollaron un taller en el que intercambiaron estrategias y discutieron perspectivas educativas para los museos.

- El Encuentro "En busca del tesoro perdido: Museología Social y Museos Universitarios" organizado por el Observatorio de Museos Universitarios (OMU) ${ }^{72}$ de la Red de Museos ${ }^{73}$ de la Universidad Nacional de La Plata y al Archivo Histórico Provincial ${ }^{74}$, que además funcionó como sede del encuentro. Allí la principal expositora fue Verónica Jeria, y junto con una nutrida concurrencia de equipos de los museos universitarios platenses pude volver a cruzarme con Verónica Stáffora, Anabelle Castaño y Leonardo Casado. También se encontraban Alicia Sarno y Florencia Lloret quienes trabajan en el Archivo Histórico provincial, quienes a su vez me presentaron a Mariana Santamaría quien forma parte del Museo de la Facultad de Física ${ }^{75}$ de la UNLP y es referente del Observatorio de Museos Universitarios. Así como también me encontré con Constanza Pedersoli ${ }^{76}$ de la Red de Museos de la UNLP. En dicho encuentro además de la charla inicial sobre museología social a cargo de Verónica Jeria, luego se desarrolló un taller en el que se intercambió experiencias en grupos y se desarrollaron producciones.

La participación y observación en estos espacios me sirvieron para seguir ampliando la percepción de esa red que ya se me tornaba cada vez más densa y visible. A la vez que a partir de la concurrencia y participación activa en las propuestas (en conjunción con el estudio de bibliografías específicas que fui desarrollando en paralelo) me sirvieron para comprender de otro modo sus

70 https://museohistoriconacional.cultura.gob.ar/

71 https://www.ungs.edu.ar/cultura/imaginario-museo-interactivo/museo-imaginario

72 http://www.reddemuseos.unlp.edu.ar/articulo/2018/3/22/el observatorio de museos universitarios omu

73 http://www.reddemuseos.unlp.edu.ar/

74 http://www.ic.gba.gov.ar/archivohistorico/areas/r historica.php

75 http://museo.fisica.unlp.edu.ar/

76 A quien también conocía de manera previa, por haber sido ella evaluadora de mi trabajo de tesis de Maestría en Comunicación y Educación (FPyCS UNLP). 
lenguajes, sus referencias, me permitió acceder a muchas otras experiencias, en definitiva a seguir profundizando de manera compleja en el discernimiento de sus sentidos y repertorios de acción.

\section{Olga Bartolomé}

En la continuación con el desarrollo de las entrevistas, el siguiente contacto fue con Olga Bartolomé a quien conocí en Córdoba como una de las principales organizadoras de las jornadas, como una de las referentes del Encuentro de Educadores de Museos, y como destacada integrante del equipo de educación del Museo Nacional Estancia Jesuítica de Alta Gracia y Casa del Virrey Liniers $^{77}$, espacio que tuve la oportunidad de conocer y recorrer durante el viaje a esa provincia para participar del MINOM.

Al momento de la efectivización de la entrevista Olga había cambiado de ámbito de trabajo, trasladándose al área educativa del Museo Jesuítico Nacional Estancia de Jesús María78, a la vez que también había logrado una posición dentro del Museo Escolar - Escuela Normal Superior Dr. Agustín Garzón Agulla ${ }^{79}$.

Si bien hubo una intención inicial de desarrollar un nuevo viaje a Córdoba para realizar la entrevista in situ, y de incluso establecer algún tipo de trabajo en conjunto con el Encuentro de Educadores de Museos de Córdoba, diversos problemas logísticos impidieron que eso fuera posible. Por lo que cuando el viaje quedó descartado como posibilidad, finalmente la entrevista se realizó de manera telefónica.

En el recorrido de la charla fuimos repasando diversos puntos de su experiencia que además de permitir conocer sus perspectivas y sentidos sobre la museología social, sirvieron para conocer sobre la Red de Estancias Jesuíticas, un entramado de 5 estancias ubicadas en diversas localidades de la provincia, que sumadas a la Manzana Jesuítica de la capital cordobesa conforman un bloque de edificios históricos que fueron declarados Patrimonio de la Humanidad por la UNESCO. Sobre ese mismo eje histórico Olga participa con otras colegas de diversos museos y diversas organizaciones educativas y sociales de la provincia de la denominada "La ruta del esclavo" ${ }^{80}$, con la que se ocupan de sostener diversas actividades para visibilizar el reverso de la historia a partir de la revalorización de la presencia afrodescendiente como constitutiva del patrimonio y todo lo que esa comunidad aportó a la construcción de la historia, en sintonía con un proyecto que fue iniciado en Haití en 1993 y que logró reconocimiento de la UNESCO.

A partir de la entrevista a Olga y en adelante ya utilicé la guía de entrevistas en su versión final, la que me acompañó, con leves variantes, para el resto de las entrevistas. Muy basada en la usada con Analía y Leonardo, pero ajustada a partir de sentidos recuperados en esos intercambios y

77 https://museoliniers.cultura.gob.ar/

78 https://museojesuitico.cultura.gob.ar/

79 http://museoescolarensaga.blogspot.com/

80 https://rutadelesclavocba.wordpress.com/ 
articulados con la profundización en el rastro bibliográfico y con todo lo aprendido en las observaciones realizadas en los encuentros a los que asistí.

\section{Julieta Rausch}

La siguiente entrevista en el desarrollo de esta trama investigativa también fue mediante contacto telefónico, dada la distancia y la imposibilidad lógistica de viajar al momento del desarrollo del trabajo. No obstante se trata de otro espacio museal que he visitado en persona y que conozco con anterioridad.

Julieta Rausch trabaja como coordinadora del área educativa y del área de archivo del Museo del Puerto ${ }^{81}$ de Ingeniero White en el partido de Bahía Blanca, provincia de Buenos Aires. Se trata de un museo que se reconoce como "museo comunitario" y que se encuentra instalado en una casa de chapa y madera, clásica construcción que puede encontrarse en los barrios portuarios o ferroviarios que fueran administrados por compañías inglesas a fines de siglo XIX, o principios de siglo XX.

El museo fue creado en 1987 a partir de la recuperación de una iniciativa de vecinos de la localidad y se ocupa de la recuperación de la historia oral de sus vecinos. Una característica de este museo ocurre en la cocina de la casa que resulta un epicentro de muchísimas de las acciones, en las que se exhibe una colección de repasadores, se recuperan recetas a partir de la elaboración de dichos alimentos, y se realizan diversas actividades culturales y artísticas, fiestas, bailes y recitales.

Parte del equipo que participó de la construcción de este espacio fue después también la que colaboró a partir de 2003 en el armado del Museo-Taller Ferrowhite que se encuentra a pocas cuadras de distancia.

Un dato significativo observado en las jornadas del MINOM fue que Julieta junto con Analía Bernardi, habían llevado una pila de repasadores que vendían. Eran dos diseños que habían sido impresos en los talleres de serigrafía de Ferrowhite en los que podía leerse: "SIN Mí, tampoco hay HISTORIA" y en el otro "manchado, percudido, en uso, CON UN TRAPO también podemos hacer HISTORIA". Este trabajo colaborativo realizado entre ambas instituciones fue el que les permitió gestionarse parte de los costos del viaje para participar del simposio y a la vez era una expresión manifiesta que daba cuenta de la continuidad de la relación estratégica entre estos dos espacios vecinos.

\section{Verónica Stáffora}

Dentro de las referencias que se fueron repitiendo en las primeras entrevistas, así como en las charlas informales en Córdoba aparecía con frecuencia el nombre de Verónica Stáffora quien es actualmente la encargada del área de Acción Cultural ${ }^{82}$ del Museo Etnográfico Juan B. Ambrosetti de

81 http://museodelpuerto.blogspot.com/

82 http://museo.filo.uba.ar/actividades 
la Universidad Nacional de Buenos Aires. El equipo que ella coordina se ocupa de atender a los grupos o colectivos de personas que se acercan al museo por fuera del contexto de las instituciones educativas o los grupos escolares. Desde su área se ha trabajado fuertemente por la complejización de los criterios de accesibilidad del museo, lo que es tomado como ejemplo en muchos otros espacios. En su formación académica como Antropóloga, Verónica además de trabajar en este espacio, desarrolló experiencias en el Museo Histórico Nacional. Aunque actualmente es coordinadora de área, sigue realizando visitas guiadas en el espacio.

El Museo Etnográfico Juan Ambrosetti fue creado en el marco de la Facultad de Filosofía y Letras de la UBA, en 1904, lo que en su momento significó un importante cambio de paradigma, dado que corría a la antropología del encuadre de las ciencias naturales, lo que podría marcar todo un indicador fundante. Sus primeros años se desarrollaron en formato de un gabinete dentro de la sede Viamonte de la Facultad, para mudarse a partir de 1927 a la casona construida por Pedro Benoit donde sigue funcionando actualmente. Está ubicado en pleno casco histórico de la Ciudad Autónoma de Buenos Aires, a muy pocas cuadras de Plaza de Mayo.

En su larga trayectoria como museo, la institución a pasado por muy diversos proyectos de gestión, sin embargo tanto en sus inicios donde rompen con la episteme de las ciencias naturales, como luego a partir de dos procesos de la historia reciente, le dieron al museo un lugar importante como referencia del campo de la museología: un proceso breve en 1973, en el marco de la Universidad Nacional y Popular de Buenos Aires, el que resulta prácticamente desconocido; y otro que se inicia con la vuelta de la democracia, a partir de 1987, impulsado por la dirección de José Pérez Gollán y Marta Dujovne (y que con matices ha sido continuado hasta la actualidad por las distintas gestiones). Este último proyecto está marcado por una fuerte impronta de profesionalización y especialización de los equipos de museos, y en ese sentido en la búsqueda de formación y actualización de las perspectivas de sus trabajadores y trabajadoras ${ }^{83}$.

Por todo esto, es éste el espacio en el que más entrevistas realicé. En todos los casos se trataron de visitas a las oficinas en las que se desempeñan y en algunos casos acompañadas por recorridas por espacios o muestras específicas. En la jornada en que entrevisté a Verónica, ella me presentó a Sebastián Cohen, integrante del área de etnografía y encargado del depósito visitable del museo (a quien finalmente no entrevisté por cuestiones de tiempo), y ese mismo día también me vinculó con Carlos Molina, con quien sí pude charlar en días posteriores.

\section{Anabelle Castaño}

Realicé la entrevista con Anabelle Castaño en la misma jornada en la que charlé con Verónica Stáffora. Ella trabaja en el mismo equipo de acción cultural del Museo Ambrosetti, en vez de realizarla

83 Tanto el proceso del '73 como el del '87 en adelante,serán analizados con mayor detalle en capítulos posteriores. 
en la oficina, le pedí que fuéramos dialogando mientras me mostraba las distintas muestras del museo, la invitación fue a que produjera un recorrido orientado por los espacios y muestras que para ella resultaran más significativos.

Anabelle ingresó al museo a partir de una serie de prácticas de voluntariado mientras cursaba la carrera de Arqueología de la UBA y desde allí se fue vinculando con diversas áreas. Hizo experiencias catalogando piezas en el depósito, trabajó en el área de extensión educativa, colaboró en el montaje de muestras, y luego comenzó a trabajar como referencista de sala y como guía. Su tarea se transformó significativamente a partir de una propuesta en la que ella decidió realizar una narración para un nuevo guión de visita. A partir de allí se empezó a interiorizar y especializar en la narración oral, que hoy en día forma parte de la impronta de su tarea. Anabelle también forma parte de la Asociación de trabajadores de museos.

\section{Carlos Molina}

La entrevista con Carlos Molina fue pautada a partir de la presentación que me realizó Verónica Stáffora y fue realizada a la semana siguiente. El diálogo comenzó en el patio del museo, y luego de un rato comenzamos a desplazarnos por algunas de las salas de exhibición donde fue contándome detalles de su tarea y de sus perspectivas a partir de experiencias vividas en los distintos espacios del Museo Ambrosetti.

Carlos se formó en antropología y luego como profesor de filosofía y en ciencias de la educación en la UBA, desde que se vinculó con el museo trabajó en el área de extensión educativa, que es la que se ocupa de atender al público que llega al museo como parte de alguna institución educativa del sistema, ya sea inicial, primaria, secundario, terciario o universitario. Dentro del mismo área actualmente se especializa en realizar actividades para grupos de terciario y universitario, y en especial está a cargo del área de capacitación y formación docente ${ }^{84}$.

\section{Verónica Jeria}

Otro de los nombres que persistentemente aparecía en referencia a aquellos o aquellas personas claves dentro del campo de la museología social, es Verónica Jeria. Museóloga de formación, comienza a vincularse con la institución en 2001 tras realizar un curso auspiciado por la Fundación Antorchas ${ }^{85}$ y que tenía como sede el Museo Ambrosetti, se relaciona en particular con Fernando Veneroso con quien actualmente comparte tareas en el área de Conservación y Museografía. En esos momentos iniciales, en los que se vinculó de manera esporádica con la institución volvió a participar de otra serie de cursos intensivos que se realizaron en el mismo museo, y a partir de estos acercamientos fue convocada para otras tareas en el museo. En el mismo tiempo realizó trabajos en

84 http://museo.filo.uba.ar/nivel-superior-terciario-y-universitario

85 https://web.archive.org/web/20050424064506/http://168.96.248.2:80/antorchas.com/nuevo/index.html 
museos de La Plata y se vinculó con el sitio de memoria de la Casa Mariani-Teruggi ${ }^{86}$. Luego ya como trabajadora del Museo Antropológico de la UBA participó de una experiencia en el marco de un acuerdo de cooperación con el Museo Azzarini ${ }^{87}$ de Instrumentos Musicales dependiente de la UNLP. También trabajó en el Programa de Rescate de Bienes Culturales de la Secretaría de Cultura de la Nación tarea con la que visitó 15 provincias de la Argentina. Tuvo militancia en el desarrollo de lo Sitios de Memoria ${ }^{88}$, trabajando en la exESMA y en la mesa de trabajo del Olimpo ${ }^{89}$. También en paralelo al desarrollo de trabajo en el Ambrosetti, tuvo una importante experiencia de trabajo en el Museo Histórico Nacional, durante la gestión de José Pérez Gollán. De aquella época, y a partir del robo del Reloj de Manuel Belgrano, un hecho que fue harto difundido aún más allá del ámbito de museos, y durante el cual ese espacio fue intervenido judicialmente y cerrado, fue que Verónica junto a otras compañeras crearon la Asociación de Trabajadores de Museos.

La entrevista con ella se realizó en la misma jornada en la que hablé con Carlos Molina, y fue realizada en un soleado mediodía en el patio del Museo Ambrosetti. Tanto su mirada de la museología social como la trama de sus experiencias fueron realmente interesantes para comprender la complejidad de los alcances e implicancias que esta perspectiva puede tener.

\section{Susana Maresca}

La entrevista con Susana Maresca fue realizada en una visita al Museo Malvinas e Islas del Atlántico $\mathrm{Sur}^{90}$ en el que se desempeña actualmente como asesora pedagógica en el área de educación del museo. Tuvimos una extensa charla en un espacio multiuso que está al costado de la sala de exhibición principal, y luego continuamos el diálogo en una recorrida en la que le pedí que me fuera mostrando los espacios de muestra que consideraba significativos.

El Museo Malvinas pertenece a la red de los Museos Nacionales, se encuentra emplazado dentro del predio del Espacio Memoria y Derechos Humanos de la exESMA. Fue inaugurado en 2014 en un edifico construido ad hoc para ser museo, lo que es un caso bastante excepcional si observamos el resto del mapa de museos de nuestro país, en los que habitualmente se emplazan ocupando un edificio histórico, el que es recuperado y reciclado para ser museo. No es este el caso, dado que se levantó desde los cimientos como un museo con todas las condiciones de acceso necesarias. Está compuesto por tres plantas espaciosas de construcción moderna, iluminado y equipado con dispositivos audiovisuales de última tecnología.

Susana que tiene un recorrido de formación por la pedagogía, primero estudiando Magisterio Rural en Entre Ríos y luego Pedagogía y Educación Social en el ISTLYR ${ }^{91}$, tiene en paralelo a su trabajo

86 https://www.facebook.com/casamarianiteruggi/

87 https://unlp.edu.ar/museo azzarini

88 https://www.argentina.gob.ar/derechoshumanos/sitiosdememoria

89 https://www.argentina.gob.ar/sitiosdememoria/espacios/olimpo

90 https://www.argentina.gob.ar/derechoshumanos/sitiosdememoria

91 https://istlyr-caba.infd.edu.ar/sitio/ se trata de un espacio de formación ubicado en la Ciudad Autónoma de Buenos 
museológico, una extensa militancia en la educación popular participando de bachilleratos en organizaciones sociales (actualmente en Villa Crespo). Se inició en el trabajo en espacios museales participando de la experiencia del Museo del Juguete ${ }^{92}$ de San Isidro durante la gestión de Daniela Pelegrinelli, otra de las instituciones que eran recurrentemente nombradas como referencia significativa en las conversaciones con otros museólogos. En el diálogo que mantuvimos permanentemente fuimos y vinimos entre las experiencias del museo del Juguete y el museo Malvinas, lo que permitió un interesante tránsito para transversalizar su mirada sobre los museos en dos espacios de escalas totalmente diferentes.

\section{Nueva visita a Leonardo Casado}

Como cierre del ciclo de entrevistas con referentes del campo museológico, decidí volver a visitar a Leonardo. La entrevista fue un extensísimo diálogo (de unas 4 horas de extensión) que mantuvimos en el patio del Complejo Municipal "San Francisco"93 de Berazategui. Había pasado más de un año de aquella primera entrevista, en este caso su posición ya no era la de director de los museos municipales, y acaba de reincorporarse a sus tareas en el municipio luego de una licencia en la que se había estado desempeñando en la Dirección Nacional de Museos ${ }^{94}$ de la Secretaría de Cultura de la Nación, donde había estado coordinando tareas en la gestión del Registro de Museos Argentinos $^{95}$ (RMA), así como haciendo asesoría en la plataforma de "Museos. Formación y Redes" 96 en la que se desarrollaron una serie de cursos de formación a distancia para trabajadores y trabajadoras de museos. Uno de esos cursos, denominado "Un museo común, Museos y Comunidades"97 estaba conducido por el equipo del Museo Ferrowhite.

Esta última visita fue interesante para dialogar con Leonardo de manera más transversal, desde su mirada más global sobre los museos del país, algo que también había podido hacer aunque con menor profundidad con Verónica Jeria, así como pude desarrollar otro tipo de interrogaciones desde la mirada ya más complejizada sobre la red de contactos, y teniendo en cuenta un mapa mucho más amplio de experiencias.

\section{Lazos que sostienen una enorme red}

Tal como dije al inicio de este apartado, reflexionar sobre la trama de posibilidades y contactos que dio lugar a la realización de cada una de las interacciones resulta un dato significativo por sí

\footnotetext{
Aires y que es pionero en el campo de la recreología.

92 http://museodeljuguetesi.org.ar/

93 http://www.berazategui.gob.ar/cultura/espacios-culturales/complejo-municipal-san-fransisco

94 https:/www.cultura.gob.ar/institucional/organismos/direccion-nacional-de-museos/

95 https://www.cultura.gob.ar/que-es-el-registro-de-museos-argentinos 6777/

96 https://www.cultura.gob.ar/conoce-los-cursos-de-formacion-virtual-para-personal-de-museos-de-todo-elpais $6653 /$

97 https://www.cultura.gob.ar/curso-virtual-un-museo-comun-museos-y-comunidades 6497/
} 
mismo. Más allá del desarrollo analítico de los sentidos expresados por los sujetos en las entrevistas, lo que será parte de capítulos posteriores, me resulta necesario destacar como información aportada a la investigación el modo en que para mí se fue configurando y haciendo visible esta red de trabajadores y trabajadoras de museos que se inscriben dentro del campo de la museología social.

Resulta interesante porque a partir del recorrido que significó en tanto experiencia este trabajo de campo pude conocer una trama mucho más densa y compleja. Da cuenta del modo particular en que se desarrollan estas relaciones sociales sostenidas en el marco de intereses profesionales, posicionamientos políticos y epistemológicos, pero reforzadas por lazos de confianza o de afecto (en sus más diversos grados). Y como la diversidad de modos de comunicación, ya sea desde los encuentros interpersonales en los propios museos, los congresos de la disciplina o de otras, los talleres o encuentros de intercambio, los grupos de Whatsapp y de Facebook, así como los espacios de encuentro que se dan en los intersticios de todos estos anteriores, son todas maneras de alimentar y sostener los lazos de esa red, que en es en definitiva una red social, una red de lazos sociales, una comunidad política.

A la vez notar de este trabajo de campo que aparecen enrolados en la perspectiva una enorme diversidad de formaciones institucionales. La museología social se puede hacer presente de muy diversas maneras, no siempre monolíticas. Espacios que nacieron con esta perspectiva como rumbo y como bandera, en otras, sobre todo las mas históricas donde este posicionamiento ha tenido que ganarse su lugar a fuerza de rupturas y luchas no siempre ganadas. Se trata de una perspectiva que no siempre encontraremos expresadas en la letra del museo, pero que en muchos seguro sí estará puesta de manifiesto en posiciones -a veces laterales, otras más centrales- que se hacen notar en los modos de acción, en las metodologías de producción de visitas y sobre todo en los espacios educativos donde parece ser cada vez más visible el trabajo desde enfoques multidisciplinares o transdisciplinares que integran perspectivas críticas y sociales. En ese sentido en esta trama, y a partir del intercambio con muchos y muchas de sus integrantes se hacen presentes pequeñas instituciones, museos de pueblos con pocos años de desarrollo, otros similares pero con mayor experiencia y con definiciones más claras y sostenidas; museos provinciales y nacionales, de los viejos y de los nuevos; pequeños gabinetes y grandes museos universitarios; espacios del Siglo XIX y otros de los primeros años del Siglo XXI. Instituciones integradas y gestionadas por tres personas, o las de gran escala con extensos organigramas y empleados que muchas veces no se terminan de conocer entre sí. En todos esos espacios es posible que haya quienes sostengan y accionen desde y para la museología social latinoamericana. 
Capítulo 4

LOS MUSEOS LA CONSTRUCCIÓN DE LA

HISTORIA Y LA MEMORIA

\section{Historización de los modos de hacer museo}

Los museos tal como hoy los conocemos (o los imaginamos) son un fenómeno relativamente nuevo en términos históricos, y provienen de un contexto cultural y geográfico muy específico: la Europa del Siglo XIX.

Este origen configuró un modo esperable de hacer museos, así como también un modo de visitarlos, de mirar (o admirar) lo exhibido, y hasta produjo un protocolo esperable sobre cómo comportarse y desplazarse (de la manera pretendidamente correcta) por esos espacios. Entrar en el museo implica, poner nuestro cuerpo dentro de un espacio que culturalmente aparece altamente reglado y ritualizado. Por ello es que tal vez revisar los modos en que se hizo museo deba también incluir revisar las convenciones sobre el cómo mirar y cómo habitarlo aprehendidas por la práctica cultural.

El sentido común supone que a los museos se los transita lentamente, en silencio, y sin tocar nada. Todas estas disposiciones, muy instaladas en los imaginarios, ya no son consideradas norma en muchísimos museos de todo el mundo. Sin embargo no pueden desconocerse como sentido hegemónico, en tanto tienen su razón de ser en las convenciones que las instituciones de la modernidad han configurado sobre nuestros cuerpos, instalándose en nuestras subjetividades y por ende en la cultura, desde donde perviven.

\section{El coleccionismo}

Uno de los primeros antecedentes de los museos son las grandes colecciones de objetos que la nobleza europea acumulaban en sus residencias, donde los exhibían ante sus visitantes como modo de ostentar su poder, riqueza y buen gusto. 
Según Nuria Serrat Antolí (2005) durante aproximadamente diez siglos esas colecciones fueron prácticamente desconocidas por la mayoría de las poblaciones, ya que se trataba de espacios que estaban vedados a la gran mayoría de la población. Sólo quienes pertenecían a la aristocracia y eran amigos de los portadores tenían la posibilidad de acercarse a esos objetos de preciado valor. La única excepción podía estar dada para los especialistas o estudiosos que podían lograr algún permiso especial, pero esto rara vez ocurría.

En el Siglo XVIII, con la influencia de la mecánica newtoniana y su concepción de la naturaleza como maquinaria perfecta, la aristocracia europea comenzó a interesarse por las cuestiones científicas y por ello iniciaron colecciones de otro tipo de objetos, con un afán más taxonómico. Según Silvia Alderoqui, "la naturaleza comenzó a ser clasificada con fines de deleite e investigación. La ciencia se puso de moda" (2011:37).

En el último cuarto de Siglo XIX, muchas colecciones privadas, que por diversas circunstancias, dejaron de ser patrimonio exclusivo de nobles y científicos, y fueron donadas por esas "familias destacadas" a las ciudades por lo que pasaron a ser patrimonio de los museos y se abrieron al público, con lo que comenzaron a jugar un rol fundamental en la construcción de la identidad colectiva. En Europa según Moana Soto

donaciones como las de los Grimani a Venecia; de los Crespi a Bolonia; y de los Maffei a Verona. Pero, el primer museo tal como se los entiende hoy, surge a partir de la donación de la colección de John Tradescant, hecha por Elias Ashmole, a la Universidad de Oxford, cuando se crea el Museo Ashmolean (1683). El segundo museo público se creó en 1759, por votación del Parlamento inglés, que decidió comprar la colección de Hans Sloane (1660-1753), dando origen a lo que hoy se conoce como el Museo Británico (Soto, 2015:59). ${ }^{98}$

Al mismo tiempo, a partir de entonces y hasta principios del Siglo XX, muchos de los coleccionistas privados comenzaron a vender o donar sus colecciones a los grandes museos. Estos espacios se convirtieron entonces en depositarios (y guardianes) de ese patrimonio que se fue convirtiendo en un patrón de patrimonio cultural, y su acción educativa comenzó a tomar algo de importancia. Sin embargo la transición del criterio de la colección cerrada a la colección abierta no fue ni fácil ni inmediato. Tampoco hubo tal transición en el modo de exhibición de los museos, que en ese momento consistía, al igual que ocurría con las colecciones privadas, en la acumulación de objetos de manera abarrotada en los espacios.

Como señalan Santacana y Hernández Cardona (2006) el modo en que se constituyeron los museos en Europa y las donaciones de patrimonio que se realizaron a las Naciones se hicieron "con la finalidad de educar, instruir y hacer gozar a los ciudadanos". Los museos utilizaron las colecciones de

98 La traducción es propia. A continuación el texto en su idioma original: "doação dos Grimani à Veneza; dos Crespi à Bolonha; e, dos Maffei à Verona. Mas, o primeiro museu tal como é entendido hoje, surge a partir da doação da coleção de John Tradescant, feita por Elias Ashmole, à Universidade de Oxford, quando então é criado o Ashmolean Museum (1683). O segundo museu público foi criado em 1759, por votação do Parlamento inglês, que decidiu comprar a coleção de Hans Sloane (1660-1753), dando origem ao Museu Britânico" (Soto, 2015:59). 
objetos para educar el "buen gusto" y otros cánones de conducta aceptable, garantizándoles a sus visitantes un lugar entre los "ciudadanos de bien". Quienes trabajaban en ellos -generalmente personas de clase alta- "se aliaban a los fundadores y los directivos para transmitir la moral buena y recta" (Alderoqui, 2011:39), es decir que se constituían como parámetro educativo, a partir de los patrones sociales y culturales de las aristocracias europeas. En esa construcción histórica se configuró un modo de museo en el que la adquisición de esos patrimonios aristocráticos, joyas intocables, son adquiridos como por los Estados nacionales para ser desde entonces considerados patrimonio colectivo, aquello digno de ser admirado y resguardado.

En cuanto a los primeros antecedentes en nuestro territorio, en 1823 se creó en Buenos Aires, el "Museo del País", que reunía todo tipo de objetos, aunque se relacionaba fundamentalmente con las ciencias naturales. Tras diversas transformaciones, se convirtió en el actual Museo Argentino de Ciencias Naturales "Bernardino Rivadavia"99. A mediados de Siglo XIX, en las ciudades de Corrientes y de Paraná, también se crearon museos de ciencias naturales. Pero fue recién entre finales de ese Siglo XIX y principios de Siglo XX, en el período de organización e institucionalización del Estado nacional argentino, cuando los museos cobraron mayor relevancia.

\section{El patrimonio como objeto de transmisión cultural}

Uno de los sentidos más comunes que circulan en torno a los museos, implicaba la relación que para muchos se configuraba como "necesaria" entre la institución y los objetos que allí se guardan y exponen. En la demanda que suele registrarse por la necesidad de ver objetos en una muestra subyace un sentido regresivo y conservador sobre las funciones del museo.

En el rastreo bibliográfico aparece que "el amor por el patrimonio" parecía estar en la base de la transmisión del legado cultural en los museos hasta las primeras décadas del XX, "como si hubiera habido una generación dedicada a redactar testamentos, a 'envolver' paquetes de objetos reunidos en colecciones, constituidas así en patrimonio para entregar en manos de los jóvenes" (Tabakman, 2011: 87-88). Lo que empezó a ser discutido alrededor de la década del '60 a partir de las publicaciones de Henri Rivière, uno de los fundadores de la llamada "nueva museología" en Francia, quien produjo un giro en los procesos de patrimonialización. Según Rivière los museos pasaron por varias etapas: de ser coleccionistas de objetos, pasaron luego a constituir un conjunto de elementos de valor cultural, para llegar a ser los testimonios del hombre y su medio ambiente (hacia mediados de la década del '70) (Tabakman, 2011). En cuanto a lo particular de los museos de historia, la nueva museología propició un pasaje de la melancolía en la interpretación de la cultura material, hacia la adquisición de una mayor preocupación académica (Edelstein, 2011).

99 Ubicado en la Avenida Angel Gallardo 470, en el Parque Centenario de la Ciudad Autónoma de Buenos Aires. http://www.macnconicet.gob.ar/ 
Otro pasaje del movimiento francés se da entre la predominancia del mito fundador que buscaba imponer una "identidad nacional" (como ocurría en nuestro país a fines de S. XIX y principios de S. XX) para pasar hacia una "identidad comunitaria" o "identidad cultural". Desde esta perspectiva, "la comunidad no aceptaría el patrimonio como un elemento que les es transmitido, sino que debe haber un proceso de elección, una reinterpretación o reapropiación" (Tabakman, 2011: 88). Esta propuesta resulta atractiva, en tanto coincide con nuestra voluntad de tomar los objetos del museo, no como conservación del pasado, como herencia estática, sino como soporte para leer el pasado y resignificarlo desde el presente.

Como espacios públicos educativos los museos deberían realizar todas las acciones posibles para incluir en el relato del museo a los sectores que han sido excluidos de la historia.

Como espacio público aparece la responsabilidad, sabiendo que cuando un objeto se elije para ser exhibido en un museo, se está generando una operación que lo convierte en un objeto de valor, en un objeto de algún modo merecedor de ser considerado patrimonio (cultural, artístico, histórico, etc.) y por ende un objeto digno de ser parte del recorte de la cultura que una generación le lega a la próxima.

A la vez el museo, por su carga institucional histórica, también genera una operación a la inversa haciendo que muchas personas se pregunten si son dignas de estar en ese espacio, o que por lo mismo, ni siquiera se animen a cruzar la puerta de entrada.

Hay una "doble dignidad" dice Yannis Tsiomis (1998: 18) ${ }^{100}$ que debe ser tenida en cuenta, la de reflexionar qué es lo que convierte a un objeto digno de nuestra mirada, así como qué es lo que vuelve digna nuestra mirada para poder ver.

Esto es parte de lo que también construye un museo, ya sea consciente o inocentemente, en cada operación de selección de un fragmento de la cultura para ser expuesta como objeto, se está demarcando una herencia, una transmisión cultural ${ }^{101}$, a través del discurso comunicacional de la muestra. Aunque como dijimos antes, lo que vemos en el museo también es el resultado de los dispositivos de percepción que nos hemos construido históricamente como sociedad, los que nunca son unívocos, sino que dependen de los contextos situados.

Al respecto es interesante retomar lo dicho por Silvia Tabakman, quien asegura que la primer organización de los museos que hoy conocemos "ha quedado como huella que se revela en el modo de presentarse al público de cada una de esas instituciones, ya sea ratificando ese mensaje -decidido tiempo atrás-, o instalando un debate con esa narrativa originaria" (2011:89).

100 Citado en Alderoqui, 2004.

101 Uso transmisión el sentido que propone Jacques Hassoun (1996), en tanto pasaje de relato a las generaciones nuevas que presente la historia de la diferencia, de lo particular, que preserve y provoque una memoria activa con una narrativa que supere los puntos de vista únicos y que pueda ser revisada críticamente. No se trata de transmitir todo, ni de recordar todo: es necesario reconocer el lugar del olvido, ya que es imposible vivir sin olvidar. Solo es posible recordar aquello que deja huella y marca, y es transmitido en ese sentido. Dice Hassoun: aquello que permita al sujeto apropiarse de una narración para hacer de ella un nuevo relato es tal vez el recorrido que estamos convocados a efectuar. 
En ese sentido puede observarse como los museos que reivindican su origen se ocupan de resaltar a sus fundadores y sus legados, o el valor de sus colecciones; mientras que los que intentan discutir el sentido y los proyectos institucionales fundantes para proponer nuevas miradas sobre el pasado, se ven obligados a realizar enormes esfuerzos en la comunicación de la propuesta, un esfuerzo extra en producir una propuesta pedagógica para re educar la mirada de quienes visitan el espacio. Las que implican recuperar miradas diversas, producir textos con explicaciones y explicitaciones sobre el diseño y sobre los sentidos propuestos, tanto en las descripciones de la muestra, como en los materiales y relatos utilizados durante las visitas.

\section{El inicio de las exposiciones masivas}

En la segunda mitad del Siglo XIX y como un emergente del auge de la modernidad, los países que en ese momento desde la lógica centro-periferia se auto denominaban como "países centrales" comenzaron a organizar una serie de exposiciones llamadas "nacionales", "internacionales" y hasta "universales" en las que convocaban a representantes de los diversos países para dar a conocer el grado de avance en materia de desarrollo tecnológico y pujanza industrial que cada nación tenía.

Uno de los primeros antecedentes fue la Gran Exhibición de Londres de 1851, cuyo nombre completo, "Gran Exhibición de las Obras Industriales de Todas las Naciones" hablaba por sí mismo de sus pretensiones universalistas. Así como también denotaba sus ambiciones, en el sentido de ostentación del poderío económico y tecnológico que Gran Bretaña había conseguido.

Las exposiciones universales son los primeros acontecimientos públicos de un mundo que se reconoce globalizado, y requiere de posicionamientos geopolíticos de otro orden, por ello

congregan a los países en crecimiento en una suerte de exaltación nacional que es, al mismo tiempo, una demostración de su capacidad creadora y productiva, y una autoafirmación de cara a sí mismos y a los demás (...) En ellas se erigen prestigios, alianzas, influencias, autoridades, y sobre todo, se consolida el poder del país anfitrión en tanto cimienta el entorno donde la construcción de estos valores se hace posible (Alonso, 2012: 28).

Pero además de demostrar poder, estas exposiciones fueron un gran muestrario para las poblaciones locales. Quienes asistían podían observar de cerca los nuevos materiales y adelantos técnicos, como máquinas industriales, locomotoras de ferrocarril, puentes, o nuevos productos de mercado que se publicitaban de maneras novedosas. Si bien ésta como otras muestras estaba centrada en la producción fabril, incorporaban también una amplia variedad de productos de los países que participaban, incluyendo la creación artística. En la Exhibición Universal de París de 1881, por ejemplo se realizaban lo que denominaban como "recitales de teléfono", en los que los visitantes podían oír mediante un aparato la música del Teatro de la Ópera de París. Con el paso de las exposiciones, la dimensión artística ganaría cada vez más espacio e importancia en las muestras, 
llegando incluso a independizarse con la realización de la primer edición de la Bienal de Venecia en 1895 (Alonso, 2012: 28).

Podemos considerar estas ferias como las primeras exposiciones que fueron diseñadas expresamente como muestras abiertas. A diferencia de las colecciones, que solían ser más bien la apertura al público de los espacios privados donde se guardaban y exponían -más o menos prolijamente- los acervos patrimoniales.

En estos casos se trataba de composiciones construidas ad hoc, generalmente emplazadas en amplios espacios o paseos públicos, en los que los equipos de cada país diseñaba y construía su propia instalación con lo que consideraban la mejor forma de mostrar al mundo lo más destacado de su nación. Estos espacios fueron proyectados y armados por colectivos de destacados arquitectos, ingenieros y artistas, que intentaban sorprender al resto con diseños de vanguardia. Dados los desarrollos técnicos -y de materiales de la época-, significaron la construcción de pesadas estructuras arquitectónicas en las que predominaron materiales como el hierro, el vidrio y la madera. Por lo que en muchos casos, una vez finalizadas esas muestras solo algunas eran desmontadas, y muchas de las construcciones quedaban allí emplazadas como testimonio de las muestras.

Como debe imaginarse, tanta difusión de la modernización, implicó que estas exposiciones internacionales fueran además el escenario ideal para innumerables encuentros políticos, de concreción de alianzas estratégicas y nexos de negocios. Alli se conocieron por primera vez los inventos de Thomas A. Edison, tal como lo destaca José Martí en sus crónicas. Allí fue también donde Domingo F. Sarmiento conoció al paisajista francés Carlos Thays, quien luego se trasladaría a nuestro país para diseñar los parques y plazas de las principales ciudades argentinas. Y fue el mismo Sarmiento, quien en 1871 -durante su presidencia- impulsó la realización de la primer Exposición Nacional de Córdoba, donde cada provincia expuso sus productos regionales, como frazadas tejidas con lanas de Córdoba, treinta y un variedades de madera de La Rioja, ladrillos refractarios para fundición de metal de Catamarca, bordados sobre pañuelos de San Juan, etc. (Tabakman, 2011: 45).

\section{Otros espacios de exhibición en el Río de la Plata}

En nuestra región, a partir de mediados de Siglo XIX, se empezaron a diversificar las ofertas culturales en las principales ciudades de la naciente nación. E incluso en el proyecto modernista de la "Generación del '80", se pensaba a la misma ciudad como un espacio de exposición a ser considerado para su goce, lo que puede observase a partir de la monumentalidad de los edificios públicos construidos en esa época. La ciudad de La Plata, con su planeamiento urbano, sus plazas, ramblas, parques y edificios -públicos y privados-, es un claro ejemplo de lo que ese proyecto político buscaba. En este sentido es interesante el aporte de María Belén Fernández para quien el espacio tiene en las culturas "un sentido simbólico y un significado mítico", por lo que enfocar la mirada sobre el espacio 
puede aportar "no solo lo que la historia legitimó en sus monumentos, sino algunas pistas para la comprensión de la comunicación, las relaciones sociales y las relaciones de poder, desde el imaginario y, por ende la potencialidad transformadora del espacio" (1997: 106).

Además de las exposiciones en los museos, y de las ferias, en esa época también se podía acceder a otros espacios como las "panorámicas" en los denominados "gabinetes ópticos"102, o las funciones de "teatro mecánico"103, e incluso pequeñas exposiciones de artes plásticas en los cafés. En las grandes ciudades de esa época se diversificaban las ofertas en teatros, salones, clubes; así como en poblaciones más pequeñas o rurales con las pulperías, las carpas de circos y del teatro criollo.

En la segunda mitad del Siglo XIX también circulaban por algunas ciudades de América del Sur los "museos anatómico-patológicos", en estas muestras ambulantes se ofrecían una serie de preparados médicos o figuras de cera usados como parte de un espectáculo de variedades, en los que se mezclaba lo artístico y el conocimiento científico de la época (Podgorny, 2009), los que generalmente eran explotados por empresas comerciales que aprovechaban el impacto para vender sus productos farmacéuticos. 0 en otros casos eran utilizados con fines educativos, para prevenir enfermedades venéreas y el alcoholismo, inculcando a la población mediante el espanto producido por el espectáculo (Podgorny, 2009).

En esta época también comenzaron a utilizarse de manera frecuente las imágenes de artistas, ya sea de pinturas, litografías, grabados, dibujos, que aparecían como parte de los envases de ciertos productos, o por ejemplo en los almanaques que se colgaban en las casas ${ }^{104}$. En el caso de los almanaques por ejemplo, esas ilustraciones permanecían colgadas en las casas, más allá de la finalización del período. Esta costumbre de los sectores populares fue proliferando en la medida en que los avances de las tecnologías de impresión y de la fotografía permitieron incorporar una variedad de motivos y paisajes. Así se fueron convirtiendo de algún modo en dispositivos mediadores de la entrada de imágenes del mundo, generadoras de estéticas, de gustos y de consumos culturales que configuraron todo un tipo de prácticas. Un verdadero fenómeno de ampliación en la circulación de imágenes.

Para sectores más acomodados algo similar ocurría con la llegada desde Europa de las guías de viajes y revistas temáticas ilustradas, que proponían lugares que "debían" visitarse, y a la vez de ese modo establecían una educación de la mirada mediante crónicas y descripciones detalladas de puntos turísticos, de valoración de edificios históricos, o de puntos panorámicos que se alentaba a conocer en persona.

102 Espacios en los que se disponía de una serie de dispositivos mecánicos que proponían ilusiones ópticas a partir de la utilización de espejos, obturación ocular y la interacción con el movimiento del dispositivo. La mayoría de estos, son previos a la difusión del cine, como las denominadas "linternas mágicas", "fantasmagorías", "zootropos", "neoramas", "diafanoramas", "silforamas" y "dioramas".

103 Especie de marionetas que eran dinamizadas mediante palancas, engranajes, cuerdas y correas.

104 Tal vez uno de los ejemplos más arquetípicos en nuestro país lo hayan establecido los almanaques de la compañía Alpargatas, que incluían las ilustraciones con motivos criollos de Florencio Molina Campos que lograron instalarse como un símbolo con diversos grados de apropiación en muchos sectores de Argentina. 
Todos estos fenómenos convivían con los museos y de algún modo los fueron modificando. A la vez que fueron educando la mirada y ampliando el gusto por los consumos culturales de la población.

\section{La República de los Niños}

Dentro de esta historización de diversos espacios expositivos y modos de hacer museo, interesa destacar dentro de los espacios creados en nuestro país, un hito que resulta central dentro del imaginario popular: la República de los Niños. En tanto constituye un antecedente de un espacio público educativo y recreativo impulsado por una política pública que buscaba ampliar el acceso de los sectores populares infantiles a estos espacios de aprendizaje y esparcimiento.

Un parque temático ubicado en la localidad de Gonnet (La Plata) que es considerado el primero en el continente americano en su tipo. Dentro del espacio se reproduce un conglomerado que recuerda al de una ciudad característica de la pampa húmeda, con su circunvalación y sus ejes principales, "ablandados" por la atención al paisaje. Una Zona Urbana que a la vez se dividiría en Centro Cívico: para las actividades administrativas y sociales, Iglesia, Gobernación, Legislatura, Palacio de Justicia, Banco, Comisaría, Primeros Auxilios, Correo, Escuela, y Centro Comercial, con locales para negocios, Mercado, Abastecimiento, Estación Ferroviaria, Aeropuerto, Teatro, Periódico, Imprenta. Y el Centro Residencial, con casa habitación individuales y colectivas y Hotel. Además de la Zona Urbana, el anteproyecto contemplaba una Zona Agrícola con granja, quinta, huerta, lago y obrajes; una Zona de Deportes, con estadio, piletas, pistas y vestuarios; y una Zona Fabril, con locales destinados a talleres industriales, artes y oficios, trabajos manuales, y telares. Por último, se preveía la construcción de un ferrocarril con estaciones en las áreas de abastecimiento, un puerto y muelle, avenidas para tránsito rápido y senderos para peatones y bicicletas. Todo construido en un estilo arquitectónico muy particular, y en una escala de $2 / 3$ que se proponía acorde a las dimensiones antropomórficas de un niño de 10 años (Clarke, 2012).

Fue ideada por el gobernador Domingo Mercante (1946-1952) y construido por el Instituto Inversor de la Provincia de Buenos Aires ${ }^{105}$, sobre un predio de 95 hectáreas de un club de Golf que

105 El Instituto Inversor de la Provincia de Buenos Aires fue creado como ente autárquico en junio de 1948 cuando el ejecutivo provincial -a cargo de Domingo Mercante- eleva al Senado provincial el proyecto de ley para su creación. Se buscaba como organismo inversor que "propendiera al desarrollo y fomento de diversas zonas, en una acción y un campo en el que la actividad privada no podía actuar por falta de alicientes. Su competencia en funciones comerciales e industriales no debía inspirarse exclusivamente en la idea del lucro sino en las normas de una política de fomento territorial". Aprobado por ley 5399 en diciembre de 1948, "le correspondía al Instituto la inversión de los fondos y rentas líquidas pertenecientes a las secciones del Instituto de Previsión Social" (Masa, Bruno :63).

Al mes de reglamentado su funcionamiento en octubre de 1949, por ley 5557 del mes de noviembre se aprueba el aumento de su capital transfiriéndole las siguientes tierras: 1) Las tierras expropiadas para el ensanche del ejido de la ciudad de Necochea. Compuesto por cuatro lotes del frente costero con una profundidad variable de alrededor de 500 metros - lotes sujetos a expropiación por Decreto 15.677 y de acuerdo a lo dispuesto por ley 3928- fueron objeto de un concurso internacional de anteproyectos de urbanización, organizado por el Instituto Inversor como una de sus primeras acciones.27 Como ocurría frecuentemente el plan resultante no tuvo aplicación, y en 1950 se aprueba el plan de Desarrollo Urbanístico para el lote mar 4, que analizaremos seguidamente. 2) Las tierras que componían el Vivero Dunícola "Florentino Ameghino" de Miramar y las expropiadas para su ampliación. En 1952 se aprueba un plan de 
fueron expropiadas a la empresa Swift. Se realizó en una época en la que la infancia y la educación cobraron un lugar central. La "política de la infancia" implicó

la movilización de los niños y adolescentes, su visibilidad pública, no solo a través de sucesivos y sostenidos eventos (entrega de juguetes, bicicletas y becas; los campeonatos deportivos 'Evita' y 'Perón', las colonia de vacaciones, etc.) sino también en distintos dispositivos institucionales, con el objetivo no solo de reparar y recomponer las desigualdades sociales que afectaban a distintas generaciones, sino además, construir otro tipo de reproducción social y política (Longoni, 2012: 64).

En consonancia con el lema 'los únicos privilegiados son los niños' en la Provincia el Plan Integral de Edificación Escolar puso en pie un millar y medio de establecimientos, pero también la formación de futuros ciudadanos comprometidos con la realidad social y cívica fue contemplada desde otras instituciones. "En la República los Niños podían jugar a ser senadores, periodistas, maestros, en los diferentes edificios públicos, fabriles, comerciales de la pequeña ciudad" (Belinche, Panella, 2012: 97). En el mismo sentido según Longoni

la política del primer peronismo hacia al niño fue 'integral': la dignificación social del niño y el adolescente se complementó con un conjunto de contenidos culturales y pedagógicos, en procura de la formación de 'un buen ciudadano', no abrumado por el enciclopedismo ni el intelectualismo (Longoni 2012) ${ }^{106}$.

La obra proyectada por Jorge Lima (parte de la firma de arquitectos Lima, Cuenca y Gallo) comenzó en 1950, ni bien fue conseguida la expropiación del predio. En una de las últimas entrevistas que le hicieron al arquitecto antes de morir, Lima contó que para el proyecto se había inspirado en los cuentos infantiles. El planteo apuntaba a que "cada centímetro de cada edificio remitiera a la arquitectura de la fantasía infantil recreada desde lo literario: edificios pintorescos, de colores contrastantes y vivos, y sobre todo pequeños, a la medida de los chicos y las chicas que lo visitaran" (Badenes, Maniago, 2012: 31). De este modo recuperando estéticas y símbolos de todo el mundo, el arquitecto pensó una estructura que contendría los ideales del momento:

urbanización con carácter de barrio parque en esas tierras propiedad del Instituto. 3) 1000 hectáreas de tierras fiscales del Parque Sierra de la Ventana. 4) 95 hectáreas en el partido de La Plata, próximas a la estación Gonnet, que se encontraban en trámite judicial de expropiación y en las que el Instituto debía realizar un centro de recreación infantil. Eran las tierras del Swift Golf Club de Gonnet expropiadas para el usufructo y esparcimiento popular, donde luego el Instituto inversor realizó la República de los Niños (Masa, Bruno :63).

"Los gobiernos peronistas desarrollaron una ambiciosa planificación urbana sobre la zona -quizá la última que pensó cabalmente la región-, que fomentó las áreas verdes de uso popular como no ocurrió en ningún otro período, con el inconcluso "Plan Integral de Recuperación del Bosque", la expropiación de terrenos de la familia Pereyra Iraola para la formación del "Parque de Derechos de la Ancianidad", y también la del Swift Golf Club para crear la República de los Niños con sus áreas verdes" (Badenes, Maniego, 2012: 35).

106 "La reforma educativa planteada inicialmente en el Primer Plan Quinquenal, propuso profundos cambios que alteraron la tradición educativa liberal, especialmente en la educación primaria y universitaria, provocando un acalorado y extendido debate con la oposición. La democratización educativa se tradujo en "igualdad de oportunidades" firmemente garantizadas por el Estado, creando y sosteniendo los establecimientos y el personal necesarios, entregando libros y útiles, instalación de comedores, internados y semi internados, compensaciones familiares cuando el niño era sostén del hogar, transporte o diseño de circuitos alternativos en lugares donde faltasen escuelas, etc." (Longoni, 2012: 64). 
desde plantar una semilla hasta ser presidente. Los niños debían conocer todo lo que involucraba la vida ciudadana. Tan importante fue para Lima la ciudadanía, que el eje del predio es el Centro Cívico, y a pocos pasos pueden encontrarse las instituciones con más peso simbólico de la época: la Casa de Gobierno, la Legislatura, la Iglesia, el Banco y el Museo Histórico (Badenes, Maniego, 2012: 31).

Se trataba en definitiva, de una pequeña República, construida a escala infantil, que permitía a los niños hacer más accesibles los distintos organismos del Estado: mediante el juego se estaba construyendo ciudadanía.

El predio fue inaugurado el 26 de noviembre de 1951. En el acto estuvieron presentes, el presidente Juan D. Perón, el gobernador saliente Domingo Mercante y el gobernador electo Carlos Aloé ${ }^{107}$. En el palco también estuvo el presidente del Gobierno Infantil de la República, Eduardo Bertolo, alumno de sexto grado de la Escuela N 19 José de San Martín de La Plata ${ }^{108}$, quien "junto al Presidente de la Nación y al Gobernador de la Provincia hizo uso de la palabra, poniendo de manifiesto el sentido pedagógico y de formación ciudadana de la República" (Belinche, Panella: 97).

Al igual que lo que ocurrió con otros espacios creados por el peronismo, luego de 1955, en los que se buscaba la eliminación de todo lo que remotamente sonara a peronismo, la República de los niños sufrió una modificación en su identidad

en un momento en el que no se podía nombrar a Perón ni a Evita sin tener consecuencias violentas, la República pasó a ser otro proyecto con otro nombre: el 'País de los Niños'. En los '60, aprovechando su arquitectura, que resulta casi un muestrario de lenguajes arquitectónicos del mundo, comenzó a ser explotado con fines turísticos. Pero las visitas no encontraban una coherencia discursiva acerca del proyecto institucional que contenía el lugar. Pocos podían contextualizar la creación de la República, vincularla con los ideales formativos de su época, entenderla como símbolo de la infancia, disfrutarla en su plenitud ideológica. Al concluir la década, finalmente, se entregó en concesión a manos privadas (Badenes, Maniego, 2012: 3334).

En los '70 se profundiza la distancia con el proyecto original, al concretarse una privatización del espacio que pasó a manos de Zanón S.A., empresa que en ese momento era dueña del Italpark en Buenos Aires. Con el cambio de gestión se enfatiza el uso del espacio como parque de diversiones, pero además en ese momento se la despoja de los vínculos con las instituciones de la democracia: "no podía existir un parlamento cuando el país entero estaba en estado de sitio. Recién en los 80 se retomarían las actividades vinculadas a la formación ciudadana" (Badenes, Maniego, 2012: 34-35).

107 La esperada presencia de María Eva Duarte de Perón en el acto de inauguración no fue posible ya que se encontraba agravada su enfermedad.

108 Para la elección de las autoridades de ese primer gobierno infantil solo participaron niños de esa escuela del barrio "La Loma" de La Plata, quienes fueron designados de manera provisional por sus calificaciones. Ellos tendrían la tarea de convocar a elecciones democráticas para cubrir cada uno de los cargos (Clarke, 2012). Aunque eso no ocurrió por circunstancias políticas. Desde la vuelta de la democracia, la República de los Niños cuenta con un gobierno infantil, que es elegido todos los años por niños de diversas escuelas de la región. 
Asimismo, en 1979 el predio y su manejo administrativo fueron cedidos por la provincia a la gestión municipal ${ }^{109}$.

Actualmente "La Repu" bajo la administración Municipal del intendente Julio Garro (perteneciente a la coalición Cambiemos) le ha otorgado una nueva modificación al predio. Si bien sigue siendo un espacio de acceso gratuito para niños menores de 8 años y con un valor de entrada relativamente accesible para mayores, es en su interior una muestra más de la ya mencionada tendencia a la semiprivatización del espacio público. Los distintos edificios que representan los distintos organismos de gobierno se encuentran semideshabitados y con varias habitaciones a las que no se puede acceder y solo puede mirarse por la ventana. Pero además los edificios de la avenida principal se encuentran concesionados a diversas franquicias de cadenas nacionales de comidas rápidas, golosinas y helados, las que resultan de acotado acceso para quienes no cuentan con poder adquisitivo. Así como se habilitó una zona en la parte posterior del parque a modo de "circuito gastronómico" que funciona también durante horario nocturno, en la que los valores son elevados. Tanto el parque de diversiones, como el paseo en barco por el lago del predio también requieren de pagar un bono extra. Lo mismo ocurre con el sector del Hangar donde se instaló un avión de Aerolíneas Argentinas, al cual para acceder es necesario pagar una entrada extra que es mucho más costosa que la entrada al parque, y en la que los niños no están exentos de pago. En todos estos espacios se repite este esquema, el parque es público, pero para acceder a la mayoría de las actividades es necesario sumar pagos extra, propiciando esta interpelación a consumir como parte de la experiencia. Por lo que el acceder de manera integral a "la Repu" está habilitado para pocos, mientras que resulta privativa para la gran mayoría de las familias de la región que no pueden cubrir todos esos gastos en una visita.

En el mismo predio también algunos edificios son usados actualmente como espacio comunitario dependendiente de la Municipalidad, en el que se pueden realizar trámites, a la vez que que se desarrollan algunas actividades, entre as que se cuentan talleres de la Dirección de Cultura para los vecinos de la zona (para los que si bien se trata de costos bajos, también hay que pagar).

Una interesante experiencia que podríamos considerar dentro de la perspectiva museológica que estamos investigando, es la desarrollada desde hace unos 8 años en el marco del "Programa Mundo Nuevo de popularización y enseñanza de las ciencias" ${ }^{110}$, de la UNLP en convenio con la Municipalidad de La Plata y la Dirección General de Cultura y Educación de la Provincia, y apoyo de la Fundación Florencio Pérez. La instalación se desarrolló durante un buen tiempo en el sector de hangares (que en ese momento estaba desocupado) con la propuesta denominada "Hangares de la

109 Es interesante hacer notar que es en 1979 también cuando la provincia transfiere al ámbito municipal la gestión del Museo Histórico Regional Alte. Brown de Bernal. Este dato permite dar cuenta de que probablemente la municipalización de instituciones públicas provinciales tuvo que ver no con decisiones aisladas, sino con un movimiento de descentralización y desafección de recursos, de achicamiento del Estado.

110 http://www.mundonuevo.unlp.edu.ar/ 
ciencia". Alli se desarrollaron muestras, jornadas educativas y recreativas, espectáculos realizados por un grupo integrado por profesionales de diversas disciplinas, que también se desplaza por algunos espacios del predio, así como realizan muestras itinerantes y talleres en colegios, instituciones y otros espacios de la región. Desde el cambio de gestión municipal y con la instalación del avión de Aerolíneas como atracción en los hangares, el equipo de Mundo Nuevo trasladó su espacio de muestra hacia un edificio cercano al lago, denominado Espacio Educativo Cultural Mundo Nuevo, que es de acceso libre y gratuito, en el que actualmente despliegan las muestras "DESmedidos. Excesos y Mandatos en la Sociedad de Consumo" y "Feria de apariencias: estética, salud y publicidades" ambas con una variedad de dispositivos que invitan a la discusión y reflexión en torno a la construcción de estereotipos, las construcciones de belleza, las presiones del mercado, los consumos, las publicidades, el lugar de las infancias, entre otras cosas.

\section{Feria de América (1954)}

Existe otro antecedente a destacar que a pesar de haber sido un evento de importancia en su momento, no aparece como parte de la memoria de los espacios expositivos abiertos en nuestro país. Se trata de la "Feria de América" realizada entre enero y abril de 1954 en el Parque General San Martín ${ }^{111}$ de la ciudad capital de Mendoza, durante la segunda presidencia de Juan D. Perón.

Ubicada en un predio de 30 hectáreas dentro del paseo público, se presentaba como "la primer feria del continente americano dedicada a la ciencia, el arte y la tecnología". Contaba con 93 pabellones que contenían exposiciones de doce países extranjeros, industrias nacionales y regionales, organismos del estado, diez ministerios nacionales, representaciones de provincias y territorios $\operatorname{argentinos}^{112}$, construcciones para servicios de uso público y un espacio privilegiado para la Torre Alegórica ${ }^{113}$, ubicada en el ingreso del parque. Contando con un total de mil cien expositores (Quiroga, 2012; Jorajuria, 2012).

El proyecto se ideó en 1952 y al año siguiente comenzaron los preparativos para inaugurar el evento que se lanzó el 14 de enero de 1954. "Aunque planeaban cerrar en marzo con la celebración popular de la Fiesta de la Vendimia, se extendió hasta el 14 de abril de 1954 con la conmemoración del Día de la Confraternidad Continental" (Quiroga, 2012: 41).

111 Un paseo público al pie de la Cordillera muy popular en la ciudad que había sido diseñado en 1896 por el paisajista francés Carlos Thays, habitualmente usado para la realización de festivales, festejos y eventos culturales de diversa indole.

112 Los territorios Nacionales fueron denominados desde 1951 provincias Eva Perón y Juan Domingo Perón, correspondían a las provincias de La Pampa y Chaco, respectivamente.

113 Obra arquitectónica escultórica inscripta en el arte concreto, diseñada por César Jannello y Gerardo Clusellas. Estaba conformada por una estructura central vertical de 50 metros de altura construida con tubos metálicos, sólida, pero al mismo tiempo ligera y transparente, rodeada por cinco cubos de iguales características dispuestos en espiral. Dentro de la misma había una serie de pirámides unidas por el vértice hechas en malla metálica. La torre además contenía una obra de música electroacústica compuesta por Mauricio Kagel que sincronizaba pasajes instrumentales con sonidos industriales, y todo se sincronizaba con la iluminación de las pirámides (Quiroga, 2012). 
Proyectada en el marco del Segundo Plan Quinquenal, iniciado en 1952, el programa de la feria instalada en Mendoza ${ }^{114}$ tenía tres objetivos primordiales:

dar visibilidad a esta provincia cuyana (...) afianzar la imagen política del peronismo tras mostrar un país en constante desarrollo industrial que gozaba de propuestas culturales de avanzada (...) se esperaba incrementar las alianzas económicas con los diferentes países latinoamericanos. La industria se constituyó en el caballito de batalla para alcanzar estos fines y el marco diagramado para albergarla implicó la creación de diversas formas en clave de modernidad (Jorajuria, 2012: 13-14).

Asimismo, según Wustavo Quiroga, el acontecimiento se planteo como "un gran espectáculo de atracción para los habitantes de la región y visitantes" (Quiroga, 2012: 8). También fue sede de un certamen internacional en el que se presentaron a concurso stands de industrias, cámaras de empresarios, cámaras de comercio y sociedades comerciales.

Para Rodrigo Alonso,

la abrumadora presencia de pabellones argentinos busca poner de manifiesto los avances que en materia tecnológica realiza el país de la mano del peronismo. De hecho, uno de los principales y más promocionados es el del IAME (Industrias Aeronáuticas y Mecánicas del Estado), que presentaba su lanzamiento más reciente, el Automóvil Justicialista (1953), junto a sus productos ya consagrados, como los tractores Pampa, las motocicletas Puma, los vehículos de carga Rastrojero y los aviones Pulqui (2012: 29).

En este sentido, resulta interesante repasar un fragmento del boletín "Sucesos Argentinos"115 en el que se enuncia claramente este ideario:

...obreros y técnicos trabajan incansablemente por establecer en el país una industria equiparable a la extranjera. $\mathrm{Y}$ éstos son los resultados promisorios de tan progresista iniciativa. De esta manera inquebrantable se van cumpliendo en todo orden de cosas los patrióticos objetivos del Segundo Plan Quinquenal (en Jorajuria, 2012: 13).

A excepción de la Exposición Nacional de Córdoba, impulsada por Sarmiento en 1871, no se conocen otros antecedentes de este tipo. Aunque según Silvia Fernández (2012), éste se trató del primer antecedente de un proyecto integral, en el que se involucraba la arquitectura, el diseño, el arte y la música, en el que se contaba además

con el Estado como comitente y con un equipo dedicado al proyecto de marcado perfil modernista. (...) para la búsqueda de un referente latinoamericano y, a pesar de no haber sido un proyecto integral, se puede analizar la Primera Bienal de Arte de Sao Paulo en Brasil en octubre de 1951, la mayor muestra de arte realizada fuera de EEUU o Europa durante esa época (Fernández, 2012: 55).

114 Durante la gobernación de Carlos H. Evans (1952-1955), gestión afin al peronismo, en una provincia que se planteaba como llave para las alianzas estratégicas que Perón planeaba con Chile.

115 Cortometrajes informativos que se proyectaban en los cines de todo el país antes de cada película. 
Aunque a diferencia de la Feria de América, dicha Bienal estuvo ligada a la iniciativa privada con apoyo oficial. De este modo, por sus singularidades, la Feria se instaló

como uno de los principales hitos del Movimiento Moderno de arte, arquitectura, música y diseño en Argentina. Este fenómeno se manifestó en un sistema integral que implicó el ejercicio de una audaz arquitectura para la instalación de pabellones y stands; así como también, un original diseño de mobiliario, una identidad visual propia (Quiroga, 2012: 8).

En el mismo sentido, Quiroga agrega que

estos elementos de vanguardia sentaron los antecedentes fundamentales para el desarrollo del pensamiento moderno en el oeste argentino. Igualmente, establecieron las bases para la conformación de la primer Escuela de Diseño del país, creada en la Universidad Nacional de Cuyo (...) no obstante este grandioso despliegue, las circunstancias históricas, políticas y económicas de nuestro país se encargaron de ocultar este hecho de gran relevancia (Quiroga: 7-8).

Las circunstancias, a las que refiere Quiroga, tienen un punto de inicio clave el 16 de septiembre de 1955 cuando en Córdoba comienza el golpe cívico-militar que dio origen a la denominada "Revolución Libertadora", que comenzó derrocando al presidente Perón, pero que además proscribió y buscó persistentemente la erradicación del peronismo en todas las formas posibles,

se inicia un movimiento tendiente a borrar la memoria histórica de esta fuerza en todos los ámbitos de la vida política, cultural y comunitaria. No es casual, entonces, que poco tiempo después de su triunfal y resonada realización, la Feria de América haya pasado a formar parte de las producciones que no debían dejar marca para la posteridad. Tras su abrupto silenciamiento, los propios creadores, trabajadores y participantes del evento, y hasta el público asistente, fueron olvidando su existencia, sin conservar siquiera su impacto o su leyenda (Alonso, 2012: 38).

\section{Tecnópolis}

Un antecedente más cercano en el tiempo, y probablemente deudor del anterior, en cuanto a los espacios de muestra abiertos lo constituye Tecnópolis. Creada a partir del Decreto N. $2110^{116}$ firmado por Cristina Fernández de Kirchner el 29 de diciembre de 2010, en el que se aprobó la ejecución del proyecto "Tecnópolis del Bicentenario, Ciencia, Tecnología y Arte" como parque temático interactivo de actividades permanentes en el ámbito de la Secretaria General de la Presidencia de la Nación. Un espacio que inicialmente estaba planeado para realizarse en los parques de Recoleta y Palermo de la Ciudad Autónoma de Buenos Aires (CABA) luego de los festejos del Bicentenario. Pero el por entonces Jefe de Gobierno porteño, Mauricio Macri, negó la habilitación de dicho espacio ${ }^{117}$, por

$116 \mathrm{El}$ texto completo de la norma puede leerse en http://servicios.infoleg.gob.ar/infolegInternet/anexos/175000179999/177942/norma.htm

117 https://www.pagina12.com.ar/diario/sociedad/3-157234-2010-11-20.html 
lo que su construcción se trasladó a un predio de 50 hectáreas ubicado en Villa Martelli, Vicente López, a pocos metros de la Avenida General Paz, franja vial que constituye la frontera de la Ciudad Autónoma de Buenos Aires.

Según su sitio oficial ${ }^{118}$ se la describe como una "mega muestra permanente de ciencia, tecnología, industria y arte" que se realizaría de julio a noviembre de cada año con entrada libre y gratuita. Al llegar al predio llamaban la atención un enorme portal metálico iluminado del que colgaban una constitución argentina, una balanza para evocar a la justicia y varias urnas, así como una inmensa torre de energía iluminada, y una pirámide de 18 metros de alto, y un modelo a escala real del Tronador II (el lanzador de satélites industria nacional) y otra enorme cantidad de construcciones y stands ${ }^{119}$ de diseño novedoso pensados para "dar a conocer la tecnología de punta de nuestro país y las posibilidades de trabajo del sector productivo público, privado y de la sociedad civil". Dada la extensión del recorrido, en el predio se instaló un kilómetro y medio de vías, por las que circulaba un tren que unía los extremos de la feria, pasando por 4 estaciones intermedias.

La primer edición fue inaugurada el 14 de julio de 2011, bajo el lema "Decir presente mirando al futuro", contó con la colocación de 100 stands de diversos organismos del estado y de industrias nacionales repartidos en 5 zonas, denominadas "Continentes" que representaban elementos esenciales: agua, tierra, aire, fuego e imaginación. Según Fabiana Solano (2016) Tecnópolis

fue pensado como un dispositivo central que utilizaba a las políticas culturales como encargadas de la reconstrucción de la esfera pública y la trama social a través de la transmisión de ciertos valores y narrativas (...) se partió de la idea de que lo cultural deconstruye las lógicas de poder, multiplica imaginarios sociales, genera nuevos recursos y modifica las prácticas cotidianas de las personas.

En la edición 2012 "Energía para transformar", en el marco de la reciente recuperación de YPF por parte del Estado. Inaugurada también el 14 de julio, contaba esta vez con 10 espacios denominados "parques temáticos", complementando con la presencia de 125 empresas privadas en los diversos espacios y 33 atracciones ${ }^{120}$. Según la descripción del sitio oficial:

Es una muestra de lo que fuimos y somos capaces los argentinos cuando avanzamos por el camino del conocimiento, la creatividad y la innovación. Es también un evento de masas del que se ha adueñado el pueblo argentino como un espacio de encuentro y celebración. Una oportunidad de participar, aprender y disfrutar ${ }^{121}$.

En la edición 2013 "La aventura del conocimiento", iniciada el 12 de julio, se contaba con 164 empresas privadas y 100 espacios para visitar, se dejaron de lado los sectores temáticos y se

118 http://www.tecnopolis.mincyt.gob.ar/ consultado en noviembre de 2015.

119 Una detallada descripción de los espacios de esa edición puede encontrarse en la nota "Cinco semanas para el asombro" de Leonardo Rossi publicada en el diario Página 12 publicada el 14 de julio de 2011. Disponible en https://www.pagina12.com.ar/diario/elpais/1-172249-2011-07-14.html

120 En esta dirección se puede acceder a un mapa interactivo de esa edición http://web.archive.org/web/20141124224534/http://tecnopolis.ar/2012/mapa interactivo 121 De su sitio oficial 2012 http://web.archive.org/web/20141003151114/http://tecnopolis.ar/2012/acerca de 
colocaron 10 atracciones principales, además de contar con la participación de Brasil como país invitado. Fue el año de la consolidación de las actividades permanentes y en el que además se realizaron una serie de festivales culturales. Se incorporó un gran acuario y se extendió el predio ferial en el que se desarrolló la muestra "Ciencia para todos".

La edición 2014 "Un mundo por descubrir" abierta el 16 de julio, se trabajó en la realización de actividades para atraer a los visitantes que aún no se habían acercado a la muestra. En este caso se organizó el espacio en ocho recorridos por todo el parque, entre ellos se destacaba el Acuario Argentino y el stand de Aerolíneas Argentinas "La aventura de volar". En la dimensión cultural y artística el objetivo era representar la mayor cantidad de culturas y grupos sociales a través de una programación acorde a los intereses particulares, y la articulación entre los públicos que aportara una mirada diferente. Se desarrollaron el "Festival Néctar" de cultura Hip Hop; "Fluir", el primer festival de arte urbano y playa; "Toque", festival internacional de Percusión; y el "Encuentro por el cuidado del planeta (ECO)", para promover el cuidado del planeta. Se realizó por primera vez "El Encuentro Federal de la Palabra", que conjugó en un mismo espacio a diferentes formas de narrativa como la literatura, el cine, el teatro, el periodismo, las culturas digitales, la música, el humor, la historieta y otras expresiones de la palabra en todas sus manifestaciones.

La edición 2015 "Futuro para siempre" contaba con la presencia destacada en el portal de entrada de una réplica del ARSAT I, y allí mismo se encontraba un importante stand sobre el primer satélite geoestacionario construido íntegramente en el país, que se encontraba en órbita desde el año anterior. Contaba entre sus atracciones principales con una pista de patinaje sobre hielo. La exhibición fue cerrada el 29 de noviembre de ese año con un récord de convocatoria de 5.200.000 visitantes. De ese momento también hay cifras que colectan la suma de visitas de cada una de las ediciones desde 2011 hasta 2015, que hablan de más de 22 millones de personas que recorrieron la muestra, de las cuales 2.650.000 fueron alumnos de escuelas y visitantes de organizaciones sociales de todo el país ${ }^{122}$.

A partir de la asunción de la administración macrista, el predio cambió de órbita de gestión, pasando al Sistema Federal de Medios y Contenidos Públicos a cargo de Hernán Lombardi. Continuó su funcionamiento en la edición 2016, bajo el lema "Punto de encuentro", aunque cambió marcadamente el sentido político y pedagógico, dando mayor lugar a las iniciativas privadas y a contenidos de la industria cultural masiva a partir de una convocatoria pública que abrió mayor participación a iniciativas de particulares, que incluyeron sobre todo la posibilidad de usar el predio para realización de festivales y espectáculos de empresas de entretenimientos privadas ${ }^{123}$. Durante

122 Según nota en el sitio oficial http://www.tecnopolis.mincyt.gob.ar/que-esta-pasando/hay-futuro-para-siempre/ consultada en diciembre de 2015.

123 De este período es también recordado un episodio en una jornada en la que por dos horas no permitieron entrar al público general a la muestra para que los hijos del Ministro de Educación, Esteban Bullrich, y los hijos de los integrantes de la plana mayor de su cartera pudieran hacer uso exclusivo del predio. Detalles de este hecho pueden leerse en las siguientes notas periodísticas https://www.pagina12.com.ar/diario/elpais/1-311027-2016-10-05.html o en 
ese año también se produce una importante reducción en el personal, despidiendo a más de 100 trabajadores de la feria ${ }^{124}$ y se desmantelan algunas instalaciones y construcciones, entre ellas el Parque Temático dedicado a Zamba ${ }^{125}$-el característico personaje animado de la señal PAKA PAKAen el que se recorrían distintos momentos de la historia argentina, el que fue reemplazado por el "Parque de los laberintos" en homenaje a Jorge Luis Borges. También se desmanteló la atracción de Aerolíneas Argentinas.

Según los registros oficiales, en el año 2016 bajó el número de visitas a Tecnópolis, las que rondaron los 2 millones de visitantes, lo mismo para la temporada $2018^{126}$ según se publica en su sitio oficial donde hablan de 2.028,777 visitantes, en comparación con los 4,5 millones en 2011, 3,3 millones en 2012, 4,2 millones en 2013, 4,7 millones en 2014 y los 5,2 millones de 2015.

\section{La ampliación del acceso al museo como horizonte político}

Tanto en nuestro país, al igual que lo que ha ocurrido en otros lugares del mundo, estas exposiciones populares que comenzaron a fines de Siglo XIX y se han desarrollado durante todo el Siglo XX atravesando incluso el Siglo XXI, convivieron con los museos ya existentes y les produjeron algunas modificaciones indirectamente. A diferencia de lo que pasaba inicialmente con los museos en los que era necesaria una autorización o invitación para ingresar, estas exposiciones temporarias desde sus orígenes pudieron ser visitadas por un público amplio y además estaban destinadas a la población en general, por lo que se volvieron de acceso popular. Según Silvia Tabakman fue tan grande la cantidad de personas que visitaron estas ferias, que produjo un impacto inesperado: a partir de la enorme cantidad de personas interesadas en visitar estas exposiciones se produjo una ampliación en el acceso a los museos, "la presencia de visitantes no especialistas fruto de este efecto democratizador generó un público al que había que instruir" (2011: 46).

Esta observación viene bien para desnaturalizar la pregunta sobre quiénes están habilitados para ingresar a los museos, y quiénes se sienten habilitados social o culturalmente para habitarlos. Así como la pregunta sobre quiénes están educados para entrar a un museo y quiénes se sienten educados para entrar a un museo. Permite discutir estos sentidos hegemónicos profundamente instalados y naturalizados. Y a la vez empezar a preguntar por la accesibilidad de los museos.

Éste es un aspecto que desde las experiencias de los museos investigados se intenta cuestionar de manera permanente. Las que se busca desnaturalizar mediante acciones concretas que abren el museo invitando a aquellos y aquellas quienes muchas veces no se sienten habilitados, o

http://www.tiempoar.com.ar/articulo/view/60905/cerraron-tecnopolis-para-que-fueran-los-hijos-de-funcionarios 124 http://www.bigbangnews.com/politica/Tecnopolis-despiden-a-100-empleados-y-destruyen-a-Zamba--201604290011.html

125 En una nota publicada en el diario Perfil sobre el desmantelamiento del parque de Zamba, Hernan Lombardi lo justificó diciendo que "no era seguro, Zamba estaba podrido por dentro". http://www.perfil.com/politica/lombardi-justifico-elretiro-del-muneco-k-zamba-estaba-podrido-por-dentro-0429-0085.phtml

126 https://www.argentina.gob.ar/noticias/tecnopolis-2018-recibio-mas-de-2-millones-de-visitantes 
cuyos universos culturales de algún modo los han demarcado -por la mirada hegemónica- como sujetos por fuera de ese circuito de consumo cultural. Por ello lo interesante de las interpelaciones a trabajar con visitas escolares, con las comunidades de los territorios más alejados del museo ya sea por distancias geográficas o simbólicas, y de desarrollar acciones articuladas con comunidades, con organizaciones sociales, o con diversos tipos de centros culturales, para permitir que aquellos que han sido históricamente segregados puedan habitar efectivamente el museo, y además lo puedan sentir como un espacio propio, como un lugar en el que poder intervenir o proponer desde su propia mirada.

\section{Los museos de historia y las configuraciones del tiempo histórico}

Los primeros museos en el país fueron fundados en los inicios del Siglo XIX a poco de declararse la independencia de España. El primero espacio fue inaugurado en 1823 en la ciudad puerto, que ya comenzaba a concentrar su hegemonía, y fue denominado Museo Público de Buenos Aires, e incluía un patrimonio muy diverso, mayormente dedicado a la historia natural. Este museo luego se transformaría en el Museo Argentino de Ciencias Naturales. Lo mismo ocurría en otras ciudades como Corrientes o Paraná donde a mediados de Siglo XIX se crearon museos de ciencias naturales. Recién a fines de Siglo XIX y principios de Siglo XX, con el avance de algunas discusiones en el campo específico (impulsadas por las discusiones en el campo científico) se empezaron a crear museos en lo que aparecían intereses específicos o temáticas especiales.

Aquí resulta interesante y provocadora una propuesta de Silvia Tabakman, quien dice que en la Argentina "los procesos de patrimonialización en los museos del Siglo XX muestran un ir y venir temporal: entre el futuro -de la mano del progreso- y las sucesivas vueltas al pasado" (2011:103). En el sentido de identificar cómo las distintas matrices políticas y los proyectos de país también se expresaban en las configuraciones y los discursos de los museos. E incorpora la idea de que visto desde la historia intelectual "la formación de los museos de historia puede ubicarse en torno a las preocupaciones dominantes, desde el romanticismo rioplatense decimonónico hasta la crisis del paradigma de la civilización occidental en el período de entre guerras ya en el Siglo XX" (Tabakman: 104). La autora retoma a Oscar Terán (1999) quien identifica una serie de factores históricos, entre ellos "la conflictiva etapa de constitución de un orden político que atravesó la primera mitad del Siglo XIX, junto con un clima de ideas donde el romanticismo rioplatense fue en busca de un pasado mítico, sin encontrarlo", lo que el propio Terán nombra como

la paradoja del romanticismo rioplatense por la cual el pasado hispánico y criollo y, aún más, el pasado indígena, resulta un legado a superar, y en lo posible a erradicar, porque forman parte 
de la contrafigura del proyecto social de implantar la civilización (europea) en estas tierras

(Terán: 104).

El otro punto de partida lo encuentran en la "Historia de Belgrano" escrita por Bartolomé Mitre, donde se configura la historiografía hegemónica para el relato de la conformación de la Nación Argentina. Según Devoto y Pagano esta obra es el surgimiento "de la concepción genealogista de la Nación: ella preexistía a las provincias, configurando un núcleo localizado desde la conquista española (principio de unidad) pero cuyas características sociales eran claramente diferentes respecto del resto de Sudamérica (principio de exclusividad)" (2009: 41). Así según esta teoría, el argumento de la "Historia de Belgrano" consistía en dar cuenta del "desarrollo gradual de la ida de independencia del pueblo argentino desde sus orígenes hasta la descomposición del régimen colonial y la revolución" (Tabakman, 2011:104).

Este proceso historiográfico trascendió la discusión áulica para materializarse en instituciones que empezaron a hacer efectiva esta mirada, así como con la nacionalización del Museo Histórico de la ciudad de Buenos Aires, que en ese momento (1890) fue refundado como Museo Histórico Nacional ${ }^{127}$, aparecieron otra serie de instituciones entre las que se pueden contar como insignias al Archivo General de la Nación ${ }^{128}$ y la Biblioteca Nacional ${ }^{129}$. Según Tabakman, el propósito fundacional del museo era "mantener las tradiciones de la Revolución de Mayo y de la guerra de la independencia", pero tropezó con dificultades políticas y presupuestarias que lo mantuvieron en situación precaria hasta 1914.

\section{Dejar el pasado y mirar al futuro}

En toda esta primera etapa de construcción del Estado Nacional moderno, fines de Siglo XIX y hasta 1914, los museos construidos se situaron en reforzar la "fe en el progreso", y en la misma sintonía iba también la Exposición Nacional de Córdoba de 1871 -impulsada por Sarmientomostrando la pujanza de las provincias de la naciente Nación.

Según Tabakman, los museos de ese momento evitaron los objetos del período colonial vinculadas a lo hispánico, ya que lo consideraban como símbolos del atraso frente a la modernidad. Del mismo modo que en la ciudad se desmantelaron edificios emblemáticos como la Recova de Plaza de Mayo, demolida en 1883, en vistas de rediseñar el aspecto de la ciudad quitándole su faz colonial y buscando la arquitectura moderna Europea (principalmente francesa) para preparar la ciudad para los festejos del Centenario en 1910. Paralelamente los museos se dedicaron con especial afán a "evangelizar" en nombre de la ciencia. Lo que por ese entonces significaba hablar casi exclusivamente de las ciencias naturales.

127 Más información en https://www.cultura.gob.ar/institucional/organismos/museos/museo-historico-nacional/ 128 http://www.agnargentina.gob.ar/

129 https://www.bn.gov.ar/ 
En ese mismo sentido, en 1909, en el marco de un proyecto de enseñanza nacional, Ricardo Rojas organizó la creación de lo que se denominó como "Museo Histórico de Reproducciones". La propuesta consistía en el envío a las principales escuelas del país, de lo que se llamaron "cajas enciclopédicas" o "museos escolares" con materiales para la enseñanza de la naturaleza, a partir de la visualización de muestrarios taxonómicos con insectos, hierbas, hojas de árboles, minerales y derivados industriales. La propuesta de Rojas se expresaba en un momento en que el Consejo Nacional de Educación había centralizado la distribución de bibliografía, útiles y otros materiales didácticos a todas las escuelas.

\section{En busca de un nuevo pasado}

Finalizados los festejos del Centenario de la Nación y entrando en los procesos políticos del primer tercio del Siglo $X X$, que procuraban la construcción del nacionalismo y al rastreo de los orígenes culturales de la Nación. En esa búsqueda, se genera una nueva sensibilidad al pasado que antes había sido negado, se vuelve a recuperar lo colonial y particularmente a revalorar la cultura criolla simbolizada con el gaucho.

Ésta se manifestaba con claridad en producciones artísticas e intelectuales de la época, y como momento político dominante en ámbitos culturales y sociales, en las prácticas de las élites políticas y económicas, pero también en los medios masivos, en las radios, teatros y en las fiestas populares que se fueron instalando por ese entonces. En este camino, se creó por ejemplo, el Parque Criollo y el Museo Gauchesco Ricardo Güiraldes en la localidad de San Antonio de Areco, provincia de Buenos Aires, en $1937^{130}$.

En estas cuestiones aparecen claramente marcadas las relaciones entre los macro procesos de una política nacionalista y conservadora, y un economía que posicionaba al país como "granero del mundo", o como principal exportador de carnes con el Pacto Roca-Runciman en 1933, políticas económicas que nos ubicaban en una nueva relación colonial con los países de Europa, lo que se sostenía y reforzaba en lo local a partir de esta idealización de lo criollo. Una suerte de "vuelta al campo", a la reinvención de un pasado campestre que lejos de la construcción propuesta por los románticos de 1830 (que simbolizaban al campo con el atraso y la barbarie), se proponía la instalación de mecanismos institucionales para la construcción de un auténtico ser nacional. En este período las denominadas "fuerzas vivas"131, las instituciones civiles, colaboraron con este trabajo para la instalación de museos históricos locales, como instituciones de educación patriótica.

130 Según charlas que tuvimos con trabajadores del Museo Histórico de dicha ciudad, en oportunidad de un congreso, la instalación de ese Museo en esa época, fue todo un proceso de construcción simbólica. Fue una estrategia de generación de una ciudad criolla donde no la había. Ese movimiento simbólico se manifestó en consecuencias concretas, como la eliminación de algunas actividades industriales (por ejemplo un molino harinero) que fue cerrado y demolido, porque de algún modo contradecía la característica rural y pastoril que las autoridades de ese momento, consideraban oportunas para mostrar al mundo como una ciudad criolla, de arrieros de a caballo, en sintonía con la político económica nacional que priorizaba la actividad agro-ganadera por sobre la fabril o industrial.

131 Conformadas generalmente también por miembros de las mismas familias de los sectores de poder hegemónico. 
Muchos de estos espacios nacieron a partir de iniciativas individuales, de intelectuales o "prohombres" de las comunidades, que tenían interés por la creación de un museo, y en varios casos muchos de ellos luego fueron los directores de esos espacios una vez que fueron pasados a la gestión estatal. Como ejemplos notorios aparecen los casos de Enrique Udaondo en el Museo de Lujan, o de Adolfo Carranza en el Museo Histórico Nacional.

De ese mismo clima de época surgieron una infinidad de Museos Históricos, no solo en las grandes ciudades, sino que diseminaron estas iniciativas en una infinidad de localidades más pequeñas del territorio nacional. Poniendo este dato en el contexto de producción del nuevo pasado histórico, se puede comprender que ésta no fue una aventura aislada. Y esto no implica desconfiar de las buenas intenciones de los sujetos que seguramente dedicaron mucho de su tiempo y probablemente de sus recursos para la concreción de los museos. Pero sí implica inscribir estas iniciativas en la ideología hegemónica de su tiempo, en un clima de época bien específico, que se perciben en las características que se comparten estos museos históricos que en su mayoría datan de la década del '30. Estos sujetos emprenden la manifestación a escala local, desde las "fuerzas vivas", desde la producción del tejido social que encarna la trama cultural hegemónica.

Una acción política y cultura que era expresión de un fenómeno que ocurría a escala nacional, y que incluso tenía políticas específicas impulsadas desde la presidencia de Agustín P. Justo (quien fue presidente de facto entre 1932 y 1938) y de Ricardo Levene desde la presidencia de la Junta de Historia y Numismática, quienes impulsaron políticas de Estado sobre el desarrollo de la memoria histórica nacional. Según Silvia Tabakman fue en la década de 1930 cuando el clima de ideas emergentes desde el Centenario cristalizó social y políticamente,

ello fue posible en parte por la crisis del consenso liberal, un proceso que abarca el período de entre guerras en las sociedades occidentales en el mundo, pero que adquiere formas particulares en la sociedad argentina, producto del golpe de 1930 y del impacto de la gran depresión en la economía y el Estado (2011:108).

Así además de la enorme cantidad de museos históricos locales, se creó la Comisión Nacional de Museos, Monumentos y Lugares Históricos, que impulsó durante esa época la declaración de sitios como patrimonio histórico, muchos de los cuales fueron destinados a albergar museos. Según Olga Bartolomé (2014) durante la década de 1940 numerosas viviendas son convertidas en "Casas Museos" como modo de reforzar esa identidad nacional buscada. Según afirma

En la arquitectura también se busca un instrumento de representación de la Nación. Se encuentra en las construcciones una manera de crear un imaginario de identidad apoyado en el lenguaje arquitectónico colonial, de allí la revalorización otorgada a las residencias de los próceres o lugares donde acontecieron hechos significativos "para la Patria".

Las casas museos tienen entonces esa carga simbólica de haber pertenecido a una persona considerada especial en el desarrollo de la historia. Este hecho también coloca a sus 
trabajadores frente a otro desafío, que es la comunicación de aquello que se busca transmitir al público según los intereses de cada contexto histórico y el espíritu de quien ha vivido en esa casa (Bartolomé, 2014:57).

Con esta misma impronta, aunque adaptados a las posibilidades de cada escala, se fueron creando los museos de historia regionales y provinciales, como una característica predominante en la creación de espacios de museo entre 1930 y 1940, los que a su vez fueron acompañados con producciones culturales de la época como manuales escolares, revistas de divulgación, que fueron construyendo una mirada específica sobre la historia nacional, la que de alguna manera se fue instalando como el sentido histórico hegemónico para el resto del Siglo XX.

\section{$\underline{\text { Revisionismo histórico }}$}

Si bien la corriente conocida como "revisionismo histórico" no logró hacerse de un lugar preponderante en las instituciones en su época de surgimiento, de todos modos forma parte de los antecedentes -y de las miradas históricas- que conformaron parte de las genealogías de la historia argentina, y lograron cierta notoriedad pública sobre todo a partir de los festejos del Bicentenario, en 2010, donde diversas acciones y producciones culturales le otorgaron relieve a estas perspectivas de manera clara, como forma de propiciar una lectura crítica del pasado y del modo en que había sido recuperado, por lo que resulta necesario presentarla como parte de este recorrido.

No se trata de una línea surgida en Argentina, aunque se configuró de un modo muy particular a partir de las producciones de los diversos intelectuales que la constituyeron en nuestro país, orientada a proponer una visión crítica a la historia hegemónica, identificada con la corriente iniciada entre otros por Bartolomé Mitre y Vicente López. En las miradas mas lineales, se considera de manera despectiva a los revisionistas como los defensores de los caudillos federales, tales como Juan Manuel de Rosas, Facundo Quiroga, o Chacho Peñaloza, a quienes la historia liberal había considerado como los depositarios del atraso político y cultural de nuestro país.

Según Norberto Galasso, no se trata de condenar a los historiadores liberales por 'tendenciosos' o parciales. Sí, en cambio, les reclamamos que se reconozcan como tales. El gran engaño no consiste en que Mitre o Grosso interpreten la Historia desde su concepción conservadora-liberal, sino que lo hagan pretendiendo que sus versiones no obedecen a ideología alguna y por tanto, deben enseñarse en las escuelas como la única y verdadera Historia (1995: 9).

Desde la mirada de los revisionistas, es luego de las batallas de Caseros y Pavón, que el bando vencedor propone una Historia Oficial a partir de la cuales, los vencedores lograron instalar de manera hegemónica su modelo político, económico y social el que fue institucionalizada en la organización del Estado Nacional. Uno de los primeros objetivos del revisionismo histórico tuvo que ver con poner perspectiva sobre los autores quienes escriben la historia siendo además artífices de 
ésta, por lo que se les reclama falta de objetividad, y usar la historia para justificar sus acciones políticas. Para Arturo Jauretche, el problema no es tanto de historiografía como de política:

lo que se nos ha presentado como historia es una política de la historia, en que ésta es sólo un instrumento de planes más vastos destinados precisamente a impedir que la historia, la historia verdadera, contribuya a la formación de una conciencia histórica nacional que es la base necesaria de toda política de la Nación. Así, pues, de la necesidad de un pensamiento político nacional ha surgido la necesidad del revisionismo histórico (2006: 16).

En el mismo sentido Galasso agrega que se trata de manifestaciones en la historia de las diversas corrientes ideológicas que confrontan en Argentina se manifiestan diversas corrientes historiográficas, no porque mantengan entre ellas diferencias de tipo metodológicas o de referentes a los que tributen, sino "porque detrás de cada una, batallando por la interpretación del ayer, hierven concepciones contrapuestas que son las mismas que disputan en la política del presente con proyectos distintos para el futuro" (Galasso, 1995: 9). Dando cuenta además, de que detrás de cada versión histórica y de cada ideología, se encuentran grupos sociales con intereses contradictorios:

la revisión de la historia ha puesto ya en evidencia que todos los conflictos que han precedido a Caseros no han sido más que los distintos aspectos de la lucha entre el país que quería realizarse, según su modo americano y tradicional, y la finalidad británica de acomodarlo a su esquema imperialista (Jauretche, 2006: 18).

Se considera a Adolfo Saldías como uno de los primeros autores de esta corriente, quien en 1888 publica una investigación denominada "Historia de la Confederación Argentina" en la que logra conseguir documentación y fuentes que permiten contrastar la historia de Mitre. A pesar de no ser una obra apologética, al trabajar desde criterios liberales pero con honestidad intelectual lograba destacar en Rosas su defensa de la soberanía nacional durante los bloques franceses e ingleses (1830-1850).

En 1890 aparece "Buenos Aires, sus hombres, su política", del ex gobernador bonaerense Carlos D'Amico, en la que se atacaba a Mitre. En 1898, Ernesto Quesada publicó "La época de Rosas" en cuatro tomos sobre la guerra civil de 1840. En 1906 se publica "Juan Facundo Quiroga" de David Peña, versión en libro de una serie de conferencias publicadas años antes en la Facultad de Filosofía y Letras de la Universidad de Buenos Aires, la que fue la primer reivindicación histórica del caudillo riojano, que hasta entonces era sinónimo de barbarie, atraso y crueldad. En 1912 aparece un libro que a pesar de ser liberal propone una versión diferente de la historia, "Estudio sobre las guerras civiles argentinas", de Juan Álvarez, el que logra demostrar que los motivos de las guerras no tuvieron que ver con motivos ideológicos, o con disputas personales, sino que fueron causadas por razones de dominio económico.

Todas estas obras fueron prácticamente escondidas por la prensa de la época, de entre cuyos medios se destacaba La Nación, perteneciente a la familia Mitre. En este sentido Jauretche le asigna 
un doble mérito a los historiadores revisionistas, quienes tuvieron que sumar a su tarea investigativa la capacidad

para penetrar en la oscuridad y ocultación organizadas, una gran conducta, porque debieron afrontar el sistema de la intelligentzia que así como premia con el prestigio y la difusión a los serviles de la falsificación, castiga con el anonimato o la injuria al verdadero historiador (2006: $46)^{132}$

Relatará en el mismo sentido que la generación revisionista de su época había tenido que acceder a obras como la de Saldías y otros a partir de ediciones realizadas en México, Montevideo o Madrid, porque aquí no era posible encontrarlas.

Recién en 1922 aparece un libro que logra trascendencia pública: "Juan Manuel de Rosas" de Carlos Ibarguren, el que por la pertenencia patricia de su autor tuvo que ser retomado por sus adversarios, quienes se vieron obligados a discutirlo y criticarlo, pero no pudieron negarlo.

Otro escritor que comienza a escribir con actitud crítica hacia Bartolomé Mitre y Vicente López es Dardo Corvalán, quien era funcionario de Hipólito Yrigoyen. Varios de sus trabajos fueron publicados en dos libros "Sombra histórica" (1923) y "Rosas" (1929). A diferencia de Saldías y Quesada, su trabajo era abiertamente agresivo y estaba escrito en un lenguaje que pretendía llegar a un público amplio al que buscaba convencer de su posición. Apuntando sus críticas no tanto a Mitre y López -a quienes de todos modos criticaba- sino más bien a sus difusores públicos como José Rivera Indarte y José Mármol.

En 1925 se publicó "Historia de la historiografía argentina" de Rómulo Carbia, el iniciador del revisionismo hispano católico. Más tarde publicó "Historia de la leyenda negra hispanoamericana" y "La nueva historia del descubrimiento de América".

En términos generales, como escuela historicista, el revisionismo expuso su método de investigar y explicar el pasado. Una profunda labor investigadora; la aplicación de un método crítico para reconstruir los hechos históricos; y por último, la interpretación, no desde la libertad o la humanidad, sino desde las instituciones, y las posiciones ideológicas situadas desde la Argentina como nación y como integrante de la hermandad hispanoamericana. Sin embargo, de acuerdo a la mirada de Jauretche, no puede hablarse de revisionismo en singular, sino en plural: "en la corriente revisionista no hubo nunca uniformidad ideológica, ni siquiera en sus comienzos. El único denominador común del revisionismo ha sido su rechazo al liberalismo político y económico que nutre a toda la historiografía académica" (2006: 98). De ahí que la mayoría de los trabajos revisionistas no se ocupan tanto de demostrar las inexactitudes de los liberales, si no más bien de crear enfoques polémicos entre corrientes y autores, incluyendo a los propios revisionistas.

132 Según Galasso "Esta circunstancia ratifica la estrecha dependencia entre Historia y Política porque Mitre ejerce, al mismo tiempo, el liderazgo de la clase dominante a partir de Pavón (...) y además, el predominio de sus ideas se aseguró con la fundación del matutino "La Nación", siendo Mitre, como dijera Homero Manzi, 'un prócer que se dejó un diario de guardaespaldas'. (Galasso, 1995: 11). 
Dentro de esta mirada plural, Norberto Galasso (1995) identifica varias corrientes que se manifiestan en diversos momentos históricos:

a) el "revisionismo histórico rosista": que surge en reacción al golpe de Uriburu en septiembre de 1930. Un grupo de intelectuales que se encontraban publicando de manera aislada comienzan a congregarse y a dar visibilidad a la corriente revisionista, en reacción al liberalismo, elitismo y autoritarismo de los golpistas desde un "nacionalismo oligárquico". En 1934 se formó la Junta Americana de Homenaje y Repatriación de los Restos de Rosas, que a pesar de no conseguir su cometido, permitió generar la reunión de un colectivo histórico que se encontraba disperso. Se institucionalizó en 1938 con la creación del Instituto de Investigaciones Federalistas, en Santa Fe, conmemorando el centenario de la muerte de Estanislao López. Y en 1941 se forma el Instituto de Investigaciones Históricas Juan Manuel de Rosas ${ }^{133}$, el cual publica una revista donde se cuestiona la Historia Oficial, "tanto por sus deficiencias -intencionadas muchas veces- en el plano de la heurística, como por su interpretación de los sucesos, ostensiblemente favorable a la vinculación de la Argentina como semicolonia respecto al Imperio Británico" (Galasso, 1995: 16). En este sentido este grupo tendrá en sus inicios una posición de "nacionalismo oligárquico" expresión que por reacción al posicionamiento pro-británico oficial se presentará como hispanófila.

b) el "revisionismo histórico forjista"134: esta corriente del revisionismo surge a mediados de la década del '30 de un sector ligado al radicalismo popular disidente que se encuentra agrupado en la FORJA $^{135}$, la que realiza aportes originales retomando la raíz federal del radicalismo -en el momento en que paradojalmente su conducción política se subordinaba a las ideas de la clase dominanteponiendo al descubierto la intervención de los intereses británicos en nuestro acontecer histórico. De este período sobresalen los aportes de Raúl Scalabrini Ortiz con "Política británica en el Río de La Plata" e "Historia de los Ferrocarriles. En el mismo camino, aunque muchos años después Jauretche publicará "Política nacional y revisionismo histórico" (1961) desnudando la "política de la historia" manejada por los sectores dominantes.

Estas miradas si bien se sostenían dentro del nacionalismo, ya no eran reaccionarios como el grupo de los revisionistas rosistas, sino que se trataba de un nacionalismo popular, que se inscribiría

133 Presidido por Juan Ithurbide e integrado por Manuel Gálvez, Ernesto Palacio, Julio Irazusta, Rodolfo Irazusta y Ricardo Font Ezcurra. A los que más tarde se sumarían José María Rosa y Arturo Jauretche.

134 Según Galasso esta corriente tuvo como antecedentes los trabajos de "algunos francotiradores que cuestionaron aspectos parciales de la Historia Oficial: Adolfo Saldías con su 'Historia de la Confederación Argentina' (1892), Ernesto Quesada con 'La época de Rosas' (1898), David Peña con su reivindicación de Facundo Quiroga (1906) y Juan Álvarez con su 'Estudio sobre las guerras civiles argentinas' (1919). Asimismo, contemporánea a la irrupción del irigoyenismo y su llegada al poder, se desarrolla la "nueva Escuela Histórica Argentina" en la cual sobresalen Diego Molinari y Emilio Ravignani sobre los cuales resulta evidente su influencia de la vieja raíz federal del Radicalismo" (Galasso, 1995: 17).

135 Sigla que nombra a la Fuerza de Orientación Radical de la Joven Argentina fundada en 1935 por un grupo de intelectuales del radicalismo yrigoyenista que se oponían al golpe, entre los que se encontraban Arturo Jauretche, Homero Manzi, Luis Dellepiane, Gabriel del Mazo, Oscar y Guillermo Meana, entre otros, así como contaba con la participación no orgánica de Raul Scalabrini Ortiz. El grupo fue disuelto luego del llamado a elecciones de 1945, dado que el grupo consideraba que sus objetivos se habían cumplido. Algunos de sus miembros trabajaron en la campaña de la candidatura de Perón, y participaron luego aportando como intelectuales de los gobiernos peronistas. 
de a poco en el peronismo. A la vez tenían una pretensión de llegada popular y de intervención política que trascendiera la disputa académica. Sobre Scalabrini Ortiz el propio Jauretche dirá que su revisionismo fue "un arma de combate, una herramienta de lucha para la liberación de su patria y la redención de su pueblo" (Jauretche, 2006: 118).

c) el "revisionismo rosista peronista": durante los gobiernos del peronismo, el revisionismo logró dominar el ámbito académico ${ }^{136}$ nacional y se extendió teniendo cierta prédica en la intelectualidad dirigente. De todos modos esta incorporación es a medias, lo que se demuestra por ejemplo cuando el propio gobierno peronista bautiza a los ferrocarriles nacionalizados con nombres de próceres liberales (Galasso, 1995; Jauretche, 2006). Recién con la caída del peronismo, tras el golpe de 1955 logrará alcanzar cierto reconocimiento en la sociedad

al calor de las analogías entre Perón y Rosas (ambos desterrados y denigrados, sus partidarios perseguidos y el Alte. Rojas reivindicando la línea Mayo-Caseros) el pueblo comienza a desconfiar de la Historia Oficial. Si ahora se tergiversaban los hechos, seguramente lo mismo se habría mentido antes (Galasso, 1955: 19).

Con la proscripción del peronismo impulsada por los golpistas, los intelectuales del revisionismo fueron duramente perseguidos, expulsados de las cátedras en las que dictaban clases, y sus libros fueron ocultados o incluso destruidos, así como fueron vueltos a negar en el periodismo dominante. A pesar de ello, algunos de sus autores reaccionaron produciendo con mayor fuerza durante este período: Scalabrini Ortiz, Jauretche, o Rosa. Otros autores destacados fueron Juan José Hernández Arregui, Milcíades Peña, León Pomer, Rodolfo Puiggrós, Jorge Abelardo Ramos y Manuel Ugarte.

Ahora Rosas resultaba exaltado como defensor de la soberanía ante la prepotencia anglofrancesa ${ }^{137}$. También los escritos de Arturo Jauretche juegan aquí un rol importante, desde una óptica popular y democrática. Asimismo desde la izquierda peronista se producen incursiones historiográficas, como las de John William Cooke, y más tarde por parte de Rodolfo Ortega Peña y Eduardo Luis Duhalde, en cuyos trabajos se observa la intención de asentar, cada vez más, el relato histórico en el protagonismo de las masas (Galasso, 1955). Este rosismo popular alcanza ${ }^{138}$ gran

136 Mientras que durante este período la posición liberal clásica quedo relegada, aunque se mantuvo recluida en la Academia Nacional de la Historia, que funcionaba en la que había sido la casa de Mitre.

137 De este período es la "Historia Argentina" de José María Rosa, redactada en varios tomos "intentando mostrar al Restaurador no solo como caudillo bonaerense sino como defensor de un proyecto nacional" (Galasso, 1955: 20).

138 En este sentido, es interesante destacar el rol del sello "La Siringa", dentro de la editorial de Arturo Peña Lillo, con libros de bajo costo que se distribuían en kioscos de revistas. Reconocido por participar activamente con sus empresas editoriales en la conformación de la trama político-ideológica de la Argentina del período que se inició a fines de los años 60 y que se extendió hasta 1976. Publicaciones como "El medio pelo en la sociedad argentina", de Arturo Jauretche (1966) e Historia de la Nación Latinoamericana, de Jorge Abelardo Ramos (1968), entre otras, dieron identidad a la casa editorial. Sin embargo, del análisis de la Colección LS, se desprende que Arturo Peña Lillo (APL) inició su proyecto editorial mucho antes, en el contexto inicial de la proscripción política al peronismo (de Sagastizabal, 2013: 1). "El trabajo editorial que se plasmó en "La Siringa" tuvo una actitud militante y se involucró frontalmente con la escena política de su tiempo. Puso en discusión ideas pertenecientes a distintas interpretaciones de la historia, seleccionó ejes políticos que luego fueron los centrales de los 70. Jerarquizó los sujetos protagonistas del escenario político y social: las Fuerzas Armadas, los trabajadores peronistas, los sectores populares en general, los militantes, y, en términos del discurso del propio Peña Lillo, lo que consideraba "los enemigos del pueblo, el imperialismo y sus personeros internos, los traidores" (de Sagastizabal, 2013: 3). 
predicamento entre los sectores populares y sobre todo entre el alumnado universitario en la segunda mitad de los años sesenta.

d) el "revisionismo federal-provinciano, socialista o latinoamericano": dentro de esta caracterización de corrientes del revisionismo propuesta por Galasso (1955), se consigna otra corriente historiográfica que puede considerarse como la repercusión, en el campo de las ideas históricas, de la mayor presencia alcanzada por los trabajadores en las luchas políticas. Desde el punto de vista de las figuras reivindicadas (Artigas, Peñalosa, Felipe Varela y en general, los caudillos populares del interior y del litoral) se la ha llamado "revisionismo federal-provinciano". Si se la observa según la cosmovisión ideológica empleada para interpretar el desarrollo histórico (rechazo del culto a los héroes, explicación de los acontecimientos en función del enfrentamiento entre las clases sociales, y consideración de los sectores populares como protagonistas principales del progreso histórico), cabe calificarla como "revisionismo socialista". También se la suele definir como "revisionismo latinoamericano" en tanto se niega a la óptica localista y considera "nación" a la Patria Grande de San Martín y Bolivar (identificando por ejemplo que solo desde una perspectiva latinoamericana resulta posible entender la Revolución de Mayo, coincidente con otros estallidos en diversas capitales latinoamericanas) (Galasso, 1955: 30).

Pueden considerarse precursores de esta corriente al Juan Bautista Alberdi de "Escritos Póstumos", al "Estudio sobre las guerras civiles argentinas" de Juan Álvarez y las producciones de Manuel Ugarte, entre otros. Asimismo, se pueden sumar los ensayos de Juan José Hernández Arregui "Imperialismo y cultura" y "Formación de la conciencia nacional".

En esta interpretación de la historia los sectores populares resultan protagonistas del progreso histórico de los argentinos, en permanente lucha contra los intereses económicos de los poderosos nativos aliados al capital extranjero (Galasso, 1955). Desde esta perspectiva también se recuperan las producciones de Raúl Scalabrini Ortiz, Arturo Jauretche, Manuel Ugarte, John W. Cooke, Agustín Tosco, Rodolfo Walsh y otros tantos convertidos en "malditos" por el aparato de la "colonización pedagógica" a partir de su lucha por la emancipación nacional y social.

A pesar de este reavivamiento, las posiciones de los revisionismos nunca lograron entrar en la Academia Nacional de Historia, y la suerte fue aún peor a partir del golpe civico-militar de 1976. Las producciones de esta corriente se sostuvieron en los márgenes del campo y recién a fines de Siglo XX y principios de Siglo XXI comienza a resurgir, por ejemplo con las producciones de Norberto Galasso y de Mario O'Donell. Este último sería el presidente del Instituto Nacional de Revisionismo Histórico Argentino e Iberoamericano "Manuel Dorrego" fundado en 2011.

Durante este último período el revisionismo histórico puede leerse como perspectiva presente en los discursos de muchos de los dirigentes de las gestiones del kirchnerismo. Desde las que se promovieron acciones reivindicatorias que se expresan en el establecimiento en 2006 del 24 de 
marzo como día feriado inamovible, creando el "Día de la Memoria por la verdad y la justicia"139; del feriado nacional del 20 de noviembre como "Día de la soberanía" en conmemoración de la "Vuelta de Obligado", la promoción a generales de las figuras de Juana Azurduy y Felipe Varela, la recuperación de la figura del Gaucho Rivero y el desagravio a caudillos federales como Manuel Dorrego y Andresito, durante los festejos del Bicentenario de 2010. Así como una nueva recuperación del legado de intelectuales revisionistas como Jorge Abelardo Ramos, José María Rosa, Arturo Jauretche, Manuel Ugarte, Fermín Chávez, Ortega Peña, Eduardo Luis Duhalde ${ }^{140}$, entre otros, quienes fueron reeditados y retomados en producciones de los medios públicos y en productos gráficos distribuidos a nivel nacional por el Ministerio de Educación.

Durante todo este período en función de la recuperación de las memorias históricas desde una mirada nacional y popular, desde la reparación desde la consigna "memoria, verdad y justicia" para revisar los atropellos del terrorismo de Estado- y con las acciones impulsadas desde los festejos del Bicentenario de la Revolución de Mayo, se crearían una infinidad de museos, muchos de los cuales contienen un posicionamiento historiográfico revisionista.

\section{Memoria, Verdad, Justicia}

A partir de los crímenes de lesa humanidad cometidos por el terrorismo de Estado, que desarrolló un plan sistemático de secuestro, tortura y desaparición de personas durante la última dictadura cívico-militar ocurrida entre 1976 y 1983, los movimientos y organizaciones de derechos humanos de nuestro país -entre los que las Madres y Abuelas de Plaza de Mayo son sus principales referentes- han luchado incansablemente por generar brechas de verdad en la búsqueda de los detenidos desaparecidos, de los niños apropiados, y por generar instancias de justicia hacia los responsables del accionar represivo, no solo en los ámbitos militares que se mantuvieron impunes incluso mucho tiempo después de recuperada la democracia, sino también en los ámbitos civiles y eclesiásticos, cuyas complicidades resultan aún más impunes en la inmensa mayoría de los casos.

A partir del año 2003 el Estado Nacional, bajo la presidencia de Néstor Kirchner encara una serie de acciones que dan muestra del compromiso por terminar con la impunidad, luego de avances y retrocesos dados a partir del regreso de la democracia. Así aparecen imágenes como la ocurrida el

139 En enero de 2017 el Decreto de Necesidad y Urgencia N. 52 el presidente Mauricio Macri generaría polémica, por declarar como movible el feriado del 24 de marzo, lo que luego de múltiples manifestaciones en desacuerdo de los más diversos sectores sociales y políticos debió darse marcha atrás con la firma de otro Decreto (DNU N. ${ }^{\circ} 80$ PEN) en el que volvía atrás con la modificación de esos feriados.

Link al texto completo del Decreto N52/17 http://servicios.infoleg.gob.ar/infolegInternet/anexos/270000274999/271094/norma.htm Link al texto completo del Decreto N. ${ }^{\circ} 80 / 17$ http://servicios.infoleg.gob.ar/infolegInternet/anexos/270000274999/271382/norma.htm

140 Quien además en esos años cumpliría importantísimas tareas en la restauración de la memoria, la verdad y la justicia desde su designación como Secretario de Derechos Humanos de la Nación para el ciclo 2003-2007 acompañando la presidencia de Nestor C. Kirchner, y de Cristina Fernández de Kirchner para el período 2007-2012, mandato que fue interrumpido por su muerte, y que fuera sucedido por Martín Fresneda. 
24 de marzo de 2004 cuando el Presidente ordena descolgar los cuadros de los represores Jorge Rafael Videla y Reynaldo Bignone que se mantenían en el Colegio Militar. Ese acto cargado de potencia simbólica, fue acompañado a la vez por un discurso brindado ante una multitudinaria concurrencia en el frente de lo que había sido el centro clandestino, donde dijo

Las cosas hay que llamarlas por su nombre y acá si ustedes me permiten, ya no como compañero y hermano de tantos compañeros y hermanos que compartimos aquel tiempo, sino como Presidente de la Nación vengo a pedir perdón de parte del Estado nacional por la vergüenza de haber callado durante 20 años de democracia por tantas atrocidades ${ }^{141}$.

Ambas expresiones simbólicas fueron luego operacionalizadas por acciones legales concretas, cuando el presidente Kirchner impulsó durante ese año la declaración de nulidad de las leyes de "Obediencia Debida" y "Punto Final" que fue aprobada por mayoría en el Congreso de la Nación. Luego en 2005, la Corte Suprema de Justicia de la Nación sumaría la proclama de inconstitucionalidad de esas leyes, dando lugar a la reapertura de las causas judiciales contra los responsables del terrorismo de Estado.

Junto con estas acciones se resolvió que los edificios de la Escuela de Mecánica de la Armada (ESMA) en Ciudad Autónoma de Buenos Aires, y "La Perla" en ciudad de Córdoba -ambos paradigmáticos sitios de la represión que fueron usados como centros clandestinos de detención, tortura y exterminio-, fueran utilizados como espacios de memoria y promoción de los derechos humanos, y dejaran de estar en manos de las Fuerzas Armadas.

Esto a su vez derivó en la legislación de la Ley 26.691 de junio de 2011 de "Preservación, señalización y difusión de sitios de Memoria del Terrorismo de Estado" ${ }^{142}$, reglamentada por el Decreto 1986/14 ${ }^{143}$. Acompañado también por la Ley $27.103^{144}$ de diciembre de 2014 para la modificación de la Ley 12.665 de 1940 sobre "creación de la Comisión Nacional de Museos, Monumentos y Lugares Históricos"145.

A partir de esa decisión se señalaron desde el Estado 106 sitios a lo largo de todo el país que habían sido utilizados por el terrorismo de estado ${ }^{146}$. En tanto que 34 espacios fueron resignificados como espacios de educativos, centros culturales y museos para la formación, promoción y construcción de una cultura respetuosa de los derechos humanos ${ }^{147}$.

141 La transcripción completa del discurso se encuentra disponible en https://www.casarosada.gob.ar/informacion/archivo/ 24549-blank-79665064

142 http://www.saij.gob.ar/legislacion/ley-nacional-26691-preservacion senalizacion difusion sitios.htm?5

143 http://www.saij.gob.ar/1986-nacional-reglamentacion-ley-n-26691-preservacion-senalizacion-difusion-sitiosmemoria-terrorismo-estado-dn20140001986-2014-10-29/123456789-0abc-689-1000-4102soterced?

144 http://www.saij.gob.ar/27103-nacional-modificacion-ley-12665-crea-comision-nacional-museos-monumentoslugares-historicos-Ins0006059-2014-12-17/123456789-0abc-defg-g95-06000scanyel?

145 http://www.saij.gob.ar/12665-nacional-creacion-comision-nacional-museos-monumentos-lugares-historicosIns0002258-1940-09-30/123456789-0abc-defg-g85-22000scanyel?

146 Se calcula que son más 600 los lugares que fueron utilizados para el secuestro, la tortura, el asesinato y la desaparición de personas.

147 https://www.argentina.gob.ar/sitiosdememoria/mapacentrosclandestinos 
En 2008, bajo la presidencia de Cristina Fernández de Kirchner, se sancionaron cinco leyes de reforma del Código Procesal Penal de la Nación con el fin de acelerar los juicios contra los represores que estaban empezando a morir de viejos sin haber sido enjuiciados o condenados por sus hechos. Otra modificación de importancia ocurrió en 2009 cuando se modificó el artículo 218 bis del Código Procesal Penal que permite la obtención de muestras de ADN tanto del imputado como de otra persona por medios alternativos. En 2013, se sumaron recompensas para quienes pudiesen aportar datos relevantes a efectos de localizar a jóvenes apropiados durante la última dictadura militar.

A partir de todas estas acciones se han realizado procedimientos judiciales que respetan todas las garantías constitucionales de los acusados, en los que hasta el momento se ha condenado 921 genocidas, se han logrado 153 sentencias y se cuenta con alrededor de 900 procesados. A la vez que se han restituido la identidad a $128^{148}$ personas que habían sido niños y niñas nacidos en cautiverio y/o apropiados durante la dictadura ${ }^{149}$.

En el marco provincial, durante todo este período es destacable la tarea que realiza la Comisión Provincial por la Memoria (CPM) en diversas líneas. Por una lado, la investigación que realizan sobre el archivo de la DIPBA (Dirección de Inteligencia de la Policía de la Provincia de Buenos Aires) donde existen fichas de espionaje político-ideológico realizadas por la fuerza policial entre los años 1956 y 1998, y la apertura para el acceso pública de estos documentos desde $2003^{150}$. Asimismo diversas tareas pedagógicas, como cursos de formación para docentes de los diversos niveles de la provincia, y la más resonante de sus iniciativas, el Programa "Jóvenes y Memoria" 151 , que convoca a estudiantes secundarios a la realización de proyectos de recuperación de memorias locales sobre la historia reciente y que finaliza con un encuentro provincial en el predio vacacional de la localidad de Chapadmalal, donde los jóvenes de los proyectos seleccionados, presentan sus trabajos y realizan actividades educativas y recreativas durante una semana.

\section{$\underline{\text { Los festejos del Bicentenario (2010) }}$}

En el contexto regional de gobiernos de orientación nacional y popular que se acercaban a sus bicentenarios, el Estado de nuestro país, al igual que otros ${ }^{152}$, se dedicó a realizar una serie de

148 En este link figuran los nombres de cada uno y una. Haciendo click en el nombre se accede a una breve historia del caso de desaparición, la identidad de su padre y madre, así como algunos detalles de la investigación que permitió construir datos para llegar a la identificación https://www.abuelas.org.ar/caso/buscar?tipo=3

149 Para estas tareas también ha sido fundamental el aporte del Equipo Argentino de Antropología Forense que se ha constituido con su trayectoria sostenida desde 1984 en la construcción de una metodología cientifica para la identificación de personas que actualmente es reconocida a nivel mundial a través de los pedidos de colaboración realizados por organizaciones de derechos humanos a nivel global. Sobre el equipo puede encontrarse más información en https:/leaaf.typepad.com/eaaf sp/

150 http://www.comisionporlamemoria.org/archivo/

151 http://jovenesymemoria.comisionporlamemoria.net/

152 Los bicentenarios del resto de los países de la región fueron: el 25 de mayo de 2009 por la "Revolución de Chuquisaca" en Bolivia, el 10 de agosto de 2009 en Ecuador, 20 de julio de 2010 en Colombia, el 16 de septiembre de 2010 en México, el 18 de septiembre de 2010 en Chile, el 28 de febrero de 2011 recordando "el grito de Asencio" en Uruguay, el 15 de mayo de 2011 para Paraguay, el 5 de noviembre de 2011 para El Salvador. En el mismo sentido, diez países latinoamericanos (Argentina, Bolivia, Chile, Colombia, Ecuador, El Salvador, Paraguay, México, Venezuela y España como 
acciones que tendieran a propiciar una recuperación histórica singular, en vistas de cumplirse los 200 años de la revolución patriótica que iniciara el camino hacia la independencia de España. Momento ideal para hacer una revisión del pasado, un posicionamiento del presente y una apuesta política hacia el futuro.

En esa dirección en 2005 el presidente Néstor Kirchner firmó el decreto $1016^{153}$ que creaba en el ámbito de la Jefatura de Gabinete de Ministros el "Comité Permanente del Bicentenario de la Revolución de Mayo 1910-2010". A partir del cual se realizarían una serie de ciclos anuales de estudio y promoción de publicaciones relativas a problemáticas históricas bajo el título "Debates de Mayo". Luego con la firma del decreto $278^{154}$ de 2008 se declaró que 2010 sería "Año del Bicentenario de la Revolución de Mayo", creándose a tal fin una Secretaria Ejecutiva de Conmemoración del Bicentenario en el ámbito de la Secretaría General de la Presidencia de la Nación.

Durante ese período se fueron preparando los festejos que se materializaron entre el 21 y el 25 de mayo de 2010 con la construcción del denominado "Paseo del Bicentenario" en la Ciudad Autónoma de Buenos Aires, pero que además antes y después se acompañaron con una diversidad de acciones y políticas públicas de largo plazo que implicaron la instalación de una serie de dispositivos institucionales a nivel nacional. La creación de espacios y eventos que se dedicaron a propuestas con un fuerte énfasis en la recuperación crítica de la historia (y de la historia reciente) desde una matriz popular.

El Paseo del Bicentenario, constituyó una gran feria emplazada a lo ancho de la Avenida 9 de Julio, entre las avenidas Belgrano y Corrientes. Con tres enormes pórticos intervenidos por artistas nacionales. Seis postas donde había muestras sobre Ciencia y Tecnología, Juventud y Educación, Medio Ambiente, Cultura, Derechos Humanos y Producción. Ferias de las provincias, con stands sobre su historia, producciones económicas y artísticas, atractivos naturales, un puesto destinado a la "Provincia 25" en la que se exponían actividades y productos de argentinos residentes en el exterior. Un paseo gastronómico con 72 puestos de comida repartidos entre los de las provincias, otros de organizaciones sociales y de distintas comunidades migrantes. Muestras de países invitados, ubicados en 4 edificaciones con stands de Bolivia, Chile, México, Francia e Italia.

A estos paseos se le suma una importante agenda ${ }^{155}$ de espectáculos culturales con artistas populares que resultaron multitudinarios ${ }^{156}$. Entre estos eventos, un atractivo central fue el desfile en el que participaron más de 2000 artistas de colectivos culturales, que narraban en 19 escenas durante el recorrido diversos acontecimientos de los 200 años de historia nacional. También se

\footnotetext{
nación invitada) crearon en 2009 el "Grupo Bicentenario" (Guzmán, 2011: 16).

153 http://servicios.infoleg.gob.ar/infolegInternet/anexos/105000-109999/109126/norma.htm con esta norma también se dejaba sin efecto el decreto 1561 de 1999.

154 http://servicios.infoleg.gob.ar/infolegInternet/anexos/135000-139999/137852/norma.htm

155 http://web.archive.org/web/20120119041346/http://www.bicentenario.argentina.ar/es/agenda/grandes-eventos/ paseo-del-bicentenario-16.php

156 Según datos publicados en las coberturas mediáticas, al evento asistieron alrededor de 3 millones de personas.
} 
realizó el "Desfile de la Integración" en el que participaron una infinidad de colectividades residentes en el país.

En el marco del cierre de las conmemoraciones, se realizaron dos anuncios. Uno tenía que ver con que se estaba preparando una exposición permanente de ciencias tecnología y arte denominada "Tecnópolis" prevista para noviembre de ese año y que luego fue lanzada en julio de $2011^{157}$. Y por otro lado la creación del Centro Cultural del Bicentenario en el antiguo edificio del Correo Central de Buenos Aires ${ }^{158}$.

Así como en su momento ocurrió con los fastos del Centenario, en 1910, estos festejos constituyeron una fuerte marca en la memoria de la población, y de algún modo comenzaron a plantear una nueva mirada sobre los procesos políticos a nivel nacional y regional. Tal como propone Guzmán Carriquiry Lecour, conmemorar el bicentenario exige,

aproximarse con seriedad a la verdad de los acontecimientos históricos que desembocan en la independencia de los países iberoamericanos más allá de las mitologías o lecturas ideológicas, superando las limitaciones y distorsiones de la historiografía liberal que fue por muchas décadas la referencia oficial, académica y escolástica dominante y que en buena medida conserva aún sus persistencia y vigencia (2011: 84).

En función de un movimiento que busca la revisión y reconstrucción de sentidos políticos de lo que significa construir la Patria, que pone énfasis en recuperar la soberanía desde una mirada decolonial crítica, "esta recapitulación histórica también requiere superar la memoria romántica y presuntamente "patriótica" que reviste los procesos de independencia con un halo elegíaco y ejemplar, sin tener presente todos sus grandes fracasos y costos" (Carriquiry, 2011: 84). Se propone así una perspectiva inclusiva que integra a los sectores populares como ciudadanos y a los diversos grupos migrantes que habitan el territorio nacional como compatriotas.

Desde un horizonte que busca mayor justicia social, la recuperación del rol del Estado como mediador en función de evitar los abusos de los intereses hegemónicos (sobre todo de los sectores concentrados en el mercado) para apoyar a los sectores más desprotegidos. Se trata de afrontar las grandes tareas históricas pendientes que aquel legado plantea a nuestra actualidad. El que

según decía José Martí hacia finales del Siglo XIX 'Lo que Bolívar no ha hecho, ha de hacerse todavía'. Se trata de crear las condiciones de una 'segunda independencia' -más determinada por la propia tradición, por los propios recursos humanos y materiales, por las propias políticas, por los propios intereses e ideales que por las potencias que dominan el escenario internacional-, por obra de una nueva gesta patriótica en América Latina, en el contexto de los actuales procesos de mundialización, que son de interdependencias múltiples (Carriquiry, 2011: 85).

157 Ver apartado al respecto en esta Tesis.

158 Este luego sería rebautizado como Centro Cultural Kirchner (CCK) e inaugurado el 21 de mayo de 2015. 
Para lo cual es necesario reforzar de todos los modos posibles la integración política, económica y cultural con el resto de los países de América Latina.

\section{Los festejos del bicentenario de la Independencia (2016)}

En un contexto político muy diferente al de 2010, tanto a nivel nacional como regional, la realización de los festejos por los 200 años de la Declaración de la Independencia realizada en el Congreso de Tucumán de 1816, tuvo una matriz totalmente diferente, acorde a los cambios políticos de la gestión de turno.

Los festejos centrales se realizaron en San Miguel de Tucumán y en la Ciudad Autónoma de Buenos Aires. En la capital tucumana las acciones principales fueron realizadas el 9 de julio, día del bicentenario, encabezadas por el presidente Mauricio Macri, acompañado por el gobernador tucumano Juan Luis Manzur. La jornada comenzó con el izado de la bandera argentina, acompañada por el Himno Nacional y una salva de 21 cañonazos en la plaza principal. Luego el presidente, junto a los gobernadores de las provincias firmaron en la misma sala de la Casa Histórica la denominada "Acta por el Bicentenario", para después participar de un Tedeum en la Catedral de la ciudad, y finalmente concurrir al Acto principal que ocurrió frente a la Casa de la Independencia donde el único orador fue Mauricio Macri. Del acto no participaron los ex mandatarios y mandatarias nacionales, ni presidentes ni presidentas de la región ${ }^{159}$ (quienes en algunos casos enviaron a sus vicepresidentes 0 ministros), mientras que el gobierno presentó con aclamación la presencia del ex monarca Juan Carlos I Rey Emérito de España. Dicha presencia que de por sí significó un contrasentido para muchísimos sectores políticos y organizaciones sociales que se expresaron en contra de la presencia del ex monarca en un acto de festejo de la independencia, fue refrendado como importante por el propio presidente Macri quien en su discurso emitió un llamativo pedido de disculpas al español

en esta Casa Histórica de Tucumán, porque acá es donde empezó la historia; acá un conjunto de ciudadanos se animaron a soñar.

Y hoy estamos todos movilizados con los gobernadores que estuvimos ahí dentro asumiendo compromisos de futuro y tratando de pensar y sentir lo que sentirían ellos en ese momento. Claramente, deberían de tener angustia de tomas la decisión, querido Rey, de separarse España ${ }^{160}$.

un mensaje que lejos de proclamar soberanía, evidenciado en la falta de diálogo político desde la solidaridad regional marcada por las ausencias de los mandatarios en el acto, pero también en las palabras del discurso desarrollado, buscaba por el contrario señas de acercamiento con Europa y con

159 https:/www.clarin.com/politica/bicentenario-macri-conformarse-juan-carlos 0 SkeTKupl.html 160 El texto de discurso completo figura en https:/www.casarosada.gob.ar/informacion/discursos/36724-palabras-delpresidente-mauricio-macri-en-el-acto-por-el-bicentenario-de-la-independencia-en-tucuman en el siguiente link está la transmisión en video te estos actos https://youtu.be/KeQufe5xcuA 
la nación ex colonizadora mediante la invitación a este ex monarca y del lugar central que tuvo en su discurso.

El acto además cerró con un desfile cívico-militar en el que participaron distintas unidades de las Fuerzas Armadas de la región, así como Gendarmería y otras fuerzas de seguridad provinciales. Luego del paso de todas las fuerzas de seguridad, el presidente se retiró del palco, sin presenciar el paso de las instituciones civiles.

Al día siguiente, se realizó el cierre de los festejos en la Ciudad Autónoma de Buenos Aires, el que consistió en un desfile militar por Avenida del Libertador, en el que participaron alrededor de 4000 efectivos representantes de distintas fuerzas, y que fue fuente de controversias dado que contó con la participación de oficiales militares vinculados con la última dictadura ${ }^{161}$. El desfile finalizó con un acto el Campo Argentino de Polo, en el que participó el mandatario argentino, donde 17 bandas militares realizaron una presentación conjunta.

Todas estas acciones, a diferencia de las ocurridas en los festejos del Bicentenario de 2010, dan cuenta de una ausencia del pueblo como participante, relegándoles al rol de espectadores, quedando el protagonismo solo para las figuras públicas, principalmente gobernantes, y en segundo lugar se destaca la preponderancia otorgada a las fuerzas armadas y sus ritualidades, representadas por los cañonazos, la presencia de las bandas y los cuerpos armados desfilando por el espacio público, exhibiendo sus vestimentas y sobre todo su armamento.

\section{La producción museográfica en contexto histórico}

Todo este recorrido por los entornos museográficos y por otros espacios de construcción de memoria, permiten dar cuenta de lo complejo de su configuración en diversos tiempos históricos, cada cual con su pasado, su presente y su futuro. Posiciones que se superponen en sentido conflictivo, tensionando los campos de intervención, configurando los modos de entender un museo, de contarlo como un repertorio propio dentro de los consumos culturales. Con sus modos de habitar el espacio, de pararse frente a lo exhibido. Modos de presentarlo, de leerlo, de observarlo. Todas construcciones de sentido impulsadas por sujetos, que se desarrollaron en largos procesos que han requerido de años y años, en variedad de experiencias y dinámicas que implicaron las particularidades culturales. Por ende dicha construcción no puede prescindir del desarrollo histórico situado. Así

161 Algunas referencias en medios y sitios de organizaciones https://www.telesurtv.net/news/Polemica-por-homenaje-aAldo-Rico-en-desfile-militar-argentino-20160710-0018.html

https://www.politicargentina.com/notas/201607/15211-polemica-por-la-presencia-de-aldo-rico-en-el-desfilemilitar.html

http://www.lanacion.com.ar/1917164-aldo-rico-desfilo-en-los-festejos-por-el-bicentenario

https://www.pagina12.com.ar/diario/elpais/1-304017-2016-07-12.html

https://www.politicargentina.com/notas/201607/15212-una-asociacion-de-ex-combatientes-de-malvinas-noparticipo-del-desfile-militar-porque-iban-torturadores.html

https://www.nueva-ciudad.com.ar/notas/201607/27048-ex-combatientes-de-malvinas-no-desfilamos-junto-atorturadores.html

https://www.diarioregistrado.com/bottom-dweller bullrush aides-memoire 
mismo, el modo de ser visitante de un museo hoy en día también hay que pensarlo a partir de estos sentidos históricos superpuestos, que nos interpelan -incluso con el cuerpo- como sujetos de la cultura.

Y del mismo modo que el momento fundante de los museos se configura marcado por un momento político determinado, las intervenciones también ocurren en un contexto que es posible identificar claramente, y con el que de algún modo u otro nos estamos relacionando, ya sea por adscripción o resistencia.

Cada museo, cada sitio de memoria, cada espacio con cada exposición o muestra que se emprende está tomando -de modo expreso o implícitamente- un posicionamiento político que se configura en oportunidad para convertir las narrativas en mitos intocables, o para transformar las memorias colectivas en parte de la historia, dependiendo de la voluntad de transformación o de reproducción de los sentidos hegemónicos que ese proyecto tenga. Los museos, de acuerdo a sus propias posibilidades, a sus formas de comunicación y expresión, asumen así sus propios desafíos, proponen interrogantes, construyen figuras y hasta proponen olvidos y omisiones, eligen poner el foco sobre situaciones, objetos o momentos, ya sea para buscar una mirada armónica, o por el contrario para proponer preguntas críticas, marcar situaciones traumáticas o conflictivas. Siempre hay un posicionamiento por más que no esté enunciado de manera expresa. 


\section{Capítulo 5}

\section{ALGUNAS ESPECIFICACIONES EN EL}

CAMPO DE LA MUSEOLOGÍA

\section{Recuperación de diversas perspectivas en el campo de la museología}

Así como antes propuse el carácter histórico del dispositivo museo y desde esa historización pudimos proponer una mirada sobre cómo estos modos configuraron con sus particularidades las maneras de producir y habitar los museos, también me resulta interesante presentar una cartografía de diversas perspectivas y debates que se dieron en el campo de la museología y museografía a lo largo de la historia, que de algún modo permitan especificar decisiones conceptuales tomadas a lo largo del desarrollo de este trabajo. El punto de partida para este rastreo fue a través de dos trabajos, uno realizado por Silvia Alderoqui y Constanza Pedersoli (Paidós, 2011) y otro coordinado por Silvia Tabakman (Biblos, 2011) en los que se desarrollan algunos de los puntos de estos recorridos, los que luego fuimos complementando con otras miradas y preocupaciones propias o más afines al campo comunicación/educación, así como con los aportes de las personas entrevistadas como referentes del campo museológico en el trabajo empírico. Este recorrido, es importante aclararlo, no pretende ser exhaustivo, y de hecho como punto de partida sabemos que al igual que cualquier otra construcción de conocimiento no puede ser total, y que por ende va a incluir omisiones, algunas de estas omisiones serán decididas pero seguramente muchas otras tantas serán involuntarias, por mero desconocimiento aún habiendo puesto el mayor esmero por lograr una búsqueda rigurosa y sistemática. Tampoco pretende ser ésta una construcción de orden cronológica, la intención es más bien poner en contexto la diversidad de perspectivas que coexisten -muchas veces de manera conflictiva o contradictoria- en los museos, poder reconocer los múltiples debates que están presentes en el campo. El surgimiento de un paradigma no inhabilita a los paradigmas anteriores, solo abre lugar a nuevas posibilidades, a nuevas interpretaciones, a nuevas (o viejas) herramientas para enfrentar nuestros problemas. En ese sentido, los paradigmas que se encuentran cohabitando esos espacios de maneras más o menos conflictivas son también expresión de las pugnas y 
tensiones que las corrientes epistemológicas y disciplinares que, en conjunto con las experiencias sociales e históricas, han confluido en diversos modos de producir intervenciones en los museos, y que todos los días se disputan esos espacios a partir de las prácticas de las personas que allí realizan las tareas más diversas.

Dentro de este particular rastreo me interesa poner especial énfasis en una corriente producida en nuestro continente. La que se conformó institucionalmente a partir de un encuentro realizado en Santiago de Chile en 1972, en el contexto del gobierno de Salvador Allende. Esta perspectiva interesa en especial, porque de algún modo habla un idioma de posibilidad parecido -y tiene raíces similares- a las que Jorge Huergo propone como las memorias constitutivas del campo comunicación/educación y por lo que este trabajo intenta trazar articulaciones que profundicen esas relaciones y ensanchen sus trazos transversales. $Y$ porque además se trata de un hito histórico dentro del campo de la museología que todas las personas con la que hablamos en las entrevistas reconocen como un punto importante, como un hecho significativo.

Dicho encuentro se trató de una mesa redonda de especialistas de la temática conocida como "Mesa de Santiago"162 cuya impronta latinoamericana -en el contexto de un tiempo revolucionariopropuso un giro en la museología. Aunque luego esta propuesta fue prácticamente enterrada, escondida, por los diversos procesos de dictaduras que ocurrieron en los países de la región. A pesar de ello, es una perspectiva que lentamente está siendo recuperada, practicada, actualizada y reinventada, en algunos espacios museográficos. Y además como decíamos resulta coherente con las memorias y el horizonte estratégico del campo de comunicación/educación en el que me inscribo.

La recorrida cartográfica que planteo resulta necesaria como proceso de reconocimiento, para poder producir una especificación conceptual del posicionamiento propuesto. Para dar cuenta de que se trata de una dirección elegida de entre muchas otras posibles. Y que como toda posición no es homogénea, a la que vez que tampoco se encuentra exenta de acciones y estrategias de resistencia y oposición.

En este mismo sentido, este rastreo resulta particularmente importante para disputar un sentido que parece estar instalado como un modelo único de intervenir desde la museología. Una concepción que podríamos caracterizar como un enfoque altamente instrumental, muy centrado en la preocupación por el acervo (los objetos y las colecciones), y desde ellos, en el interés en las técnicas de conservación de los objetos. Pero sin tener tanto en cuenta los sentidos de las muestras, sin discutir críticamente las perspectivas epistemológicas desde las que se producen. Sin una mirada sobre los sentidos políticos estratégicos que se están enunciando. Esa mirada que parece ser la dominante en los espacios de formación de museólogos se manifiesta en una preocupación por los 
objetos, por la necesidad de colocarlos en vitrinas, fuera del alcance del público, preocupados por la integridad física de los objetos. Lo que resulta legítimo y comprensible, desde el punto de vista de la responsabilidad que cargan los museos con respecto a la conservación del patrimonio, pero que a la vez, de tan hegemónica que resulta esta propuesta, se la naturaliza y se la presenta como la única posible, y por ende no se la establece o explicita como una perspectiva desde las que proponer la elección de los objetos, o mucho menos desde dónde posicionar discusiones. Se trata de una mirada fuertemente instrumental y que aún pervive a pesar de ser muy cercana a las propuestas museológicas de fines de Siglo XIX y principios de Siglo XX.

En ese sentido, historizar las perspectivas que configuraron la construcción de los museos puede ser un punto de partida interesante para empezar a plantear desde dónde se configuran los posicionamientos museológicos. Esta historia también de articularse con los planteos del capítulo anterior, sobre las convenciones de la mirada de los museos y exhibiciones aprehendidas culturalmente justamente a partir de consumir esas exposiciones. Incluye también una historia de otras formas de mostrar y ver, previas y contemporáneas a los desarrollos de los museos en Europa que también debe ser reconocida. La de los manuales y diarios de viajeros, los medios masivos, las de los espectáculos callejeros, el circo, ferias de rarezas (que hoy llamaríamos freaks), las ferias masivas, los almanaques, la influencia de las diversas tecnologías como la fotografía, el cine, los lenguajes audiovisuales y las transformaciones a la percepción y la mirada que impulsaron e impulsan los dispositivos multimedia digitales. Todas son cuestiones que de algún modo han educado la forma de ver el mundo y por ende también a los museos. Dentro de ese marco, según Silvia Tabakman, "por mucho tiempo se atribuyó a los museos de historia la creación de un público dócil capaz de contemplar el pasado sólo en función de la nostalgia y el patriotismo" (2011: 13), aunque paralelamente a eso reconocemos que existen desde hace un buen tiempo otras experiencias que intentan proponer apelaciones a la historia social, a la participación comunitaria y a las lecturas críticas. Estas experiencias son de algún modo novedosas para los museos, aunque no lo son tanto en cuanto a las perspectivas que sustentan, incluso dentro del campo de la museografía, dado que algunas han sido planteadas hace más de 40 o 50 años, aunque como suele ocurrir en la mayoría de los campos disciplinares, hay posturas que por su perfil emergente, o crítico, han sido sepultadas en el ocultamiento y el olvido, o han tenido que remar contra la corriente en correlación a los procesos históricos y políticos. Esto ocurre con especial fuerza en nuestro continente, plagado de una mirada colonizada, la que se ha reforzado en su lamentable historia de sucesivas interrupciones democráticas por parte de intervenciones cívico-militares, en los que se fueron impulsando sucesivos embates neoliberales, neoconservadores y/o neocoloniales, asociados a movimientos de restauración que se ocuparon de atentar, de intentar ocultar -o incluso intentaron hacer desaparecer- a los 
representantes de los movimientos emergentes y a sus expresiones, y sobre todo atentaron contra aquellos enfoques de corte popular.

\section{El museo como lugar para los cuerpos}

Visitar un museo implica llevar nuestro cuerpo dentro de un espacio profundamente institucionalizado, repleto de supuestos sociales y culturales, de reglas implícitas de comportamiento. Entrar a un museo implica -como en definitiva en cualquier otro espacio- una experiencia integral. Cuando se ingresa a un espacio, colocamos allí nuestro cuerpo y todas sus percepciones, podemos ver lo que se exhibe, percibir las diversas iluminaciones, podemos leer los textos y sus ilustraciones, escuchar los sonidos del ambiente, oír rumores o conversaciones, podemos movernos de diversos modos, percibir otros cuerpos (otras personas como nosotros), sentir la temperatura de la sala, los olores (hay museos que tienen un característico "olor a museo"), una diversidad de sensaciones que se conectan con nuestras experiencias personales, conectando inmediatamente con nuestras memorias -con nuestras sensibilidades-, con nuestra cultura de habitar espacios. Sin embargo durante mucho tiempo todas estas dimensiones parecieron estar vedadas en los museos, en los que parecía que solo se podía mirar, en tal caso "apreciar" lo que allí se expusiera, pero debía hacerse sin tocar absolutamente nada, moviéndose lentamente, en silencio, sigilosamente, sin molestar.

Y esto tiene que ver con lo que antes consignamos como los primeros antecedentes de los museos, las colecciones privadas de los nobles o aristócratas, a las que se podía acceder mediante permisos especiales. Pues en esas condiciones quienes visitaban esas muestras estaban accediendo en realidad a las propiedades privadas de esos dueños de las colecciones, y de algún modo estaban "de prestado" rigiéndose por las normas de la casa, según los modales y reglas de cortesía de un sector social (que era la aristocracia), sometidos en definitiva a construcciones culturales e históricas muy específicas, con normas de cuidado que respondían al patrón de las joyas de esa aristocracia a la que se estaba visitando.

Y si bien estas normas se extienden en el tiempo y en el espacio, resulta necesario poner en discusión este modo de "deber ser" dentro de los museos, dado que ya no se trata -en la enorme mayoría de los casos- de colecciones privadas, y sobre todo considerando que por el contrario se trata de espacios públicos y de patrimonios públicos. Sin embargo parece continuarse acríticamente con estas normas implícitas, que sostienen hábitos de comportamiento que no son los nuestros, con pautas sociales que hacen que esos espacios se experimenten como cerrados, privados, excluyentes.

\section{La educación EN los museos}

Si bien hoy en día parece una obviedad pensar a un museo como una institución educativa, en términos históricos no hace tanto que el enfoque educativo está presente como parte de sus 
fundamentos. En los museos del Siglo XIX había una voluntad de exhibir colecciones, y en los primeros museos de ciencias de algún modo existía una intencionalidad formativa a partir de la exhibición de las taxonomías que repartían al universo en reinos, razas, especies, etc. pero no necesariamente existían criterios pedagógicos en sus muestras.

Los primeros antecedentes en este sentido ocurren en museos de ciencias destinados a un público infantil, donde puede reconocerse una clara intencionalidad didáctica. Son los primeros museos en los que hay cosas para tocar, sogas para tirar, botones para apretar. En estos museos surgidos en su mayoría en Estados Unidos se engendran las primeras ideas de los museos interactivos.

Según Alderoqui el término educación no estaba incluido en la definición de museos de 1946 cuando se funda el Consejo Internacional de Museos (ICOM) ${ }^{163}$, y recién apareció con la creación del Comité para la Educación y la Acción Cultural (CECA) ${ }^{164}$, aunque para la década de 1980 se consolidó la idea de que los museos eran una "institución educativa de primer orden" (Alderoqui, 2011: 40).

Esto es especialmente fuerte en nuestra región, donde al igual que con otros procesos de apropiación cultural, muchos dispositivos fueron importados -o impuestos colonialmente según el planteo de Hugues de Varine (1979)- desde los modelos europeos sin demasiada crítica. Sumado a eso, si recuperamos el origen comunitario de muchos de estos espacios, en los que existía más voluntad que recursos técnicos o estructuras, es comprensible que la dimensión educativa, así como otras tantas, hayan quedado opacadas por la materialidad de los objetos conservados y por su valor en tanto patrimonio.

\section{Museos hacia la comunidad y el representante del público (perspectiva anglosajona)}

Uno de los primeros antecedentes acerca de la educación en museos aparece documentada en la obra titulada The New Museum de John Cotton Dana (1856-1929), quien fuera fundador y codirector del Museo de Newark (New Jersey) en 1909. Dana es una referencia en términos de educación en museos en Estados Unidos y fue uno de los impulsores de la denominada "educación progresiva", junto con el filósofo y pedagogo John Dewey (1859-1952).

Dentro de su perspectiva, consideraba que lo más importante en los museos era su público, la comunidad a la que estaba dirigida esa institución. Desde ese enfoque entendía a los museos como un servicio publico que debía tener por misión enriquecer la vida -la calidad de vida- de los visitantes

163 El ICOM sigla que representa al Consejo Internacional de Museos (en inglés: International Council Of Museums, ICOM), que fue creado en 1946. Según lo definen en su sitio, el ICOM es una red de profesionales de museos que actúan en una amplia variedad de disciplinas relacionadas con el patrimonio y los museos. Se asumen como la única organización de museos y profesionales de museos con alcance mundial dedicada a la promoción y protección del patrimonio cultural y natural, presente y futuro, material e inmaterial. Cuenta con aproximadamente 35.000 miembros en 136 países,. http://icom.museum/

164 http://network.icom.museum/ceca/L/1/ o también se puede consultar en http://icom.museum/los-comites/comitesinternacionales/comites-internacionales/comite-internacional-para-la-educacion-y-la-accion-cultural/L/1/ 
por sobre la acumulación de objetos patrimoniales para el engalanamiento del museo. Su lema era "felicidad, sabiduría y confort de los miembros de la comunidad".

En ese mismo marco proponía algo que resultaba profundamente provocador para los sentidos de la época, diciendo que los museos tenían que basarse más en sus comunidades y no tanto en las disciplinas científicas. También proponía un planteo de correspondencia y colaboración con la escuela, asumiendo que los museos no debían convertirse en "escuelas de educación", sino que ambas instituciones debían colaborar entre sí. Planteando allí una primer noción de apertura de lo educativo, en tanto no estaba relacionado solo con el público escolar, ni tampoco a cuestiones del aprendizaje del público en general. Sino más bien, una estrategia de alianza pedagógica para educar a la comunidad.

La perspectiva instalada por John Cotton Dana, tendría entre mediados y fines de Siglo XX una réplica ampliada en los museos públicos de Gran Bretaña donde se instaló la figura del "defensor del público" dentro de los equipos de gestión, quien participa en los desarrollos contribuyendo en el diseño de la programación y planificación de las exposiciones. En el año 2001, la Autoridad Inglesa de Museos, Bibliotecas y Archivos, estableció que los museos podían hacer "diferencias verdaderas" en la vida de las personas si usaban sus colecciones como inspiración, aprendizaje y diversión, y que en ese sentido los museo estaban siendo repensados como espacios físicos y virtuales en donde las personas pudieran involucrarse y aprender mediante la interacción con objetos para descubrir su propia historia. (Alderoqui, 2011: 22-23).

\section{Los museos para niños y los museos de ciencia}

A mediados de Siglo XX y luego de este primer impulso generado por la postura de Cotton Dana, en los Estados Unidos se empiezan a desarrollar una serie de museos que tienen un público destinatario muy específico, los niños. El Museo de Niños de Boston, dirigido por Michael Spock fue uno de los iniciadores de esta corriente con un claro enfoque didáctico, donde las exhibiciones estaban centradas en que los niños aprendan -sobre todo sobre ciencias naturales- mediante la experimentación.

Otro exponente destacado es el Exploratorium de San Francisco (California), fundado por Frank Oppenheimer, considerado una referencia obligada en este enfoque, y como unos de los primeros museos de ciencias en incorporar innovaciones en las que los niños pueden aprender experimentando con técnicas y dispositivos con diversos grados de interactividad. Consistían básicamente en que los dispositivos se activaban mediante acciones que debían realizar los niños: ya sea tirar de una cuerda, apretar un determinado botón, abrir una puerta, etc., lo que en términos comunicacionales no es necesariamente interactividad, dado que no hay posibilidades de diálogo, de que el otro en la relación comunicacional pueda modificar el curso del relato, sino que se trataba más 
bien de un modelo comunicacional dentro del esquema "de los efectos", en los que la acción esperada (una luz o pantalla que se enciende, una figura que se ilumina, una puerta que se abre) ocurre -como una especie de premio- solo cuando el interlocutor despliega la respuesta adecuada, de otro modo, nada ocurre.

El espacio del Exploratorium fue especialmente desarrollado por Elaine Heuman Gurian quien antes había trabajado 16 años en el Museo de Niños de Boston. Heumann Gurian se proponía como un interesante objetivo para su museo, que cada visitante se sintiera "bienvenido, revitalizado y con ganas de volver" (Alderoqui, 2011: 21).

\section{La nueva museología (perspectiva francesa y española)}

A mediados del Siglo XX se empezó a hablar de "nueva museología" o nouvelle muséologie, a partir de las postulaciones de referentes teóricos de Francia y Quebec (Canadá), una generación de museólogos progresistas entre los que se destacan George Henri Rivière, Hughues de Varine-Bohan y André Desvallées quienes se ocuparon de poner en relieve el rol social de los museos. Aunque como ocurre siempre, su incorporación en el campo no fue inmediata, por lo que si bien las primeras de estas publicaciones remiten a 1958, es recién en la década del '80 cuando este enfoque se instala con mayor fuerza en algunos museos y se lo empieza a citar como referencia.

Su propósito es dinamizar las estructuras de los museos, haciéndolos más abiertos a los aportes de la educación y a la búsqueda de participación social, modificando sus lenguajes y prácticas expositivas, así como también comienzan a discutir los modos de concebir su función patrimonial.

Oponiéndose a la museología clásica, impulsan la necesidad de pensar al museo más en términos de un territorio en vez de considerarlo como edificio. Desnaturalizaban la concepción del patrimonio, despegándola del patrimonio físico y diversificándola en natural, cultural, material, e inmaterial. Así como a la vez proponen pensar más en términos de la comunidad del museo, más que en el público el museo (Alderoqui: 50).

Georges Henri Rivière también se proponía dar un papel más activo a los visitantes. Consideraba la "acción cultural" del museo desde un punto de vista participativo, donde buscaba el "enriquecimiento de los puntos de vista del visitante" (Alderoqui: 24).

A esta perspectiva Hughues de Varine, quien era un integrante de la generación del mayo francés del '68, le aportó en 1971 el concepto de "ecomuseo", aportando en la dirección de entender al museo como territorio con una comunidad de pertenencia. En este mismo sentido de Varine proponía que "el museo moderno, universidad para el pueblo, a través de los objetos, es un museo que puede abarcar la totalidad de la comunidad a la que sirve" (1979: 20). Desde esa perspectiva, los museos serían como dice Georges Rivière "un instrumento que el poder político y la población conciben, fabrican y explotan conjuntamente" (1985: 182). Al mismo tiempo que lo compara con "un 
espejo" en el sentido de que no muestra la realidad tal cual es, sino tal como la comunidad la quiere ver. Por lo tanto esos "museos espejo" serían instituciones en donde

la población se contempla para reconocerse, donde busca la explicación del territorio en el que estaba enraizada y en el que se sucedieron todos los pueblos que la precedieron, en la continuidad o discontinuidad de las generaciones. Un espejo que la población ofrece a sus huéspedes para hacerse entender mejor, en el respeto de su trabajo, de sus formas de comportamiento y de su intimidad (1985: 182).

En esta misma dirección en "Los museos en el mundo" (1979) Hugues de Varine plantea un ejemplo a partir de un espacio que gestionaba personalmente en ese momento:

comprende una zona industrial, con 22 comunas, 22 pueblos y ciudades, 150.000 habitantes, $500 \mathrm{KM}^{2}$; todo ello constituye el museo de esa comunidad, el cual funciona a través de exposiciones montadas no en un solo edificio sino en 22 edificios distintos, entre los cuales hay marcados unos itinerarios de observación. El conocimiento de este museo es esencial para tener una visión sólida y correcta de las interioridades de la comunidad. Evidentemente, este museo no es para los turistas. Es para la propia población (de Varine, 1979:20).

Según el mismo autor "un museo es siempre la expresión y el reflejo de la clase social que lo crea" (1979:81), y por ello incita a crear otro tipo de museos, en los que cada individuo pueda encontrar lugar para su desarrollo "como ser humano y miembro de una sociedad compleja" (1979:81). Y va un paso más allá en su formulación para definir la idea de por dónde pasa lo nuevo en su definición de nueva museología: "el museo del futuro ha de ser una obra colectiva y cooperativa, en la que todo miembro de la comunidad ocupe el lugar que le corresponde" (1979:81).

\section{Museología crítica}

La denominada "museología crítica" es una corriente más reciente y menos consolidada que se nutre de los debates y aportes de diversas corrientes disciplinares entre las que se puede reconocer la antropología, la antropología social, la sociología, la historia del arte, la historia social, la historiografía, la pedagogía crítica, entre otras. Si bien no tiene referentes tan identificables como en el caso de la "nueva museología", se propone una revisión en términos teóricos y epistemológicos, y en las prácticas en museos y exposiciones.

También es necesario mencionar que muchos investigadores y museólogos en diversos espacios, nombran a la "nueva museología" y a la "museología crítica" como sinónimos, o como matices de un mismo enfoque. Lo que en algún punto resulta comprensible, dado que ambos se proponen una revisión de la museología clásica, y en algún sentido, resultan aportes complementarios al campo.

Tal vez la mayor diferencia radica en que la "nueva museología" como un enfoque se propone ser la "renovación" de la museología, mientras que los críticos desde su enfoque epistemológico 
entienden que no se trata de encontrar una novedad, dado que eso resultaría efímero, sino que lo que importa realmente es desnaturalizar los enfoques, ponerlos en perspectiva histórica, proponer una mirada crítica.

En este sentido Jesús Pedro Lorente (2003) propone una provocación: "La nueva museología ha muerto, jviva la museología crítica!" poniendo el foco en la contradicción de llamar "nueva" a una corriente que tiene más de 30 años de desarrollo.

Según algunos registros los aportes de la museología crítica comienzan a finales de la década del 70. Para Lynne Teather (en Lorente, 2006) la expresión fue utilizada por primera vez en la sección de museología de la Facultad de Bellas Artes en la Reinwart Academie de Ámsterdam, y según Alderoqui (2011), es en el Reino Unido, en Estados Unidos y en el Canadá anglófono donde más se está propagando esta perspectiva.

La corriente de la museología crítica concibe a los museos como espacios de diálogo, conflicto, tradición, contradicción, resistencia, colisiones, fusiones y transformaciones sociales. Para Carla Padró y Fernando Hernández (2001) ${ }^{165}$, la museología crítica implica una reorganización radical de la cultura del museo. Implica revisar no solo los contenidos, sino también las estructuras organizativas, las exposiciones y las culturas profesionales que intervienen para trabajar desde una perspectiva narrativa y dialógica. En este sentido las narrativas de los visitantes son tan protagonistas como los objetos. Los procesos de producción, curaduría, gestión y educación son revisados a partir de estructuras de trabajo colectivo, participativo (Alderoqui, 2011). Desde este enfoque se revisa la posibilidad de ser más democráticos, habilitando la participación "el verdadero poder del museo puede estar situado en aquellos a quienes les transfiere autoridad" (Volkert, 1996) ${ }^{166}$.

En este sentido, la museología crítica, en consonancia con las pedagogías críticas señalan la ausencia de determinados contenidos e ideas en el marco de las instituciones, en el mismo sentido en el que Apple o Giroux por ejemplo hablan del "curriculum oculto" en las escuelas. Y en el sentido de poder romper esa situación de poder desigual, se propone que las instituciones de museo -al igual que las escuelas- ofrezcan información sobre las decisiones tomadas y las perspectivas utilizadas, para que la autoridad sea compartida y habilitar a que los visitantes también puedan construir significados en relación a lo expuesto, al poner las cartas sobre la mesa, se abre el lugar a la duda y hasta se puedan proponer críticas.

Este posicionamiento implica que el momento de la visita sea considerado como un momento de diálogo e intercambio, donde se parte de los conocimientos, valores y creencias de los visitantes, para a partir de lo aportado en la exposición permitir la generación de preguntas productivas, a configurar nuevas indagaciones. Una contrastación de ideas, un intercambio reflexivo y dialógico de 
narrativas entre la institución y los visitantes. Como se puede comprender por lo expuesto, en este enfoque, los educadores ocupan un lugar destacado.

Se puede observar que en todo este recorrido se va operando un desplazamiento del rol de los educadores en las distintas perspectivas. Desde un lugar no existente, no considerado. A ser luego considerados guías, con un rol muy limitado, que implicaba que debían aprender de memoria los contenidos disciplinares del museo para luego "transmitirlos" literalmente a los visitantes ${ }^{167}$. A pasar a tener un rol más activo y hasta creativo, dentro de las visitas donde actúan como facilitadores de una conversación provocadora entre el museo y los visitantes. Y por ello también tiene un espacio considerado dentro de los equipos de diseño de los contenidos y exposiciones. Donde pueden proponer abordajes, dispositivos, así como en muchos casos en la actualidad, son los que se encargan de la evaluación -o autoevaluación- de las muestras, así como del diseño de diversos tipos de guiones según especialidades, inquietudes o enfoques disciplinares para provocar diferentes lecturas sobre lo exhibido.

La museología crítica plantea la posibilidad de considerar a la educación en los museos como una práctica social articulada, y propone caminos para que los educadores de museo encuentren vías de diálogo, aún en instituciones con prácticas educativas tradicionales.

En sus investigaciones, se insiste en la necesidad de profesionalizar la actividad de los educadores de museos y en dejar atrás la imagen del guía como "trabajador artesanal" y "vocacional" que solo puede aprender su labor en la práctica, a partir de las vivencias en las salas de museos (Alderoqui: 25-26). Según Silvia Tabakman (2011), en estos últimos veinte años los museos han cambiado sus propuestas de visita. Muchos pasaron de la mera descripción y visita expositiva a las llamadas "visitas participativas y activas", en las que los guías invitan a opinar, a interpretar, a dar respuestas.

Al respecto de esta cuestión es importante no confundir una propuesta pedagógica con la forma. Es decir, no confundir la necesidad de interpelar a los visitantes para provocar su participación, con la forma en la que el guía puede estar haciendo hablar a los visitantes o haciéndoles preguntas pero sin escuchar o hacer lugar a lo que éstos dicen. Tal como suele ocurrir en algunos espacios de educación o comunicación popular donde se confunde por ejemplo la forma de sentarse en ronda pero luego quienes conducen el espacio no escuchan a quienes forman parte del espacio. Por el contrario, en el mismo sentido, se puede lograr interpelación y participación, sin que haya un guía conduciendo, o sin que los participantes estén hablando. Ya está por demás comprobado que también existe actividad cognitiva o procesos de aprendizaje crítico, en el momento de la recepción, cuando se observa una imagen en silencio o se atiende a una explicación. Es la propuesta de interpelación y el

167 Algo que en algunos museos de la actualidad sigue siendo todavía un enfoque persistente. Y que sigue siendo un imperativo en la formación de los guías. Aunque por lo visto durante el trabajo de campo también existen hermosas excepciones a la regla, museos en los que los guías son alentados a la construcción de sus propios guiones, obviamente desde la investigación y la planificación necesaria para que sean de calidad. 
modo en que se realiza y no tanto la forma, lo que asegura que una propuesta sea crítica, horizontal, o participativa.

\section{La perspectiva latinoamericana desde la "Mesa de Santiago" (1972)}

Dentro del marco de la museología crítica hoy en día es posible hablar de una perspectiva latinoamericana. Esa corriente tiene un antecedente en un tiempo histórico preciso, que se manifestó en la "Mesa Redonda sobre la Importancia y el Desarrollo de los Museos en el Mundo Contemporáneo" llevada a cabo entre el 20 y el 31 de mayo de 1972 en Santiago de Chile. A la vez, se trata de una perspectiva que resulta pertinente a lo que Jorge Huergo señala como las memorias constitutivas del campo comunicación/educación. En este caso esta reunión se realiza fuertemente interpelada por el contexto del gobierno socialista de la Unión Popular con la presidencia de Salvador Allende, quien llegó al poder mediante elecciones democráticas en 1970 y propició políticas públicas que resultaron revolucionarias para la época, así como se trataba en términos regionales de un momento de particular efervescencia para los movimientos y las ideas insurgentes de todo el continente.

Esta mesa fue organizada en el marco de una serie de seminarios regionales organizados por el ICOM (Consejo Internacional de Museos) los cuales habían sido realizados, en Río de Janeiro (1958), Nigeria (1964) y Nueva Delhi (1966). Aunque en esta oportunidad se decidió proponer una variante en la modalidad con respecto a las reuniones anteriores en las que, invariablemente, un grupo de expertos museólogos, en su mayoría europeos y norteamericanos, hablaban de manera más o menos dogmática, en francés o inglés, a "colegas" locales, en un continente que no habla casi inglés o francés, y que en ese particular momento político e histórico no necesitaba recibir lecciones, por el contrario desde sus diversas experiencias insurgentes estaba hablándole fuerte al mundo.

Fue por lo tanto, en el ámbito de ese gobierno socialista y democráticamente electo, en un momento de tensión política para toda América Latina, que se realizó lo que para el museólogo y poeta brasileño Mario de Souza Chagas fue "uno de los encuentros más emblemáticos y fecundos de la museología en la segunda mitad del Siglo XX" (2007b: 34).

Según el informe enviado por quien fue director del encuentro, el uruguayo Héctor Fernández Guido, el tema central del encuentro lo constituyó el siguiente interrogante: "el Museo, como institución docente de difusión del conocimiento científico y la cultura ¿es capaz de responder al desafío que le presentan ciertos aspectos del desarrollo social y económico de la América Latina actual?" (en Nascimentos, Trampe, Santos, 2012a: 39). 
Según los relatores fue la primer reunión de este tipo que tuvo un "carácter interdisciplinario". Todos los tipos de museos estuvieron representados: artes, ciencias sociales y humanidades, ciencias naturales y tecnología avanzada.

La participación más amplia que la usual y la naturaleza interdisciplinaria de la reunión llevaron a la constatación, realizada por todos los presentes, de que los museos en América Latina no estaban adaptados a los problemas suscitados por el desarrollo de la región y que deberían esforzarse por cumplir su misión social, que es permitir que el hombre se identifique con su ambiente natural y humano en todos sus aspectos. El museo no se preocupa apenas con la herencia del pasado, sino también con el desarrollo (en Nascimento, Trampe, Santos, 2012b: 108).

Para el chileno Luis Alegría Licuime (2007) la clave de la mesa de Santiago es que hay que entenderla como "un ejercicio crítico" sobre los museos de Latinoamérica, en un sentido teórico y práctico. Y propone que debemos

recuperar su forma de leer la realidad, sus aspiraciones en torno al rol social de los museos, (...) aquellas que cuestiona ciertas forma que aparecen como redentoras de la institución museo en el actual escenario de globalización, pero que en definitiva sólo reproducen muchos de los vicios del modelo tradicional (Alegría, 2007: 55).

En consonancia con el tiempo político latinoamericano, y el que particularmente estaba ocurriendo en el país anfitrión, en el discurso inaugural de la reunión Juvencio Del Valle, director de Bibliotecas, Archivos y Museos de Chile se dirigía a los asistentes y les daba la bienvenida a "este país en revolución", y comenzaba tensando el origen mítico de los museos diciendo que

primitivamente, entre los griegos, este recinto fue templo de los dioses. Pero en aquella lejana época los dioses andaban entrometidos en las querellas y los negocios de los hombres. Por obra de estas interminables guerrillas, los dioses abandonaron la partida y los hombres, débiles como siempre ante el encanto de las musas, dejaron a éstas como únicas moradoras de esos recintos de sabiduría. (...) no ha llegado todavía el tiempo de echar a esas deidades de su antiquísima casa, y no habría razón para hacerlo (...). Pero nuestra preocupación de hoy es que llegue a convivir con ellas el pueblo tumultuoso. La entidad pueblo, como conglomerado total, ha estado siempre al margen de estos resortes claves para el estudio y comprensión del pasado del hombre y de su medio.(...) Solamente así el museo podrá impresionar como un organismo en vigencia, cual un cuerpo que respira, palpita, y lucha codo a codo con su creador, el hombre (citado en Nascimento, Trampe, Santos, 2012a: 23).

Y a esto le sumaba una lectura sobre el rol educativo de estos espacios, a los que consideraba una oportunidad para la educación permanente

el museo ciertamente, es una universidad infinitamente más universal y adelantada que las universidades tradicionales (...) para ingresar en ella no se requieren certificados, títulos, estudios. No es de rigor siquiera saber leer y escribir. Basta con tener ojos y mirar. Mirar 
mucho, con impertinencia si es necesario, con cuatro ojos, como el mercader que sopesa con

sus ojos avaros la calidad de una joya (en Nascimento, Trampe, Santos, 2012a: 24).

A partir de ésta y otras muchas afrentas que los museólogos recibieron en los 11 días que duró la reunión (en las que además de sentarse a discutir recorrieron territorios e instituciones chilenas), los museos que hasta ese momento proclamaban su neutralidad política y su alejamiento de los problemas sociales, fueron estremecidos y desafiados a enfrentar situaciones concretas que no se referían sólo al pasado idealizado, sino también al cotidiano y a la contemporaneidad de las sociedades en que estaban insertos.

A partir de esta reunión, trabajar en museos pasó a significar también tener interés en la vida social y política no solo de las personas, sino también "de las colecciones, de los patrimonios culturales y naturales y de los espacios y, por esa vereda, a ser un ejercicio explícito de operar con relaciones de memoria y poder por medio de la mediación de las cosas concretas" (Chagas, 2007b: 36).

\section{Cambios de eje y propuesta de diálogo}

Es interesante revisar cómo, al igual que en otras varias cuestiones ya repasadas en este trabajo, parte de toda esta perspectiva museológica propia se origina a partir de un contexto político situado en el que el "aquí y ahora" de ese momento interpela a ensayar nuevas formas y modelos. Las que en este caso además podemos considerar como un transformaciones en el modelo comunicacional de la reunión. Según relata Hughues de Varine, quien estaba en ese momento a cargo del ICOM, se optó "por cambiar las reglas del juego y pedir, sistemáticamente, a los no museólogos que hablasen a los museólogos sobre el mundo contemporáneo" (2012: 97).

También es interesante el dato de que en principio, el encuentro iba a ser moderado por Paulo Freire ${ }^{168}$. Según relata de Varine "él había prometido reflexionar sobre una nueva concepción del museo como instrumento al servicio de la liberación del hombre y del desarrollo" (de Varine: 97). Aunque como el ICOM se encuadra dentro de las organizaciones de la UNESCO, en este marco el delegado del régimen militar brasileño ${ }^{169}$-que había encarcelado y expulsado a Paulo Freire de su país en 1964- vetó su participación considerándolo "personalidad subversiva" (de Varine: 97).

Al no poder contar con el pedagogo brasileño, la organización optó por elegir cuatro comentaristas que no fueran del ámbito de la museología para que hablaran en formato de "mesa

168 Según el relato de Hughes de Varine, la relación con el pedagogo surge a partir de una una ONG internacional Ilamada "Instituto Ecuménico para el Desarrollo de los Pueblos" que se estaba creando en Francia, cuya presidencia había sido confiada a Freire. El brasileño entonces era consejero para la Educación en el Consejo Ecuménico de las Iglesias en Ginebra. A la vez que conocía muy bien Chile por su actuación allí durante el gobierno de Eduardo Frei (1964-1970).

169 Brasil en ese momento se encontraba en el marco de una dictadura militar. En el vecino país a diferencia del nuestro, en el que hubo una serie de interrupciones democráticas, tuvo una sola pero larguísima experiencia dictatorial entre el 31 de marzo de 1964 cuando fue derrocado el presidente João Goulart y que duró hasta el 15 de marzo de 1985 cuando asume de forma democrática el presidente José Sarney luego de una fuerte presión social ejercida mediante una campaña política encabezada por el movimiento Diretas Já (Directas Ya). 
redonda" sobre 4 temas: urbanismo, agricultura, tecnología, y educación ${ }^{170}$. Por primera vez en un encuentro de la UNESCO, tanto los expertos como los asistentes eran latinoamericanos. LoS "extranjeros", que representaban a la UNESCO y al ICOM, actuaron como observadores internacionales, sin derecho a voz durante los debates. Además, el único idioma de trabajo de la reunión fue el español (de Varine: 96).

Dentro del cambio comunicacional que implicó esta mesa redonda -según lo que consta en el informe del director del encuentro- a diferencia de las reuniones tradicionales, a los expertos, no se les solicitó la preparación de documentos de trabajo para la orientación de la discusión ${ }^{171}$, sino una meditación profunda, un esfuerzo de preparación personal, dentro de su especialización y en relación con la interrogante adelantada, con miras a una restructuración moderna de la vieja institución 'Museo' a los efectos de llenar una necesidad, cada vez más compleja, y mejor adaptada a los vertiginosos cambios que el adelanto en el campo científico esta imponiendo en la sociedad moderna, particularmente en la cada vez más imperiosa necesidad e una educación permanente (Nascimentos, Trampe, Santos, 2012a: 39).

En tanto que a los participantes también se les solicitó un trabajo de preparación previa "integral y responsable, un aporte personal y profesional" en vistas al horizonte de trabajo propuesto

la mesa redonda deberá determinar las soluciones que los museos han de dar a ciertos problemas planteados por la sociedad en vías de transformación y por el desarrollo. (...) Por esta razón es necesario que todos los participantes se consagren durante los tres meses próximos a preparar su participación (Nascimento, 2012: 6).

De modo que la mesa redonda se realizó a partir de 4 problemáticas generales planteadas por los expertos a los que se denominó como "animadores", y un segundo grupo de especialistas con experiencia en museos (de instituciones de Chile, Bolivia, Brasil, Colombia, Costa Rica, Ecuador, Guatemala, México, Panamá, Perú, y El Salvador ${ }^{172}$ ), considerados "participantes", a quienes se

170 En el marco de los intereses de la UNESCO y de esta reunión también pueden denotarse los temas de interés de la doctrina desarrollista de la "Alianza para el progreso". Aunque claro, los temas en sí no significan una direccionalidad cerrada, y por el contrario, pueden usarse como punto de crítica.

171 Las charlas finalmente fueron: a) Los museos y el desarrollo cultural en el medio rural y el desarrollo de la Agricultura, a cargo del Prof. Enrique Enseñat, de la Facultad de Agronomía de la Universidad de Panamá. b) Los museos y los problemas sociales y culturales del medio, por el Arq. Jorge Hardoy, Investigador Jefe, Centro de Estudios Urbanos y Regionales. Instituto Di Tella, Argentina. c) Los museos y el desarrollo científico tecnológico. Realizada por el Prof. Mario Teruggi: Jefe División de Minerología y Petrología, Museo de La Plata, Argentina. Este tema había sido asignado inicialmente al Dr. Federico Pannier, CONICIT, Caracas, Venezuela, quien no no pudo concurrir a la Mesa Redonda. d) los museos y la educación permanente. A cargo del Dr. César Picón Espinoza, Director General de educación Escolar y Laboral, Ministerio de Educación Lima Perú. Paralelamente al desarrollo de las sesiones se había previsto una serie de excursiones a instituciones y zonas de Chile, como complemento informativo de cada uno de los temas de debate. (extraído del informe del Director del encuentro en Nascimento, Trampe, Santos, 2012a: 40).

172 La lista completa de asistentes a la Mesa Redonda de Santiago estaba compuesta por: Director Sr. Héctor Fernández Guido, ingeniero, Director del Planetario Municipal Agr. Germán Barbato, Montevideo (Uruguay). Moderadores de discusiones: Profesor Enrique Enseñat, Facultad de Agronomía de la Universidad de Panamá (Panamá). Sr. Jorge Enrique Hardoy, arquitecto; jefe de investigación del Centro de Estudios Urbanos y Regionales del Instituto Di Tella, Buenos Aires (Argentina). Profesor Mario E. Teruggi, Jefe de la División de Mineralogía y Petrología del Museo de La Plata, La Plata (Argentina). Dr. César Picón Espinoza, Director General de Educación Escolar y Vocacional del Ministerio de Educación, Lima (Perú). Representantes de la Unesco y del ICOM Sra. Raymonde Frin, Editora de la Museum, Sección de Normas, Investigaciones y Museos, Departamento del Patrimonio Cultural. Sr. Jacques Hardouin, Especialista en Programas, Sección de Desarrollo del Patrimonio Cultural. Sr. Hugues de Varine-Bohan, Director del ICOM, Casa de la Unesco, París 
deseaba motivar con lo expuesto por los animadores, para que planteasen mediaciones desde los museos para informar, interesar y promover inquietudes dentro de las colectividades y que sirvieran para extender su campo de acción. De esta dinámica fue que surgió el animado diálogo que dio origen a un pronunciamiento de la mesa redonda al finalizar el encuentro.

\section{Lectura crítica de los museos y su relación con el entorno}

Tanto de lo dicho por los animadores, como por los participantes, el encuentro de la Mesa de Santiago demarcó un legado, en una lectura profundamente crítica sobre los retos que los museos, en tanto instituciones educativas, debían afrontar para aportar a la emancipación en el particular momento que vivía la región.

A partir de la recuperación del rol educativo del museo, asumiendo las tensiones e inequidades que vivía el continente, es necesario asumir las ambigüedades y peligros que los museos juegan en la educación, considerando a quiénes han estado históricamente manejados y a quiénes se han consagrado. En un contexto en que la educación escolar y universitaria estaba siendo objeto de crítica y se le reprochaba el imponer conocimientos sin permitirle a los sujetos ejercer su espíritu crítico y su creatividad. Así pues había que revisar y reprochar al museo, quienes también con frecuencia han impuesto a su público un pasado con frecuencia incomprensible.

Entendiendo a la educación para la liberación, los sujetos no deben ser objetos de enseñanza sino sujetos de la construcción de nuevos valores en función de sus deseos y preocupaciones. En ese sentido allí se decía que el museo "ocupa un lugar privilegiado en estas formas de educación ya que en el museo los objetos están en las murallas y en las vitrinas, mientras que el visitante puede ser, más fácilmente que en otros lugares, un verdadero sujeto" (Nascimento, Trampe, Santos, 2012a: 27). Así como se veía que en los museos podía haber mayor lugar para "la gran enseñanza de la vida", la que según proponía César Espinoza ${ }^{173}$ no estaba tan presente en los sistemas educativos, atribuyendo "un peso exagerado a los certificados y títulos" (Nascimento, Trampe, Santos, 2012a: 72).

Esta mirada crítica sobre los sistemas educativos no implicaría que los museos los ocuparan su lugar, o que compitieran con ellos, sino que complementaran "incentivando la creatividad y el

\footnotetext{
(Francia). Participantes Dra. Teresa Gisbert de Mesa, Directora del Museo Nacional de Arte, La Paz (Bolivia). Sra. Lygia Martins-Costa, Instituto del Patrimonio Histórico y Artístico Nacional, MEC, Río de Janeiro (Brasil). Dra. Grete Mostny Glaser, Curadora del Museo Nacional de Historia Nacional, Santiago (Chile). Dra. Alicia Dussán de Reichel, Jefe de la División de Museos y Restauración, Instituto Colombiano de Cultura, Bogotá (Colombia). Sr. Luis Diego Gómez Pignataro, Director de la División de Historia Natural del Museo Nacional de Costa Rica. Sr. Hernán Crespo Toral, arquitecto, Director del Museo del Banco Central de Ecuador, Quito (Ecuador). Sr. Luis Luján Muñoz, Director del Instituto de Antropología e Historia, Guatemala (Guatemala). Profesor Mario Vázquez, Subdirector del Museo Nacional de Antropología de México (México). Profesor Raúl González Guzmán, Jefe de Museos y Exposiciones, Directorio del Patrimonio Histórico Nacional (Panamá). Dr. Federico Kauffmann Doig, Director de Conservación del Patrimonio Cultural de la Nación, Lima (Perú). Sr. Carlos de Sola, Director General de Cultura, San Salvador (El Salvador) (extraído de un facsímil en Nascimento, Trampe, Santos, 2012a: 21)

173 "Los museos y la educación permanente".
} 
deseo de descubrir y proporcionar una visión global e integrada de los ecosistemas" (Gómez Millas en Nascimento, Trampe, Santos, 2012b: 126).

En los debates se coincidía la "tremenda potencialidad" de los museos en relación con la educación permanente. Y para ello proponían que se deben poseer grupos de profesores guías para atender grupos de estudiantes diversos y también al público en general. Así como deberían ofrecer cursos de perfeccionamiento y ofrecer la posibilidad de desarrollar actividades extraescolares. En este mismo sentido también se impulsaba que se planearan las exhibiciones en forma tal que pudiesen ser interpretadas fácilmente "por las poblaciones marginadas y los analfabetos". Para actuar de manera contraria a lo que suele suceder habitualmente, tanto en los museos como en los medios de comunicación de masas, donde la comunicación es unidireccional, no existiendo la posibilidad de intervenir en el relato. Para ellos mismos también sería de importancia contar con educadores "entre los dirigentes de los museos", quienes además pudiesen establecer métodos de evaluación de las actividades del museo.

En cuanto a la problemática urbana movilizada por Jorge Hardoy ${ }^{174}$, se tomó como preocupación el peligro de ruptura del equilibrio biológico, así como el deterioro del paisaje a partir del desarrollo desmedido que en ese momento ya tenían las ciudades. Misión que debería ser impulsada por la discusión de los problemas propios en cada comunidad, aprovechando de manera crítica el modo en que esas problemáticas eran o no recuperadas por los medios masivos (Nascimento, Trampe, Santos, 2012a: 61).

En cuanto a la problemática rural moderada por Enrique Enseñat ${ }^{175}$, se propuso una función política para llevar debidamente su función dentro del ambiente contemporáneo rural -que en ese momento estaba siendo profundamente transformado-. Los museos debían

constituirse en el elemento de cambio social que a la vez que luchen por la dignificación del hombre del campo, contribuyan al proceso de concientización social dentro de cuyo marco habrá de ocurrir el cambio de las estructuras anacrónicas, que impiden el proceso verdadero del hombre que trabaja la tierra (Nascimento, Trampe, Santos, 2012a: 49).

En general se propuso mejorar la forma de presentar y exponer, acudiendo para ello al asesoramiento de especialistas, la creación de grupos multidisciplinarios que trabajen en el desarrollo de las muestras y la vinculación del museo con otros organismos vinculados. Aprovechar el valor de los objetos como generadores de una narrativa en el contexto de las exposiciones "en la planificación y en la organización de la exhibición de objetos, el museólogo codifica los materiales y los fenómenos. Al hacerlo, transmite sus conocimientos de acuerdo con los códigos que le son familiares" (Gómez Millas en Nascimento, Trampe, Santos, 2012b: 126). Hay allí una oportunidad para hacer que los objetos instalados en las muestras produzcan preguntas a los visitantes:

174 "Los museos y los problemas sociales y culturales del medio".

175 "Los museos y el desarrollo cultural en el medio rural y el desarrollo de la Agricultura". 
hay una corriente continua en los dos sentidos, en que las preguntas y respuestas educan y estimulan tanto al museólogo como al visitante y dan nueva vida a lo que parecía estar muerto y olvidado. El museo se transforma en un centro vital. Los objetos que antes fueron cosas vivas -sagradas o profanas- asumen una vida nueva, sugiriendo nuevos puntos de vista y se convierten en objetos capaces de contribuir a la creación de un futuro (Nascimento, Trampe, Santos, 2012b: 126).

Asimismo que dada la distancia con algunas comunidades (como las suburbanas o las rurales) sería necesario desarrollar exhibiciones itinerantes. Con el fin fundamental de que la planificación y las actividades del museo estén en verdadera vinculación con los problemas de la comunidad (Nascimento, Trampe, Santos, 2012a: 50).

Según lo que planteaban, la gran meta del museo sería cumplir una función educativa que no se cumplía según lo que diagnosticaban,

el museo debe despertar la curiosidad y promover el interés del asistente. Si el museo sólo debe exponer objetos, su presentación debe hacerse en forma tal que ello lo humanice en un ambiente vivo y dinámico y fundamentalmente que no sea sólo pasado sino también presente y futuro, ligado a la ida del hombre y de la civilización que le dio origen (Nascimento, Trampe, Santos, 2012a: 75).

De este modo también se planteaba una transformación en la direccionalidad del tiempo histórico que dominaba a los museos. Allí se expresaba que

el museo tiene la oportunidad de convertirse en la institución donde es posible observar el horizonte de la cultura, de las relaciones entre el hombre y el mundo y las maneras de integrarlos. Allí, las personas pueden ser colocadas cara a cara con sus dilemas más graves y tienen la posibilidad de ver cómo se abren las perspectivas obscurecidas por la rigidez de las estructuras sociales y por la explotación descontrolada de los recursos utilizados con fines de producción y consumo" (Gómez Millas en Nascimento, Trampe, Santos, 2012b: 127).

En definitiva se soñaba con museos permeables, que favorecieran el reencuentro con las comunidades a través de una comunicación más dialogante e inclusiva; museos que se hicieran cargo de hablar de las problemáticas territoriales y de nuevos, múltiples y diversos patrimonios; museos que se reconocieran como agentes de cambio y promotores de desarrollo, que dieran un salto cualitativo para transformarse en plataformas de gestión con el objetivo de colaborar a mejorar la calidad de vida de las personas (Trampe, 2012: 8).

\section{Algunos detalles de la declaración de la Mesa de Santiago}

Si revisamos algunos de los considerandos de la declaración firmada en Santiago de Chile el 30 de mayo de 1972, nos encontramos con fundamentos que resultan interesante destacar en tanto lectura y crítica del momento: 
La tecnología a propiciado un gigantesco adelanto de la civilización que no va a la par con el desarrollo de la cultura. Eso propicia un desequilibrio entre los países que han alcanzado un gran desarrollo material y los otros marginados del desarrollo y aún avasallados a través de su historia. A la mayoría de los problemas que evidencia la sociedad contemporánea están enraizados en situaciones de injusticia y las soluciones son inalcanzables mientras éstas no se corrijan. La problemática que planta el progreso de las sociedades en el mundo contemporáneo requiere una visión integral y un tratamiento integrado de sus múltiples aspectos - la solución de sus problema no pertenecen al dominio de una ciencia o de una disciplina - la decisión sobre las mejores soluciones y su ejecución no corresponden a un grupo de la sociedad sino exigen la participación amplia, consciente y comprometida de todos los sectores de la sociedad.

El museo es una institución al servicio de la sociedad, de la cual es parte inalienable y tiene en su esencia misma los elementos que le permiten participar en la formación de la conciencia de las comunidades a las cuales sirven y a través de esta conciencia puede contribuir a llevar a la acción a dichas comunidades, proyectando su actividad en el ámbito histórico que debe rematar en la problemática actual; es decir anudando el pasado con el presente y comprometiéndose con los cambios estructurales imperantes y provocando otros dentro de la realidad nacional respectiva. Esta perspectiva no niega a los museos actuales, ni implica el abandono del criterio de los museos especializados, pero se considera que ella constituye el camino más racional y lógico que conduce al desarrollo y evolución de los museos para su mejor servicio a la Sociedad. La transformación propuesta se dará en algunos casos, paulatinamente o aún experimentalmente; pero en otros casos, podría ser ella la dirección básica (Nascimento, Trampe, Santos, 2012a: 31).

Al revisar las resoluciones de la mesa más de alguna nos parecen obvias, pero no lo eran así si consideramos el contexto de nuestro continente y nuestros países hace 45 años atrás. De ahí su mérito, ya que demuestra la visión y el espíritu de los participantes.

Si vamos a las resoluciones, en la primera de carácter general se propone la necesidad de "apertura del museo hacia las otras ramas que no le son específicas, para crear una conciencia del desarrollo antropológico, socio-económico y tecnológico de las naciones de América Latina, mediante la incorporación de asesores en la orientación general de museos" saliendo a buscar en la comunidad el apoyo para realizar el trabajo museográfico necesario desde un abordaje transdisciplinario ${ }^{176}$.

También es muy actual la segunda resolución de carácter general en la que se plantea que "los museos intensifiquen su tarea de recuperación del patrimonio cultural para ponerlo en función social para evitar su dispersión fuera del medio latinoamericano", con lo cual no sólo señalaban la urgencia de la conservación y el estudio del patrimonio sino que se advierte una señal con respecto al extravío y tráfico de bienes patrimoniales, problema cada día más frecuente en los museos de nuestro

176 En el lenguaje de la "Mesa de Santiago" en realidad se hablaba de "interdisciplinariedad". 
continente, a raíz de una rapiña colonial de coleccionistas privados que luego venden a museos del "primer mundo".

Muy actual es también la quinta resolución de carácter general que señala "que los museos establezcan sistemas de evaluación, para comprobar su eficiencia en relación con la comunidad", método que en los museos recién se comenzó a implementar en los '90 como evaluación de la gestión y de las exhibiciones.

\section{Legados conceptuales de la Mesa de Santiago}

Si bien esta reunión se apoyó en muchos de los preceptos de la denominada "nueva museología" francesa (sobre todo a partir de los vínculos de este colectivo con Hughues de Varine quien en ese momento actuaba como mayor representante del ICOM, y desde esa función fue un importante impulsor de lo que ocurrió en Santiago), se realizaron durante el encuentro apropiaciones y aportes situados que fueron fundamento para la creación de una perspectiva latinoamericana dentro de la "museología crítica". Entre ellos, los dos conceptos que se recuperan como centrales fueron los de "Museo Integral" (e integrado) y la idea de la "Museología Social".

"Integral" por ocuparse de otros aspectos -distintos a los tradicionales- que le permitirían estar más cercanos a los requerimientos de las personas y a la vitalidad cultural de las sociedades en las que los museos estén insertos. Implicaba cruzar fronteras y doblegar resistencias conservadoras. Se continuaría con las funciones técnicas clásicas de resguardar, conservar, documentar, investigar y comunicar (propuestas desde los postulados del ICOM), aunque adquirían otro sentido en vistas de que - por lo expuesto en el encuentro- ya no eran suficientes para las expectativas emergentes. Por otro lado, "integrado" por entenderse como parte activa y orgánica de una estructura social y cultural que lo excede, por actuar como un integrante más de una relación y ya no como una fortaleza -o una isla- a lo que sólo algunos privilegiados podían acceder.

Esta concepción museológica considerada por el colectivo reunido como una herramienta necesaria para la transformación social quedó claramente expresada en "los fundamentos para la creación del Museo Integrado" que formó parte de la declaración de la reunión, donde decían:

Los participantes acordaron que, para la solución de dichos problemas es necesaria la comprensión por parte de la comunidad de los aspectos Técnicos, Social, Económico y Político involucrados. La creación de una conciencia sobre la situación existente, y sobre las alternativas posibles para su solución, fue considerado como un paso fundamental para llegar a la integración prevista. Es en esta función que los integrantes de la Mesa Redonda consideraron que los Museos pueden y deben jugar un papel decisivo en la Educación de la Comunidad (Nascimento, Trampe, Santos, 2012a: 30).

Si hoy es posible hablar de museos participativos, sin que resulte extraño. Si se puede hablar de museos al servicio de la sociedad, de incorporar a la comunidad, de recuperación y valoración de 
nuevos patrimonios, sobre el aporte a la educación y al desarrollo comunitario, o al trabajo transdisciplinario, en parte se lo debemos a esta reunión de Santiago. Según Mario de Souza Chagas esta idea propone un "museo considerado como acción" que compromete la totalidad de los problemas sociales, como un "instrumento dinámico del cambio social". Y propone una apuesta aún mayor ya que la combinación de esas dos nociones permitió que

se lanzase en el campo del olvido aquello que durante más de 200 años se presentaba como paradigma de la identidad de estas instituciones: la misión de la colecta y de la conservación. Por ese camino se llegó al concepto de patrimonio global a ser administrado en el interés del hombre y de todos los hombres (Chagas, 2007b: 34).

Por supuesto, que esta nueva forma de enfrentar el trabajo museográfico, debía ir acompañado de un cambio en la mentalidad de los museólogos y de las autoridades de las que dependen las instituciones. Dado que se postulaba una visión integral y un tratamiento integrado de la problemática social. Puesto que las decisiones sobre las mejores soluciones para la comunidad y su ejecución no corresponderían de manera exclusiva a un grupo reducido de la sociedad sino que exigían la participación amplia, consciente y comprometida de todos los actores de ella.

En la misma tónica, se comenzó a establecer la idea del "museo social" a partir de la idea del museo integrado, el que no necesariamente implicaría la creación de nuevos museos, sino más bien, un cambio de mentalidad en las exhibiciones de los museos ya existentes. En la Mesa Redonda se llegó al consenso de que el museo debía asumir un papel protagónico en el desarrollo de sus comunidades y que su territorio debía exceder el de las paredes del museo, extendiéndose hacia el ámbito de su comunidad. Tal como propuso Mario Teruggi ${ }^{177}$ en su exposición,

invertir el sentido del vector temporal, cuyo punto de partida se sitúa en algún momento del pasado, llegando al presente, pero cuyo extremo, la 'punta de la flecha', es el punto más distante en el futuro. De alguna manera, el museólogo está siendo instado a dejar de meramente excavar los restos del pasado para convertirse, en un especialista en el presente y ser capaz de predecir el futuro ${ }^{178}$ (Nascimento, Trampe, Santos, 2012b: 111).

En este sentido, se examinó, en las diversas presentaciones y debates, cuál debería ser el lugar ocupado por el objeto en un museo que colabora con la comunidad en la solución de sus problemas, donde se llegó a un consenso en lo que se refiere a que el objeto es el punto de partida del museo y su justificación, "premisa que causó sorpresa entre los no museólogos, que no conseguían entender

177 Fue un geólogo especializado en petrología reconocido a nivel internacional, aunque también se dedicó a la literatura y a la lingüística estudiando el lunfardo. Fue un referente del Museo de Ciencias Naturales de La Plata en el que fue Director de la institución y Jefe del Departamento de Minerología y Petrología. También participó en la creación del Planetario de Buenos Aires. Fue el padre de Diana Teruggi de Mariani, quien fue asesinada por las fuerzas armadas el 24 de noviembre de 1976 en La Plata, donde fueron tiroteados en la casa que compartían con Daniel Mariani, en un operativo de unas 4 horas de duración en el que sitiaron la propiedad y la tirotearon con metrallas, y de donde se llevaron con vida a su hija Clara Anahí Mariani Teruggi -quien aún hoy en día es buscada por sus familiares-. Daniel Mariani sobrevivió a ese ataque por no estar en ese momento en la casa, pero fue asesinado en La Plata por las Fuerzas Armadas el 1 de agosto de 1977. La casa actualmente es un Sitio de Memoria que se constituye en un elocuente testimonio del terrorismo de Estado.

178 "Los museos y el desarrollo científico tecnológico". 
lo que les parecía ser la deificación del objeto por el museólogo" (relato de Teruggi en Nascimento, Trampe, Santos, 2012b: 111), incluso hubo quienes sugirieron la posibilidad de generar museos sin objetos $^{179}$.

El punto central sería que la función básica de los museos debería ser la de ubicar al público dentro de su mundo para que tome conciencia de su problemática como hombre-individuo y hombre social. Para cumplir este fin los museos deben presentar esta problemática y también las perspectivas que permitan al hombre dar un sentido constructivo a su existencia (Nascimento, Trampe, Santos, 2012a: 85).

Entre los legados uno que no suelen citarse y que también resultó central para la continuidad de este legado, considerando que su presencia dentro del ICOM era minoritaria, y dado que por lo general los encuentros internacionales se realizaban en países de Europa, fue la creación de la Asociación Latinoamericana de Museología que se organizó en 3 regionales (América Itsmica, Países Andinos y Cono Sur) para profundizar los lazos y la comunicación entre las instituciones de la región. La primera acción de esta asociación fue la creación de un boletín informativo sobre la actividad de los museos de la región y con artículos que apoyaran la formación de los museólogos.

\section{$\underline{\text { Los museos comunitarios a la mexicana }}$}

Esta corriente, para algunos denominada como "Nueva Museología Comunitaria" (Méndez Lugo, 2001) nace en México entre finales de los '60 y los primeros años de los '70 al calor de los planteos de la Nueva Museología en el seno del ICOM, y sobre todo a partir de las declaraciones de la Mesa Redonda de Santiago de Chile en 1972 en cuanto al planteo de integrar a los museos a las dinámicas de sus comunidades, para la investigación, difusión y conservación de su patrimonio natural y cultural y para el fomento y desarrollo de su identidad cultural.

Se inicia con dos experiencias propiciadas por el Instituto Nacional de Antropología e Historia (INAH): uno denominado "La Casa del Museo" a cargo del arquitecto Mario Vázquez, quien había asistido como participante de la Mesa Redonda de Santiago. Por ello su intensión era poder efectivizar los compromisos asumidos en Chile a través de un proceso de concientización y apropiación de la historia y la búsqueda colectiva de soluciones a problemas comunes. La experiencia se desarrollo en el Distrito Federal Mexicano por unos 8 años en los que se extendió por varias colonias del territorio (Méndez Lugo, 2001). La idea de Mario Vázquez era

que fueran los propios hacedores de las cosas quienes decidieran lo que querían decir, cómo lo quisieran decir y en el momento en que quisieran expresarlo, pues el museo tenía que ser visto como una plataforma de investigación y un laboratorio para la puesta en marcha de políticas públicas de servicio comunitario (González Meza, 2016:185-186).

179 Algo que actualmente ocurre con los denominados "centros de interpretación". 
La otra experiencia fue el Programa de Museos Escolares, que estuvo a cargo del museógrafo Iker Larrauri, que intentaba la formación de pequeños espacios museales en las instituciones escolares con la participación de maestros, alumnos y padres. La finalidad alli era conformar dispositivos didácticos que permitieran una mejor comprensión de los contenidos brindados en la escuela.

Ambas experiencias luego son integradas a partir de 1983 en una política pública del INAH que se denominó Programa para el Desarrollo de la Función Educativa de los Museos (PRODOFEM) bajo la coordinación de Míriam Arroyo Quan y un equipo interdisciplinario integrado por antropólogos, historiadores, psicólogos, comunicadores, arquitectos, pedagogos, profesores de educación primaria, museógrafos y biólogos. Es según Raúl Méndez Lugo (2008) durante esta época cuando se habla por primera vez de museos comunitarios en México. Los museos escolares como programa desapareció y se inicia la aplicación práctica de la concepción teórico-metodológica del Museo Comunitario, herencia directa de la experiencia de la Casa del Museo (Méndez Lugo, 2008).

Sus referentes serán luego también importantes en la concreción del Movimiento Internacional para una Nueva Museología (MINOM) que se comienza a constituir en Quebec en 1984 y se termina de sellar en Lisboa en 1985.

Por ello una vez institucionalizado como programa, el museo comunitario se concibió "como un instrumento de educación popular" (Méndez Lugo, 2008:9), inspirados en la Mesa Redonda de Santiago de Chile (1972) y de los postulados de la Declaración de Quebec (1984).

En 1982 se crea el Museo Nacional de Culturas Populares a partir de los aportes encabezados por el antropólogo Guillermo Bonfil Batalla, considerado como otro de los fundadores de la Nueva Museología Mexicana (González Meza, 2016:180).

En octubre de 1984, cuando hacia una semana había terminado la reunión de Quebec y se declaraban los "Principios básicos de una nueva museología" 180, se da otro importante hito para la museología mexicana a partir de la realización de la "Reunión de ecomuseos: el hombre y su entorno" que se realizo en Oaxtepec, en el estado de Morelos. Y como resultado de la cual se generó la denominada "Declaratoria de Oaxtepec. Ecomuseos Territorio-Patrimonio-Comunidad" ${ }^{181}$ en la que al estilo de la realizada en Chile aparece un marcado mandato

En cuanto al patrimonio, la comunidad y el territorio es indispensable una visión de la realidad integrada, que contrarreste la parcelación de la división técnica, social e internacional del trabajo.

La participación comunitaria evita las dificultades de comunicación, características del monólogo museográfico emprendido por el especialista, y recoge las tradiciones y la memoria colectivas, ubicándolas al lado del conocimiento científico.

180 http://museosdesantafe.com.ar/wp-content/uploads/2014/08/DECLARACION-DE-QUEBEC.pdf 181 http://www.ibermuseus.org/wp-content/uploads/2014/07/declaracao-de-oaxtepec.pdf 
Concentrar el patrimonio en un edificio modifica el contexto original que le corresponde. La consideración del espacio territorial como ámbito museográfico de una realidad completa, valora dicho contexto.

A la vez que junto con esa declaración de principios trazaba su lealtad y adscripción al movimiento social históricamente construido con las declaraciones anteriores y en su pertenencia latinoamericana

Esta declaratoria se solidariza con la orientación eminentemente social del papel de la museología, de la Mesa Redonda de Santiago de Chile de 1972, con el proyecto de Declaración de Quebec de octubre de 1984, con los conceptos de la nueva museología y ecomuseología internacionales, así como con todo esfuerzo latinoamericano que vea en la museología un instrumento para el libre desarrollo de las comunidades.

Volviendo a la tarea del Programa para el Desarrollo de la Función Educativa de los Museos (PRODOFEM) que coordinaba Míriam Arroyo Quan y su equipo fueron quienes se encargaron de desarrollar algunas definiciones sobre el concepto de museo comunitario, al que describieron como aquel que

desde sus inicios, y mediante la participación activa de la población, cumple con la función de servir a la comunidad, puesto que las temáticas que desarrolla están siempre ligadas a los intereses y necesidades de la misma (...) el museo es un instrumento que impulsa la identidad y conciencia nacional, porque constata e inspira el respeto a las diferencias regionales siempre atento a la unidad nacional (Desemec en Ramírez, 2016:5).

De este modo entre 1983 y 1991 es el momento de mayor proliferación de los museos comunitarios por el territorio mexicano, a partir del trabajo realizado por los promotores sociales de la política pública que proponía el Estado mexicano. Los promotores cumplían un papel indispensable al ser quienes realizaban diagnósticos para determinar en qué localidad debía ubicarse el museo, organizaban actividades culturales e intentaban convencer a los miembros de la comunidad de la importancia del proyecto. Y si esto no ocurría, los promotores solicitaban su transferencia a otra zona para iniciar el mismo proceso (Ramírez, 2016).

A partir de 1993 se reestructura el Programa Nacional de Museos Comunitarios y se crea una coordinación nacional a partir de un convenio de colaboración entre el INAH y la Dirección General de Culturas Populares, ambos dependientes del Consejo Nacional para la Cultura y las Artes. Y finalmente el programa de museos comunitarios vivió un proceso de descentralización a través de las Unidades Estatales de Culturas Populares dependientes de los gobiernos de los estados mexicanos (Méndez Lugo, 2008).

En algunos estados, además de contar con el apoyo de instituciones gubernamentales, se han creado organizaciones sociales que coordinan acciones entre los museos comunitarios, entre ellas la 
más destacada es la Unión Nacional de Museos Comunitarios y Ecomuseos de México A.C. ${ }^{182}$ inaugurada en 1994.

De entre la enorme variedad de experiencias que este sistema impulsó hay una vertiente que ha logrado reconocimiento puertas afuera. Se trata del caso de los museos del estado de Oaxaca que tienen como referentes del INAH a Cuauhtémoc Camarena y Teresa Morales. En este estado es en donde más museos se han creado, pero además siguen funcionando y buena parte de ellos continúan desarrollándose (Ramírez, 2016: 6).

Esta experiencia generó un particular modo de gestión comunitaria tomando como apoyo el sistema de gobierno local de cargos civiles-religiosos. $\mathrm{Y}$ por su parte el sistema tradicional de gobiernos locales los ha reconocido como parte de sus labores, a tal punto "los museos creados en comunidades zapotecas, mixtecas, chocholtecas y chinatecas la Asamblea del pueblo discute la creación y operación del museo y nombra un comité para dirigirlo" (Camarena, Morales, en Ramírez, 2016:6).

Estas referentes con el tiempo han aportado a la construcción conceptual y metodológica mediante la realización de un manual que es de libre acceso y que se encuentra publicado en el sitio de la Red de Museos Comunitarios de América ${ }^{183}$. Según la definición construida en el "Manual para la creación y desarrollo de museos comunitarios"

Un museo comunitario es creado por la misma comunidad: es un museo "de" la comunidad, no elaborado externamente "para" la comunidad. (...) es una herramienta para que la comunidad afirme la posesión física y simbólica de su patrimonio, a través de sus propias formas de organización. (...) es un espacio donde los integrantes de la comunidad construyen un autoconocimiento colectivo, propiciando la reflexión, la crítica y la creatividad. Fortalece la identidad, porque legitima la historia y los valores propios, proyectando la forma de vida de la comunidad hacia adentro y hacia fuera de ella. Fortalece la memoria que alimenta sus aspiraciones de futuro. (...) genera múltiples proyectos para mejorar la calidad de vida, ofreciendo capacitación para enfrentar diversas necesidades, fortaleciendo la cultura tradicional, desarrollando nuevas formas de expresión, impulsando la valorización del arte popular y generando turismo controlado por la comunidad. Un museo comunitario es un puente para el intercambio cultural con otras comunidades, que permite descubrir intereses comunes, forjar alianzas e integrar redes que fortalece cada comunidad participante (Morales, Camarena, 2009: 15).

La particular construcción que junto con las comunidades oaxaqueñas han desarrollado responde sobre todo al reconocimiento de sus derechos y necesidades, principalmente el derecho a educarse y a afirmarse y autovalorarse como comunidades

\footnotetext{
182 https://www.museoscomunitarios.org/redes/paises/101-union-nacional-de-museos-comunitarios-y-ecomuseos-demexico-a-c

183 https://museoscomunitarios.org/
} 
El museo nace en respuesta a las necesidades que la población siente. Muchas veces la necesidad de afirmar la posesión de su patrimonio surge cuando una comunidad siente el riesgo de perderlo. (...) La valoración del pasado propicia la reflexión sobre el presente. ¿Por qué la comunidad se ha transformado y qué se busca para el futuro? En el museo la comunidad confirma que tiene el derecho de analizar tales preguntas por sí misma. Confirma la posesión de su patrimonio y su decisión de qué hacer con ella. Responde al derecho de todos sus habitantes de conocerse, de educarse, y de recrearse (Morales, Camarena, 2009: 17).

Otro punto central es la cuestión de la autogestión que si bien es promovida desde la acción de los promotores o promotoras sociales llevados al territorio por la política pública, una vez generado el proceso de creación queda en manos de la propia población

La comunidad es dueña del museo. Un museo comunitario pertenece a toda la comunidad. (...) es la dueña de su edificio, de sus colecciones y de los beneficios que genera. Cuando existen colecciones de Bienes federales o estatales, estás se encuentran en custodia de la comunidad (Morales, Camarena, 2009:18).

En cuanto a lo metodológico, es interesante notar que el centro de la recuperación y construcción de las memorias de la historia local se logra mediante un particular proceso de recuperación de la historia oral, la que es conseguida por los propios miembros de la comunidad

La historia oral, a través de la entrevista, reconstruye la vida de la gente. Nos ayuda a entender la vida de los hombres y de las relaciones sociales de las que forman parte, en función de sus propios cambios y significados. La historia oral es el rescate de los testimonios orales sobre las experiencias y las vivencias de los protagonistas de la historia (Morales, Camarena, 2009:58).

Para lograr este cometido desde 1988 se desarrollaron talleres de historia oral para la creación de museos comunitarios en todo el estado de Oaxaca, impulsados por el INAH y la Asociación para el Desarrollo Cultural de Comunidades Indígenas del mismo estado. Según enuncian los autores el objetivo es que se impulse a las comunidades

a apropiarse de técnicas que les permitan conocerse a sí mismas. El estudio y el análisis de la historia no es patrimonio exclusivo de especialistas. Es importante que todos nos veamos, y que las comunidades se vean a sí mismas, tanto como sujetos que hemos construido nuestra historia como sujetos que la podemos estudiar y construir (Camarena, Morales, Necochea, 1994:5).

La idea es bien clara. Todos hacemos historia, día a día. La historia se crea a partir de la vida de cada individuo que le otorga un significado a su propio actuar en la vida en comunidad.

partimos del supuesto de que los habitantes de los pueblos son los actores de la historia. Así la historia de las comunidades es la historia de los hombres en términos de sus propias vivencias, pero también debe vérseles en relación con aquellos otros con los que convive cotidianamente: familia, comunidad, trabajo y grupos. Estas relaciones tienen características 
de solidaridad y armonía o de desigualdad y conflicto, en donde hay elementos tanto de cohesión como de dispersión (Camarena, Morales, Necochea, 1994:7).

Este trabajo de formación sobre historia oral luego dio lugar también a la constitución de la Unión de Museos Comunitarios de Oaxaca en 1991. Y más adelante a la constitución de otras redes como la ya mencionada Unión Nacional de Museos Comunitarios, creada en 1994; o la Red de Museos Comunitarios de América conformada en el año 2000 por organizaciones de Bolivia, Venezuela, Panamá, Costa Rica, Nicaragua, El Salvador, Guatemala y México, a la que luego se sumaron museos de Brasil, Colombia, Chile y Perú.

Para cerrar este segmento dedicado al legado de la museología comunitaria mexicana parece interesante recatar una propuesta vitalista, en un sentido que es de total actualidad para la propuesta que estamos discutiendo en este trabajo, el museo como un "espacio vivo" dedicado a encontrar los mejores caminos para que los sujetos sociales de las comunidades puedan vivir mejor, y para ello se deba involucrar de todas las maneras posibles a esos sujetos en cuestión, a esos hombres, mujeres, niños, niñas y jóvenes que la integran

El museo comunitario es un espacio vivo, un espacio de organización, establecido para fortalecer la identidad, propiciar la reflexión crítica y la creatividad, y generar múltiples proyectos para mejorar la calidad de vida. Para concretizar esta visión, el comité deberá emprender proyectos concretos que respondan a las prioridades y necesidades de la comunidad. El mejor camino para definir cuáles proyectos son prioritarios, es consultar a los mismos sectores o grupos comunitarios (Morales, Camarena, 2009:100).

\section{El museo Ambrosetti en la Universidad Nacional y Popular de Buenos Aires (1973)}

Hay una experiencia muy breve, y a la vez prácticamente desconocida en el ámbito de la museología, pero que por su modo de construcción y posicionamiento político es necesario recuperar dentro del presente trazado de la genealogía de la museología social. Se trata de un proceso emblemático porque ocurre casi en paralelo con la Mesa de Santiago y sobre todo porque es emergente del clima de época de la Argentina, o al menos de la ciudad de Buenos Aires, de la vuelta de la democracia de 1973.

Tras 7 años de dictadura cívico militar ${ }^{184}$ y tras 18 años con el peronismo proscripto, la asunción de Héctor J. Cámpora como Presidente de la Nación, y la promesa del regreso de Juan Domingo Perón al país, se vivía como un particular clima de movilización popular expresada en organizaciones sociales que se manifestaba de muy diversas maneras, y que fue también expresado en la composición del gabinete y en el tono de las políticas que este gobierno propuso.

184 El golpe militar que estuvo acompañado por diversos sectores civiles tuvo tres etapas que fueron encabezadas por Juan Carlos Onganía entre junio de 1966 y junio de 1970, por Roberto Levingston entre junio de 1970 y marzo de 1971, y por Alejandro Lanusse entre marzo e 1971 y mayo de 1973. 
En el ámbito de la educación, Cámpora designó a Jorge A. Taiana como Ministro de Cultura y Educación, quien es recordado en su gestión por ser el impulsor de la Campaña de Reactivación Educativa para adultos (CREAR) ${ }^{185}$ una ambiciosa campaña de educación popular para combatir el analfabetismo para la que estableció lazos con Paulo Freire quien en ese marco fue traído a nuestro país para realizar capacitaciones a educadores (Martínez, 2015:47). Aunque ocurrió un año después de la experiencia que describiremos, también es recordado por la promoción de la Ley 20.654 Ley Orgánica de las Universidades Nacionales, conocida como "Ley Taiana" ${ }^{186}$. En ese proyecto se logran institucionalizar la gratuidad de los estudios universitarios ${ }^{187}$, el ingreso irrestricto, las cátedras populares, el cogobierno de la universidad con la participación con voz y voto de la representación estudiantil y no docente, sumada a la de los docentes que ya contaban con esa posibilidad. Así como se promovía la repatriación de docentes que habían sido expulsados por razones políticas entre 1955 y 1973. Estas dos iniciativas, que obviamente no fueron las únicas que realizó durante su gestión dan cuenta de una voluntad crítica y de transformación estructural del sistema público educativo en el marco de la perspectiva de la educación para la liberación.

En la misiva que encabezaba para la presentación del proyecto de Ley de Universidades ante el Congreso de la Nación, el Ministro de Cultura y Educación Jorge A. Taiana, decía:

a nadie escapa la trascendencia de la educación superior en el proceso de unidad, reconstrucción y liberación nacional emprendida por el Gobierno Popular. Es conocida la situación conflictiva en las casas de altos estudios (...) la carencia de participación en el gobierno de esas instituciones por parte de los diversos claustros que componen la comunidad universitaria; la falta de interrelación con el medio (...) la obsolescencia de las estructuras y métodos del sistema de educación superior, en relación con los requerimientos políticos, culturales, sociales y económicos de la hora.

(...) La universidad debe estar al servicio del pueblo y no de sus componentes; no es una isla, por avanzadas o revolucionarias que sean las inspiraciones de sus integrantes, ni un Estado dentro del Estado.

(...) el proyecto establece las bases de un tipo de Universidad insertada en el pueblo argentino, expresado por un gobierno popular en un momento histórico de definición y reencuentro nacional (Taiana, 1974).

Un año antes de la aprobación de aquella Ley, apenas Taiana había asumido su gestión en la cartera de Educación, puso en acto esas ideas que luego vimos plasmadas en la letra legislativa. Lo hizo nombrando a Rodolfo Puiggrós como Rector de la Universidad de Buenos Aires.

185 Sobre esta política educativa en particular recomiendo leer la recuperación analítica que produce Darío Martínez en su tesis de doctorado titulada "Saberes, experiencias y subjetividades de la educación de jóvenes y adultos en la ciudad de La Plata. Un abordaje desde la perspectiva comunicación/educación", donde también se citan testimonios del propio Freire en los que evalúa el clima de época. La tesis está disponible en http://hdl.handle.net/10915/49538

186 Fue aprobada por el Congreso de la Nación el 14 de marzo de 1974 y promulgada con la firma de Perón, Taiana y Gelbard el 26 de marzo del mismo año.

187 Recuperando el mandato del Decreto 29.337 sobre Supresión de Aranceles Universitarios firmado por Juan D. Perón el 22 de noviembre de 1949. 
En su mandato que fue aún más breve que el de Taiana, desarrolló una enorme batería de provocaciones a la matriz hegemónica del sistema universitario argentino, haciéndolo desde el sillón principal de una de las mayores instituciones de educación superior del país. A partir de su asunción propuso que la institución pase a denominarse como Universidad Nacional y Popular de Buenos Aires. Según afirma Julián Dércoli, "se trataba de construir una nueva universidad democrática, no entendida a la luz del reformismo, sino en el marco del proceso de liberación nacional" (2017:14) poniendo a la universidad en sintonía con las políticas que promovía el gobierno recientemente asumido a nivel nacional.

Puiggrós consideraba que la Reforma era un "movimiento verbalista", que se había quedado en los dichos, pero que no había avanzado en transformaciones concretas. Tenía una evaluación dispar de aquel Manifiesto Liminar de 1918 cuyos "postulados generales deben ser recogidos, desarrollados y sobre todo llevados a la práctica" (Puiggrós, 1974: 49). De todos modos, el nuevo proyecto de Universidad que se proponía no se pensaba tanto en enfrentamiento con la reforma, sino que según afirma Dércoli, más bien se manifestaba

en oposición al proyecto cientificista y desarrollista del frondicismo, así como al tecnocrático de la Revolución Argentina. Estos eran los antagonistas inmediatos, que en una mirada de largo plazo no eran más que nuevas formas de la Universidad dependiente (en las que incluían la del reformismo) como parte de las estructuras de subordinación a las que estaba sometida la Argentina (2017:14).

De este modo, se planteaba un crítico llamado de atención a la comunidad universitaria para que rompiera los históricos cercos de la especialización y de la esterilidad política, y se pusiera en el ejercicio de la acción acompañando el marco coyuntural de las transformaciones emancipatorias que se estaban desarrollando en diversos países de nuestro continente, pero que también podían observarse en Asia y África con los movimientos de descolonización. En ese marco la propuesta se orientaba a actualizar y nacionalizar la enseñanza universitaria promoviendo la articulación Universidad/Estado/Sociedad en el marco de un proyecto de liberación soberana. En estos términos, nacionalizar significaba abandonar la práctica colonial de incorporar de manera acrítica y descontextualizada las propuestas intelectuales, generalmente traídas de europeas, para empezar a producir conocimientos propios para la solución de los problemas propios.

Es en este contexto regional, en este contexto nacional y en este particular contexto institucional de la Universidad Nacional y Popular de Buenos Aires que se desarrolló la experiencia que me interesa instalar en el marco de las referencias históricas que aportaron a la museología social latinoamericana ${ }^{188}$.

$188 \mathrm{El}$ acceso a esta experiencia lo tuve a partir de algunas referencias laterales en diálogos informales en el trabajo de campo, y sobre todo a partir de la entrevista con Verónica Jeria, la que luego puedo recuperar de manera consistente a partir de un interesante artpiculo publicado por ella en una revista científica. 
En el marco de profundas transformaciones que se estaban desarrollando en la casa de altos estudios, el Museo Etnográfico Juan Ambrosetti también se vio conmovido, dado que a partir de ese año pasó a ser sede del Centro de Recuperación de la Cultura Popular "José Imbelloni" (Jeria, 2016). Según lo recuperado por la investigadora de documentos de la época

el objeto de la modificación institucional implementada en el Museo se encuadraba dentro de la Política cultural Justicialista, y por lo tanto lo que era del pueblo debía volver al pueblo. Al abrir las puertas de la casa de cultura popular se pretendía ofrecer "un lugar donde se encuentre la palabra y la memoria de lo que fue y es la más firme decisión de construir una Patria Justa, Libre y Soberana, para lo cual 400 años de luchas testimonian y jalonan con sangre ese anhelo que se materializa en la cultura popular. Quedarán en este centro recuperados momentos de nuestra marcha, como la de nuestros hermanos: los pueblos todos del Tercer Mundo."(Anónimo 1973d en Jeria,2016:12)

Al igual que ocurría en el resto de la Universidad, en el museo también se transformó, la estructura orgánico funcional pasó a estar integrada por un triunvirato a cargo de Jorge De Persia, Arturo Sala y Miguel Palermo, representantes de los claustros que conformaban la planta del museo. Y del mismo modo, el proyecto de gestión planteaba objetivos que eran coherentes con esta misma perspectiva política y que Jeria recupera de la resolución ${ }^{189}$ del Consejo Directivo de la Facultad que aprobó la designación del triunvirato:

- Crear las condiciones infraestructurales para mantener, acondicionar, exponer, recuperar, rescatar y documentar elementos expresiones culturales de los pueblos del tercer mundo.

- Cubrir en forma dinámica y creativa la tarea pedagógica y de integración comunitaria a fin de que el pueblo se reencuentre con su cultura, con las raíces de su ser.

- Rescatar, integrar y cohesionar los valores culturales propios de nuestro pueblo, a fin de integrarlos en la forja de nuestra cultura nacional y popular.

- Fomentar a través de la práctica sistemática de lo estético, lo político y lo histórico-social, lo que cada uno -de los participantes en las muestras- tiene de individual y único conjugándolo al mismo tiempo con las raíces del hombre con las simientes de la nacionalidad y las luchas de los pueblos por su liberación.

- Tender a lograr una lúcida y testimonial "toma de conciencia" frente a los múltiples estímulos y conflictos de la realidad, tratando de entrenar el espíritu de pertenencia nacional y de pertenencia continental, desde una posición de lucha práctica en el campo de la cultura (citados en Jeria, 2016:12-13)

En ese marco y con la participación de trabajadores y trabajadoras del museo, pero también con la participación de docentes y estudiantes voluntarios se trabajó en el tramado y montaje de la única muestra que pudo realizarse durante este período de gestión, denominada "Patagonia 12.000 años de historia". Según afirma la investigación de Verónica Jeria el guión de la muestra "hablaba de

189 Resolución Consejo Directivo FFyL Nº 946 del 2 de octubre de 1973 citada en el artículo. 
las prácticas genocidas llevadas adelante por el Estado argentino durante los siglos XIX y XX en la construcción del Estado-Nación y sus características geopolíticas y culturales" (2016:13-14), incluyendo como parte del relato "la ocupación y explotación de los recursos naturales del territorio, la denominada "Campaña del Desierto", las prácticas genocidas implementadas contra las poblaciones originarias en el siglo XIX y la represión contra el movimiento obrero de siglo XX" (2016:14).

Jeria también destaca que lo interesante del argumento de la muestra era que se ocupaba también de mirar las situaciones de abuso y explotación en tiempo presente, atendiendo la situación de los habitantes de la Patagonia en la década del '70. Según cita "Aún hoy los peones de campo todavía viven en ranchos de cuatro chapas y duermen sobre cueros de capón. En la mayor parte de los casos pasan solos el invierno, teniendo como única compañía el caballo y los perros" (2016:16).

Esta experiencia se terminó de manera abrupta en 1974 con el reemplazo de Taiana por Oscar Ivanissevich en el Ministerio de Educación, quien dispuso la intervención de muchas universidades, entre las que se incluyó la de Buenos Aires. en el marco de una restauración conservadora en la que se dio marcha atrás con muchas de los derechos y reformas, a lo que se sumó el inicio de un marco de persecución política como antesala de lo que luego sería la feroz represión desarrollada por la dictadura cívico-militar comenzada en marzo de 1976.

La breve experiencia de gestión del triunvirato, ocurrida en un peculiar contexto de movilización política y social, resulta un antecedente interesante para la museología social. El que en términos de Verónica Jeria, se prioriza la mirada histórica por sobre el patrimonio, y se intenta vincular el pasado con el presente, a la vez que les interpela a desafiar la tarea actual del museo, "su forma de organización, planificación y construcción nos hizo pensar en cómo nos organizamos hoy, cómo nos comprometemos con nuestra tarea, y cómo nos formamos para llevarla adelante" (2016:25).

\section{Continuidad de la museología latinoamericana}

Como ya relatamos, a poco de realizada la Mesa Redonda de Santiago, en Chile ocurrió el golpe militar del 11 de septiembre de 1973 que terminó de la peor manera con la experiencia del gobierno socialista de la Unión Popular, el que al igual que ocurriría en el resto de las dictaduras instaladas en el continente en esa década y la siguiente, incluyó la persecución, tortura y desaparición de intelectuales y militantes sociales y políticos.

El oscuro deseo propiciado por las dictaduras de silenciar la construcción de lo que Mario Chagas (2007b) denomina como "una nueva imaginación museal", un enfoque popular, participativo y utópico, no fue del todo eficaz, dado que 10 años después, 20 y aún 35 o 40 años después, los principales temas de aquella mesa redonda resurgieron para ocupar agendas en otros encuentros y otros espacios. 
El primer taller internacional realizado en 1984, en la ciudad canadiense de Quebec, fue la ocasión en que fueron retomadas explícitamente las resoluciones de la Mesa Redonda de Santiago de Chile y fueron lanzadas las bases de lo que decidió llamarse como Movimiento Internacional de la Nueva Museología (MINOM) ${ }^{190}$ (Chagas, 2007b), que continuó con el movimiento de la "sociomuseología" con la convicción de que los museos pueden y deben asumir un rol emancipador en la sociedad (Santos, 2012). Del mismo modo, los ecomuseos de desarrollo, en Francia, Portugal, Quebec, Suecia y Noruega, son herederos asumidos de Santiago. EI MINOM y sus sucesivos talleres internacionales se han referido explícitamente a Santiago, así como sucedió en las declaraciones de Quebec (1984), Lisboa (1985), Oaxaca (1993), La Habana (2014), Nazaré (2016) y Córdoba (2017).

En el plano latinoamericano, se organizó en 1992 un encuentro en Caracas, Venezuela, para celebrar el $20^{\circ}$ aniversario de la Mesa de Santiago. El seminario "La misión del museo en América Latina hoy: nuevos retos", buscó reanimar y actualizar la idea del museo integral al servicio del desarrollo, enfocando su potencial de comunicación como instrumento de diálogo entre diferentes fuerzas sociales y de alianza con las comunidades. Alli se recuperó y actualizó la declaración de Santiago, para las nuevas generaciones, así como se propuso producir una nueva declaración (De Varine, 2012: 98). En la "Declaración de Caracas (1992)" se hace explicita referencia a la mesa de Santiago y se agregan una serie de considerandos y recomendaciones, muchas de las cuales tienen una mirada comunicacional.

Por ejemplo se apunta al fortalecimiento de la identidad cultural:

[el museo] debe constituirse en instrumento eficaz para el robustecimiento de la identidad cultural de nuestros pueblos y para su conocimiento mutuo -fundamento de la integraciónTiene también un rol esencial en el proceso de desmitificación de la tecnología, para su asimilación al desarrollo integral de nuestros pueblos (VVAA, 2013: 24).

Incluso se llega al punto de considerar al museo como un medio de comunicación:

(...) los museos no son sólo fuente de información o instrumentos de educación, sino espacios y medios de comunicación que sirvan para establecer una interacción de la comunidad con el proceso y los productos culturales. Es necesario definir la naturaleza específica del "medio" Museo, considerando que su forma tradicional, todavía dominante en América Latina, no responde a los cambios ocurridos en el mundo contemporáneo (VVAA, 2013).

En un sentido similar recupera la potencialidad del museo como constructor de un lenguaje propio, de un relato que potencie la identidad y la educación comunitaria:

(...) en América Latina los museos, generalmente, no son conscientes de la potencialidad de su lenguaje y de sus recursos de comunicación (...) el museo es un importante instrumento en el

190 El MINOM desempeñó y desempeña un rol importante al subrayar la dimensión política del concepto del museo integral, es decir, del museo como acción, como un instrumento al servicio de la sociedad e involucrado en la solución de sus problemas. Para el MINOM, la declaración de Santiago ofrece los fundamentos para una (nueva) museología, cuya primera y principal preocupación es "el mejoramiento de las condiciones de vida, el desarrollo de las poblaciones y sus proyectos para el futuro" (Declaración de Quebec, 1984). 
proceso de educación permanente del individuo. (...) no puede existir un museo integral, o integrado en la comunidad, si el discurso museológico no utiliza un lenguaje directo, democrático y participativo (VVAA, 2013).

En cuanto a los objetos y la patrimonialización propone que tradicionalmente se han utilizado criterios restringidos en la valoración de los objetos que constituyen el patrimonio museable, valiendo sólo aquellos representativos de las disciplinas académicas, de 'importancia histórica' y 'excepcionales' por su naturaleza, excluyendo determinadas formas de expresión cultural igualmente valiosas e importantes (VVAA, 2013: 24-25).

\section{En tal sentido se recomienda}

que se valorice el entorno y su contextualización para ser considerados como criterio de partida en la conformación de las colecciones, atendiendo a su valor referencial y sin discriminar ningún objeto o disciplina. Que se reformulen las políticas de formación de colecciones, conservación, investigación, educación y comunicación, en función del establecimiento de una relación más significativa con la comunidad con la cual el museo desarrolla sus actividades (...) Que el museo incentive la investigación generada por la comunidad para el reconocimiento de sus propios valores (VVAA, 2013: 25).

En la misma senda de recuperación a 35 años del encuentro de Santiago, se desarrolla el primer "Encuentro Encuentro Iberoamericano de Museos", celebrado del 26 al 28 de junio de 2007, en la Ciudad de Salvador, Bahía, que se constituye como "heredero contemporáneo de la Mesa Redonda (...), y también de los aportes teóricos y prácticos de las denominadas museología popular, museología social, ecomuseología, nueva museología y museología crítica" (VVAA, 2007: 18) en el que se propuso la creación del Programa Ibermuseos, la Red Iberoamericana de Museos, el Programa de Formación Profesional y Capacitación Técnica para Museos; el Registro de Museos Iberoamericanos, el Observatorio Iberoamericano de Museos y el Portal Iberoamericano de Museos (VVAA, 2007: 19).

A modo de continuación de una especie de tradición, en esta reunión también se redactó una declaración, en la que se propone principal atención en los múltiples valores de la cultura a la que se debe garantizar su acceso en tanto derecho,

comprender la cultura como bien con valor simbólico, derecho de todos y factor decisivo para un desarrollo integral y sustentable, sabiendo que el respeto y la valorización de la diversidad cultural son indispensables a la dignidad social y al desarrollo integral del ser humano (VVAA, 2007: 25).

En cuanto a los objetos del acervo se propone "el uso creativo y la apropiación crítica del patrimonio museológico" (VVAA, 2007: 25). Así como asumir a los museos en tanto

valorizar el patrimonio cultural, la memoria y los museos, comprendiéndolos como prácticas sociales estratégicas para el desarrollo de los países (...) como procesos de representación de las diversidades como las étnica, social, cultural, lingüística, ideológica, de género, creencia y 
orientación sexual (...) asegurar que los museos sean territorios de salvaguarda y difusión de valores democráticos y de ciudadanía, colocados a servicio de la sociedad, con el objetivo de propiciar el fortalecimiento y la manifestación de las identidades, la percepción crítica y reflexiva de la realidad, la producción de conocimientos, la promoción de la dignidad humana y oportunidades de esparcimiento (VVAA, 2007: 25).

En términos de derechos se asume que debe garantizarse "el derecho a la memoria" de grupos y movimientos sociales y "apoyar acciones de apropiación social del patrimonio y de valorización de los distintos tipos de museos, como museos comunitarios, ecomuseos, museos de territorio, museos locales, museos memoriales (resistencia y derechos humanos) y otros", así como valorizar "la vocación de los museos para la comunicación, investigación, educación, documentación y preservación de la herencia cultural, así como para el estímulo a la creación contemporánea en condiciones de libertad e igualdad social" (VVAA, 2007: 25). Del mismo modo en términos educativos se propone "reafirmar y amplificar la capacidad de los museos y del patrimonio cultural y natural como estrategias de transformación de la realidad social" (VVAA, 2007: 25).

En 2012 se realizó en Montevideo, el VI Encuentro Iberoamericano de Museos "Museo: ¿territorio de conflictos? Miradas contemporáneas a 40 años de la Mesa Redonda de Santiago de Chile" organizado por Ibermuseos, en el que una vez más se recuperó y valoró el aporte de 1972 y se produjo una nueva declaración. En la que entre otras cuestiones se propone que los museos, insertos en la realidad social

deben ser un espacio de reflexión sobre los conflictos existentes en la sociedad, poniendo sus recursos y herramientas al servicio de este objetivo (...) que el alcance del concepto de comunidad ha variado en los últimos cuarenta años y han surgido nuevas formas de organización y movilización social que requieren una nueva aproximación por parte de los museos (VVAA, 2012: 2).

A partir de nuevas discusiones y de diálogos en el eje sur-sur, nos encontramos con que la perspectiva de los museos comunitarios también se está desarrollando por ejemplo en Kenia, donde algunas iniciativas de gestión comunitaria convierten al patrimonio en una fuente de ingresos colectiva para la construcción de escuelas o sistemas de agua; o en Sudáfrica, donde artistas activistas trabajan a favor de la conciencia crítica y de la participación de los jóvenes en la acción social (Santos, 2013).

\section{La conferencia de MINOM en Córdoba (2017)}

Con una tónica similar en octubre de 2017 se realizó en la ciudad de Córdoba (Argentina) la XVIII Conferencia Internacional de MINOM-ICOM con la organización local de la Asociación de Trabajadores de Museos ${ }^{191}$ y el Encuentro de Educadores de Museos de Córdoba ${ }^{192}$. Durante 5 días se 
desarrollaron diversas actividades a las que concurrieron más de 100 integrantes de equipos de gestión de museos de todo el país y de países como Chile, Colombia, Brasil, Perú y Portugal. Los primeros tres días estuvieron destinados a la realización de unas jornadas de reflexión sobre museología social ${ }^{193}$ a cargo de Mario de Souza Chagas y Marcelle Pereira (presidente y vicepresidenta de MINOM respectivamente) en las que por las mañanas se desarrollaban perspectivas de formación y se revisaban experiencias de museos de Brasil y por las tardes se realizaban visitas a diversos museos y sitios de memoria de Córdoba para trabajar sobre las visitas de manera crítica y reflexiva. Los últimos dos días estuvieron destinados a la realización de paneles en el marco del Congreso propiamente dicho, con presentaciones de casos y mesas redondas para el intercambio de saberes en torno a dos ejes centrales: "Museos y acciones patrimoniales en torno a cuestiones de género", y "Museos, acciones patrimoniales y experiencias educativas en espacios de privación de la libertad".

Al finalizar la semana el colectivo integrante del encuentro redactó la denominada "Declaración de Córdoba" 194 en la que se reivindicaban las declaraciones de MINOM de Nazaré (2016), La Habana (2014) y Río de Janeiro (2013) y se asumía como inicio una frase que fue lanzada por Mario Chagas en la primer jornada y que fue retomada y reiterada cada día como un mantra: "La museología que no sirve para la vida, no sirve para nada", así como recuperaba el sentido afectivo diciendo que "La museología que practicamos involucra los afectos, la fraternidad, la reciprocidad, el amor, la alegría, la poesía". Al mismo tiempo que recuperaba el sentido constructivo y propositivo de las memorias considerando que

la memoria constituye una forma deliberada de resistencia, de lucha contra el arrasamiento de los modos de vida que no se encuadran en toda forma de colonialismo -el sistema capitalista, el patriarcado, entre otros-. Al mismo tiempo es afirmación de los valores humanos, de la dignidad y la cohesión social, colocándose como acción propositiva de ocupación del presente e invención de futuros (VVAA, 2017: 1).

También se proponía allí una deconstrucción de la noción de patrimonio que resulta potente e interesante para pensar otro tipo de museos

La noción hegemónica de patrimonio carga con un sentido patriarcal y patrimonialista, incapaz de abarcar los múltiples sentidos y solidaridades implicados en la producción y comunicación de las culturas, y están dadas las condiciones para el reconocimiento de una herencia que se construye y se comparte aquí y ahora y que puede ser denominada como fratrimonio y soromonio, integrando lo natural y cultural, lo material e inmaterial (VVAA, 2017:2).

Sobre este encuentro seguramente podría seguir profundizándose mucho más aún, por el momento es interesante marcarlo además como un momento de puesta en cuerpo, de encuentro

193 El curso de formación fue denominado "Museología social en América Latina: Poética y política en movimiento a partir de experiencias concretas".

$194 \mathrm{El}$ texto completo puede leerse en http://www.minom-icom.net/files/minom 2017 - declaracion de cordoba esp-port-fr-ing.pdf 
cara a cara de referentes que se encuentran dispersos por el territorio, de cierta institucionalización de la perspectiva de la museología social en Argentina, dada la cantidad de representantes de museos que alli se hicieron presentes. Con esto podría afirmarse que aún hoy en día la Mesa Redonda de Santiago y su "nueva imaginación museal" (en términos de Chagas) sigue vigente, continúa marcando un horizonte político que resulta vitalizante para los museos. Seguramente se podrían (y se han hecho) actualizaciones en el concepto del museo integral desde 1972, sin embargo algo permanece en el tiempo. Los retos planteados se transformaron, pero siguen vigentes como interpelación a nuestras prácticas, permanece el imperativo de la toma de posición, y el compromiso ético y político con la transformación social.

\section{"Hay una gota de sangre en cada museo"}

Desde la modernidad a este tiempo, los museos son reconocidos por su poder. Poder que les da la posibilidad de producir significados, de adaptarse (o conservarse) a pesar de los condicionamientos históricos, sociales, así como por su vocación para la mediación cultural. Los museos producen gestos comunicacionales que permiten anudamientos entre lo simbólico y lo material, lo racional con lo sensible y lo ininteligible. Para Mario de Souza Chagas se los puede comparar con un "puente lanzado entre tiempos, espacios, individuos, grupos sociales y culturas diferentes" (Chagas, 2007a: 13), un puente que se construye generalmente con imágenes, por lo que también reside en el imaginario de los sujetos sociales.

En esas operaciones de poder, los museos tienen la capacidad de seleccionar de la totalidad de la sociedad y de la cultura, destacando elementos y por ende excluyendo otros. Por eso es que Chagas (2006) habla de que "hay una gota de sangre en cada museo", haciendo notar la enorme responsabilidad que existe en el momento de mediación y producción de una muestra museográfica, a la vez que implica asumirlo como un acto que nunca está exento de violencia, enmarcada en una enorme historia de injusticias, atropellos, omisiones, y olvidos, que forman parte de una institución que proviene desde las entrañas coloniales de la cultura europea.

No obstante, desde hace mucho tiempo ya, los museos están pasando por procesos de democratización, de resignificación y de apropiación cultural. Por lo que la preocupación actual, es tanto democratizar el acceso a ellos, como también democratizar al propio museo en tanto tecnología y herramienta de trabajo para ponerla al servicio de los movimientos sociales como "dispositivo estratégico para una relación nueva, creativa y participativa con el pasado, el presente y el futuro" (Chagas, 2007a: 14) para la construcción de soberanía, solidaridad y justicia social.

En el marco de brindar a los museos como herramientas a la comunidad, Chagas (2007a) dice que los museos pueden usarse con dos fines: a) Accionados por los movimientos sociales como mediadores entre tiempos distintos, grupos sociales y experiencias distintas, los museos se 
presentan "como prácticas comprometidas con la vida, con el presente, con lo cotidiano, con la transformación social y son ellos mismos entes y antros en movimiento" a los que denomina como "museos biófilos" que pueden servir "para la generosidad y para la libertad"; b) o también puede usarse para "tiranizar la vida, la historia, y la cultura; para aprisionar el pasado, los seres y las cosas en el pasado y en la muerte" en los que denomina como "museos necrófilos" (Chagas, 2007a: 15). De aquí que resuene tan potente esta afirmación que fue marca en el Encuentro de MINON de Córdoba: "La museología que no sirve para la vida no sirve para nada".

Es importante señalar también que esto no queda solo en posicionamientos teóricos, o en experiencias aisladas, sino que por el contrario en Brasil, durante el mandato de Luiz Inácio Lula da Silva como presidente de la República Federativa de Brasil, estos horizontes de la museología social se transformaron en política pública mediante la creación del Instituto Brasileiro de Museus (IBRAM) ${ }^{195}$ como instrumento autárquico creado por ley ${ }^{196}$ vinculado al Ministerio de Cultura.

Ese espacio se transformó, a partir del Programa Pontos de Memória em movimento en una plataforma de consolidación de la formación de una serie de espacios museales que se inscriben claramente en las perspectivas propuestas por Mario Chagas, quien se desempeñó en dicho organismo. Por citar algunas referencias destacadas se pueden nombrar los siguientes espacios museales: Museu de Favela, Ponto de Memória Museu do Beiru, Ponto de Memória Museu Cultura Periférica - Jacintinho, Ponto de Memoria Estrutural, Ponto de Memória Terra Firme, Ponto de Memória Museu Mangue de Coque, Museu Lomba do Pinheiro, Ponto de Memória Museu de Periferia - Sítio Cercado, Ponto de Memória Brasilândia, Ponto de Memoria Museu do Taquaril, Ponto de Memória Grande São Pedro, Ponto de Memória Grande Bom Jardim ${ }^{197}$. Todos estos espacios construidos en barrios populares y con la participación y gestión de organizaciones sociales y políticas barriales, motivados en general para dar cuenta de sus problemáticas urgentes, son ejemplos de esta búsqueda por deconstruir los modos de producción museal, y por reconocer en dichos espacios sociales su capacidad patrimonial, su vitalidad y su potencia política.

Como dice Mario Chagas, la "gota de sangre" implica reconocer "el poder antropofágico del museo, su agresividad y su gesto de violencia con relación al pasado", a la vez que "el mayor desafío sea reconocer que esas instituciones crean y acogen lo humano, y por eso mismo, pueden ser devoradas. Devorar y resignificar, he aquí un desafío para las nuevas generaciones" (Chagas, 2007a: 19).

Siguiendo con la perspectiva de Chagas, desde esa mirada compleja los museos todavía son:

195 http://www.museus.gov.br

196 http://www.planalto.gov.br/ccivil 03/ ato2007-2010/2009/Lei/L11906.htm

197 Para conocer sobre estos espacios museales, recomiendo leer la tesis de doctorado de Marcelle Pereira, "Museologia Decolonial: os pontos de memória e a insurgencia do fazer museal" aprobada en 2018 para la obtención del título Doutor em Museologia en el Doctorado en museología de la Universidade Lusófona de Humanidades e Tecnologias, de Lisboa, Potugal. 
cantos que pueden disolver el presente en el pasado y también hacerlo desabrochar en el futuro; antros ambiguos que pueden servir indistintamente a dos o más señores; campos que tanto pueden ser cultivados para atender a intereses personalistas como para favorecer el desarrollo social de poblaciones locales; espacios que pueden ser celdas solitarias como sitios abiertos e iluminados por el sol; casas habitadas, al mismo tiempo, por los dioses de la creación, de la conservación y del cambio (Chagas, 2007b: 28).

Por todo esto, es necesario acercarse a intervenir en los museos sin ingenuidad, y sobre todo con el cuidado de no caer en la arrogancia de saberlo todo. Uno de nuestros desafíos es aceptarlos en su complejidad, como campos de tensión entre el cambio y la permanencia, entre la movilidad y la inamovilidad, entre lo fijo y lo volátil, entre la diferencia y la identidad, entre el pasado y el futuro, entre la memoria y el olvido, entre el poder y la resistencia. Y por ello, el museo debe llegar a los sujetos sociales desde todas las dimensiones posibles. Debe interpelarlos tanto desde lo técnico, desde el dato, como de lo sensitivo. Debe promover el goce estético, a la vez que debe motivar al movimiento, a la reflexión, a la creación, a la explosión de sus capacidades y a la generación de preguntas críticas que provoquen a mirar alrededor y desnaturalizar y deconstruir todo lo que parece dado, para hacer vibrar todo lo que parece fosilizado o inmovilizado. 


\section{Capítulo 6}

\section{DESARROLLO DE LA RECUPERACIÓN DE SENTIDOS Y EXPERIENCIAS A PARTIR DE LAS ENTREVISTAS}

En este capítulo presentaré una serie de reflexiones que fueron construidas a partir de analizar los relatos de las personas entrevistadas, recuperando a partir de los sentidos presentes en los relatos de sus biografías, sus prácticas, perspectivas y propuestas. Vale la pena aclarar que no se busca una mirada sobre la museografía de los museos visitados, ni sobre dichas instituciones, sino que se busca construir una serie de reflexiones transversales en las que se articulan miradas desde la comunicación/educación y la museología social a partir de entramar los diálogos con los entrevistados y entrevistas y las genealogías conceptuales propuestas en los capítulos anteriores. Con el objetivo de aportar a una sistematización, aún en necesaria construcción dado que este trabajo es solo un aporte a ese mapa, que permita empezar a caracterizar y hacer visibles las particularidades que la museología social va adquiriendo en nuestro país a partir de las prácticas de los sujetos que la practican de algún modo en sus espacios de intervención cotidiana. Prácticas que no son homogéneas, y que este trabajo no pretende alisar, ni desconocer sus matices, sino que se trata de un intento por producir una plataforma que de visibilidad a la red de sujetos a partir de lo que expresaron en las entrevistas realizadas. Por tanto se trata como antes decía de una construcción parcial, que omite sin mala fe sino por cuestiones operativas, a muchos actores, espacios y prácticas, y que por las posibilidades del trabajo de investigación también tiene logros parciales considerando la magnitud y complejidad de esta trama que se extiende por el territorio nacional, y aún más allá de las fronteras en diversas latitudes de nuestro continente.

También es importante aclarar que además del proceso reflexivo que de por sí implica el momento performático de realizar la entrevista, con cada una de las personas luego realicé un proceso de validación de datos, a partir de compartir las transcripciones de los audios y las notas de entrevista. 


\section{Matriz de interpretación de los sentidos producidos en las entrevistas}

Para la producción de estas reflexiones construí una matriz de interpretación en la que fui ordenando los sentidos propiciados por las entrevistas, los que se fueron organizando por dimensiones de análisis (algunas surgidas desde las matrices teóricas de los rastreos bibliográficos, y otras surgidas de lo que las personas entrevistadas proponen en sus relatos). Estas matrices se desarrollaron en dos niveles de configuración de esa información en los que además se fueron recuperando categorías, que fueron luego las organizadoras de las reflexiones que siguen.

El primer registro de organización fue generando 11 núcleos a modo de dimensiones. En una segunda ronda de lectura, un segundo orden de configuración de los datos construidos en el que fui sumando categorías para esas dimensiones, a la vez que en esa lectura más densificada por la aparición de las categorías permitió comenzar a constituir cierta jerarquización entre éstas, y estableciendo vínculos que se pusieron en relación en función de algunas de esas dimensiones que resultan nodales para otras. Estas relaciones no son excluyentes, es decir no se busca una organización por conjuntos, o cuadrículas, sino más bien pensándolos como una trama, por ello este trabajo de configuración lo fui realizando de manera textual, a modo de hojas sueltas que fui enredadando. Se trata de un esquema que (a falta de herramientas a mano) no puedo representar en 2 dimensiones, el modo adecuado de mostrar esta red de relaciones es un entramado en dimensiones, subdimensiones, categorías o subcategorías, que pueden estar conectadas unas con otras más allá de los niveles y jerarquías, o entre categorías y dimensiones. Por lo que para poder visualizarlo de una manera más parecida a como lo imagino, requeriría de un gráfico en 3 dimensiones, lo que está fuera de mis posibilidades técnicas actuales. La forma de imaginarlo también se podría parecer un poco a los mapas celestes, o al modo en que diversas poblaciones han construido las cartografías de constelaciones estelares. Es decir, una red de puntos de diversos tamaños y luminosidades, que se encuentran dispersos en el universo, muy distantes entre sí, pero que la imaginación del observador u observadora desde un punto en la Tierra le permite construir una relación, una serie de líneas imaginarias que las une, de conexiones que configuran un sentido a partir de esas interconexiones que en realidad no existen de por sí, y que incluso podrían ser configuradas de modo totalmente distinto por otro observador u observadora, desde otro punto de vista, o incluso compartiendo el mismo mirador.

Con este criterio de organización de los datos desarrollé un nuevo ordenamiento en el que los nodos de esa red se fueron nucleando sumando densidad en función de la mayor interrelación con otras dimensiones y categorías. Será a partir de este último entramado que se desarrollará la descripción analítica durante el capítulo.

En paralelo a esta herramienta analítica también fui construyendo una línea histórica a partir de las referencias temporales que fueron apareciendo en las entrevistas, como otro modo de romper 
la fragmentación de los relatos y tratar de encontrar ejes de sincronía que de otro modo tal vez se me harían invisibles.

Como última aclaración, para simplificar las referencias y evitar reiteraciones, las citas textuales que corresponden a los entrevistados y entrevistadas serán referidos durante este capítulo mediante un sistema de siglas para reconocer a cada de una de las personas y sus trayectorias profesionales en el campo, tanto desde los espacios de intervención actuales como en los que se desempeñaron en el pasado, según el siguiente esquema:

\begin{tabular}{|c|c|}
\hline AB - Analía Bernardi & Museo-Taller Ferrowhite Ing. White - Bahía \\
\hline & Blanca - Pcia. de Buenos Aires \\
\hline LC1 - Leonardo Casado (1ra visita) & Dirección de Museos Municipales de \\
\hline & Berazategui - Pcia. de Buenos Aires \\
\hline OB - Olga Bartolomé & Museo Jesuítico Nacional Estancia Jesús \\
\hline & María / Museo Escolar Escuela Normal \\
\hline & Agustín Garzón Agulla / Museo Nacional \\
\hline & Estancia Jesuítica de Alta Gracia y Casa del \\
\hline & Virrey Liniers - Pcia. de Córdoba \\
\hline JR - Julieta Rausch & Museo del Puerto - Ing. White - Bahía \\
\hline & Blanca - Pcia. de Buenos Aires \\
\hline VS - Verónica Stáffora & Museo Antropológico Juan E. Ambrosetti / \\
\hline & Museo Histórico Nacional - Ciudad \\
\hline & Autónoma de Buenos Aires \\
\hline AC - Anabelle Castaño & Museo Antropológico Juan E. Ambrosetti - \\
\hline & Ciudad Autónoma de Buenos Aires \\
\hline CM - Carlos Molina & Museo Antropológico Juan E. Ambrosetti - \\
\hline & Ciudad Autónoma de Buenos Aires \\
\hline VJ - Verónica Jeria & Museo Antropológico Juan E. Ambrosetti / \\
\hline & Museo Histórico Nacional - Ciudad \\
\hline & Autónoma de Buenos Aires \\
\hline SM - Susana Maresca & Museo Malvinas e Islas del Atlántico Sur - \\
\hline & Ciudad Autónoma de Buenos Aires / Museo \\
\hline & del Juguete - San Isidro - Pcia. De Buenos \\
\hline & Aires \\
\hline LC2 - Leonardo Casado (2da visita) & Dirección de Museos Municipales de \\
\hline & Berazategui - Pcia. de Buenos Aires \\
\hline
\end{tabular}




\section{La configuración de los sentidos del proyecto en el marco de un museo}

En el desarrollo de este entramado analítico lo primero que es necesario aclarar en función de atender a la búsqueda de especificidad y complejidad, es que si bien este trabajo busca sistematizar experiencias en el campo de la museología social desde una mirada de comunicación/educación, lo analizado corresponde al espectro del universo de los sujetos entrevistados, y a la vez tener en cuenta que existen particularidades, peculiaridades y matices entre ellos, en términos de no provocar una homogeinización en la lectura de las construcciones y experiencias de las personas y los espacios en los que intervienen o han intervenido.

También presento la preocupación de evitar la construcción de un sentido políticamente correcto, que vacíe la potencia política de las intervenciones, así como tampoco se busca establecer un marco moral, una especie de imperativo o de "deber ser". Dado que estas categorías desprovistas de sus contextos y de sus horizontes políticos podrían ser vaciadas del sentido que tienen en estas experiencias. Esta precaución se hace presente porque pueden evidenciarse algunas de estas miradas también en el discurso de sectores conservadores, liberales, empresariales, o del marketing, pero donde la finalidad pasa a ser totalmente otra, y de algún modo actúan en sentido opuesto a lo que aquí se propone y se busca. Convirtiendo a estos conceptos y categorías en eufemismos que terminan por clausurar sentidos, cristalizar estructuras de poder, y por supuesto, aportando a lo que las empresas tienen como fin último, obtener ganancias.

\section{Algunos datos de contexto}

La totalidad de las personas entrevistadas se desempeña y se ha desempeñado en espacios museales que se encuentran en el ámbito de lo público desde distintas esferas, ya sea desde lo municipal, lo provincial o lo nacional, y dentro de lo nacional en uno de los casos, un museo universitario. Al tratarse de espacios públicos hay una serie de recurrencias que podemos entender en el marco de las coyunturas históricas, políticas y sociales, las que serán desarrolladas específicamente más adelante en este capítulo.

Por el lado de las particularidades se podrían caracterizar dos grandes grupos de espacios en función de su historia institucional: aquellos espacios que fueron creados más recientemente, en los que las perspectivas propuestas forman parte de sus sentidos fundantes, dentro de lo que se podrían caracterizar como museos comunitarios ; y por otro lado aquellas instituciones que cuentan con más históricas, de corte más tradicional, que por su larga trayectoria han pasado por distintos tipos de matriz de gestión, y en los que la museología social se ha ido introduciendo lentamente, en procesos emergentes impulsados por algunos sujetos. Más allá de eso, en todos los casos, en los más recientes y en los de más larga trayectoria, la museología social tiene distintos sentidos y se ha 
practicado además en función de los marcos de posibilidad. Por eso mismo este trabajo se propone recuperar esas experiencias a modo de aporte de sistematización, para establecer algunas caracterizaciones que les den visibilidad en un marco común.

También es importante destacar que es justamente el entramado que estos sujetos van produciendo, las redes que van trazando entre sí, las que de algún modo han ido potenciando los espacios de ampliación de la perspectiva y potenciando las estrategias de resistencia en aquellos donde es un emergente instituyente. Esto también será desarrollado en profundidad más adelante, dado que se trata de un importante aspecto formativo y uno de los principales elementos de articulación de la comunidad política que conforman.

\section{Epistemología crítica y la pregunta por el sentido}

Si hay algo que en el relato de las personas entrevistadas se presenta como un rasgo común es que todas y todos presentan discursos que se encuadran en perspectivas críticas. Cada cual desde su formación disciplinar (donde aparece cada vez mayor diversidad incluyendo obviamente a museólogos/as y conservadores/as, pero también educadores/as, pedagogos/as, historiadores/as, antropólogos/as, arqueólogos/as, narradores/as orales, comunicadores/as, poetas, clowns, etc.) y por la propia formación en el desempeño profesional, apelan de manera permanente a la pregunta por el posicionamiento, y en ejercicio crítico hacia la museología que denominan como "tradicional"

LC1: ... a veces sienten que hacemos cosas más innovadoras, o diferentes a un museo tradicional.

JR: ...ha sido muy creativo en los proyectos, siempre muy corridos de una museología más tradicional.

VS: la problematización de ciertos contenidos en términos de subversiones más tradicionales, contenidos antropológicos, digamos, una cierta puesta a algún tipo de exhibiciones más con una cierta estética,(...) ...pensar que sea un museo que se posicione con respecto a temas que son controversiales o complejos, o que están en entramados más duros en la sociedad.

y desde allí a cierta vocación de diálogo que les permite poner en duda y en tensión tanto la propia práctica como la del espacio en el que se encuentran, para articular con los saberes de los sujetos de las comunidades.

JR: La mayoría somos con formaciones profesionales, tenemos otros saberes y otras disciplinas diferentes que permanentemente esos saberes que tenemos articulan con los saberes de los vecinos de la comunidad, el saber del pescador, del ferroviario, de la cocinera, del joven, de su experiencia cotidiana, digamos, los saberes o las disciplinas en general se entre cruzan con la otra pata que es necesaria que es la comunidad.

A la vez que pretenden interpelar con esa mirada crítica a quienes se vinculan con el museo, y para ello un aspecto central es también la participación de otros sujetos. En los espacios de origen 
más comunitario, como son los casos del Museo del Puerto y Ferrowhite (ambos de la localidad de Ingeniero White, en el partido de Bahía Blanca) como de los museos de la Municipalidad de Berazategui, las propias demandas de los vecinos a las conducciones comunales, como la relación sobre todo con las personas mayores resultan de importancia para establecer tanto el sustento para la instalación del espacio, como para generar los primeros relatos y la construcción de las primeras memorias, lo que de algún modo propone una relación fundante con esos sujetos de la comunidad

JR: (...) se arma una comisión de vecinos por el festejo de los 100 años [de la comunidad], esa comisión de vecinos, en 1985 hace un pedido, una serie de pedidos, como un petitorio a la municipalidad (...) entre ellos estaba la creación de un museo en la localidad, porque hasta esa época no había museo (...) en esa lógica de recuperación democrática del país, y con esto de salir a la calle y pensar los proyectos de manera colectiva, de juntarse con otros, la subsecretaria de ese momento, toma esta demanda de los vecinos y empieza a pensar un posible museo, pero con estos vecinos. No se podía crear un museo sin esta demanda inicial que surge de la comunidad.

AB: (...) sumado a la necesidad de constituir un espacio de conservación, que hizo que se recuperara el espacio físico de ese lugar que había sido recientemente desguazado y transferido a la Municipalidad (...) por otra parte existían desde hacía algún tiempo una colección de objetos ferroviarios sobre todo que los propios trabajadores se habían ocupado de juntar en el proceso de privatizaciones, a la espera de un museo que nunca podían concretar. Y cuando estas dos cosas se combinaron terminó apareciendo Ferrowhite. Ahí hay una necesidad muy fuerte, este patrimonio que las personas habían ido juntando, bueno, todavía tenia algo que decir, todavía tenía mucho por contar para ellos. Y entonces en esta relación fue que un poco surgió el para qué de este museo...

LC1: la génesis de este museo tuvo una serie de socios que eran las personas mayores, que fueron como el germen, se construyó mucha mistica, socios de estar y ayudar...

Tal vez por esta relación inicial también es que la recuperación de sus memorias se vuelve un objetivo central en el trabajo de esos museos

$A B$ : ...otra forma de hacer historia, y hacer museo desde otro lugar, esto apelando a la voz de los vecinos, de los trabajadores, resignificando esto de los saberes... (...) ya había una necesidad y una acción que había comenzado antes de la generación del museo, como que la demanda estaba antes de que existiera Ferrowhite... y en parte es como justamente escuchando ese reclamo o esa necesidad, es que bueno, hay un sentido por lo que estar reconstruyendo esa memoria de trabajo ferro-portuario.

JR: fue desde la propia comunidad la demanda, la necesidad de tener un museo, y con esto, la necesidad de recuperar las memorias de estos padres y abuelos...

En la mayoría de los casos se remarca esta necesidad de vínculo con la comunidad, y si bien estos espacios toman como un referente importante a los museos comunitarios de México, establecen a su 
vez algunos matices, aunque conservando la necesidad de articulación permanente con sus comunidades.

JR: ...hay algo que diferencia a los museos comunitarios de México como por ejemplo el de Oaxaca, en que el Museo del Puerto es un museo estatal igual, es municipal, hay un equipo de trabajo que somos trabajadores municipales, es decir que no es gestionado y llevado adelante por la propia comunidad, por los vecinos, si bien siempre articulamos y nuestro trabajo se basa en eso, en tener lazos y vinculos estrechos con la comunidad, y generar espacios de participación permanente y eso se de efectivamente, no es una gestión, no es una autogestión de la propia comunidad, sino que está primero sostenido por el estado y principalmente por sus trabajadores.

En los museos con mayor historia e institucionalidad, como por ejemplo es el Museo Etnográfico Juan E. Ambrosetti dependiente de la UBA, o el circuito de los Museos de las Estancias Jesuíticas de Córdoba, donde se viene trabajando en esa articulación y donde se desarrolla un punto de contacto interesante a partir de los procesos de consulta, la participación también en términos del ejercicio de la pregunta, buscando la habilitación del otro

VS: hubo desde primeras consultas por ejemplo para ver si se hablaba de determinadas personas o no, hubo vinculación con las familias de algunas de las personas de las que hablábamos en la exhibición para... no solo para obtener documentación, sino para decirles, estamos pensando en esto... ¿están de acuerdo? Que no es menor para mí...

LC1: Cuando este museo cumplió 21 años, el aniversario no fue una exposición, sino que fue un taller de un tarde (...) invitamos a los visitantes a pensar el museo (...) fue un espacio genial, vinieron como 70 personas... se generó esta instancia de intercambio y de repensar el museo, de abrir el museo a grupos distintos que se han acercado. Y es interesante y hasta necesario.

o yendo a buscar a sujetos a los que se quiere involucrar de manera directa, tomando la iniciativa, saliendo del museo hacia los espacios de pertenencia de esos sujetos

SM: trabajar con jóvenes en sus propios espacios de pertenencia para que empezaran a poner en diálogo eso que venían a ver en el museo, cómo lo transformaban en conocimiento, y en patrimonio, para que estuviera en diálogo, sino siempre... uno dice que quiere que la gente participe y eso... ¿pero cómo uno le da voz a eso?

En este posicionamiento crítico hay una preocupación por explicitar el lugar desde el que se dicen las cosas, dar visibilidad al posicionamiento político, dando cuenta de la variabilidad que estos posicionamientos pueden tener en una institución como un museo, que atraviesa en el marco de coyunturas de gestión

JR: comunicar el posicionamiento del museo, (...) ...entendemos que el museo no es un museo como un ente, sino que son grupo de personas, con determinados posicionamientos políticos ideológicos, que también están en disputa, claramente, y que en este momento, en 
este presente, está llevando adelante la gestión de este museo, que después puede venir otra gente y hacer otra cosa. (...) todas estas acciones que te digo, reflejan el modo de trabajo, y el modo de pensar, del museo, o del modo de pensar del equipo del museo de este momento, (...) es muy importante siempre pensar desde dónde decimos lo que decimos, es como un ejercicio interno (...) lleva mucho trabajo interno de debate, de discusión, de pensar bien las palabras que usamos, los colores que utilizamos, las imágenes.

En esta explicitación aparece con recurrencia un desplazamiento con respecto a la "museología tradicional" que tiene que ver con correr el eje de atención desde los objetos patrimoniales hacia las personas, hacia los sujetos sociales de las comunidades.

VJ: ...pensaron un proyecto a largo plazo y que tenía que ver con trabajar sobre las personas, no sobre las colecciones.

LC1: ... otra cuestión central o que transversaliza es el cuidado de la escala humana en el medio de todo eso, buscando de cuidar, de humanizar, de hablar de cada cara del vecino, la vecina, hablar de lo cotidiano, no hablar de mega relatos, buscar el pasado tomándolo en el presente, qué pasa hoy en día, la proyección de futuro, pero todo pasando en la escala humana, nuestros museos son casas en las que vivieron personas, están en el entramado del conurbano, y territoriales donde son escalas de barrio,

También aparece una preocupación que tiene que ver con evitar con que se trate de una perspectiva impuesta, que la idea de trabajar con la comunidad surja desde un planteo situado de quienes trabajan en el museo y de construir la necesidad con la comunidad y no como un imperativo impuesto por la aplicación de un sistema externo, a modo de dogma

AB: empieza a plantarse como un nuevo dogma... pero donde hay una vocación del museo participativo, (...) que los museos tienen que tener relaciones con sus comunidades... y que se yo... capaz que no.. (...) si eso tiene que ver con una práctica puntual, con una trayectoria que habilita como a que esto suceda, porque tiene un por qué, una necesidad bien concreta, pero no forcemos todo a que se vuelva comunitario, porque sino se termina diluyendo la especificidad... como la teoría que reconoce esta trayectoria práctica pero no como algo que se vuelve dogmático, a partir de lo cual todos tienen que devenir tal cosa...

esta mirada también apunta claramente a la necesidad de producir un sentido al interior de los equipos de trabajo, donde tampoco son homogéneos, en el marco de sentidos en disputa. Sobre todo considerando la diversidad de miradas y propuestas que pueden existir en los museos de mayor historia y con mayores estructuras de personal, o con organizaciones por equipos y áreas, en donde especificar la direccionalidad e intencionalidad de las propuestas presentadas resulta aún más necesario,

OB: [hablando en relación a los procesos de toma de decisión] ... a las miradas teóricas y prácticas, por ejemplo qué implica la museología social podemos todos estar de acuerdo, pero luego la estamos pensando de maneras cabalmente diferentes. Y más en este contexto que todo va a estar como políticamente correcto usar el lenguaje inclusivo, trabajar con 
determinadas comunidades, pero bueno, para mi hace falta un trabajo de discusión, de análisis, de consenso...

son estas disputas las que permite justamente la oportunidad de construir, o al menos iniciar el camino de construcción de esos sentidos, o su actualización.

En esto obviamente hay un enorme abanico de posibilidades a considerar a partir de la diversidad de escalas que tienen los museos en que trabajan e intervienen los y las personas entrevistadas, desde aquellos en los que cinco o diez personas se ocupan de casi todos los aspectos que implica la gestión del museo, a los de mayor tamaño que son estructurados en áreas, no siempre en contacto, estructuras numerosas en cuanto a cantidad de personal, lo que hace casi imposible que se encuentren, si no es que se generan estrategias a tal efecto.

\section{$\underline{\text { Reconocimiento de conflictos y resistencias }}$}

Al tratarse de un posicionamiento que no es hegemónico, y que al igual que la mayoría de las perspectivas críticas no se encuentra difundido o reconocido en la totalidad de los espacios de formación, así como tampoco en los ámbitos de intervención. Por ello es frecuente que aparezcan resistencias o inhabilitaciones desde sectores de mayor poder sobre estas prácticas.

En este sentido, en el caso de los museos, suele tener mucha presencia el imaginario del museo en términos de lo que estos sujetos llaman el "museo tradicional", vinculado a la imagen hegemónica construida tanto desde los productos culturales como desde lo que es reconocido desde la educación más tradicional. Por ello en ocasiones ocurre que quienes acuden a estos museos experimentan choques de percepción entre expectativas de lo que para ellos o ellas "debe ser un museo" y lo que allí se practica

LC1: sí a veces se generan espacio de discusión "ah no... porque en otro museo... hacen esto..." (...) está el estigma, (...) pero muchas veces hemos metido en el medio, que eso sea abierto, y nosotros somos muy proclives a la pregunta y la repregunta y al "¿qué te pareció?", y que participen, que se acerquen, abrir canales, hemos hecho estrategias de participación y debate.

$O B:$ la gente se resiste, tiene sus motivos para resistirse, y está bueno que se resista, pero también está bueno escuchar esa resistencia y entenderla, si porque la gente es profundamente religiosa, si es porque siempre se hizo asi, si es porque tienen miedo, si es porque... o sea construir el sentido, de por qué... (...) no digo para que la gente lo acepte, sino para que vea que todo tiene un por qué, y no es la cuestión de este "par de locas" que se les ocurre tocar lo intocable.

En esos casos el conflicto, se transforma a partir del ejercicio de la pregunta, en oportunidad de diálogo, de intercambio para poder establecer discusiones sobre el sentido y explicitaciones de las perspectivas asumidas. A partir de asumir el conflicto como parte constitutiva de la tarea de trabajo 
con otros, se permiten transformar la resistencia en una oportunidad de interpelación del otro, en una intervención en el espacio público que genera oportunidades de trabajar con la diferencia en un marco de diálogo respetuoso, para la desnaturalización y comprensión de las posturas adoptadas por cada quien. En esa acción de intervención los sujetos muchas veces comprenden que tienen allí una oportunidad de ser parte, de poder aportar su mirada, y que esa mirada es escuchada y reconocida. Una interpelación formativa en términos educativos, a partir de la transformación de los modos de relación entre sujetos en un espacio social.

\section{La importancia del horizonte político de intervención}

Muchas de las posiciones y prácticas explicitadas en los apartados anteriores podrían ser aplicados o entendidos desde muchas perspectivas críticas, de muchas de las disciplinas que actualmente intervienen en los museos, el diferencial del aporte desde la museología social parece estar dado por el énfasis explícito puesto en la politicidad de esas prácticas, que tienen como principal objetivo provocar transformaciones concretas en la sociedad. Es decir que la museología no solo sea una intervención en el espacio concreto del museo sino también extenderla en el territorio más amplio que construye como institución a partir de las prácticas y relaciones sociales de sus trabajadores y trabajadoras.

\section{VS: ...llego a esas lecturas sobre museología social, pensando en estas vertientes más} latinoamericanas, llego después que a otras lecturas que venían más del lado de la educación en museos, que ya planteaban en paralelo algunas de esas cosas, tal vez sin un componente político tan explícito, tal vez... no se si... algo así digamos, no se si es exactamente eso, porque también tenían un componente político, pero me parece que hay algo del tipo de transformación que suponen, transformación social, y la incidencia de los museos en eso que plantea la museología social (...) ... hay mucha gente de educación en museos que habla de museos más abiertos, de museos participativos, de museos foros, en los que se incluyan las minorías, museos en donde hay que repensar las tomas de decisiones, la representación del otro, el relato, un montón de cosas. Yo no lo tengo tan claro, pero me parece que hay en la museología social, un planteo un poco más... que asume más fuerte la figura del compromiso político con esa transformación y tal vez por el modo en que lo plantean, que lo escriben, que lo relatan, más... hay un poner el cuerpo distinto, no se si tiene que ver con la forma de escritura, no lo tengo tan claro, pero yo siempre tengo esta sensación de que no es lo mismo cuando se habla de participación en un espacio o el otro, que no es lo mismo cuando se habla de inclusión en un espacio que el otro, que no es lo mismo cuando se dice política en un espacio o el otro...

y dentro de esa politicidad se plantea una cuestión central que viene como referencia desde los planteos de la Mesa Redonda de Santiago, que tiene que ver con la función social de los museos 
VJ: muchos de nosotros y nosotras, estamos pensando al museo, y más como museo universitario, con una función social. Como la prioridad en la función social, en el abordaje de problemas sociales (...) en la discusión y representación de procesos sociales, y bueno, como profundizar en eso, también con las lecturas de qué está pasando en el entorno, en los problemas que actualmente aquejan a nuestra sociedad.

Dentro de esas intervenciones políticas una de las más reconocidas en la mayoría de las entrevistas tiene que ver con repensar la historia de manera crítica

AB: ...para mí hay una cuestión de reflexión crítica de lo que tiene que ver con la historia y en vinculación, en articulación con el presente, para poder pensar nuestro presente, que ahí yo le veo un rol o un sentido político al museo.

Y del mismo modo aportar miradas críticas sobre las disciplinas científicas y su rol en la constitución de los problemas, o aportando reflexiones desde esas disciplinas

VS: ...intentamos dar a conocer posicionamientos más teóricos o científicos que para nosotros tienen incidencia en cuestiones sociales y politicas(...) como se piensa hoy ese concepto, no es algo aislado en lo académico sino que tiene que ver...con ver la fuerza que tuvo una concepción científico política anterior que se metió en todos lados (...) plantear ciertas preguntas y discusiones en el marco de las actividades del museo

para todo ello lo que se plantea es un trabajo con las comunidades que conforman sus territorios

LC1: lo que habría que lograr es una inserción mayor de cada museo en su territorio inmediato. (...) fortalecer más ese trabajo territorial, en pos de la participación de esa comunidad que está alrededor, cuidando además esas complejidades, obviamente sin descuidar la conservación, pero que todas las áreas del museo estén concomitadas para lograr esa inserción en el territorio

Otro de las claves de su posicionamiento político tiene que ver con aportar con la emancipación de esos sectores que reconocen como "populares", "subalternos", los "no legitimados"

AB: a un trabajo con lo que serían "otros sectores" para la historiografía, los sectores populares, los sectores subalternos, empezar a dialogar con otras voces que no son las que están legitimadas en los museos pero que empiezan a construir otra historia y tienen otras cosas para decir...

del mismo modo es interesante cómo en uno de los casos se plantea la idea de ser "caja de resonancia", proponiendo al museo como un espacio público que articule las voces de esos colectivos para que puedan ser escuchados por otras comunidades a las que tal vez no tendrían alcance de otro modo

VS: [venimos pensando] cómo nos hacemos más permeables a las voces de los representantes de pueblos originarios, y qué lugar podemos dar para que esas voces se escuchen acá, teniendo claro, que no vamos a dirimir conflictos internos entre ellos, ...sino pensando en que por ahí (...) poder pensarnos desde un lugar de caja de resonancia, pensar que nosotros llegamos a otra gente a la que ese mismo dirigente en otros espacios no llega 
en esta misma operación se genera otra operación interesante, que tiene que ver con la legitimación que le puede aportar el museo, como institución reconocida socialmente, si estos sujetos tienen cabida y pueden expresarse allí. Aún en el reconocimiento de los sujetos y en un trabajo que busca la habilitación de los sectores subalternos, en el aporte de herramientas para la recuperación de sus memorias, el museo debe reconocer que cuenta que una asimetría de poder, desde la que de todos modos puede tomar la decisión de escuchar y aprender de los otros

AB: y ahí tenemos un sentido político de estar habilitando y estar queriendo aprender y entrar en relación con los sectores que socialmente están subordinados o dominados,

y yendo un paso más allá, incluso habilitar a la posibilidad de que los representantes de esos colectivos no solo puedan hablar y ser consultados, sino también puedan tener injerencia en las decisiones que se toman en la institución.

OB: hacia la construcción colectiva de propuestas con otros, y entre nosotros, (...) yo sé que no se puede cambiar el mundo, pero si se puede generar estos espacios de prácticas más horizontales y de... que se yo... de poder trabajar entre nosotros y me suena esto de nosotros y los otros como una cosa así de división, pero en realidad para mí primero hay que construir un nosotros interno y también ampliarlo hacia la comunidad local (...) ...estoy convencida además porque lo he vivido, en el proyecto con las comunidades rurales en Alta Gracia, que se pueden generar otro tipo de prácticas, más horizontales y no sea solo el conocimiento que el museo arma, o comunica, sino el conocimiento que se construye con el otro. [En la muestra de objetos de Arroyo Leyes] se dispusieron los objetos como la comunidad afro pidió y forma un camino hacia el altar, está en el centro de los objetos, todos en vitrinas, en el medio de la iglesia y les cruzaron líneas rojas y negras, y nos explicaron que significa Exu que es el Dios que abre caminos y quedó como abriendo camino hacia el altar, para mí eso fue como recontra simbólico, no fue la muestra del museo solo sino que en el museo se pudo proponer un Dios en otros Dioses. Son pequeñas cositas (...) que te muestran que podemos construir un conocimiento con otros.

Todos estos posicionamientos se vuelven aún más importantes y trascendentes si además pensamos que se están produciendo desde espacios públicos que son gestionados por diversas agencias del Estado. Y en tal caso el posicionamiento, que si bien sigue siendo una decisión, ya no es un favor, no es solamente un gesto, sino que se trata de una obligación del rol público por la promoción y profundización del acceso de los sujetos a sus derechos.

\section{Deconstrucción decolonial del museo}

En los relatos de las personas entrevistadas aparece con recurrencia la idea de que los museos son instituciones coloniales (de Varine, 1979), de cómo se trata de un dispositivo ideológico que surgió con un criterio clasificatorio de la realidad 
CM: ....un espacio ideológico de construcción de identidad, como la mirada más crítica respecto del museo, ahi arrancamos la visita, sobre todo con la idea de lo clasificatorio, en términos geográficos, la idea de pensarlo en términos jerárquicos, y de lo exótico...

Otro aspecto dentro del posicionamiento político crítico que resulta central y que a al vez es una recurrencia en los sentidos de las entrevistas realizadas tiene que ver con el énfasis en la mirada situada,en el marco de una disputa política más grande

SM: otro rol político es... una de las grandes disputas que hay acá es la de pensar nuestra historia (...), desde una mirada latinoamericana y no desde una mirada eurocentrista (...) empezar a pensar, aunque no sea la historia, aunque sea el presente en tensión... y también qué significaba para América Latina esta causa colectiva,

$A B$ : ...siento que hay una necesidad de empezar una producción o una reflexión más desde acá, y ver cuáles son las características de "ese acá", que no se si capaz que Latinoamérica nos queda demasiado grande, pero si eso... y me parece que... lo he notado en estos encuentros en los que hemos participado, que escuchando a los que vienen de Europa o Estados Unidos, que todavía sigue estando eso de que cuando vienen acá vienen a darnos cátedra de lo que hay que hacer, y que sin embargo con que acá eso ya se está haciendo, o salen preguntas que no son nada nuevas, o a veces es que ya tenemos nuestras propias respuestas, y entonces hay que empezar una reflexión y una teorización un poco más sistemática...

allí hay dos cuestiones, por un lado, pensar la historia desde nuestro posicionamiento situado, pero a la vez también entender que formamos parte de una "causa colectiva" que nos excede y en la que estamos interpelados a sentirnos incluidos. Pero para eso a la vez existe la necesidad de generar un sentido, de proponer discusiones para establecer los criterios de esas propuestas.

También en poder reconocer la operación que los modelos hegemónicos de museos (sobre todo los de ciencias naturales, o los antropológicos) que se construyen a partir de exhibiciones en las que se expone desde una mirada eurocéntrica el exotismo de las culturas no eurocéntricas. En este sentido las exhibiciones de esos museos conforman como espacios de representación, y como esas representaciones generan y sustentan relatos de saberes, imaginarios, es decir ideologías

CM:...un espacio al que se puede trabajar, y que tiene sus particularidades, que parte de la idea de cómo los museos se conformaron, en esta mirada de exhibir al otro, estos no son ni los Yámanas, ni los Selk'Nam, ni los misioneros, es el diseño que un curador y un museólogo hicieron para pensar qué contar respecto de estas poblaciones en este contexto, pero no son esa realidad.

A partir de pensar las muestras como puesta en escena, como construcción de relato, también se empieza a deconstruir la operación se constitución de los objetos patrimoniales y cómo en la práctica de exhibición se da un pasaje de un objeto de uso a un objeto simbólico digno de ser admirado y 
conservado. A la vez que se lo presenta alienado, en un espacio que está totalmente descontextualizado

CM: ...en la realidad nunca los objetos están así, es interesante como cambia el objeto desde por poner un ejemplo, tenés un raspador, que acá está detrás de un acrilico que no se puede tocar, y está ahí con condiciones de preservación y demás cuando era un objeto que se usaba para limpiar el cuero, entonces simbólicamente el objeto tiene otro lugar social, por qué de repente acá es un objeto para ser observado, cuando en su vida cotidiana era un objeto para ser usado, y ni hablar, como se podía reponer, y si bien exigía su trabajo y su esfuerzo armarlo y tenerlo como herramienta, estaba pensado para ser usado, en cambio este objeto no se puede tocar. Ahí hay una concepción de lo que significa el patrimonio también, desde donde se lo piensa, y para pensarlo críticamente.

Teniendo en cuenta que ese "digno de ser mostrado" que le daba sentido al patrimonio justamente tenía que ver con un criterio desde el exotismo, que implicaba colocar a las culturas no europeas por detrás, en un cierto retraso cultural, en términos de la mirada evolucionista eurocéntrica moderna.

\section{Deconstrucción decolonial del patrimonio}

Desde mismo criterio instituciones como el Museo antropológico Juan Ambrosetti, vienen desarrollando una serie de acciones de largo plazo como el proyecto por el que posible acceder al depósito del museo, el que se ha conformado como otro espacio visitable, bajo ciertas pautas de cuidado, pero que apuntan a dar una mayor apertura del patrimonio, para ponerlo en relación con las comunidades, haciéndolos de algún modo más disponibles.

A partir de esa apertura, en una de las ocasiones el museo se vio interpelado a realizar acciones de deconstrucción que los enfrentó a diversos desafíos: dos docentes mapuches descubren que en el museo hay dos rehue, tallas de madera de aproximadamente dos metros de alto, que en términos del museo son objetos de conservación, pero que para la comunidad mapuche se trata de sujetos sagrados,

VS: ellos hacen un pedido al museo de hacer estas ceremonias a partir de verlos y que les genera una cosa de mucha incomodidad, angustia, dolor entonces, frente a eso, ¿qué podemos hacer? A la gente de conservación y de etnografía, les toca una parte, (...) esa vez que llovía se planteó hacer la ceremonia afuera y que los rehues queden adentro, que no es lo ideal, pero la verdad que en términos de responsabilidad... otras veces que no llovió se hizo afuera, sin problema, y como pensando, por ejemplo, se pone comida, bebida, todo esto, cómo se usa esto... en vez de apoyarlo directamente en el pasto, se ponen superficies de apoyo... a mí me toca pensar en cómo se presenta eso a los visitantes, cómo... desde la mirada más estructurada, o más occidental, por ponerle un nombre, los rehues son esculturas, son objetos, para ellos son sujetos, entonces en la difusión hubo que ver cómo poner eso, como plantearlo. Ese tipo de cosas, son las cosas que yo estoy aprendiendo, y que me cuestan un 
montón... porque tienen que ver con repensar un montón de cuestiones... Asumir las historias que plantea como procesos históricos y en vinculación con procesos más amplios, no una mirada aislada o estática de estos grupos

A partir de la realización de la actividad ${ }^{198}$ solicitada por estos representantes del pueblo mapuche, quienes trabajan en el museo se ven interpelados e interpeladas a discutir su propia formación, su propia concepción del mundo. Algo que para la cultura desde la que trabajan era un objeto en conservación, es interpelado como un sujeto sagrado al que presentarle respetos y realizarle celebraciones. De repente algo que desde la mirada museológica colonial debía estar bien guardado para evitar su daño material, cambia de perspectiva a partir de este planteo en el que se pide la realización de acciones ceremoniales para mejorar la condición espiritual de los rehue. Según el texto en el que se invitaba a la actividad se trataba de una acción para "curar su sufrimiento"

Lucas Curapi y Elisa Tripailaf nos invitan a cumplir el ciclo iniciado el año pasado y realizar una segunda ceremonia en torno a los rehue. El encuentro permitirá ofrecerles aire y sol, curar su sufrimiento, encontrarnos para compartir alimentos, cantar, conversar, dar vida al museo y a quienes lo habitan ${ }^{199}$.

en el texto puede identificarse que el museo adopta un discurso institucional en el que pone a disposición la mirada de esos otros sin exotizarlo, sino respetando los términos que estos sujetos proponen.

Esta acción va en consonancia con todo otro movimiento de deconstrucción del patrimonio, en el que un claro referente es el Museo de Ciencias Naturales de la Universidad Nacional de La Plata, que desde hace tiempo viene trabajando con representantes de comunidades indígenas para la restitución de restos humanos que forman parte de los bienes del museo ${ }^{200}$. En una dirección similar el museo Ambrosetti, si bien aún no ha avanzado en acciones de restitución de los restos humanos que poseen, sí han construido un protocolo para la no exhibición que existe desde aproximadamente 20 años

VS: ...posicionamientos grandes que ha tenido este museo hace yo calculo unos 20 años, se planteó, la no exhibición de restos humanos, cuando todavía no había ni una ley al respecto. Sigue habiendo restos humanos, todavía no se avanzó en términos de restituciones. (...) Hay un protocolo que se está armando (...) internamente para poder avanzar en eso, pero desde hace mucho se planteó la no objetivación de los sujetos, por decirlo de algún modo.

un movimiento de revisión que implica un cambio de matriz, deconstruyendo una mirada fundante de los museos con colecciones antropológicas y arqueológicas, los que basaron la constitución de sus

\footnotetext{
198 La actividad denominado Ngellipun se realizó en dos oportunidades en el museo. La actividad se realizó en el marco de una acción del Museo Antropológico Juan E Ambrosetti que se denominó como "Objetos/sujetos vivos: cultura, idioma y patrimonio mapuche" y contó con la participación de los dos docentes que realizaron el pedido: Lucas Curapil y Elisa Tripailaf de la Comunidad Meli Nom Mapu de Füshcüg Menuco (Gral. Roca - Río Negro).

199 Extraído del sitio del museo http://novedades.filo.uba.ar/novedades/taller-y-ceremonia-mapuche-en-el-museo-etnogr $\%$ C $3 \%$ A 1 fico

200 Sobre este tema desarrollé un apartado específico titulado "XXXX" en el capítulo anterior.
} 
colecciones a través de la acumulación de restos humanos, los que además muchas veces eran extraídos de sus sitios por los propios científicos del museo, y luego tratados en el museo con la misma distancia con la que se trataban otros objetos recuperados del mismo sitio arqueológico. De allí que estas acciones requieran de mucho debate, dado que se trata de planteos políticos y éticos que remueven los cimientos de las disciplinas implicadas, así como interpela a la revisión de las responsabilidades y posiciones que cada quien sostuvo respecto a ese tema.

La deconstrucción decolonial en las prácticas de las personas entrevistadas también refiere -a partir de esas primeras posturas críticas- en operacionalizar otro tipo de estrategias de vinculación entre el museo y las comunidades, entre los legitimados y los que en términos hegemónicos no lo están. En este sentido, así como se atiende a la solicitud que pueden hacer los representantes de pueblos indígenas, una de las prácticas recurrentes también apuntan a la búsqueda de cierta horizontalidad atendiendo a los saberes que puedan compartir los visitantes durante un recorrido guiado por alguna de las muestras del museo

VS: repensar, por ejemplo, yo puedo ser la voz autorizada, en una visita guiada, porque vengo leyendo mucho sobre un tema, pero leyendo mezcla, leyendo desde testimonios hasta producciones académicas, y en otros momentos, no la única voz autorizada, claramente, pero puedo tener algo para decir en determinados contextos, y hay otros en los que la verdad [no], en las visitas pasa que de repente, hay alguien que o vivió en determinada región, o pertenece a determinada tradición y viene leyendo ciertas cosas o... tuvo una determinada profesión que le hace saber un montón de cosas que te cuenta y para nosotros es importante que ese espacio esté.

Algo similar puede plantearse en cuanto a la actividad propuesta por el Museo Histórico de Berazategui cuando en la instancia de festejar su $21^{\circ}$ aniversario decidió realizar un taller con vecinos de la comunidad en el que invitó a discutir y repensar de manera colectiva el sentido del museo. Son este tipo de acciones las que propician una deconstrucción de los modos de gestión del museo, así como a desarticular y descentrar los saberes legitimados y los sujetos de saber legitimados para dar lugar a aquellos que han sido negados, silenciados, o escondidos, generalmente desde perspectivas eurocéntricas.

\section{Abriendo a las comunidades, nuevos roles, nuevas miradas}

Las alusiones a la palabra comunidad son mucho más que frecuentes en las entrevistas realizadas, y en esto a la vez hay que reconocer que se trata de un elemento que es fuertemente reconocido en el campo museológico desde ya hace mucho tiempo a partir de la consolidación de perspectivas como la nueva museología (años '60 en adelante), o la museología crítica (años '70), 
donde ya se hablaba de atender a la comunidad, con la consolidación en nuestro continente de la museología social (también a partir de fines de los '60), la idea de comunidad adquirió otros matices, entre ellos a partir de la instalación del rótulo de "museos comunitarios" que algunos espacios adquieren en asociación con el modo de acción instalado en México. En algunos casos esta denominación, es percibida como un rótulo del que reniegan por considerarlo externo a sus formulaciones

$A B$ : hemos recibido este rótulo como bastante frecuente de museo comunitario, que es una palabra que venía más de afuera, que no sé si nosotros mismos la hubiésemos propuesto desde el museo

esta necesidad de redefinición, implica también como ya fue expresado antes una mirada crítica, en la que la sociedad está compuesta por diversos colectivos en relación conflictiva, y donde hay a su vez una diversidad de polos de interpelación subjetiva, lo que es también reconocido por los y las especialistas con quienes dialogamos

$A B$ : ¿qué es la comunidad?... todo el tiempo se nos escapa esa pretensión universalizadora que diga la comunidad es ésto y englobe a un colectivo enorme... reconocemos más bien lo contrario, que en esa comunidad hay muchas ideas de comunidad, hay muchos actores, que esos actores a veces están incluso en disputa, o que hay negociaciones, que no es armónica esa comunidad, sino que es más bien conflictiva.. que ha ido cambiando históricamente, o que está tensionada por otros discursos que intentan definirla, sobre todo las del mundo de las empresas, aquí nos rodean, todo el tiempo están generando otra idea de de comunidad.... ese es un término más bien complejo o que hay que salir a definirlo todo el tiempo.

JR: el concepto de comunidad está bastante discutido, (...) como singular ya no la podemos definir, ya hablamos más de comunidades. Hoy en día también discutimos si el concepto no es tradicional y endogámico, yo prefiero hablar de colectivos, porque en realidad uno lo observa claramente en ingeniero White, no es una comunidad homogénea y armoniosa para nada, al contrario, hay grupos de poder incluso, hay otros sujetos o empresas, las empresas efectivamente piensan el concepto de comunidad y tienen otro criterio de comunidad de ingeniero White. Nosotros como museos estatales pensamos cierto territorio de un modo y a la vez y paralelamente y al lado nuestro están estas empresas multinacionales que tienen un departamento de recursos humanos que también piensa la comunidad y genera lazos, intenta generar lazos desde otros lugares que le convienen a ellos con ciertos sectores de la comunidad, entonces la comunidad de ingeniero White está hiper fragmentada, es bastante contradictoria.

en ambos testimonios además de la búsqueda de especificación, y del reconocimiento del conflicto del sentido que para el museo adquiere la comunidad, o las comunidades, aparece claramente una tensión muy fuerte con las empresas multinacionales. Las que al igual que los museos también interpelan a los sujetos de la población desde sus discursos que también construyen comunidad. Esto 
es central en este caso, como lo puede ser también en otras tantas pequeñas localidades del país, donde hubo un fuerte corrimiento subjetivo. Se trata de comunidades que giraban en torno a vivir y trabajar en un ámbito relacionado fuertemente con el puerto, con el ferrocarril y con empresas del Estado, que eran sus principales empleadores. Estas empresas proponían una especial forma de relación, reforzada con la organización sindical y organizaciones políticas y sociales de la comunidad que conformaban un conglomerados de sentidos sobre sus identidades. En contextos de achicamiento del Estado y de privatizaciones que pusieron a estas empresas en manos de capitales extranjeros con matrices de producción distinta, donde las relaciones con sus trabajadores, con los sindicatos y con las organizaciones políticas y sociales se transforma profundamente.

En este contexto la pregunta puede abrirse con matices también a otras muchas comunidades en términos de profundas transformaciones en las matrices estatales a nivel regional, así como de fuertes cambios en las interpelaciones a la participación social desde diversas agencias, incluyendo también a los medios masivos de comunicación, o las redes, que apelan a sentidos más individuales, por lo que resulta aún más necesario intentar generar algunas definiciones de carácter situado, para lograr identificar quiénes son los sujetos de esas comunidades con los que los museos se conectan y a las que intentan interpelar

AB: para mi más fácil cuando lo pienso en concreto y digo "¿cuál es la comunidad?", entonces, son los que vienen al museo, los que participan, los que colaboran, están los entrevistados que por ahí los ves una vez, o a veces establecés un vínculo y empiezan a venir al museo, están los amigos que están toooodos los fines de semana recibiéndote, están las amigas de la Asociación que colaboran con distintas actividades, está la comunidad de los ferroviarios, pero también están los vecinos de Ingeniero White, que se pueden no sectorizaro reagrupar en función del criterio que estemos mirando... dicho así creo que eso, que la comunidad hoy por hoy tiene que ver con estos amigos, ex trabajadores, colaboradores, que tienen una presencia muy fuerte, que para ellos el museo también es eso... una casa, un espacio eh... digamos de vida,

aparece alli una primer definición que tiene que ver con aquellos que logran establecer lazos sólidos con el museo, al punto de tomarlos como otra "casa", o como un "espacio de vida". En este sentido es interesante como aquellos sujetos que participan de manera activa, que logran sentirse reconocidos, provocan un sentido de vitalidad para el espacio. Sujetos con los que el museo puede sostener diálogos, en el profundo sentido del término, interacciones de ida y vuelta, intercambios de saberes, más o menos cotidianos

VS: hay visitantes que ya conocés, que saludas, porque vinieron muchas veces, que te cuentan, o te traen un artículo de diario, porque pensaron que te puede servir para una cosa que estás trabajando, eh... o que te critican, y te dicen "mirá esto que vos dijiste que era distinto"..., 
También hay otro tipo de vínculos, tal vez más esporádicos, generados en función de la visita al museo

AB: gente que efectivamente entra en vínculo ya sea porque va a visitarlo, y tenemos ese público en general, familias, escuelas, adultos mayores, un montón de grupos que 10 visitan, después entrar en relación con todo lo que es los entrevistados...

en estos casos, las claves para el anclaje con esas comunidades muchas veces no son tan claros y para ello es necesario poder identificar la diversidad de los contextos de los que vienen y las situaciones que los acercaron al espacio

VS: la primera lógica tiene que ver con pensar en qué contexto vienen esos visitantes al museo. (...) una visita, hay como una revisita, una vuelta que tienen más que ver con una decisión personal, gente que por ahí no viene en todo el año, y todos los agostos viene a Pacha Mama (...) Cambian mucho los grupos que se conforman en el museo, pero también mucho los grupos y las motivaciones para venir.

cuando el museo tiene un posicionamiento que es explícito en sus acciones, o en el caso de actividades planteadas en torno a un eje problemático específico, otra clave de identificación y de vinculación parece estar dado por la relación política, ya sea en clave de afinidad, de adhesión, de resistencia, o de rechazo

VS: cuestiones más de afinidad política, gente que está acompañando el reclamo de pueblos indigenas, entonces se acerca al museo buscando y reclamando un posicionamiento sobre eso, gente que se enoja por eso, eh... otra diferencia fuerte, es que cuando vos armás una actividad para esto que llamamos público general, no se conocen todos ente sí, entonces, son grupos que tienen una experiencia compartida en ese día, o en el tiempo que dure esa acción, no es que tienen un vínculo previo...

otro tipo de vínculo tiene más que ver con conformaciones grupales diversas, en las que no siempre habrá una motivación personal por llegar allí

VS: en la mayoría de los casos hay una decisión más personal de venir, también hay grupos, hay grupos de jubilados o adultos mayores, o turistas, o centros de jubilados, pensando más en grupo vienen más en esos contextos de centros de jubilados, o un grupo scout...

LC1: Tenemos visitantes aislados, del barrio, o de otras localidades de Berazategui y de otros partidos, también hay un programa de turismo cultural que depende de secretaría de cultura, que es nuestro órgano madre, donde traen contingentes

En todos los museos parecen coincidir en que el mayor números de visitantes que llegan a las exhibiciones tiene que ver con lo que se denomina como el "público escolar", grupos que llegan desde el contexto de pertenencia a alguna institución educativa de los diversos niveles, desde inicial a superior, en los cuales una de las características a tener en cuenta es que se da una superposición de 
reglas y pautas de relación que incluyen tanto a las del museo como las de la institución de la que provienen y sus contextos de evaluación, que de algún modo intervienen en el modo de interacción

LC1: el grueso que tenemos tiene que ver con escuelas

$A B$ : las escuelas que es otro universo, del cual a veces se desprende alguna relación y otras que no, quedan en una visita de alguna vez... pero eso también forma parte de la comunidad un poco más lejana

VS: un docente que elige que sus estudiantes vengan al museo, para trabajar determinados contenidos que en algunos casos tienen que ver especificamente con los contenidos de las exhibiciones, en otros no, y en otros, vienen porque les interesa que se acerquen a un museo como institución, entonces el contenido es el propio museo, más allá de las muestras (...) hay una demanda enorme y mucho mayor que la que el personal de ese área puede cubrir,

son estos casos donde se produce el más cotidiano de los intercambios de los museos con sus visitantes, y en esto tal vez puede reconocerse como persiste cierta noción didáctica de los museos.

\section{Ampliar el acceso de las comunidades}

Las entrevistadas y entrevistados dan cuenta en sus relatos de una preocupación que forma parte de los horizontes políticos de los museos en los que intervienen, que tienen que ver con propiciar la ampliación de los márgenes de intervención a partir de identificar las diversas barreras que se interponen entre las comunidades y el museo, para tratar de ampliar el acceso al espacio para aquellas comunidades que por alguna razón no lo están logrando

VS: hay una primera que tiene que ver con esta mirada Bourdieu de los museos como espacios más ligados a la élite y como un espacio de derechos para ciertos grupos, que esa para mí fue como la primera preocupación por los no habilitados (...) pensar en grupos... que por cuestiones sobre todo económicas y simbólicas, podían quedar afuera de estos espacios, entonces siempre las visitas estaban pensadas, desde que yo entré y por la gente que ya venía trabajando, desde este concepto más amplio de accesibilidad, de que el museo como institución tiene todo un imaginario y unas determinadas barreras que hacen que ciertas personas se sientan como pez en el agua y otras sientan que no pertenecen a ese lugar (...) los primeros inhabilitados van por el lado de quienes no consideran este espacio como un espacio propio, y ahi es desandar lo obvio, desnaturalizar ciertos lenguajes, que todo el mundo tiene que saber para dónde ir, hay un montón de cosas, de lo que no se puede hacer pero también de lo que sí se puede hacer, que a veces la gente que no tiene hábitos de visitar museos se pone restricciones demás.

aquí aparece un matiz interesante, la búsqueda de pasar de esa "mirada Bourdieu" que busca reconocer la cantidad de barreras sobre todo simbólicas que hacen que las personas no accedan a los museos, para empezar además a reconocer que una vez logrado el acceso al espacio, hay toda otra 
serie de barreras que tienen que ver con lograr una experiencia integral, compleja, del museo. Que estos sujetos no solo puedan lograr estar, sino también poder participar, sentirse habilitados y reconocidos en toda su dignidad mientras habitan ese espacio.

Dentro de las comunidades con las que trabajar hay un particular énfasis en aquellas de mayor vulnerabilidad, niños, niñas, adultos mayores, personas con diversas discapacidades, por citar algunos, con las que es necesario poder también de un modo diversificado y respetando sus diferencias, tratando de no establecer homogeinización o identificación solo en función de ese agrupamiento de vulnerabilidad, entendiendo que entre esos mismos agrupamientos puede haber diferencias en sus pretensiones de acceso, o en el modo en que prefieren relacionarse, para ello resulta central el reconocimiento de los criterios en sus propios términos. Sumado a eso también entendiendo sus subjetividades de formas más complejas, evitando alienar sus experiencias y poniéndolas en vinculación con otras personas diferentes a ellos y ellas

VS: por lo menos para mi es un posicionamiento fuerte tienen que ver pensando en las personas con ceguera, y en general en las personas con discapacidad, en que no son sujetos aislados, entonces que esas perspectivas de derecho en las que una plantea que como espacios culturales, tenemos que favorecer su acceso, no supone ni un acto de bondad ni mucho menos, es una obligación, pero que más allá de eso, hay que pensar en instancias que tienen que ser compartidas, con las particularidades de cada grupo obviamente,

de ese modo se propician además espacios de encuentros en los que todos y todas quienes participan pueden experimentar y aprender del otro, en el marco del ejercicio de sus derechos de la manera más plena posible.

\section{El acceso a partir de actividades culturales}

En muchos casos la pauta de relación entre los sujetos de las comunidades y el museo se establece a partir de la participación en las actividades culturales que forman parte de la programación del museo, o por ejemplo a partir de talleres, u otro tipo de espacios formativos que se realizan con cierta regularidad en el museo. Alli suelen presentarse oportunidad de conocer a otro tipo de público con el que articular, por donde luego ampliar en base a la construcción de redes de confianza, en el marco de procesos de mediano plazo

AB: ...la práctica ha sido la que está extendiendo el límite, por ejemplo esto de las familias... hasta el año pasado por ahí el vínculo era... nosotros teníamos más claramente con los chicos, y por ahí las familias participaban en algún evento, eran invitadas, pero ahora estamos pensando en fortalecer esta relación, porque los chicos vienen con la familia, ¿qué es esa familia que está detrás? Entonces este año empezamos por ejemplo a intentar generar pequeños encuentros de las mamás de esos nenes, aparte, en otros días, para pensar otras cuestiones. Y eso es algo que se dio en una oportunidad, un poco de manera intuitiva, a partir 
de la demanda de una mamá que dijo "¿y por qué no hacen algo para las madres?" y entonces a partir de leer o de atender este comentario, esta necesidad, es como se establece un vínculo más fluido con determinado grupo... aparecen demandas todo el tiempo desde el exterior...

este relato da cuenta de cómo una pregunta, tal vez circunstancial, puede ser escuchada e interpretada como una demanda sentida, para poder empezar a trabajar en la dinamización de ese colectivo en el marco de los horizontes de los equipo de los museos. Eso puede tener varios niveles de acción, a partir de trabajar con esas comunidades inmediatas, o en un caso similar, también lo puede ser intentar vínculos con aquellos sujetos de la comunidad que se acercan al predio del museo, en los casos en los que esos espacios públicos cuentan con espacios verdes o con plazas que suelen ser usados con asiduidad como paseo

OB: el museo está en un predio de 5 hectáreas, con un parque lleno de árboles, con un laguito artificial, eso es muy usado por la gente, que lo usa como un parque viene con su reposera, con el mate, (...) estamos siempre pensando cómo hacer para vincular a esa gente, para que entre al museo, hemos llegado a pensar en alguna intervención en el parque, para que los haga venir a curiosear acá adentro.

hay en estos posicionamientos, un cambio de mirada, una acción más activa de parte del equipo del museo, que deja de mirar por la ventana esperando que el público entre, a salir a buscarles de algún modo.

Ese salir a buscar puede tener varios rangos de distancia, comenzando por salir al predio del museo, pero también como se relata en varias entrevistas existen prácticas que implican dejar la comodidad del museo para salir hacia los espacios de pertenencia de lo sujetos a los que pretenden acercarse. En ese movimiento se genera una operación que resulta interesante porque junto con el edificio se quedan algunas de las barreras simbólicas que se cargan como estigma de las instituciones de museo, implica perder algunos privilegios y ubicarse en una posición de relativa vulnerabilidad para los equipos del museo que se encuentran jugando "de visitante" en el territorio del otro al "llevar la casa afuera"

SM: salir del museo es en principio llevar un poco de lo que pasa o de lo que pensamos o de lo que creamos, de los sentidos que creamos acá, llevarlos un poco afuera, y empezar a ver qué pasa cuando no tenemos esta estructura establecida que es el museo, que es esta cosa imponente, o este prejuicio previo a... a lo que debería ser o no un museo. Porque un museo es... todos los museos que surgen en torno a un museo... es aburrido, qué voy a hacer, bla bla... que los trabajadores y trabajadoras no tengamos esta estructura que nos haga sentir... bueno, o sea... llevar la casa afuera, ir al encuentro con otros poniendo ese patrimonio sobre la mesa, empezar a charlarlo, qué cosas surgen... lo que nos dábamos cuenta es que cuando uno sale del museo y va a otro espacio donde el otro se siente, si se quiere "de local"... 
Cuando se habla de comunidades y territorios a los que ir a jugar "de visitante", una de las experiencias tal vez más desafiantes son las que se están dando con personas en contexto de privación de la libertad

OB: fuimos a trabajar con la cárcel, en una de las cárceles acá de Córdoba, junto con otros museos, que se llama "Liberar las musas"201 que lo hicimos como desprendimiento después del encuentro de MINOM en el que uno de los ejes era contextos de privación de la libertad, de ahí nos quedamos movilizados los espacios de áreas educativas de acá de Córdoba, decidimos armar un proyecto (...) desde el espacio de áreas lo armamos y nos sumamos, el Museo de la Estancia, el del Garzón Agulla, el de Antropología y el Genaro Pérez, y entre los 4 armamos el proyecto que se llamó "Liberar las musas", que se llevó desde julio hasta noviembre, que bueno, que terminamos con una pequeña muestra itinerante colectiva.

Como un matiz en el mismo sentido, en las entrevistas también aparecen diversos relatos de actividades realizadas en el museo con la participación de representantes de algún colectivo. Actividades en las que en marco de consultas desde el museo, terminan generando un vínculo más profundo que permite quebrar de algún modo la asimetría dando mayor peso específico a estas personas, en el marco de construcción de lazos de confianza y respeto mutuo, y a la vez tratando de romper con relaciones que podríamos incluir dentro de las "relaciones coloniales", de cierto estractivismo unilateral por parte de las instituciones, para en este caso reconocer y legitimar la importancia de los sujetos, de sus aportes y saberes

VS: hay ciertos lugares donde es políticamente correcto hacer estas cosas, entonces, a mí me puede dar como museo antropológico universitario, un aura de "qué progres que somos" no se como... sí se cómo explicarlo, es eso, es pensar en que ella no sienta que yo me estoy queriendo dar lustre en función del trabajo que ellas están haciendo, y a la vez a la inversa, poder reconocer el trabajo que ellas están haciendo y verlo como una actividad en conjunto. Ese tipo de cuestiones que parecen mínimas, son del tipo de cosas que yo espero que se vayan como en el mediano y largo plazo, profundizando en función de una línea de trabajo, poder pensar con quiénes y cómo nos relacionamos, nosotras venimos desde el área, trabajando como haciendo actividades fuera del museo, en algunos centros comunitarios, en algunos espacios que tienen que ver con organizaciones de personas ciegas, pensando en algunos eventos en el espacio público, en algún espacio que tenía que ver con organizaciones sociales o artistas, venimos llevando nuestras actividades, pensando en esta idea más desde el museo como territorio.

201 Se puede ampliar la descripción de este proyecto en los siguientes links https://museoescolarensaga.blogspot.com/p/liberar-las-musas.html https://youtu.be/pZ055XuxM5A 


\section{Garantizar derechos desde lo público}

Como ya hemos dicho antes, esta vocación de salir a buscar a las comunidades para dar espacio de acceso al museo, y a la vez ampliando su territorio, tratando de reconocer las diversas barreras que impiden el acceso, tomando una posición activa, incluso al punto de ir a buscar a las personas a sus propios territorios para ofrecerles la oportunidad de experimentar alguna de las dimensiones del museo resulta aún más pertinente considerando que se trata de museos públicos, por lo que se trata no solo de una acción desde una perspectiva política, desde un horizonte de deseo, sino que es a su vez una responsabilidad en el marco de la obligación que los espacios públicos y sus trabajadores y trabajadoras tienen en la promoción del ejercicio de los derechos, democratizando el espacio sobre todo para los sujetos de los sectores más vulnerables o desplazados

$A B$ : pensando que es un museo público, municipal y público, bueno ahí hay una dimensión de que en teoría es un espacio democrático que debe llegar a todos, después en el cómo y... si se está dando con lo que el museo plantea o no... O se da un espacio de discusión es otra cuestión, pero que también... ésto, que en principio que esté abierto... es un signo de que todos podemos caber ahíadentro ¿no?

y en el mismo sentido resulta interesante el siguiente aporte, que propone pensar que los museos que trabajan desde este posicionamiento pueden funcionar como parte de un entramado cuyo sentido se centre en la defensa de esos derechos, en la posibilidad de generar cruces de experiencias entre sujetos diversos

SM: Empezar a pensar que no es solo un museo, que estamos dentro de una trama, y de que de alguna manera es lo que le da sentido a defender esos derechos culturales de los que hablamos... (...) El sentido de lo que uno hace tiene que ver justamente con las propias experiencias de los sujetos en relación. Sólo no... digo, porque eso también es una discusión a este momento histórico neoliberal, también es una forma de resistencia, que podamos pensar estas instituciones creadas para generar sentido sobre lo que sería la cultura elitista, bla bla bla, romperla y decir, no, somos nosotros los constructores de la historia en comunidad, con tensiones, con discusiones, creando sentidos, pidiendo solidaridades,

Solo como para establecer un panorama parcial, recuperando algunas de las experiencias de los equipos de museos entrevistados, podemos identificar la vinculación de los museos con colectivos de personas no videntes y con disminución visual, con personas mayores, con comunidades de afrodescendientes, con escuelas rurales, con organizaciones barriales, con centros culturales, con colectivos de artistas populares, con bachilleratos populares, con comunidades indígenas, con colectivos migrantes, con comunidades trans, con organizaciones de diversidad sexual, con colectivos de trabajadores jubilados, con organizaciones sindicales, comunidades en contextos de encierro, con grupos de jóvenes. Es solo una enumeración de un abanico considerablemente amplio para un grupo reducido de espacios museales que forman parte del recuento. Y que permiten dimensionar de algún 
modo las implicancias que este posicionamiento desde la museología social tienen en cuanto a alcanzar e intervenir políticamente con colectivos y comunidades.

En este sentido también resulta interesante recuperar sus sentidos en cuanto al marco de decisiones y los matices que se construyen en el contexto de las circunstancias de la gestión de cada espacio público y las coyunturas en las que navegan

$A B$ : hay un derecho a la cultura que a veces sentimos que estamos reivindicando por una cuestión de lo que piensan las personas que trabajan adentro de los museos, (...) que esto no es una linea que baje orgánicamente que baje de algún lado, sino lo que ha pensado y practicado la gente en concreto y las limitaciones que tenemos con eso.

desde sus posibilidades de acción toman la responsabilidad de accionar sobre espacios que en el marco de gestiones de gobierno se ejercen en el cuidado del patrimonio público de una "casa" que debe estar abierta porque es "de todos"

LC1: desde la calidad de lo público y desde el sentido de lo público, o sea los espacios son de la comunidad, nos toca a nosotros, en un marco de gestión hacernos cargo y llevarlos adelante, pero están concebidos desde esa plataforma. Son espacios de participación, de discusión, esto te pertenece, es tu casa, y nos toca a nosotros cuidarla y ayudarla a que esto continúe. Toda la política de cultura tiene que ver con el cumplimiento de los derechos culturales... generar espacios de cumplimientos de derechos... habrá variabilidad de las formas, pero está esa plataforma, y los museos son eso, espacios para el cumplimiento de derechos...

Una decisión que sobre todo se sostiene en los museos municipales en los que trabajan las personas entrevistadas, con relación a los derechos se sostiene un criterio que tiene que ver con la gratuidad para el acceso a los espacios

LC1: ...la persona que entra es una persona con nombre y apellido, puede ser o no vecino, pero la calidad del servicio eso no tiene que variar, no tienen un costo, no hay una barrera de costos. Nuestras actividades son en el 99.9 por ciento son gratuitas.

AB: hay un corrimiento del Estado de participar, tanto en lo económico, como en lo social y lo cultural, con esa base reivindicar la dimensión pública gratuita, del museo, también incluso dentro de lo que hoy es el modelo de pensamiento dentro del Estado, que es más gerencial, hasta como que va en contraposición con las ideas hegemónicas o dominantes. Defendemos esa condición de lo público que es otro gran campo de disputa, pero que eso se sintetiza en que es un museo... en la gratuidad del museo...

Aquí se plantea claramente una marca de desplazamiento vinculado a los cambios coyunturales en las gestiones de gobierno, en una lógica de carácter "más gerencial". Lo que también se hizo presente como inquietud para los trabajadores y trabajadoras, quienes a partir de diciembre de 2015 observaron notables cambios en las condiciones de trabajo. Esto se hace particularmente 
visible en los museos nacionales a cargo de la órbita de cultura de Nación cuyas nóminas fueron parte de la ola de despidos masivos ocurridos en los primeros meses de 2016.

$O B$ : ...generó un montón de... cambios que se venían y no sabíamos quiénes seguíamos, si seguíamos o si no seguíamos, todo esto...

En la misma sintonía también se destacada la implementación del control de ingreso y egreso del personal mediante datos biométricos, lo que significó la desarticulación de muchas de las estrategias logísticas instituidas, que se basaban en la compensación de horarios para el trabajo durante los fines de semanas y feriados, o la aplicación de sistemas con horas extras para el trabajo fuera de la sede, o para el montaje de exposiciones, una serie de transformaciones implementadas taxativamente desde un modelo de gestión rígida que trastocó por completo la tarea en función de las necesidades operativas que el trabajo en los museos posee, los que son muy diferentes a las que podría tener por ejemplo la tarea en una oficina de correos, donde pueden establecerse turnos de 8 horas, en los que los trabajadores o trabajadoras puedan ser cubiertos por otros que hagan la misma tarea. Lo que de ningún modo ocurre en los espacios museales, donde por un lado los equipos son más reducidos, pero además donde generalmente hay una especificidad y especialización en la tarea de cada persona.

También se marcan diferencias a partir de la desinversión, que implicó por un lado la falta de materiales para el armado de muestras, la falta de materiales específicos para la conservación, o los elementos didácticos para el trabajo con los grupos en las visitas. Del mismo modo, se observa una desarticulación en el trabajo con otras agencias del estado y con políticas públicas (sobre todo educativas y de desarrollo social), tanto en el intercambio de especialistas, en la investigación, o en la cobertura de los costos de traslado para contingentes que no pueden costearlo, con las que se potenciaba el trabajo de los museos en general, y sobre todo las tareas para la promoción de derechos

SM: Lo primero que sucedió en este espacio es que se vació de recursos, se desvinculó de la mayoría de programas de universidad, se desvinculó de la posibilidad de tener micros y demás para que la gente se pueda acercar. Como verás es un espacio de difícil acceso, no queda cerca casi prácticamente de ningún lado, entonces... desfinanciar el espacio, cortarlo de su red de programas y demás... fue como una manera de dejarlo morir... (...) el vaciamiento y demás... después tuvimos despedidos ${ }^{202}$, hubo despedidos en el predio...

202 https://www.eldestapeweb.com/despidos-empleados-del-museo-malvinas-anunciaron-un-paro-tiempo-indefinido$\underline{\mathrm{n} 14398}$ http://www.infobaires24.com.ar/tras-los-despidos-los-trabajadores-del-museo-malvinas-haran-paro-por-tiempoindefinido/ 


\section{Espacios de gestión y solidaridad colectiva}

Ante el cambio de condiciones de trabajo, el caso del Museo Malvinas e Islas del Atlántico Sur es reconocida la estrategia de gestión colectiva que asumieron ante la repentina renuncia de su director $^{203}$ en septiembre de 2018

SM: cuando renuncia el director, como espacio de trabajadores nucleados por ATE [Asociación de Trabajadores del Estado ${ }^{204}$ ] nos organizamos para seguir sosteniendo las actividades, sobre todo porque las teníamos planificadas, había gente que venía a dar charlas y demás, que en aquel momento se habían solidarizado, que es lo que nos pasa mucho, los grupos que vienen son los que se solidarizan, los compañeras del [Museo] Etnográfico [Juan Ambrosetti], del [Museo] Histórico [Nacional], todas las actividades que llevábamos eran solidaridad, porque no cobraban un mango... entonces, seguimos sosteniendo las actividades, tomamos las decisiones durante un tiempo por asamblea, hasta que pusieron a un director interino (...) lo sostuvimos 3 meses.

aquí aparece el reconocimiento del aporte que cada uno de los trabajadores y trabajadores realiza en su tarea cotidiana, sumado a la construcción con el aporte solidario de trabajadores y trabajadoras de otros espacios públicos que se sumaban desde el tejido de lazos que cada uno tenía.

SM: fue bien interesante, porque nos dimos cuenta de que en todo ese tiempo eramos los trabajadores los que habíamos venido sostenido al museo, como que también todo funcionaba porque nuestro trabajo estaba puesto ahi en valor... (...) nos dimos cuenta de que en realidad lo habíamos hecho todo el año, solo que la toma de decisiones a través de asamblea generaba un determinado desgaste...

En circunstancias distintas, en un espacio de mayor consonancia con la conducción del espacio pero con la visibilización de condiciones de trabajo que se dimensionan como necesarias de ser mejoradas, las trabajadoras y trabajadores del Museo Antropológico Juan E, Ambrosetti también se organizan mediante una asamblea, en la que al tratarse de un museo universitario, incluyen a participantes de los tres claustros que se encuentran representados en la nómina del museo

VJ: a partir del año 2009, nos empezamos a reunir en asamblea, nosotros. Docentes, no docentes, contratados... (...) como un espacio propio del museo, de participación, horizontal, que nos permitió abordar distintas problemáticas del museo, desde que teníamos ratas y ver cómo hacíamos para poder afrontar ese problema grave, hasta nuestros derechos laborales, entonces fue también un espacio que nos ha permitido ir creando una idea de comunidad acá adentro. (...) lo fuimos como organizando en función de emergencias, y después de las emergencias, cuando nos empezamos a conocer más entre nosotros a conocer más la realidad nuestra, visibilizar bien lo que nos pasaba en cada área, empezamos a trabajar en un proyecto de estructura orgánico funcional para los museos, desde los trabajadores,

\footnotetext{
203 https://www.infobae.com/cultura/2018/09/22/renuncio-el-director-del-museo-malvinas/

http://www.agenciapacourondo.com.ar/sindicales/el-museo-malvinas-en-estado-de-alerta-y-movilizacion 204 http://www.ate.org.ar/
} 
desde las áreas, y para eso también tuvimos que hacer todo un trabajo de investigación, sobre la historia de la institución, cómo se había organizado la institución en distintos períodos históricos, eh... buscar ejemplos de otros museos, y pensar propuestas en función del trabajo que nosotros hacemos acá, entonces estuvimos 4 años trabajando como entre el 2011 y el 2015, trabajando nosotros por área y en plenarios para generar una propuesta de estructura para el museo, y la presentamos en 2015, se aprobó en 2016, el 8 de marzo me acuerdo, por el día de la mujer, y todavía no tenemos financiamiento.

Si bien su proyecto no se ha podido cumplir en fundamental aspecto económico, al menos les permitió instalar de manera institucional una estructura que marca un rumbo político para la gestión, el que además al ser aprobado por el Consejo Directivo, sumado a esto, la posibilidad de sostener un espacio regular de encuentro entre las distintas áreas de trabajo en un museo que cuenta con mucho personal, les ha permitido generar una construcción comunitaria propia para afianzarse en sus respectivas tareas

VS: Nosotros estuvimos trabajando mucho internamente para poder desarrollar una estructura orgánico funcional, digamos, como en el trabajo de las diferentes áreas y como que el intento es... en muchos casos también desde la dirección, pero que cada nueva acción o movimiento del museo vaya como consolidando esos espacios que se definieron, sin presupuesto, en la estructura.

En el caso de los museos que corresponden al circuito de Museos Nacionales de Estancias Jesuíticas, dada también la dimensión de sus equipos, y la distancia territorial entre las distintas sedes, se han organizado mediante redes de trabajo

OB: hay dos niveles de trabajo, una red de educadores, una red de trabajadores de las estancias, que estamos un poco viendo tener cuestiones en común, en las visitas tener entre todos más o menos la misma introducción para que la gente comprenda que somos parte del mismo sistema. Y por otro lado hay una red de directores, en la que están solamente los directores, que se ponen de acuerdo en cuestiones de conservación, más a nivel papeles, o la UNESCO, (...)

en este caso parece haber una organización que se sostiene de una manera más administrativa por parte de los directivos de las gestiones, y por otro lado los trabajadores y trabajadoras de las áreas que se ocupan más del sentido de las intervenciones, preocupaciones que aún parecen no ser reconocidas por quienes se encuentran a la cabeza de algunos de esos proyectos

OB: ... hace falta mucho anclar en el trabajo con la comunidad local (...) hay que cosas que nos quedan pendientes, (...) habíamos pedido una reunión para trabajar lo conceptual y creo que no se alcanzó a visualizar la importancia de eso (...) Como que tenemos posibilidad de plantear las cosas, pero creo que hay distintas miradas que todavía no llegan a encontrarse, ni siquiera como para ponerse en discusión. (...) Esa reunión que nosotros habíamos planeado con quince días de anticipación, buscando la fecha y que se yo... Ilamaron a la reunión y cuando fuimos a la reunión nos dijo, no, no es para hablar de la muestra, es para hablar de las nuevas 
normativas laborales que hay, y punto, ¿viste? (...) ... pero yo creo que no es algo elegido, sino que es imposibilidad de ver...

Aquí se hace presente otra cuestión que suele ser un obstáculo en muchas instituciones, sobre todo en aquellas que cuentan con una larga trayectoria, que cuentan con prestigio y que han atravesado por muchas dirigencias. En las que el peso que tiene el proyecto fundante, suele parecer como un mandato obturador, como algo imposible de modificar. O haciendo que quien se atreva a criticarlo, o ponerlo en tensión, resulte estigmatizado y deslegitimado. Gestiones en las que se pone más el foco de atención sobre el ordenamiento administrativo, desde una matriz burocrática, o aquellas gestiones de corte más funcionalista que se atienen a seguir lo prescripto en las denominadas "misión y visión", o que por su posicionamiento conservador, le dan mayor peso a lo fundante, anulando la posibilidad de repensar el sentido estratégico del proyecto de gestión, y por ende de las acciones que allí se llevan adelante.

Por otro lado, en los museos municipales, que cuentan de algún modo con estructuras más reducidas y que dependen de las gestiones municipales, sin contar con estructuras por áreas, sino siendo muy pocos y pocas personas para cubrir todas las tareas necesarias y los horarios de la totalidad de la semana, deben también encontrar estrategias de encuentro para el intercambio de criterios, experiencias y problemáticas,

AB: en la dinámica cotidiana, por ahí lo que sí tratamos de hacer es al principio de la mañana, cuando vamos llegando, los que estemos nos damos un momento de encuentro, de diálogo, de mate y nos ponemos al tanto de lo que vaya pasando, ahí también es el momento donde se van planteando las discusiones, o se van elaborando... se discute algún texto, se habla de la vitrina, se plantea la actividad que se va a hacer el fin de semana... todo se comunica ahí...

Finalmente me parece interesante destacar, retomando lo ocurrido en la experiencia de gestión asamblearia del Museo Malvinas e Islas del Atlántico Sur, la recuperación de la mirada no solo de las comunidades con las que se vinculan los museos, o la construcción de la propia comunidad de trabajadores y trabajadoras de los museos, sino también la comunidad que se genera de manera más transversal entre los trabajadores y trabajadoras de los distintos museos que comparten esta perspectiva, reconociendo que aquello que no se tiene o no se sabe en un espacio, probablemente esté disponible en otro

SM: empezar a pensar este espacio no como un espacio que lo tiene todo y lo puede todo, sino que es necesario articular con otros que ya vienen trabajando dentro del campo de los museos, creo que eso ha sido una de los grandes hallazgos de los últimos años,

con lo que se genera un entramado que potencia su trabajo a partir de relaciones de solidaridad y reciprocidad, con la finalidad última de promocionar y potenciar el ejercicio de derechos por parte de los sujetos de las comunidades con las que interactúan desde su trabajo en espacios públicos. 


\section{Intervenciones para la memoria desde los lenguajes}

Otra de las dimensiones que resultan interesantes de destacar a partir del trabajo de análisis sobre los relatos construidos en las entrevistas tiene que ver con el particular modo en que se desarrollan los relatos de los museos observados, es decir tanto en sus museografías, como también en cuanto a los relatos que se producen desde el museo y en torno a los museos.

\section{El doble filo}

En este sentido parece haber en la mayoría de los casos trabajados una especie de doble filo en el modo en que se construyen los textos de la museografía. Por ejemplo en el caso del MuseoTaller Ferrowhite plantean una construcción de capas compuestas por un plano de lo testimonial y otro plano de corte más conceptual o teórico, una mediación producida por el equipo

$A B$ : creo que por un lado hay una dimensión, que es una lectura que hace sobre todo... que ha hecho el equipo de trabajo del museo, siempre en articulación con lo que vamos aprendiendo de quienes son nuestros entrevistados, también de lecturas, de la revisión teórica y bibliográfica, todo eso (...) hay una mirada, una serie de textos que los hacemos nosotros planteando nuestra mirada de las cosas, y después hay otro plano más testimonial y biográfico donde aparece el relato de los propios trabajadores, contándote distintas anécdotas...

En cuanto a los textos que son de corte principalmente conceptual, el caso tal vez más paradigmático lo constituye el Museo Antropológico de Buenos Aires, que al tratarse de un museo universitario carga con expectativas sobre temas disciplinares que deben poder ser explicitados en sus espacios de exposición al igual que en el modo en que se conduce el relato de las visitas y de las guías para los grupos. En cuanto a ésto, el equipo vienen haciendo un trabajo en la búsqueda de cierto balance entre contener los datos o conceptos científicos, pero desde un lenguaje que no excluya en el marco de la accesibilidad para los diversos públicos a los que pretenden llegar. Allí el doble filo se construye entre la precisión y la amabilidad de los textos, pero sin perder el carácter problematizador que estos conceptos tienen para discutir las construcciones sociales que en el marco de su proyecto les interesa poner en escena

VS: precisión, por un lado... no academicismo por otro, sin pasarnos demás... y... una cuestión de calidez y amabilidad (..) cuando digo lo de no academicismo, si tengo un sinónimo que es más simple, lo uso, (...... no queremos un lenguaje cerrado... y si hay palabras que tengo que usar porque son términos muy especificos que no los puedo nombrar de otro modo, tengo que poder explicar qué es.

CM: poder trabajar sobre todo contenidos actualizados, y sobre todo problematizados, y en este sentido, parte del objetivo de las propuestas tienen que ver con 
problematizar estas categorías... salir de definiciones clásicas de cultura, romper con ideas esencialistas sobre los pueblos originarios, dejar de decir "los indios son esto", entonces se juega la categoría de identidad, mucho de la antropología tienen que ver con correrse de las definiciones más esencializantes...

Ese doble juego también suele darse en los relatos entre aquellos textos que tienen más datos que podríamos llamar "duros" y otros textos más "amables" en los que también se puede jugar con otros registros más poéticos

LC1: me parecía que los textos condensaban (...) que estuviera lo informativo, pero apelar a la pregunta, a la repregunta, a la retórica, a la poética... lo dicho y lo no dicho...

En estos dobles juegos, que de algún modo dan cuenta del carácter dialógico que se plantean, lleva a otro trabajo que tiene que ver con recuperar lo que se construye en esos encuentros cotidianos para actualizar las muestras. Una especie de diálogo permanente entre lo producido desde las visitas, los testimonios que pueden ser recogidos mediante las investigaciones y entrevistas, para ser puestos en relación con lo que se expone en las muestras,

$A B$ : tener un diálogo permanente con la museografía. Que tal vez hay un objeto que precisa otro que esté en dialogo, o agregarle un texto, o modificarle, algo que tal vez es imperceptible para quien... pero en realidad todo el tiempo se está modificando o repensando, capaz que mirado de afuera parece estático o que está igual, pero al interior, hay cambios, hay ajustes permanentes...

una especie de museografía en transformación permanente, que de algún modo busca evitar su cristalización.

\section{La pregunta para abrir el juego y no responsabilizar al otro}

En el marco de ese doble juego, de ese ida y vuelta dialógico, hay una intención que apunta a la apertura del discurso, a que el otro se sienta habilitado a hablar, proponer sus saberes, sentirse escuchados y validados.

Para eso la herramienta clave es la pregunta, la que aparece como una constante en todas las entrevistas, como una epistemología pedagógica desde estas perspectivas. En ese sentido aparece una inquietud interesante de atender, que apunta a una actitud reflexiva sobre cómo es que se formulan esas preguntas, para que no se transformen (en el marco institucional del museo desde donde son expresadas) en una presión, en una evaluación. Una deconstrucción del modo en que se pregunta para resituar la autoridad del o la que pregunta

VS: se plantea como esta cosa de "¿es cierto que...?", o el tono... o "como todos sabemos..." bueno, no todos sabemos, o "seguramente ustedes escucharon..." ese tipo de cosas solo pueden decirse con cosas como el Cabildo, digamos... poder pensar en cosas demasiado conocidas "tal vez mucho de ustedes..." trabajamos mucho el tipo de preguntas... 
una búsqueda por salirse de algún modo del lugar erudito, intentar deslocalizar la asimetría del saber, valorizando el saber del otro, y en el mismo sentido tratando de desacralizar al patrimonio y los objetos que en los espacios de museo son exhibidos, plantear una serie de reflexiones en el espacio de encuentro, que permitan seguir abriendo el juego y animando a que los otros también puedan aportar sus saberes, que se sientan a la altura del juego

CM: hay una concepción de lo que significa el patrimonio también, desde donde se lo piensa, y para pensarlo críticamente ¿no? Qué se pude tocar, por qué no... a mí me interesa pensar más el problema que dar una respuesta, eso es un vicio filosófico que tengo (se ríe) pero... en la medida de lo posible, trato de correrme del lugar del saber erudito... me interesa más la pregunta en algunas cosas... porque nos habilita a poder seguir pensando y preguntándonos.

En el mismo camino, en el de la apertura del juego, y en la deconstrucción de la autoridad, en la búsqueda de romper algo de la asimetría de poder, otra cuestión que se juega fuerte tiene que ver con lograr el reparto de las responsabilidades, desnaturalizar la igualdad de oportunidades para acceder al conocimiento, en esto del saber-poder

VS: Hay una cuestión fuerte que es no dar por sentado, no plantearle al visitante que tiene que saber cosas que no tiene por qué saber, no responsabilizarlo... con respecto a las cosas, no hacerlo sentir incómodo, y en ese sentido, la cuestión del lenguaje tiene que ver con mucha cuestión de la formulación, con cómo se dicen las cosas.

en una ética del cuidado del otro, evitando de algún modo la crueldad se dar por sentado que todos podemos tener la misma trayectoria formativa, como primer puerta de entrada a otra construcción de saberes colectivos.

\section{Mirada desde lo cotidiano}

Otro de los desplazamiento, si hablamos de la valorización de los saberes de los otros, también implica valorar los espacios sociales en los que los sujetos con los que estamos interactuando se desenvuelven a diario. Que las personas puedan encontrarse con que sus vidas también son dignas de estar en un museo, que pueden ser contadas en un museo. Desde la deconstrucción del patrimonio, que éste no esté constituido solo por las vidas y objetos de las personalidades destacadas, sino que también ellos y ellas pueden protagonizarla, que incluso puedan aportar sus objetos si lo desean, comprendiendo sus experiencias en la articulación con los procesos sociales, transformando sus propias vidas en claves de lectura, en lentes a través de los cuales observar la historia

JR: ...el tema del aspecto de la vida cotidiana, el hecho de que el abordaje siempre lo hacemos desde, o siempre un tema fuerte es la cocina, pensar la historia desde la cocina, la historia desde las comidas. La cuestión de la vida cotidiana, de lo ordinario, de lo que parece que no tiene valor, del repasador, por ejemplo, tiene que ver con eso, con hacer que las 
situaciones nos permitan pensar procesos mayores, procesos que identifican a un montón de personas (...) la vida cotidiano y de los objetos, de la ordinariez decimos nosotros, de lo ordinario que para nosotros tiene un valor.

En el caso del Museo del Puerto de Ingeniero White, hubo un momento en que esa especial atención por los momentos cotidianos les llevó a replantearse el relato del museo, a tal punto que entendieron desde allí que lo que debían transformar era el sentido histórico y el horizonte que debían observar a partir de ese momento. Sosteniendo siempre la centralidad de la recuperación de las memorias de los pobladores y pobladoras de su territorio, pero desplazándose desde la recuperación de las comunidades que migraron desde Europa a fines de Siglo XIX y principios de Siglo $X X$, para empezar a observar las memorias de los trabajadores estatales que habían configurado la identidad de la población durante la mayoría del siglo XX, y finalmente empezar a mirar también hacia los jóvenes y sobre el futuro de la población de la localidad. El emergente que disparó este cambio de perspectiva fue una serie de escapes tóxicos ocurridos en dos de las plantas del polo petroquímico que se encuentra a la vera de la ría, poniendo la salud de toda la comunidad en riesgo y generando movilizaciones que fueron reconocidas desde el equipo del museo como un fuerte llamado de atención para repensar su tarea

JR: el relato tuvo una crisis fuerte (...) en White hubo un gran escape de cloro y amoniaco $0^{205}$, en agosto del 2000, eso hizo que toda la comunidad se ponga en alerta, en relación a las empresas que en la década del '90 se instalaron, las empresas multinacionales que forman parte del polo petroquímico, y en el año 2000 hay en dos semanas, en 10 días más o menos, hay dos escapes uno de cloro y amoniaco, en Profértil y en Solvay-Indupa, eso genera una movilización fuerte en la comunidad y eso moviliza también al equipo del museo que comienza a pensar que la función del museo tiene que empezar a ser otra, (...) venía de eso de recuperar los relatos migratorios y de los primeros pobladores, esta cuestión de la inmigración europea, y el año 2000 poniendo en crisis al propio relato del museo, empieza a pensar que en realidad lo que se estaba poniendo en juego en ese escape, era toda una situación social en realidad, que entraba en crisis (...) en White es muy concreto como hay retiros voluntarios, jubilaciones anticipadas, la Junta Nacional de Granos que se termina de disolver, se liquida, Ferrocarriles Argentinos se privatiza, YPF se privatiza, los espacios del puerto se empiezan a privatizar, porque se instalan estas empresas que cierran sus espacios de trabajo, y eso genera todo un cambio de percepción del espacio, hasta donde puedo entrar, hasta dónde no, eso para la comunidad de White, eso es muy fuerte, (...) aparecen esos cambios que son bien concretos en el territorio, y el museo empieza a pensar que ese escape del 2000 en cierto modo es una especie de anticipo de lo que sería la crisis de 2001 a nivel nacional. (...) Hay un corrimiento temporal de dejar de lado los relatos migratorios y empezar a

205 https://www.clarin.com/sociedad/despues-cloro-llego-amoniaco 0 rkAQlf9eOYx.html https://www.lanacion.com.ar/177052-una-fuga-de-amoniaco-asusto-a-los-vecinos-de-ingeniero-white http://periodicoatico.com.ar/2016/10/17/solvay-indupa-sigue-coleccionando-incidentes-hasta-cuando/ http://informateaca.com/trece-anos-despues-del-escape-de-cloro-en-white-estamos-peor/ 
pensar en esos ex trabajadores estatales, y recuperar esa memoria de esos trabajos y todo eso. Eso fue algo que cambió mucho la lógica del museo... (...) No pensar al museo como el edificio, sino como prácticas museológicas en distintos espacios, y uno es el espacio digital, y también eso, cómo darle sentido en este museo a las poblaciones más jóvenes, cómo corrernos de esos relatos de personas mayores, poder pensar en los jóvenes de White, qué sentidos encuentran en White, y bueno... ahi estamos, vuelven a ser estas crisis que a nivel nacional repercuten también en el modo de pensar de los museos, (...) en función de eso, que estamos insertos en una comunidad concreta.

en este resumido relato, está muy clara la condensación de la historia de una población a partir de una serie de hechos puntuales, y cómo son estos hechos, leídos desde la atención en la vida cotidiana, los que indican la potencialidad de la construcción de la historia desde otros márgenes.

Estos aportes también dan cuenta, al igual que otras cuantas entrevistas, que esta tarea permite actualizar no solo la museografía, sino que aportan a la construcción de la historia de una manera más plural, incorporando a los museos la historia reciente, para remover recuerdos incluyendo la posibilidad de interpelar a personas desde la implicación de la proximidad, dado que fueron parte de ese tiempo histórico, incluyéndoles en la posibilidad de repensar sus experiencias personales en el marco de procesos que los exceden pero que pueden haber influido en sus vidas

SM: trabajar con la memoria reciente es muy fuerte porque en realidad te encontrás con los sujetos que estuvieron inmersos en esa historia, entonces... siempre decimos lo difícil que es poder leer el momento histórico actual en el que uno está viviendo... y la historia reciente también tiene algo de eso. Tiene algo del diario del lunes, pero también tiene algo de "yo estuve ahi"... entonces trabajar con eso es bien fuerte, porque de alguna manera hasta los más pequeños tienen algún vínculo de... cómo no llevarlo a la nostalgia y poder analizarlo desde... o sea... la memoria también es un músculo, entonces tienen sentido en tanto y en cuanto podemos no hacerla productiva pero sí poder ponerla en diálogo con lo que sucede y de alguna manera darle alguna continuidad, esto está acá, esto está acá, sin poder articularlo, entonces para mí, tiene que ver con eso también...

VS: posicionarse en un debate dentro de la sociedad, implica un planteo fuerte en términos de acercarnos a temas de historia reciente como tema central de la sala, implica tener en cuenta un montón de cosas que nos venían diciendo visitantes, y esa experiencia previa, implica consultas. Incluso implica cuestiones en relación a los objetos, es decir, necesitamos colecciones que no tenemos, necesitamos objetos para contar esta historia que no son parte del acervo del museo y cómo conseguirlos.

Aquí se plantean una serie de decisiones a tomar, en las que los equipos de trabajo del museo se ven obligados a repensar tu tarea, redefinir el lugar de las colecciones y de qué modo dialogan con la museología, a la vez que instalan temas polémicos que pueden generar discusiones y posiciones más tensas pero que son necesarios de poner en escena en el marco de los desafíos propuestos en los horizontes políticos del colectivo del museo 
VS: [refiriéndose a la muestra "Desafiando al silencio" ${ }^{206}$ ] para mí es un hito en esos términos. (...) se habla de genocidio, o se habla de complicidad de las sociedad civil con incidencia en el terrorismo de Estado. (...) tiene que ver con la cercanía del tema para los visitantes,... (...) Me parece que con respecto a la dictadura y al terrorismo de Estado, mucho de los que nos visitan se sienten interpelados personalmente, por lo que vivieron, por la historia que le contaron, por su historia familiar, y entonces muchas veces tienen cosas para decir...

El trabajo sobre la historia reciente, permite trabajar a la vez sobre el presente, ya que revisar el modo en que experimentamos esos hechos en el pasado también nos hacen revisar el presente, e incluso a partir de allí, hasta tensionar las perspectivas sobre el futuro, en el marco repensar la articulación de las experiencias individuales con los procesos sociales en relación a trayectorias históricas más amplias.

\section{Las imaginaciones poéticas}

Si bien no se trata de una característica que podamos atribuir de manera exclusiva a los museos que trabajan desde la museología social, sin embargo resulta interesante destacar que en la gran mayoría de los espacios que forman parte de los espacios donde intervienen, o han intervenido, las personas entrevistadas, la poética está presente de diversas maneras. Apelando no solo al lenguaje escrito, sino también en el modo en que se construye el espacio, en la puesta en escena de las exhibiciones, así como en el modo en que se construyen y se comunican los proyectos y los horizontes políticos de estos espacios.

Al hablar del rasgo poético, no me refiero solamente a la idea de componer textos que tengan una estética bella o agradable en términos del registro literario, sino a la poesía en función de su capacidad de transformar el lenguaje, de poder hacer un uso creativo, interviniendo para que un elemento puesto en otro contexto pueda ser algo nuevo, o al menos algo diferente a lo que es habitualmente. Proponiendo a los lenguajes como la primer plataforma de transformación posible

$J R$ : hubo ciertas características en los proyectos de ser muy creativo, por ejemplo desde cómo los comunicaba, lo que es la imagen, lo que es el diseño. Nosotros tenemos dos diseñadores gráficos y para nosotros es fundamental porque todo está pensando desde el diseño. Entonces tiene algo que es muy lindo, no se como decirlo bien, pero hay algo en la estética del museo, que siempre fue bien pensada, trabajada, discutida, incluso, qué palabras usar que imágenes usar, si realistas o no, como algo que a lo largo del tiempo siempre ha caracterizado al museo.

Este rasgo creativo es una preocupación que resulta permanente y que se juega de manera coherente con la epistemología crítica desde la que se sitúan quienes trabajan desde la museología 
social. En ese sentido el lenguaje poético permite dar lugar, abrir el juego, pero también permite experimentar, romper con las certezas y descentrar las palabras del poder. El lenguaje poético también interpela a la movilización, del propio lenguaje de quien lee, habilitando a una recepción más activa.

JR: la poesía es parte, además nos permite jugar, no ser tan explícitos, hacer oraciones más cortas y contundentes.

Usado como una matriz en la realización de la museografía, de las exhibiciones, resulta un modo de proponer una multidimensionalidad al tema que se está trabajando, e incluso poder entramarlo a otros temas trabajados en otros espacios o en otros momentos de manera transversal, sosteniendo siempre un lenguaje abierto. El relato que sigue a continuación de una serie de actividades realizadas en el Museo Histórico y Natural de Berazategui, da cuenta de esa relación y del modo en que fueron sosteniendo una metáfora para organizar los proyectos del museo

LC2: Para mí "Pan" [se refiere a la muestra "Pan, cultura de masas"207], fue también otra gran exposición, creo que fue uno de los mejores productos que pasaron por este lugar. (...) por el nivel conceptual de cómo estaba estructurada la muestra, de cómo fue concebida, de la visión que tenía, esto de lo universal, de lo local, y el montaje hecho con dos pesos con cincuenta. Pero a nivel estético, me encantó como había quedado... se había podido lograr trabajar con las panaderías, con el centro de panaderos... también contando con un hilo que veníamos trabajando con el eje de la comida, de la vida cotidiana... (...) habíamos trabajado con el 20 aniversario con "una porción de tortas, una porción de historias"208 una exposición en la que había un montón de tortas hechas por los vecinos que estaban acá comiendo, festejando, o en el aniversario que habíamos hecho "cocinando un museo"209, en el que invitamos a la comunidad a pensar el museo... le dábamos vuelta a un montón de cuestiones... un montón de cosas que fueron muy buenas de transitarlas... muchas locuras... cosas que hoy en día no podríamos hacerlas... o jugar mucho... en un momento, pensamos hacer que la puerta del museo fuera la puerta de un horno... o cuando hicimos lo del almacén que planteamos una campaña de donación de objetos ${ }^{210}$ y jugar con la mercancía y que la memoria no se negocia y que es un bien... todo eso fue muy piola, y fue posible por una coyuntura política que lo permitió y porque hubo sensibilidad y una muy buena respuesta del equipo de trabajo...

en la alusión a transformar la entrada del museo en la puerta de un horno, se da una alusión a cómo también se puede construir una poética del espacio, que propicie otro tipo de experiencias en

\footnotetext{
207 https://www.facebook.com/events/1994997704064487/ https://youtu.be/A3KEQfEEyew

208 https://www.facebook.com/events/379954132116306/ https://youtu.be/UGcROqaQEDU https://www.diariopopular.com.ar/quilmeno/20-anos-del-museo-historico-y-natural-berazategui-n161330 209 https://www.facebook.com/events/312157935609370/

210 http://www.berazategui.gov.ar/noticias/110-general/414-comienza-la-campana-de-donacion-de-objetos-dealmacen-de-barrio
} 
las personas que lo transitan. En este sentido otro ejemplo puede ser la entrada a la muestra "En el confín del mundo"211 del Museo Antropológico Ambrosetti

AC: me voy poniendo cada vez más poética, y con los años lo voy diciendo, a los visitantes yo les voy diciendo que piensen que en ese momento un viaje en barco vos sabías de dónde salías pero no sabías donde terminabas, y desde la puerta de la sala vos no sabes donde terminás.

esta idea está provocada a partir de la particular forma como está construida la entrada a esta sala de exhibición, la que se ha configurado a partir de un pasillo en zig-zag cuyas paredes están decoradas desde el piso al techo con una enorme paleta de imágenes en las que una persona podría quedarse mirando muchos niveles de detalles por largo rato, dado que están repletas de ilustraciones antiguas de relatos de viajeros, representaciones cartográficas medievales y una serie de textos, el pasadizo se va estrechando a medida que se avanza por él hasta que después de un par de curvas, finalmente se desemboca en la amplia sala, un espacio despejado, donde está el grueso de la muestra.

De un modo similar, otra forma de trabajar la poética de los espacios, puede ser también a través de la descontextualización de los objetos, ubicándolos en espacios que puedan resultar interpeladores para quienes los vean, como en este caso de una muestra temporaria desarrollada en el Museo de la Estancia Jesuítica de Jesús María Córdoba.

OB: un proyecto que estamos empezando a trabajar juntos que fue de incorporar piezas de Arroyo Leyes que son piezas hechas por africanos y afrodescendientes que fueron encontradas en Arroyo Leyes, en Santa Fe, que llegan acá porque el primer director era coleccionista y era arqueólogo y las tiene, pero estaban en depósito. Nosotros estamos intentando hacer un proyecto que intenta unir a todos los museos que tenemos estas piezas y a las comunidades de afrodescendientes de donde están estos museos para hacer una exhibición conjunta (...) fuimos hasta Arroyo de Leyes, nos reunimos con la mesa afro de Córdoba, ellos nos dieron un contacto con una persona de Arroyo Leyes, y entonces nos fuimos hasta Santa Fe, nos juntamos con el [Museo] Etnográfico de Santa Fe, y con la persona de Arroyo Leyes que es afrodescendiente y algunas cositas pudimos compartir, incluso en el día de la inauguración ${ }^{212}$ hizo una performance y pudimos revisar algo del texto, pero bueno, la idea es que esto sea la apertura de un proyecto. Y esto si entra en diálogo porque los objetos los pusimos en la iglesia (...) que la iglesia tenía una muestra de objetos jesuíticos, y sacarlos de ahí fue toda una tensión, pero bueno estamos haciendo ese ensayo (...) saco los objetos de la iglesia, la iglesia significa esto, incorporar a los negros acá en la iglesia significa esto, (...) la gente se resiste, tiene sus motivos para resistirse, y está bueno que se resista, pero también está bueno escuchar esa resistencia y entenderla, si porque la gente es profundamente

211 http://www.museo.filo.uba.ar/en-el-conf\%C3\%ADn-del-mundo

212 https://museojesuitico.cultura.gob.ar/actividad/late-cultura-arroyo-leyes-objetos-realizados-por-africanos-yafroamericanos/

https://www.facebook.com/events/485651168612290/ 
religiosa, si es porque siempre se hizo así, si es porque tienen miedo, si es porque... o sea construir el sentido, de por qué...

Aquí más allá del destacable trabajo articulado, y del lugar habilitado al aporte de la comunidad afro cordobesa, el rasgo poético, en el sentido de la reinvención, de la transformación, está dada por colocar piezas consideradas "profanas" en un espacio que es considerado "sacro" para una cultura religiosa. Cultura que además es profundamente hegemónica en ese espacio. Entonces colocar elementos de otra religión y cultura, la que además ha sido históricamente subyugada, además negada y escondida, implica una enorme subversión. Sumado a que para realizar esta exposición además hubo que sacar una muestra de elementos jesuíticos y guardarlos en la reserva, donde antes estaban estas piezas afro. Considerando a la vez que esta movimiento vuelve a poner en escena a la comunidad afro en las estancias jesuíticas, quienes tuvieron durante su obra una enorme cantidad de mano de obra esclavizada. Un enorme movimiento de posiciones, lo que provocó incluso tensiones a nivel interno, dado que parte de la propia comunidad del museo sintió que se estaba tocando algo intocable. En definitiva toda una propuesta que permite movilizar sentidos, desnaturalizar estructuras e instalar preguntas, para discutir el por qué de las acciones y discutir el "pero si siempre se hizo asi" que muchas veces es parte de los espacios de museos, al igual que en muchas instituciones.

En el caso del Museo-taller Ferrowhite también se hace un interesante uso del espacio de un modo poético, en algo ya mencionado, pero que resulta pertinente traer a cuento aquí. El espacio de la nave central del taller, donde se encuentra la muestra permanente, está ocupado en gran parte por espacios vacíos por decirlo de algún modo, es decir desprovistos de objetos, donde lo que se exhibe es lo que no está. Mediante siluetas dibujadas en el piso con pintura amarilla se delinea lo que sería el contorno de la bancada de un torno, o de una fresadora, para denunciar el desguace provocado por la privatización, provocando la reflexión de aquello ausente, de aquel bien material que debería estar allí ocupando espacio, pero que no está por acción del saqueo privatizador.

En esa misma muestra permanente otro espacio, lateral en esa gran nave del taller es ocupado por una instalación denominada como la "máquina de contar la historia" bajo el título de "Una historia de cartón pintado". Se trata de 8 plataformas sobre ruedas que ellos llaman "las vagonetas", cada una relata mediante un par de versos una etapa de la historia nacional, cada cual con su propio nombre: "Máquina de Hacer Patria", "Granero del Mundo", "Máquina Carnero", "Aparato Nacionalizador", "Aparato Obrero", "Grúa Financiera", "Bomba de Evaporación y Vaciamiento", "Argentinizador de Acción Manual".

Comparto los textos, porque creo que son una muestra elocuente en esto de producir relatos breves pero interpeladores para abrir sentidos y discutir, mientras a la vez dejan un claro posicionamiento político 
[Presentación]

Aquí la galería de mecanismos oxidados y engranajes que giran en falso: el brazo del líder que ya no sube, la rueda de la fortuna atascada en un embarque record, el Remington civilizador que todavía humea, la máquina increíble que se desguazó a sí misma. Habrá que desarmar y volver a montar cada pieza, reponer las que faltan, fabricar otras nuevas.

El tren de la historia es un tren fantasma, saluden a los héroes antes de que se desvanezcan en el aire

\section{Máquina de Hacer Patria}

Para que cruce el desierto un tren expreso

si hace falta se cortan mil pescuezos

qué eficaz es la acción

de la Civilización

¡y qué barbaridad es el Progreso!

\section{Granero del Mundo}

El granero argentino, claro sello

De la patria que exclama a voz en cuello:

¡Al mundo alimentamos!

$Y$ no nos preguntamos

Si el granero es "del mundo" porque es de ellos.

\section{Máquina Carnero}

Un carnero no es alguien con pereza

es un bicho que vale lo que pesa.

Amigo del inglés,

nuestro carnero es

un patriota que agacha la cabeza.

\section{Aparato nacionalizador}

Compré cada durmiente que les muestro, cada remache inglés, y todo el resto.

¿Y ven este vagón?

(se emociona Perón)

jes argentino, compañero, y nuestro!

\section{Aparato Obrero}

Si un obrero se las rebusca a diario, dale y dale, no importa el calendario, 
si a su palabra es fiel,

y es firme como un riel,

ese obrero es un obrero ferroviario.

\section{Grúa Financiera}

¿Es un globo que se escapa de las manos?

¿Es un queso gruyere todo agujereado?

¿Quién dice lo que es

(aunque sea un inglés)

Un país que está "globalizado"?

Bomba de Evaporación [su intervención está pendiendo de la grúa de la vagoneta anterior]

¡Hay que dejar el Estado en la banquina

para que ascienda como un globo la Argentina!

Se hace, y en segundos

se accede al Primer Mundo

agitando banderitas made in China.

Argentinizador de Acción Manual

El modelo anterior está agotado

Hay uno nuevo (aunque parezca usado).

Ajuste la clavija

y agarre la manija,

a ver si arranca para nuestro lado.

\section{[Cierre]}

Si el de Historia es un libro apolillado

Con algún que otro capítulo extraviado,

Si el cuento es de memoria, ¿no será que esa Historia

es una historia de cartón pintado?

Ferrowhite a partir de su definición como "Museo-Taller" también ha provocado en su tarea a otro tipo de creaciones, dando cuenta de esa otra función o dimensión que tiene como taller, en la que se ocupan de reparar objetos del pasado, así como de producir objetos del presente, o de inventar otros del futuro

AB: en la dimensión del taller están Guillermo Beluzo y Pablo Oviedo, uno que viene de las artes y Pablo es arquitecto, y que además son un poco constructores (...) ellos están más en la dimensión del museo taller... de la producción interna... la restauración de objetos, el 
planteo de nuevos objetos inventados, construidos, como en un momento las vagonetas, hoy por hoy "el arca obrera"213, o "la manifiesta" que es una locomotora manicera que reconvertimos en un dispositivo para que intervenga en manifestaciones, y por ahí ellos están más en ese laburo......) cuestiones que son parte de la infraestructura del museo, pero también objetos, artefactos construidos que inventamos para... bueno seguir problematizando a la cuestión patrimonial y dinamizando un montón de acciones aquí es interesante como además de jugar con el espacio y las cosas, además se dedican a la creación de "objetos inventados", los que tienen un potencial narrativo interpelador, como en el caso del "arca obrera" (ver nota al pie) una balsa hecha con bidones de agua que es presentada como un dispositivo de escape ante futuros derrames tóxicos, o " $\mathrm{X}^{3 \text { 2114 }}$ un cubo de tela semitransparente que se infla con aire, el que presentan como una incógnita, una cubo/pregunta con el que han intervenido en el espacio público para problematizar cuáles son los límites del territorio y que han llevado por ejemplo a los encuentro de TyPA ${ }^{215}$. O del mismo modo como hicieron en colaboración con el Museo del Puerto, los repasadores con los que se presentaron en el encuentro MINOM ${ }^{216}$, entre otros tantos ${ }^{217}$.

En estos desarrollos además es interesante que plantean que se trata de objetos patrimoniales, es decir, que el museo en su dimensión productiva se ocupa de crear objetos para que pasen a formar parte de las colecciones del museo. Una operación que de algún modo interpela y desnaturaliza a la producción museológica desde el inicio mismo del dispositivo museo y la creación de sus colecciones. Un llamado de atención sobre esa operación ideológica de los museos europeos que se ocuparon de circunscribir cuáles son y cuáles no son objetos dignos de ser guardados, cuidados y recordados.

\section{El presente como tiempo privilegiado para pensar}

En el marco de este recorrido proponiendo reflexiones en torno a las prácticas relatadas, aparece un recurrencia considerable en cuanto a que la construcción con otros tiene un sentido fundamental en el anclaje con el presente. Un tiempo histórico sobre el cual, a partir del encuentro entre sujetos no necesariamente conocidos ente sí en un espacio social es posible poner en movimiento recuerdos y experiencias, tensarlos en articulación con macro procesos para construir memorias revitalizadas

JR: nosotros siempre decimos que partimos de pensar el presente, la historia y el presente de la comunidad (...) para nosotros un tiempo privilegiado es el presente, si bien recuperamos el pasado, como se ha ido desarrollando a lo largo de los años esta comunidad, siempre el tiempo nuestro privilegiado para pensar es el presente, qué pasa hoy (...) lo otro que

\footnotetext{
213 http://museotaller.blogspot.com/2012/01/la-balsa.html

https://vimeo.com/66807022

214 https://vimeo.com/199698626

215 https://www.typa.org.ar/es/museos.php

216 Esto fue relatado de manera amplia en el capítulo 3.

217 En su blog hay un muy buen registro de todo lo que van produciendo
} 
forma parte del relato permanente, es la articulación entre lo micro y lo macro, estas historias personales, historias de vida, que son obviamente muy individuales, particulares, siempre entendemos que por sí mismas no tienen mucho más sentido que para la persona que la cuenta, siempre recupera sentido, un sentido más colectivo, forma parte de un museo, cuando eso se puede articular con procesos mayores, con procesos políticos, con momentos políticos, con momentos históricos del país, del mundo. La intención nuestra siempre es articular esos relatos de historias de vida articulados o contextualizados en situaciones politicas, sociales, culturales, económicas, de un momento determinado a nivel regional, nacional e incluso mundial.

así se provocan estas memorias, producidas de manera activa, a partir de la interpelación y la confrontación, adquiriendo un sentido colectivo a partir de esta superposición conflictiva con procesos colectivos. En el marco de los proyectos de deconstrucción de la historia para dar lugar a aquellos y aquellas que siempre han sido despreciados, o en su defecto han sido narrados por otros sin respetar sus propios términos, robándoles la voz. Aparece aquí también una preocupación por desarmar memorias que se denominan como "estereotipadas", las que condicionan los modos de recordar y que encorcetan las memorias propias

SM: hay unas memorias que son más colectivas y que tienen que ver con las construcciones sociales, hay otras que yo siento que son muy personales, como todo lo que le despierta a uno trabajar sobre determinados aspectos o cuestiones que tienen que ver con un discurso histórico... hay memorias estereotipadas ¿no? Como que nos contaron que debería ser así entonces de alguna manera de acercarnos a ese ideal de memoria... que un poco pasa con los monumentos y esas cosas... (...) un estereotipo de cómo recordar... que puede ser muy interesante pero que también te condiciona a recordar de determinada manera y no de otra...

Abrir sentidos, liberar las memorias para dar espacio a las construcciones propias, y para eso los que participan de esos procesos como parte de los equipos de los museos dan cuenta de sostener una posición discutible, en la que si bien se sostiene un posicionamiento explícito, a la vez siempre hay lugar para la duda, para la pregunta y para la búsqueda de otras experiencias en cruce con los relatos que los investigadores e investigadoras del museo han podido construir con su trabajo

$A B$ : hay un relato que plantea una cierta lectura, una cierta mirada, que intenta generalmente, ésto... como abrir sentido, poder pensar las cosas críticamente, no es que asumimos que tenemos la verdad, ni bajamos línea, sí hay una posición pero eso también es discutible, y más allá de esa lectura, te podés encontrar con lo que diríamos de la experiencia en crudo, el testimonio que te cuenta lo que vivió, ya sea a través de un fragmento de entrevista, de un video, o de la presencia misma (...) a partir de eso vos podés sacar tus propias conclusiones o darle tu interpretación... y eso está en diálogo también... es a partir de esa mirada que observa o atiende a esos testimonios, pero que también que lo cruza con otras cuestiones y también eso revitaliza la propia experiencia, empieza a haber un diálogo entre estas dos dimensiones que estarían generando un tercer relato, un meta relato. 
Todo esto es interesante para poder abrir enlaces a la construcción del siguiente apartado, que dedicaré a reflexionar en torno a la dimensión educativa en el sentido más complejo del término, en el de la interpelación de la propia experiencia y la conmoción de la propia subjetividad, la que se produce a partir del encuentro, de una experiencia compartido con otros en un espacio social.

\section{Interpelaciones subjetivas y su dimensión formativa}

Desde que el momento en que los museos pasaron de ser espacios de acumulación de colecciones y se empezó a producir una composición más intencionada en la presentación de los objetos, ya se estaba haciendo lugar a su función educativa, e incluso como ya fue desarrollado anteriormente, el aspecto educativo fue institucionalizado en la definición que el Consejo Internacional de Museos ${ }^{218}$ (ICOM) desde su creación. La definición vigente por la institución según figura en su sitio web dice:

Un museo es una institución sin fines lucrativos, permanente, al servicio de la sociedad y de su desarrollo, abierta al público, que adquiere, conserva, investiga, comunica y expone el patrimonio material e inmaterial de la humanidad y su medio ambiente con fines de educación, estudio y recreo

y si bien actualmente el Consejo se encuentra en un proceso de consulta abierta a nivel internacional para reescribir esta definición ${ }^{219}$, donde ya aparecen algunos lineamientos que direccionan miradas de mayor apertura, deslizando incluso críticas a sus responsabilidades éticas, políticas y culturales, así como animan a pensar desde cierta diversidad cultural, aún así luego del proceso es muy probable que la palabra "educación" siga apareciendo expresada en los lineamientos de la institución para lo que debe ser un museo.

Como ya hemos venido desarrollando en este trabajo, esta macro definición ha sido históricamente posicionada desde una mirada un tanto rígida de la educación, en términos de construcción institucional, como espacio reservorio, como lugar donde se conservan elementos para la transmisión cultural desde ciertos parámetros culturales y saberes.

Este argumento prescriptivo es reconocido por las personas entrevistadas, pero visto más bien como una mirada que les llega desde fuera, como un mandato, y que los vincula centralmente con sujetos del sistema educativo formal,

LC1: desde una génesis, la función del museo tuvo que ver con una función educativa con el sistema educativo formal, eso es como un sello impreso que desde el origen continua, 
es como muy fuerte, es más, la estructura y los horarios de visitas durante los días de semana, está pensado en lo escolar,

CM: Para nosotros el desafío es como poder pensarlo desde distintos lugares, no se si en este orden jerárquico, pero una cosa es poder pensar al museo como un espacio posible de articular con la escuela, digo, sobre todo para romper con esto del museo como un lugar inaccesible, (...). Entonces como habilitar este espacio, como abrirlo. Por otro lado la posibilidad en el mismo contexto de pensar a las exhibiciones en términos didácticos. Uno puede aprovechar la exhibición como una instancia más a articular con el aula (...) la articulación con algunos contenidos propios de la disciplina (...) No puedo pensar la educación sin el concepto de cultura, pero no necesariamente alguien de ciencias de la educación aborda a estudiar la cultura como objeto de estudio.

$A B$ : viene como un precepto, una de las funciones de los museos además de preservar y de conservar es la función educativa, que pensada así primero desde el rol mínimo de recibir a las escuelas, ya está muy instalado, que son recursos que complementan el aula, pero después terminás entendiendo que el sentido educativo es tan amplio como en realidad toda la actividad del museo...

en estos relatos aparece bien clara esta definición, y también allí dan cuenta de la demanda que ese criterio les genera, y si bien esto no es general a todos los espacios observados, los pedidos de las instituciones educativas llegan al punto de muchas veces tener que organizar sus agendas en función del público escolar, relegando al "púbico general". Sumado además a que hasta tanto esos espacios escolares logran conocer el perfil y la perspectiva desde la que trabajan, suelen depositar en los museos una serie de expectativas vinculados a sus imaginarios hegemónicos de lo que deberían ser y de lo que alli van a buscar con sus estudiantes.

Aunque como también vemos en el último de esos testimonios también esta clara, desde el paradigma crítico y la mirada amplia que venimos desarrollando, que la dimensión educativa de estos museos es abordada y planificada de maneras mucho más amplias, sin por eso perder la especificidad, y que eso lleva también a producir interesantes cruces en las relaciones con los educadores y educandos.

Algunas de las acciones que los museos observados están planteando tienen que ver con intervenir en el sistema de las instituciones educativas aportando algunas articulaciones, como en el caso que se relata a continuación, construido desde el área de formación docente del Museo Antropológico Juan E. Ambrosetti de Buenos Aires, en el que buscan la vinculación entre investigadores de la Universidad de Buenos Aires con los docentes de inicial, primaria y secundaria, para aportar herramientas a modo de formación en ejercicio, dentro del esquema de formación permanente

CM: Otro tipo de propuestas que hacemos, que son unas que llamamos OBL "Octubre bajo la lupa" en la que nos propusimos en esto fue generar un espacio de comunicación entre 
la facultad y los docentes, ya sea en ejercicio o en formación, o sea o estudiantes del profesorado o docentes que estén en ejercicio. Entonces durante 5 años, trabajamos distintas temáticas con algún investigador de la facu primero, que daba alguna charla sobre algún tema en particular, y después nosotros hacíamos alguna propuesta de re elaborar estas cuestiones. esta actividad resulta interesante, en tanto suele ocurrir que, por las particularidades de la tarea y por los tiempos que ocupa, los docentes del sistema formal suelen desvincularse de los espacios de formación universitaria, configurándose de algún modo una serie de circuitos diferenciados de formación que los van segregando de la posibilidad de contar con actualizaciones de calidad y que además generalmente son gratuitas.

Desde el mismo programa, también es interesante como se piensa a los educadores que se desempeñan en las instituciones educativas como agentes aliados para la articulación y multiplicación de las propuestas, problemas y preguntas del museo en otros espacios de formación

CM: hay algo que tiene que ver con pensar que el docente es un agente divulgador, 0 sea, yo trabajo con el docente, las temáticas que trabajamos con el docente, entonces el docente las puede transpolar al aula y no necesita, o no queda restringido solo a la visita del museo, sino que tienen herramientas para trabajarlo previamente, o más allá del museo,

considerando que de ese modo, aquello que desde los horizontes de intervención del museo se plantea, puede llegar más allá, hacia otros ámbitos, extendiendo de algún modo el territorio de alcance.

\section{Una mirada integral de las interpelaciones formativas}

En estos ensayos, como en tantos otros que ya hemos descripto a partir de la recuperación de los relatos construidos en las entrevistas, podemos ver que estos espacios están considerando de manera compleja los alcances formativos de su tarea. Produciendo no solo en aquellas interacciones con instituciones educativas, o en actividades que explícitamente tienen una intencionalidad educativa, sino visibilizando el alcance formador que toda acción tiene en un espacio social donde se encuentran sujetos diversos.

OB: para mí lo educativo, lo veo en todos lados, o sea, a ver... todas las cosas que te nombré son educativas (...) está en el trabajo de las cárceles, está en el proyecto de cómo exhibimos, o sea cómo comunicamos, o sea, es bien transversal,

esa transversalidad formativa, mirada desde esta complejidad, ya no está realizada solo por los integrantes del área educativa, sino en cada acción emprendida en nombre del museo, incluso en acciones que no tengan una intencionalidad educativa, en términos tradicionales. En este sentido los siguiente relatos son ejemplos interesantes para comprender los alcances de cómo esta dimensión formativa es pensada por las personas entrevistadas. 
En el primero de los casos, porque de algún modo expresan de manera coherente aquello que se propone desde lo discursivo, y si se apela a dar prioridad a los sujetos de la comunidad, tiene sentido que esos sujetos sean involucrados de la manera más amplia, cambiando también en el mismo juego el tipo de transacciones comerciales, y a quiénes se les está aportando la ganancia, a quién se les está encargando la provisión de los bienes de consumo

JR: El modo en que vos presentas las cosas, o en el hacer de una actividad, no es lo mismo comprar masitas en el super mercado, que pensar que una vecina te haga las masitas para invitar a la gente a comer, no es lo mismo. En esas pequeñas acciones nosotros pensamos que bueno, que también se da, o se pone de manifiesto lo que piensa o desde donde construye los relatos el museo

En el segundo caso tiene que ver con poner un especial énfasis sobre a dimensión humana, y por ende, cuidar que el modo en que se establecen los vínculos mantenga la calidad esperada, extendiendo esto a todas las personas que componen el territorio del museo, no solo los que se ocupan de la tarea explícitamente educativa

LC2: para mí es la sensibilidad de lo humano, de la persona, somos personas, trabajamos con personas, lo fundamental del museo son las personas, no solo los visitantes, sino las personas que conformamos esta organización, desde el que está en portería, al que está haciendo educación, o comunicación, o maestranza o mantenimiento del techo, si alguno de ellos no tienen empatía con el otro... obvio que hay un montón de complejidades, algunos les gustan unas cosas a otros otras, pero para mí esa sensibilidad de lo humano, del sujeto como objeto dentro del museo. Eso es clave, y desde ahi se marca todo... poder ver al otro, tener la sensibilidad de tratar de entenderlo, qué lo toca, qué lo conmueve, qué lo interpela...

A partir de ese reconocimiento de las personas como sujetos dignos, es que se puede empezar a construir una plataforma sobre la que posicionar de manera firme el horizonte de construir a los museos como un espacio de intercambio, como un espacio donde se puedan plantear discusiones con otros, teniendo como punta de partida el reconocimiento del otro, no necesariamente como un igual, y sin desconocer sus desigualdades, diferencias y conflictos, pero sí al menos como alguien digno, como alguien con quien tener conversaciones a la misma altura, reconociéndoles como participantes del juego en las mismas condiciones.

De ese modo puede pensarse en la configuración del museo como un espacio social de diálogo, como una arena de debate, en la que no necesariamente serán siempre intercambios placenteros o cómodos, así como tampoco impliquen la obligación de llegar a un acuerdo, pero propiciado a partir de correr al espacio de museo y a sus trabajadores y trabajadoras del lugar del saber erudito para habilitar la construcción colectiva de memoria. Un desplazamiento, que como ya hemos dicho, no corresponde solo a los espacios museales, sino que puede producirse en muchísimas otras de las acciones de sujetos que se posicionen desde epistemologías críticas para abrirse a los saberes de otros y otras 
AB: lo educativo lo pienso como un diálogo en donde lo que planteamos es bueno... una mirada, una propuesta, una lectura, pero que eso no invalide entrar en diálogo con otros, para ver lo que opinan sobre eso que estamos diciendo, no como ese lugar que tenían los museos, como de marcar lo que había que saber, lo que había que aprender y cómo, sino más como una arena de intercambio y de discusión de posturas...

VS: nos parece que es valioso, que estas posturas que se están trabajando, [Eilean] Hooper-Greenhill plantea esta cuestión de los museos como espacios seguros para interacción entre extraños, Vero [Verónica Jeria] mencionaba la otra vez que Olga Bartolomé decía que "Ios museos son espacios seguros para hablar de temas inseguros"220. Hay algo del tipo de comportamiento ceremonial, esperado en el museo, que muchas veces nos juega en contra y acá nos juega a favor porque lo que nos permite es enmarcar de determinado modo la conversación, la discusión como para plantear la diferencia, nos implica a nosotros un laburo importante, para pensar cómo moderar eso.

A partir de una mirada crítica y analítica sobre el espacio, ubicando el rol social que históricamente se les ha asignado a los museos, e identificando críticamente las pautas de comportamiento esperadas, es que aparece esta interesante idea propuesta por Olga Bartolomé recuperando los planteos de Gurian y Hooper-Greenhill de que los museos son "un lugar seguro para discutir inseguridades" (2014:56).

Lo que resulta fundamental por ejemplo cuando se trata de abordar discusiones en torno a temas de la historia reciente, en los que las personas se pueden sentir aludidas al ser interpeladas por las responsabilidades éticas o políticas que ellas, o sus familiares, pueden haber tenido en temas sensibles, o por el modo en que pueden haber procesado esas experiencias. Momentos en los que a su vez las personas que trabajan en el museo y se encuentran conduciendo esas interacciones, tienen desde los posicionamientos políticos elegidos tanto de manera personal como colectiva, una responsabilidad por no dejar pasar algunas afirmaciones

VS: situaciones en las que te plantean en relación al terrorismo de estado... hay cosas que están judicialmente probadas, entonces ya no es "yo creo que a tal o cual lo trataron bien" "mirá... está esto..." entonces hay discusiones o... en relación a por ejemplo "la Conquista del Desierto". Es una campaña militar en la que algunos se quedan con tierras y hay cuestiones muy concretas, de familias desmembradas, de matanzas, entonces ahí yo no puedo avalar que era necesario avanzar sobre esos territorios, porque hay cuestiones que son mucho más... a ver... no es por cerrar las opiniones, las opiniones pueden estar, pero uno también puede mantener cierta postura y no decir a todo que sí.

220 Recupero una cita de la tesis de maestría de Olga Bartolomé en la que habla precisamente de esto:

"La historia a contar entonces, permite poner en tensión las disputas en torno al patrimonio, evidenciar conflictos e intereses diferentes vinculados a él. Esto abre nuevas posibilidades también para el visitante que se acerca a la historia de otra manera, y puede encontrar en el museo un espacio activo, que le permite reflexionar acerca de los procesos de negociación cultural entre lo narrado y su propia mirada. De esta manera se puede sentir al museo como lugar seguro que ayuda a construir comunidad, que puede ser un lugar seguro para discutir inseguridades, lugar de encuentro con la diversidad y espacios para debatir los problemas del momento (Gurian, 2006)." (Bartolomé, 2014:56) 
tal como se cuenta en este caso, hay un compromiso, sobre todo por parte de una institución que se plantea una revisión de la historia de manera crítica, como un ejercicio democratizador, resulta fundamental el modo en que se establece esa conversación. Y resulta desde el rol ejercido en la institución un momento que invita a sacudir -en términos subjetivos- al otro, tratando de provocar una reflexión en el marco de los macro procesos sociales

SM: de alguna manera son los espacios sociales los que nos enseñan a poner esas ideas en discusión, a ponerlas en práctica... y a veces parece un discurso que hay que tratar de llevar lo más parecido a la coherencia, o sea... ser coherente en eso... el trabajo ese de la doble moral... empezar como a desecharlo, porque nos atraviesa a todos, sobre todo ahora...

a la vez, como en todo intercambio pedagógico, es esperable que ese diálogo también provoque conmociones, alteraciones subjetivas, en quien produce la pregunta. Como todo movimiento formativo, en lo inesperado del encuentro se pueden desarticular y poner en reflexión estructuras de todos los sujetos que participan de la interacción.

\section{Ver más allá de lo evidente y descubrir lo que negamos}

En la perspectiva de hacer que en el encuentro con otros se propicien otras miradas del mundo, de revisar críticamente el modo en que miramos, y producimos nuestras memorias desde el presente, configura una intervención sobre las subjetividades, y por acción performativa sobre el propio mundo.

Una acción que de algún modo produce conciencia, que pone de relieve operaciones naturalizadas, que muestra los hilos de los mecanismos sociales, sobre todo se produce la conciencia de que la experiencia de cada sujeto puede ser -si se lo permite-, en realidad una experiencia compartida, una construcción colectiva que va más allá de la propia sombra, expandiendo los territorios de la percepción

AB: podría generalizarse a todo el museo, es pensar de dónde está ubicado el museo, eso que decimos "el museo empieza afuera" tomar conciencia del sitio específico en donde está ubicado todo lo que ahí podemos ver materialmente, tangiblemente, pero también todo lo que está pasando y no vemos, entonces poder abrir esa mirada a esa lectura sobre todo del presente, y en esa dimensión del presente (...) el pasado y el futuro, tanto las memorias como los imaginarios, hoy se juegan, hoy acá, terminamos vinculándonos con la primera pregunta, la del sentido político, en ese ejercicio de abrir la mirada, de ser no sé... conscientes, críticos, de prestarle atención a las cosas, de abrir a la sensibilidad, por ahí va esta función educativa, y hace que necesariamente que eso se da o está buenísimo cuando empiezan esos intercambios y de pronto te encontrás a un chico de la escuela que se puede encontrar con un estibador y entonces el museo hace como un medio, que pone en contacto dos personas, dos experiencias, dos realidades, dos saberes, ahí creo que también está esa función educativa... de nexo... 
En esta experiencia relatada, una vez más aparece esta idea del encuentro entre sujetos extraños, el museo actuando allí como mediador para el intercambio de saberes entre sujetos que tal vez no se hubiesen encontrado en otro espacios de sus vidas cotidianas y que en el museo encuentran un lugar de cruce de sus trayectorias. El museo actuando como articulador de tramas y experiencias. Cuidando a la vez en ese ejercicio de mediación que haya posibilidad de seguir desarticulando asimetrías, y que tanto el joven como el jubilado puedan enseñar y aprender en ese intercambio

AB: y el modo ¿no? Que sea un espacio donde a veces el estibador es el que le viene a contar los chicos como era el trabajo en otras épocas, pero por ejemplo, muchas veces los chicos del taller [se refiere a "Prende"221] en otro contexto, que ya saben la técnica de la serigrafía, les enseñan a los grandes o a los chicos nuevos cómo hacer para imprimirse la remera o lo que hagamos, entonces ahí esta cosa de alterar estas jerarquías en el saber... quién es el que sabe, quién el que no sabe... poder pensarlo más... como [Jacquès] Rancièr, ahí se me viene uno... esto de los ignorantes, en definitiva todos somos ignorantes de alguna cosa, entonces el museo como ese lugar en el que nos ponemos en contacto y aprendemos unos de otros, o con otros...

De un modo similar, en el Museo Histórico de Berazategui de desarrollo un proceso de mediano plazo con personas mayores, quienes tenían a cargo la producción de guiones para visitas guiadas, con el asesoramiento del personal del museo, en una operación que les permitía sentirse valorados y donde podían dar cuenta de sus experiencias de vida y saberes en articulación con los espacios de exhibición, legitimándoles como sujetos de saber habilitados por una institución que es relevante en sus propios términos culturales

LC1: creo que en los últimos años se ha empezado a abrir la educación como fenómeno más amplio... el proyecto con adultos mayores es un proyecto educativo, que rompe con esa instancia, empezando a ver el fenómeno de la educación con otra perspectiva, pero romper con ese esquema...

SM: conocimientos ancestrales de esas familias que por ahí los silenciaron o fueron silenciados, me acordaba de esta experiencia de Tucumán que contaban, qué saberes medicinales tenían esas pobladoras de la sierra, como bueno, empezar a rescatar eso que es gran parte de lo que construye nuestra historia, el no silenciarlo. Yo creo que ya no silenciar las voces de las comunidades es un gran paso, no te digo que la revolución... pero por lo menos pone en discusión los relatos más cristalizados...

en el ejercicio de otorgar la palabra y en la posibilidad de que sus intervenciones puedan aportar a la recuperación de otras historias, desde la experiencia de estos sujetos, de saberes populares, o de

221 https://ingenierowhite.com/arranco-prende-taller-serigrafia-ferrowhite-chicos-una-luz/ https://ingenierowhite.com/podemos-decir-los-chicos-del-taller-prende-pequenos-maestros-serigrafia/ http://museotaller.blogspot.com/2018/04/prende-no-para-de-crecer.html 
saberes ancestrales que han sido negados u ocultados desde los dispositivos de transmisión cultural hegemónicos.

\section{¿Y las manzanas verdes?}

Dentro de esta construcción reflexiva de dimensiones potentes en la producciones de los museos que estamos analizando a través de los relatos de las entrevistas, hay un caso que resulta interesante para anclar la configuración en términos complejos de lo que resulta formativo en estos espacios, y que a la vez se articula con la dimensión poética que fue desarrollada con anterioridad en este capítulo.

El caso corresponde al Museo del Puerto de Ingeniero White, donde apelando a un discurso abierto en su museografía, para propiciar otros sentidos diversos, proponen a modo de instalación una serie de manzanas verdes que se encuentran en múltiples espacios. Una metáfora construida a partir de la recuperación de un saber popular que el museo convierte además en símbolo interpelador dispuesto de forma singular por todo el espacio

JR: para mí la función educativa es algo que se simboliza con la manzana verde, porque es un concepto que se retoma en las visitas porque claramente, hay tantas manzanas verdes que la gente te pregunta "¿por qué hay tantas manzanas verdes?". (...), también eso habla del museo, que hay muchas manzanas verdes y en ningún momento te dicen por qué hay tantas manzanas verdes. No es que hay un texto o algo que te explique por qué tantas manzanas, sino que la gente o se va sin preguntar y con la duda, o claramente se acerca a un trabajador del museo y lo pregunta. Eso es poner al visitante en una disyuntiva, si es más activo o pasivo, si se va con la incertidumbre o si se anima a preguntarle a una persona (...) y la manzana verde sale, tiene que ver con que la manzana verde remite a tener una memoria crítica. En realidad la explicación deviene de que muchas entrevistas del archivo oral, mujeres grandes comentan que comer manzanas en bueno para la memoria, como la zanahoria para la vista... esos saberes populares, que están, existen, el museo decidió tomar ese saber popular de las mujeres, y en función de eso elige poner la manzana verde (...) nosotros decimos en realidad, una manzana roja podemos decir que es mas bien dulce, y entonces nosotros elegimos la manzana verde porque decimos que hay que tener una memoria ácida, ¿no? y que esta memoria ácida (...) generalmente les pregunto ¿qué es una memoria ácida para ustedes? (...) una memoria crítica, reflexiva, sobre lo que nos pasa, sobre lo que nos sucede, lo que sucedió en el pasado, y lo que sucede en el presente, (...) poder desnaturalizar lo que nos rodea, como nosotros trabajamos con objetos de la vida cotidiana que están hiper naturalizados, de modo que no nos preguntamos ni de dónde vienen las cosas, eh... digamos, el área educativa trabaja mucho sobre eso, desnaturalizar los contextos, los entornos, en los cuales vivimos, trabajamos, hacemos, y poder en ese ejercicio tener una memoria crítica, reflexiva, y esto es lo que intentamos en todos los proyectos del área educativa, 
De la experiencia relatada también podemos reconocer que en eso de abrir el discurso del museo, también se juega a la imprevisibilidad, se da lugar a la elección del otro, a que quien recorre el museo y participa de esa visita produzca su propia experiencia, elija si le da lugar a su curiosidad y obtiene algún tipo de respuesta, o si se va imaginando su propia explicación para la aparición de tanta manzana verde en la casa.

Se trata de una apuesta a la experiencia, también teniendo en cuenta lo parcial de estas construcciones en términos de la formación subjetiva de los sujetos. Quienes trabajan en estos espacios tienen conciencia del rol que ocupan como parte de un entramado de espacios sociales que pueden interpelar a las personas con las que se relacionan, o tal vez no. Y al igual que en cualquier otro proceso educativo, no es posible reconocer de manera inmediata los efectos de ese cruce, dado que se trata de un momento más dentro de la sucesión de experiencias que las personas transitan a lo largo de sus vidas.

En ese sentido, aún en la responsabilidad y el deseo de producir transformaciones que otorguen mayores oportunidades y que potencien la capacidad de los sujetos para ejercer sus derechos, de todos modos reconocen la complejidad de su tarea, así como dan cuenta de ciertas experiencias que en el largo plazo, les demuestran las huellas subjetivas que sus intervenciones producen

AC: somos profesionales, somos equipos profesionalizados y profesionales que nos encargamos, que somos especialistas no solamente en el cuidado de ciertos patrimonios, pero también en la comunicación de los mismos, (...) esto es un trabajo constante y continuo, (...) los efectos nuestros tampoco son tan medibles estadísticamente, como estas estadísticas que a veces piden los gobiernos, estos resultados automáticos, y vos decís "mira.. hay un largo plazo" (...) en estos años lo que me ha pasado es que de repente sorprenderme por gente que me dijo, "yo vine a este museo cuando estaba en la primaria y ahora estoy estudiando antropología", (...), tenés eso, o gente que te dice "yo vine hace muchos años, vos me hiciste una visita guiada", "yo estuve hablando con vos de tal cosa", o incluso si no vuelven, hay un efecto ahí...

\section{Los procesos también van por dentro}

Tal como ya decíamos antes, en los procesos pedagógicos, todos los sujetos son interpelados, y por ello, los trabajadores y trabajadoras de los museos, quienes participan de manera permanente de estas experiencias de intercambio con otros, reconocen que en el proceso mismo de su trabajo, e incluso en las interacciones con sus propios compañeros y compañeras de tareas se encuentran con múltiples oportunidades de reflexión y aprendizaje, que les va interpelando también a ellos y ellas

AC: ... hay una cuestión de que a medida de que el museo toma posición, yo también lo tomo, me va acompañando, me fortalece a mí también... (...) no deja de formarme, también 
me deforma... (...) y lo que enriquece y lo que abre, es también encontrarse con colegas de otras partes, ver otras prácticas, formas de trabajo, que también nos pasa

Al igual que ocurre en muchas otras tareas, si se tiene una actitud crítica y reflexiva es posible aprender de cada desafío que la tarea profesional propone, del mismo modo que el ejercicio de experimentación de modos diversos de interacción y de gestión van generando aprendizajes colectivos para el equipo de trabajo

OB: antes trabajábamos más como por eventos o por actividades y ahora estamos trabajando más por proyectos, y creo que lo educativo está en eso, está en este proyecto que estamos trabajando con el otro, (...) a la vez, como todo en el museo, se está redefiniendo, por ahí lo contaban las chicas, que es la primera vez que trabajan así a la par, varias áreas juntas, y antes estaba todo centralizado en personas, como áreas, no se... (...) y siempre está la aspiración de trabajar a nivel interno, de poder generar estos espacios de reflexión sobre la práctica, o reuniones con el personal,

En este sentido, la posibilidad de encontrarse participando en espacios de gestión colectiva, espacios de gestión asamblearia, o de generación de proyectos articulados entre áreas, parece ser otro de los espacios preponderantes y empoderantes, que los y las entrevistadas enuncian como potentes para sus propios desarrollos subjetivos

VS: hay algo de mi aprendizaje, también al ir ganando lugar en la institución, al ir pensando qué quería hacer y no solo aceptar lo que me decían que había que hacer, al irme formando que me permitieron pararme desde otro lado, y parte de eso, tiene que ver también con la asamblea, hay algo de sentirse acompañado por pares, aún en el disenso, aún en el disenso absoluto, o en el enojo o la distancia, pero hay algo de pensarnos como colectivo que no sé si en todos los museos ocurre, que hay algo ahí de mucho compromiso con la institución, pero a la vez, de mucha reflexión sobre lo que el museo podría hacer, debería ofrecer, y un montón de cosas más...

en definitiva en el marco de proceso educativos los propios sujetos que integran los equipos de trabajo de los museos también aportan a su propia educación como comunidad, donde la reflexión sobre la práctica, como ejercicio cotidiano potencia la propia práctica del espacio que habitan y desde el que producen a diario.

\section{Una trama para potenciar horizontes políticos}

Como ya anticipé en el capítulo 3, a partir de la múltiples instancias atravesadas para la realización de este trabajo de investigación, pude visualizar que con quienes he realizado las entrevistas forman parte de una trama común, una red más grande de profesionales de diversas disciplinas que intervienen en museos. Una comunidad política de cobertura federal, quienes 
construyen sus acciones anclados en sus territorios, situados en sus comunidades, pero a la vez apoyados de manera solidaria con otros y otras integrantes de esa red de sujetos desde distintas zonas del país, e incluso con integrantes de otros países

SM: Empezar a pensar que no un museo, que estamos dentro de una trama, y de que de alguna manera es lo que le da sentido a defender esos derechos culturales de los que hablamos.

hay un sentido de pertenencia a ese colectivo a nivel macro, en el que cada una de sus acciones de algún modo refuerzan al resto, abriendo umbrales, marcando huellas que dan lugar a otras prácticas, generando marcos de posibilidad, potenciando sus horizontes políticos.

\section{$\underline{\text { Referencias compartidas }}$}

Uno de los potenciales de esta red, está justamente en las oportunidades formativas que se brindan mutuamente desde los lazos personales e institucionales a partir de los cuales se conectan. En esos intercambios de experiencias se van conformando referencias que generan impacto no solo en sus comunidades, sino también en otras, de algún modo van marcando rumbos, hitos, abriendo puertas, trazando huellas orientadoras desde sus particulares estilos de intervención.

Es importante destacar que estas referencias cruzadas, de las que solo muestro algunas, a modo de ejemplo, son una constante tanto en las entrevistas, como también lo fueron en los intercambios informales que sostuve con distintos referentes durante el trabajo de campo.

AB: El Museo del Puerto este año cumple 30 años, y evidentemente marcó como una tradición no solamente en Bahía Blanca, sino que es un museo bastante tenido como ejemplo en otros lugares, como otra forma de hacer historia, y hacer museo desde otro lugar, esto apelando a la voz de los vecinos, de los trabajadores, resignificando esto de los saberes, la cocina, un poco de ahí viene, como cierto espíritu común con Ferrowhite, que por ahí en vez de la cocina, lo va a pensar en el taller, el trabajo en el taller, sí... no se si cuánto está explicitado, cuán abiertamente se reconoce, o no se si lo tenemos claramente "viene de acá"... pero claramente hay muchos vínculos... Vinculos que es necesario reconocer que se van transmitiendo a partir de relaciones interpersonales, (...) gran parte del equipo inicial venía también de trabajar en el Museo del Puerto, por lo que esa genealogía y esa trayectoria debiera arrancar un poco antes, como que de alguna manera Ferrowhite es hijo del Museo del Puerto, de alli algunas inquietudes y maneras de trabajar

Así como el Museo del Puerto es un referente para el Ferrowhite, luego ambos son referencia de un modo particular de hacer museos comunitarios, casi al punto de que actualmente se podría pensar que el modo de los museos de Ingeniero White podrían ser un estilo identificable, el que es reconocido tanto a nivel nacional como regional.

LC1: lo que tiene que ver con praxis concretas, hay un montón de ejemplos y de casos, como cosas del Museo del Puerto, o Ferrowhite, (...) o lo que hacen en el espacio de Áreas 
Educativas de los museos de Córdoba... cosas que podés ir tomando y también uno rearmando en base a todo eso... propuestas propias...

AB: el trabajo que están haciendo en la Estancia Jesuítica en Alta Gracia en Córdoba, todo el laburo que está haciendo el sector educativo que es entre lo educativo y lo comunitario, para mi también es una referencia, algo a tener presente...

Como esta referencia al trabajo del Museo de la Estancia Jesuítica de Alta Gracia tomado como uno de los estandartes en cuanto al trabajo educativo ${ }^{222}$.

Otras de las referencias que aparecen con recurrencia son las del trabajo del equipo del Museo Etnográfico de la UBA

LC1: un montón de prácticas dentro de lo que es el Museo Etnográfico de Buenos

Aires, no solo en la acción cultural, sino en cuanto a la conservación, la comunicación de las colecciones y de su ser y estar en el mundo...

las que han marcado un antecedente para las perspectivas sociales en la museología a partir de la gestión de José Pérez Gollán y Marta Dujovne, quienes a partir de su asunción en la dirección del establecimiento a fines de los años '80, marcaron un rumbo por la modernización de los museos.

\section{Redes de formación profesional}

La referencia al Museo Antropológico Ambrosetti, es sobre todo relativa al impulso que la mencionada gestión le dio a la formación y profesionalización de su personal, así como sobre todo son referenciados porque propiciaron la realización de encuentros de formación (articulados con la Fundación Antorchas ${ }^{223}$ ) en los que participaron trabajadores de museos de todo el país, desarrollados en jornadas intensivas de cursada teórica combinadas con intervenciones sobre espacios concretos del museo

VS: las personas con las que yo me formé fueron parte de todo ese proceso que tenía que ver con la Fundación Antorchas, que promovía encuentros. Bueno eso es re importante pensando en esto de los cambios en los museos, (...) Antorchas promovió el desarrollo e exhibiciones con profesionales de diferentes lugares del país. Acá se hizo una que fue "Los señores del Jaguar"224 en la que participó gente que hoy por hoy tienen lugares re importantes en los museos en los que participaba. (...) esos espacios de formación, que se trabajaban por ejemplo con La Smithsonian ${ }^{225}$, entonces una modernización de los museos viene de ese lado, y Pepe Pérez [Gollán] venía del lado de los museos comunitarios mexicanos, él estaba en el INAH ${ }^{226}$ cuando esos museos se arman, (...) conocía esa experiencia y venia con una mirada muy distinta a lo que estaba pasando acá.

222 Para conocer en detalle esta experiencia recomiendo leer la tesis de Olga Bartolomé, presentada en 2014 para la Maestría en Asesoriamiento y Gestión Pedagógica de la Facultad de Filosofía y Humanidades de la Universidad Nacional de Córdoba. El trabajo se titula "El vínculo entre museo y escuela. Un territorio fértil para aprendizajes e identidades".

223 https://web.archive.org/web/20050424064506/http://168.96.248.2/antorchas.com/nuevo/index.html

224 http://www.museo.filo.uba.ar/los-se\%C3\%B1ores-del-jaguar

225 https://www.si.edu/

226 https://www.inah.gob.mx/ 
AC: cuando Pepe Pérez Gollán y Marta Dujovne asumen, está esta idea de modernizar el museo, y esto fue después de una muestra que se había hecho en la planta baja que se Ilamó "Los señores de jaguar," (...) fue esta experiencia colaborativa en la que vino gente de afuera para ayudar y a formarse, pensando no solo en los guiones sino también en las técnicas de montaje, (...) vino Mirta Bonnin de Córdoba, era un equipo bastante grande de gente que en la actualidad son los que que han hecho estas movidas, por eso los encuentro me encantan, por ese sentido...

VJ: en el año 2001 hice un curso de la Fundación Antorchas y ahí conocía un grupo de gente, el curso tenía una parte de su sede acá, en el museo etnográfico, y era un curso de conservación de colecciones en exhibición. Que lo vinieron a dar tres docentes gringos (...) fue super bueno, había como 20 o 25 personas de todo el país participando y con muchos de ellos todavía sigo teniendo vínculos, pero hasta el día de hoy, gente que sigue laburando en museos y todo eso. Fueron dos meses, así intensivo de 9 de la mañana a 6 de a tarde, se cursaba en el Taller Tarea ${ }^{227}$, que ahora tiene la UNSAM y que era de la fundación Antorchas y había toda una parte de desarrollo teórico, y después toda parte práctica donde se trabajaba todo lo que tenía que ver con exhibiciones, diseño de vitrinas, iluminación, soportes, documentación de las colecciones, un montón de cosas... y se visitaban distintos museos, y acá prestaron el museo para trabajar en una vitrina, y bueno, estuvimos laburando con esto...

En el mismo plano de trabajo colaborativo y formativo también se hace referencia a una experiencia de trabajo compartido entre el Museo Antropológico Ambrosetti y el Museo Azzarini ${ }^{228}$ de instrumentos musicales pertenenciente a la Universidad Nacional de La Plata, donde también se produjo un lazo de relaciones en el marco del curso de formación

VJ: estuvimos trabajando en La Plata en el Museo Azzarini, de réplica de capacitación y de intervención con la remodelación de todo el museo. Todo el año. Los lunes nos íbamos con [Fernando] Veneroso. Fue un acuerdo de cooperación entre el Etnográfico y el Azzarini, que eran universitarios los dos, y entonces el museo nos prestaba los lunes para que fuéramos a La Plata, y ahí también conocía un montón de gente de La Plata, en ese curso que tenemos vínculos hasta hoy.

Otro antecedente que es citado como una referencia importante en las entrevistas, refiere a otro ámbito de la UNLP, en relación al trabajo realizado por profesionales del Museo de Ciencias Naturales, quienes fueron los primeros en nuestro país en asumir procesos de restitución de restos humanos en atención a demandas de comunidades que los reclamaban

VJ: la gente del museo de La Plata, para mí también es referencia, María Marta Reca, y Silvia Ametrano, porque son dos personas que se hicieron cargo de la transformación, desde sus lugares y con sus limitaciones, pero con todo el valor de modificar el museo más grande de la Argentina. Transformar una parte y hacerse cargo de una demanda muy importante que empezó en los '90 que es la restitución [se refiere a la restitución de restos humanos de

227 http://www.unsam.edu.ar/institutos/tarea/institucional.asp 228 https://unlp.edu.ar/museo azzarini 
personas de comunidades indigenas que formaban parte de la colección del museo] de restos humanos y de objetos con valor patrimonial, que también es un desafí importante para los museos de antropología y de arqueología..

dicha tarea es seguida con atención por equipos de otros museos que se encuentran con la misma inquietud, en las que sueñen recurrir al museo platense para asesorarse en la concreción de acciones de distinto alcance. Ya sea mediante protocolos de no exhibición, o el avance de intercambios con representantes de comunidades reclamantes para desarrollar el circuito administrativo que implica luego poder entregar esos cuerpos y sus pertenencias a los colectivos que plantean el pedido.

En cuanto a la formación de redes formativas con otros museos, más allá de lo ya mencionado existen también otros espacios menos formalizados, construidos con objetivos puntuales, y sobre todo con distintos niveles de politicidad, y no necesariamente aportando a la perspectiva que venimos sistematizando en esta investigación. Por citar algunos ejemplos

VS: cómo nos vinculamos con otros museos, a veces a partir de pedidos o consultas, nuestras y de otros. A veces más formales que tienen que ver con préstamos de piezas, en otros casos ha habido pedidos de poder reunirnos para conversar. En un momento, Ana [Anabelle Castaño] participó más que yo, en REMCAA ${ }^{229}$ (Red de Educadores de Museos y Centros de Arte). Yo fui solo a algún encuentro, me parece que hay ahí ciertos matices.

El año pasado intentamos armar esta Red de Educadores de Museos de Ciencias Sociales, que estuvo re lindo el año pasado. A veces nos encontramos en encuentros más académicos, pero también se dan otro tipo de encuentros más informales.

Si consideramos que los y las que trabajan en museos son sujetos sociales y que por ende no están alienados, puede ser pertinente también mencionar referencias a otro tipo de redes formativas, en las que participan a título más personal, pero que en este marco resultan pertinentes como espacios productores de miradas y reflexiones que alimentan la perspectiva de la museología social desde la matriz de defensa y promoción de derechos. El caso más significativo de los nombrados es el que tiene que ver con el desarrollo de las mesas para la promoción y el reconocimiento de los Sitios de Memoria ${ }^{230}$ en el marco de la Secretaría de Derechos Humanos de la Nación desde 2004, las que comenzaron primero en Ciudad Autónoma de Buenos Aires, y en el conurbano bonaerense, pero que luego se fueron extendiendo por diversos puntos del territorio nacional a medida que se reconocían locaciones usadas por el Terrorismo de Estado

VJ: en esa época fue que me metí más fuerte a militar en temas de derechos humanos acá. En Capital, con todo el tema de los Sitios de Memoria que también me involucré digamos más en vínculos con sectores de ex detenidos y sobrevivientes, y me metí mucho con el proceso que se hizo en el Olimpori, en la mesa del Olimpo estuve como 3 o 4 años,

229 http://rededucadoresmca.blogspot.com/

230 https://www.argentina.gob.ar/derechoshumanos/sitiosdememoria

http://www.comisionporlamemoria.org/sitios/

231 https://www.argentina.gob.ar/sitiosdememoria/espacios/olimpo 
participando desde que conformó la mesa de trabajo y... también fueron espacios de aprendizaje super importantes para mí.. eso y los juicios... claro... como 10 años de mi vida muy intensos, muy vinculados a eso (...) en el Olimpo, estuvimos mucho pensando y estudiando y con lo de la ESMA también, en los primeros años, buscando todo lo que había de referencias internacionales de experiencias previas, haciendo investigación y búsquedas en torno a cómo se habían representado estos procesos en otros países del mundo. Qué experiencias de museos había habido... todo eso... pero en realidad el trabajo en el Olimpo fue muy fuerte porque además de la experiencia del museo, con esa idea más tradicional que tenía en esa época... como que la forma de organización más comunitaria y más participativa, me abrió a buscar otros tipos de museos...

Estas son algunas de las propuestas que resulta interesante destacar en el marco del plano formativo en términos amplios, tal como lo veníamos desarrollando, y que suelen ser invisibilizados o desconocidos al no estar construidos como propuestas explícitamente educativas, pero que en el marco de una investigación desde comunicación/educación, resultan pertinentes para ser encuadrados en esta dimensión.

\section{Romper el cerco (Asociación de Trabajadores de Museos - ATM)}

Dentro de estos entramados de relaciones que le van dando materialidad a esta comunidad educativa, uno de los hitos que aparecen en el trabajo de campo tiene que ver con el proceso que dio lugar a la configuración de la Asociación de Trabajadores de Museos ${ }^{232}$, la que como en todo proceso, no brotó de manera espontánea, sino que fue construida a partir de una serie de acciones desarrolladas por sujetos en contextos específicos que fueron la circunstancia para llegar a su creación.

El factor desencadenante fue operado por un actor que podríamos comprender como externo, dado que el primer motivo para juntarse tuvo que ver con el robo de una importante pieza patrimonial, lo que a su vez ocasionó una investigación judicial y la clausura del museo, lo que puso en peligro la integralidad de la colección del espacio

VS: ATM surge cuando se roban el reloj de [Juan Manuel] Belgrano ${ }^{233}$ en el [Museo] Histórico [Nacional], en términos de dar cuenta de ciertas problemáticas en relación al patrimonio(...) [también] tiene que ver con esa cuestión de pensarnos como trabajadores y pensar en las condiciones de trabajo.

\footnotetext{
232 http://trabajadoresdemuseos.blogspot.com/

233 https://www.pagina12.com.ar/diario/sociedad/3-87522-2007-07-03.html

https://www.lanacion.com.ar/922563-roban-de-un-museo-el-reloj-de-belgrano

https://www.lanacion.com.ar/922346-roban-del-museo-historico-nacional-el-reloj-de-belgrano

https://www.lagaceta.com.ar/nota/224778/informacion-general/reloj-oro-uso-belgrano-fue-robado-museo-

historico-nacional.html

https://www.lacapital.com.ar/policiales/acusados-robar-el-reloj-belgrano-n270223.html

https://www.clarin.com/policiales/descubren-ladrones-robaron-reloj-belgrano 0 BJzGA3hRptx.html

https://www.lanacion.com.ar/1186474-juicio-oral-por-el-robo-del-reloj-de-belgrano
} 
VJ: fue en 2007,...porque en abril fue el 30 aniversario de las Madres, se hizo la muestra... y para septiembre, octubre de ese año, se robaron el reloj de Manuel Belgrano (...) hubo una intervención judicial y le cerraron el museo... y ahí fue que nació ATM cuando cerraron el Museo Histórico Nacional y estuvo cuatro meses cerrado, no dejaban entrar al personal, y bueno nos juntamos tres compañeras, que... dos trabajábamos acá [se refiere al Museo Ambrosetti] y dos trabajaban allá [se refiere al Museo Histórico Nacional].

El extenso período de clausura operado desde el Sistema Judicial, desconociendo que las piezas del museo requieren de una serie de medidas de cuidado cotidiano para su conservación, había puesto en riesgo el patrimonio, y este grupo de museólogas realizaron la primer acción conjunta para dar visibilidad a la problemática y buscar que la autoridad reviera el modo de en que se ejecutaba el cierre del establecimiento

VJ: no dejaban entrar a la gente a trabajar, a hacer la parte de conservación, porque encima cuando intervinieron pusieron la fajas... y apagaron el sistema de calefacción y ventilación, o sea que empezaron a brotar los hongos adentro del Museo Histórico Nacional, (...) Nosotros ahí nos juntamos... dijimos "¿qué hacíamos, qué hacíamos?"... (...) dijimos, "vamos a hacer una juntada internacional de firmas para que se abra el museo y dejen entrar a la gente que trabaja por lo menos con las colecciones para conservación" para que no se pierda el patrimonio. (...) fue una juntada de firmas y un abrazo, (...) Hicimos el abrazo, no me acuerdo si fue en diciembre o en enero, y le mandamos todas las firmas al fiscal, al juez, a los diarios, todo eso...

A partir de esta acción en la que se pusieron en contacto con todos los profesionales que en su trayectoria habían conocido en todo el país, sirvió a la vez como la apertura de un canal de diálogo con todas esas personas dispersas por el territorio

VJ: habíamos abierto un mail me acuerdo que era tipo "re apertura del museo histórico nacional" o algo así, y nos empezaron a llegar otros mails ahí, de gente que nos decía "en mi museo pasa tal cosa".. qué hacemos con esto también... y entonces, nosotras tres, por nuestro desarrollo profesional y por nuestras prácticas teníamos muchos contactos, por mail en esa época, con gente de distintos lugares del pais, que trabajaban en temas de museo y todo eso. Decidimos reunirnos las tres, empezar a buscar información, y armar alguna vía de comunicación justamente, ente gente que trabajara en los museos, y entonces en 2008 abrimos el blog, trabajadores de museos, y ahi empezamos a... porque a nosotros nos llegaba mucha información de jornadas, de becas, todo eso... que... nada, en general, las instituciones son bastante...

A partir de la organización ante un problema puntual, y la búsqueda de alianzas solidarias con otros sujetos, decidieron generar un que en principio servía para compartir información, y de algún modo "romper el cerco", lograr sostener los lazos entre profesionales de diversas instituciones, pero que de a poco también se fue abriendo hacia la posibilidad no solo de dar cuenta de problemas, sino también empezar a compartir idea y proyectos 
VJ: entonces dijimos, "bueno, a romper el cerco" (se ríe), y entonces armamos el blog y empezamos a difundir ahí todo lo que tenía que ver con convocatorias, y empezamos a escribir notas nosotras, y a pedir a la gente de los museos que escribiera notas sobre sus propias situaciones, proyectos, o sea, no era todo para decir que estaba todo mal, bueno... contá la experiencia que estás haciendo, los proyectos en los que estás trabajando... bueno y ahí empezamos a trabajar ese blog y... bueno, y ahí arrancó ATM, y después, eso fue en 2008.

Ese movimiento de intercambio, les llevó a dar un siguiente paso, el de propiciar un encuentro presencial para discutir problemáticas, pero también para realizar actividades formativas desde perspectivas museológicas, y también proponen alli discutir sobre trabajos en cooperación, y sobre derechos laborales de los trabajadores y trabajadoras de museos, agregándole otro rasgo político que hasta el momento no estaba tan definido

VJ: empezamos a armar toda la movida, y a organizar para 2011 un encuentro nacional de trabajadores de museos, que se hizo en septiembre de 2011 en el Museo Histórico Nacional, en el auditorio (...) ahí tuvimos un crecimiento importante, (...) nosotros conocíamos ya a la gente del Museo del Puerto, (...) teníamos vínculos con gente de Córdoba, con la gente de La Plata (...) A ese encuentro de 2011 vinieron como 100 personas, de todo el país, ahí fue muy importante todo el núcleo de La Plata que participó, del Instituto 8 [se refiere al ISFDyT N. ${ }^{\circ}$ de La Plata], Alicia [Sarno], Flor [Lloret], toda esa gente que también ya venía con su propio proceso y todo eso... y ahí fue que vino Leo [Casado] que estaba estudiando, (...) ahí fue que hicimos ese encuentro que tenía varios ejes, y uno de ellos era los museos comunitarios, y lo invitamos a Sergio Raimondi para que viniera a dar una charla, eh... que estuvo muy bueno... y después bueno... temas como trabajos en red, cooperación entre los distintos museos, derechos laborales, el derecho a la salud en el trabajo en el museo, estrategias de capacitación, distintas cosas, estuvo re bueno.

Con la dimensión del encuentro presencial más establecida, el colectivo que ya encontraba más fortalecido y materializado en representaciones de muchas más personas aportando al esquema organizativo, realizan otro tipo de acción que resulta formativa pero que además implicó que la corporalidad colectiva asumiera otros matices. La estrategia elegida es la realización de viajes en conjunto en los que visitan experiencias de museos destacadas, a la vez que también viajan al congreso realizado en Santiago de Chile por los 40 años de la Mesa Redonda. A la vez que le sumaron una actividad formativa más teórica: unos seminarios de lectura , a modo de grupos de estudio sobre bibliografías específicas para luego reunirse a discutir

VJ: en noviembre hicimos el primer viaje a [Ingeniero] White, con Alicia [Sarno], Flor [Lloret], Silvia [Durá], estudiantes de museología de la escuela, eramos como 15. Y en el 2012 que se cumplían los 40 años de la Mesa Redonda de Chile, organizamos un viaje de estudios museológicos a Chile, una semana, que también viajamos como 15. Ese año hicimos un taller de lecturas sobre museos comunitarios, interno [de ATM] (...) armamos un taller para ir leyendo textos sobre museología comunitaria y nueva museología y después estuvimos 
organizando el viaje a Chile que fue en septiembre de 2012, que fuimos 3 días a un congreso de los 40 años de la Mesa [de Santiago] y después nos fuimos a hacer visitas a distinto museos,

Fueron estos espacios los que les fueron dando una mayor direccionalidad hacia la museología social y comunitaria, identificando experiencias y referentes bibliográficos sobre los que pensar proyectos. Posicionamiento que siguieron afianzando a partir de la realización de una serie de jornadas que tuvieron como sede los Museos Municipales de Berazategui y en la que nuevamente participaron profesionales de diversos puntos del país

LC1: en 2014 y 2015 organizamos acá en Berazategui ${ }^{234}$ las dos primeras jornadas de prácticas comunitarias, museos y espacios culturales, en este museo y en el del Golf. Participaron trabajadores y trabajadoras de museos de todo el país, con una serie de ponencias.

VS: esto de las jornadas de ATM en relación a las prácticas comunitarias, en términos de mi formación también fueron relevantes, en cuanto a pensar otros proyectos, a cómo los venían pensando, no se... escuchar hablar a Olga [Bartolomé] habla de una profundidad... que tiene que ver...

a la vez que esos encuentros fueron el antecedente que permitió luego la realización de las jornadas de MINON en 2017 en la ciudad de Córdoba

\section{Encuentro de Educadores de Museos (Córdoba)}

Otro de los colectivos de organización que resultan destacados y nombrados como referencia en varias de las entrevistas y diálogos informales en el trabajo de campo tiene que ver con el Encuentro de Educadores de Museos, o el Encuentro de Áreas Educativas como también es referido en otros casos. Un grupo mayoritariamente femenino de trabajadoras de museos de Córdoba.

En su caso el inicio del proceso estuvo motorizado por un proyecto del Instituto Gohete de Córdoba ${ }^{235}$ que organizó un encuentro en el que participaban referentes locales, provinciales y nacionales y que tuvo como sede el museo de Alta Gracia

OB: una de esas actividades era una charla con Silvia Alderoqui, (...) estábamos todos los educadores de los distintos museos, había gente de Buenos Aires que también había venido, y bueno se plantearon todos los temas de la catarsis del lugar que tenemos los educadores en los museos, imaginate 2012 mucho más que ahora, entonces medio que ella tiró la punta de por qué no se unen, y la tomamos.

234 http://trabajadoresdemuseos.blogspot.com/2015/05/atm-jornada-practicas-comunitarias-en.html http://reddemuseos.un|p.edu.ar/articulo/2015/9/7/ii jornada de practicas comunitarias en museos y espacios culturales

235 https://www.goethe.de/ins/ar/es/sta/cor.html 
A partir de este primer desafío configuraron un espacio formativo en el que fueron recorriendo colectivamente los espacios en los que cada una trabajaba, reflexionando sobre sus prácticas y haciéndose devoluciones

OB: Decidimos juntarnos todos los que trabajamos en espacios patrimoniales, hicimos una primera reunión al año siguiente y de allí salió constituido el grupo, juntamos los mails, pensamos qué objetivos tendríamos, y pusimos la fecha de la primera reunión, desde 2012 a la fecha empezó a reunirse este grupo de trabajadores de museos que hacíamos más que nada una reflexión sobre la práctica de la educación en cada museo. O sea, cada museo era anfitrión y recibía al resto, hacíamos la visita o compartíamos el proyecto, y le hacíamos devoluciones, y fuimos tratando de acompañarlo con lecturas teóricas.

En el proceso de organización, además de reconocer la dimensión formativa, empiezan a reconocer que hace falta dar a conocer el aspecto organizativo, y por eso deciden dar visibilidad al colectivo saliendo a ocupar el espacio público para que puedan identificarles en su grupalidad.

OB: Estuvimos asi mucho tiempo hasta que en 2016, o 2015 ni me acuerdo bien, dijimos tenemos que pasar a otra cosa más que el análisis de la visita y pensemos que le puede ofrecer cada uno a otro compañero, por ejemplo había una compañera que era narradora, entonces nos dio un tallercito de técnicas de oralidad (...) Otra como hacían estudios, y así cada una fue compartiendo algo en un taller. Y para un día de los museos decidimos que queríamos que nos empiecen a visualizar como colectivo, entonces ese año hicimos una intervención para el día internacional de los museos, todas juntas en la plaza San Martín, que es la plaza principal de Córdoba, nos empezamos a mover como colectivo, salimos en el 2016 para la marcha en defensa de los trabajadores del estado, y ya ahí recibimos la propuesta de hacer junto con ATM la reunión de MINOM.

Actualmente el grupo sigue buscando y experimentando otras posibilidades, y la configuración que han encontrado tiene que ver con la realización colectiva de proyectos, en los que poder articular fuerzas de diversos equipos para acceder a otras comunidades, entre ellas la de personas privadas de su libertad

OB: Este año fue más trabajar sobre proyectos, hicimos el proyecto de musas, hicimos una jornada de reflexión de los trabajos en los museos... (...), a diferencia de ATM, somos mucho menos politizadas, cosa que a mi me parece que le falta a nosotros, en eso, yo que pertenezco a los dos espacios, me siento más de ATM, porque creo que el espacio de Córdoba se queda solo en la cuestión de la formación, creo que es difícil desvincular la cuestión de la formación, de la cuestión política, no digo partidaria obviamente, es un grupo de trabajadores que por ahí tomamos un posicionamiento, por ejemplo, cuando hubo despidos masivos cada cual estaba en su frasco, todos compartimos prácticas o proyectos, lo que tampoco es poca cosa, porque el proyecto de la cárcel, fue bueno hacerlo con otros museos y no con uno solo, fue más creativo, fue más rico. El congreso también fue así, fue sostenido por todos, o sea, son instancias válidas. 
En este último testimonio también se da cuenta de las particularidades que este grupo tiene con respecto a ATM, aunque como se ve ellas también se han ido fortaleciendo en posicionamientos políticos que como colectivo han salido a manifestar de manera pública.

\section{Hacia la construcción de una conciencia colectiva}

A partir de la recuperación de las trayectorias de estas dos grupalidades, que terminan trabajando de manera articulada para la organización y gestión del encuentro de MINOM en Córdoba en octubre de 2017, puede identificarse el valor que provoca la movilización de voluntades hacia el encuentro.

Aún considerando que esta redes están construidas con personas que se encuentran articulando desde puntos muy distantes del país y eso implica algunas dificultades como las que se afirman en este testimonio

AB: A veces es difícil esa participación, al estar acá en Bahía, y la Asociación tiene mucha gente que está en Buenos Aires y La Plata, esa distancia kilométrica a veces... es difícil participar por la distancia, a muchas cosas es difícil ponerle el cuerpo (...) hay un montón de acuerdos, en modos de ver, de pensar la cosa, más allá de que después temáticamente los museos son muy diferentes, (...) en el fondo compartimos estas preguntas, esto de la nueva museología... ese plafón de diálogo,

en este comentario se da cuenta de la existencia de cómo se han construido algunos pisos de acuerdo, una cierta direccionalidad compartida, basada en una afinidad política construida que fortalece sus subjetividades a partir de las instancias de encuentro presencial donde a la vez se han afianzado fuertes lazos afectivos que fortalecen la grupalidad.

LC2: ATM fue un espacio clave, de organización desorganizada digo yo, o de entropía, de orden dentro del caos, para mí fue clave, el espacio de discusión muy horizontal y llano, pero transversal en un montón de disciplinas y trayectorias, (...) la gracia que tienen los espacios de conducción más horizontal, donde hay más reflexión a la práctica en sí.. y a la vez se genera revisión teórica... (...) personas que se encuentran, que quieren reflexionar, discutir, dialogar, sin importar si hay un papelito o no ...) creo que la instancia de despegarte de tu propia realidad, de tu propio universo donde estas... muchas veces cuando estas en instituciones... estás... tomar distancia y entrar en otros círculos, esos otros copados, (...) te permiten tomar distancia para volver a acercarte a tu ejercicio desde otro lugar, (...) el conocimiento de esas otras personas, en esas otras realidades, tan comunes, tan diversas, eh... y $\tan$ complementarias al mismo tiempo...

AC: encontrarse con colegas de otras partes, ver otras prácticas, formas de trabajo, que también nos pasa, porque lo que nosotros venimos haciendo, lo venimos haciendo desde hace tanto tiempo, que vos lo ves con una mirada crítica, porque le falta esto... y después empezás a decir, nosotros venimos sosteniendo esto... 
VJ: todos los encuentros son buenos, porque generan eso... básicamente, por eso cualquier política pública tiene que tener eso, promoción de encuentro y capacitaciones, es lo más importante...

en todas estas voces aparece claramente una valoración positiva de los espacios de encuentro en su dimensión formativa, y generando al igual que como fue dicho antes, un fortalecimiento de la propia subjetividad a medida que el colectivo se va fortaleciendo. En la posibilidad de salirse del terreno conocido y poder referenciarse en los trabajos de otros profesionales se aprende a la vez que se puede valorar el propio trabajo. Un proceso que va favoreciendo la construcción reflexiva de la praxis, aportando experiencias para la perspectiva de la museología social y profundizando el proceso de construcción del horizonte político que proponen

VJ: son pasos que vos vas dando para tener más conciencia... no es que... cuando pasó lo de 2016 me acuerdo que... cuando despidieron a todos los compañeros acá en cultura......) nos empezamos a juntar para las asambleas, acá las hacíamos, acá en el patio [se refiere al patio del Museo Ambrosetti], me acuerdo que había mucha discusión porque había mucha gente que decía "bueeeeno pero por qué no reclamaron antes...", bueno, porque no es así, no es que te tomás la pastilla roja o la azul y sabés... tener conciencia es un proceso, entonces, tener y conocer la historia, también es un proceso, no es que es de un día para el otro lo podés saber... pero bueno para el tema de los museos tiene mucha importancia... el tema de los vinculos, para mi es de lo más importante. Los vínculos que se establecen entre las personas, y cómo se van transmitiendo esas historias, la oralidad... sí... cómo te vas enseñando de uno a otro, y cómo vas aprendiendo en cada etapa lo que tenés que aprender o lo que podés aprender, justamente por eso, por el contexto, o por tu camino... y cosas increíbles que se han hecho acá en este país... lo que está bueno es poder ahora, para mí, después de lo que pasó en Córdoba, que también fue muy importante porque tiene, digamos... una potencialidad re grosa, para poder generar espacios de resistencia y de continuidad y de crecimiento de esa red.

Estas palabras de una de las principales referentes de la Asociación de Trabajadores de Museos es una clara muestra del horizonte político planteado, en función de construcción de espacio de resistencia, y de profundización de la perspectiva en vinculación con los problemas que la coyuntura ha puesto como contexto en estos últimos años.

\section{Articulación con el sistema de formación}

En el marco de las intervenciones que los integrantes de estas redes van realizando, también es interesante reconocer cómo han articulado con instituciones educativas que tienen carreras relacionadas a la museología. Muchos y muchas de los integrantes de colectivos han tenido lugares como formadores, tanto desde antes de la creación de las redes, y sobre todo a partir de que éstas hayan empezado a tener reconocimiento por parte de quienes integran los ámbitos formativos. 
Instituciones de corte formal, que forman parte del sistema de acreditación oficial, algunos de las cuales vale la pena mencionar porque contienen con mayor o menor profundidad algún tipo de contenidos relacionados con la museología social.

La primera de las que me interesa nombrar es el Instituto Superior de Formación Docente y Técnica N. ${ }^{\circ} 8$ de La Plata ${ }^{236}$, dado que existe desde mediados de siglo XX, siendo una de las primeras instituciones que ofrecieron formación en la especialidad.

Otro de los espacios a destacar es la Maestría en Museología ${ }^{237}$ instalada en 2012 como parte de la oferta de posgrado de la Facultad de Ciencias Naturales de la Universidad Nacional de Tucumán, siendo la primera carrera de la especialidad de este rango en el país, y con la que se han vinculado principalmente quienes desarrollan sus tarea en el centro y norte del país.

En el mismo plano, también referenciar la Especialización en Museos, Transmisión Cultural y Manejo de Colecciones Antropológicas e Históricas, de la Facultad de Filosofías y Letras de la Universidad de Buenos Aires. Carrera de posgrado más reciente, dado que fue aprobada en 2016, cuyo plantel docente está compuesto en gran parte por profesionales del Museo Antropológico Juan E. Ambrosetti.

En los tres ámbitos mencionados, actualmente varios de los integrantes de esta comunidad política de la que venimos hablando, actúan como docentes, e incluso algunos y algunas se formaron en dichas carreras. Convirtiéndose éstos en otros espacios de resonancia de sus saberes, experiencias, y de algún modo formalizando estos conocimientos.

También hay otro tipo de vinculaciones con circuitos de formación que responden a otras matrices, con las que los trabajadores y trabajadoras con los que dialogamos en la investigación interactúan, pero en relaciones de tipo más estratégicas. Un ejemplo de esto es lo que ocurre con el formato de formación para profesionales de museos de la Fundación TyPA ${ }^{238}$, un espacio privado ligado al Grupo Telefónica, en el que para participar hay que pagar elevadas matrículas, o solicitar becas de la fundación. Allí las redes se conforman con profesionales provenientes de museos de todo el continente, muchos de ellos espacios privados y con escalas muy variadas

$A B$ : hay otras instancias los que tienen que ver con la Fundación TyPA, con ellos estamos en diálogo, yo hice un Laboratorio de Gestión en Museos, y después al museo ha sido convocado muchas veces para los distintos eventos que organizan, y está bueno, porque ahí entrás en relación con otros museos y capaz que muchas cabezas y sobre todo la organización, la fundación, por ahí... a veces hay distancias... ahí también hay un diálogo, de esto hay cosas interesantes, hay cosas que podemos apropiar y otras que no... (...) estratégicamente viene bien.. y además hay cosas que esto... que aprendés... porque tenes museos que tienen planteos... desde la gestión casi empresarial, pero también está bueno 
saber que existe eso.. o plantear una posición diferente, o dialogar, o no ser tan cabeza de cerrarse, y ver que tal vez también se puede aprender.

En este caso se trata de un espacio complejo, dado que cuenta con la participación de referentes destacados del campo de la museología a nivel local y también internacional, y en los últimos años además ha prestado especial énfasis en los temas relativos a las comunidades, a la responsabilidad ética de los museos, el trabajo con los públicos, e incluso varios de las personas entrevistas han sido invitados a disertar o han realizado talleres. En los que han participado en función de aprovechar las vinculaciones que allí se propician, y porque a la vez significa legitimaciones para otros circuitos de la especialidad. Pero donde aún encontrándose participando referentes similares, donde muchos de los conceptos y temas tratados se parecen, sin embargo existen matices en cuanto a la politicidad y los horizonte político que se proponen. 


\section{Capítulo 7}

\section{ABRIR PARA NO CERRAR. DIMENSIÓN POLÍTICA DE LOS ESPACIOS SOCIALES DE FORMACIÓN}

Este capítulo es el final de este documento, y por ello lo dedicaré a presentar lo que considero como los alcances del desarrollo de esta investigación, aunque de ningún modo se trata de un cierre. Haciendo honor a la perspectiva desde la que me posiciono serán construidas como conclusiones provisorias sobre el problema de investigación, sabiendo que se trata de una mirada posible entre tantas otras, a la vez que también están tensadas por los contextos en los que fueron producidas. Por ello no hay aquí apelación a las certezas, se trata de una intervención reflexiva que se detiene sobre una pequeña porción de una enorme trama compuesta por sujetos, prácticas y espacios sociales que apenas empieza a dimensionarse y que posee un enorme potencial.

Es necesario explicitar también que se trata de un trabajo que intentó comprender este entramado vivo, complejo, conflictivo y multidimensional, tratando de sostener esas características durante todas las etapas del proceso, con el cuidado de evitar simplificaciones que alisen su complejidad y conflictividad. A la vez sosteniendo durante el proceso la articulación entre teorías y prácticas, intentando un diálogo reflexivo que busca no subestimar ni sobrestimar a ninguna de las partes, intentando producir un marco de interpretación que respete su carácter vital y en ocasiones contradictorio.

Del mismo modo es necesario sostener en esto del contextualismo radical, la recuperación del carácter histórico y por ende contingente de las acciones, las que además se producen en un momento que resulta significativo y desafiante. Un momento de importantes movimientos tectónicos en las matrices políticas a nivel no solo local, sino también regional y global, las que tienen réplicas evidentes en los espacios observados y por supuesto también en los discursos sociales.

Todos las personas con las que dialogué durante la investigación desarrollan su tarea en museos públicos, donde estas lógicas se hicieron evidentes de diversos modos. En todos los espacios hubo referencias a los cambios que la época manifiesta, lo que da cuenta de la transversalidad y capilaridad de las influencias de este proyecto político que podríamos calificar como de restauración neoconservadora y neocolonial por el tipo de direccionalidad que propicia, pero que es sin dudas 
inédito, novedoso y camaleónico en el modo en que se ejecuta, haciendo uso de todos los medios a su alcance, por lo que resulta aún muy difícil de caracterizar. Un proyecto que sin bien tal vez no está escrito en una plataforma única, sí está expresado de manera elocuente, y relativamente uniforme, por las acciones de los gobiernos en los que han logrado instalarse de manera democrática y de las políticas que desde allí han desarrollado en estos últimos años. A su vez, es notorio cómo también se hace cada vez más explícito en los dichos de funcionarios y funcionarias ${ }^{239}$ quienes de a poco con sus expresiones van corriendo significativamente los umbrales de lo políticamente correcto, dejando cada vez más lugar para declaraciones de intolerancia y violencia explícitas, de negacionismo histórico, en las que subestiman derechos fundamentales y hasta han hecho apología de genocidios. Declaraciones que en otros momentos tal vez hubiesen sido motivo de sanciones judiciales o al menos repudiadas por el grueso de la opinión pública, algo que no está ocurriendo en este particular tiempo histórico que nos toca experimentar, e incluso se transforman en marco para que muchas otras personas se sientan respaldadas para sostener posiciones públicas similares. Se trata de un núcleo problemático al que tal vez debamos prestar mayor atención, y encontrar los modos de plantearlo en los espacios públicos en los que nos desempeñamos, para tratar de evitar llegar a puntos de no retorno, o al menos a situaciones que tengamos que lamentar. En este sentido, museos como en los que se desempeñan los sujetos de esta investigación, resultan ámbitos más que pertinentes como espacios para la discusión y desnaturalización de los sentidos circulantes apelando a procesos sociales e históricos, como arenas de discusión crítica sobre temas actuales.

Estas preocupaciones son pertinentes sobre todo teniendo en cuenta que el horizonte político que mueve tanto al campo de comunicación/educación como a lo que se expresa desde los espacios que impulsan la museología social, tienen que ver justamente con sentidos emancipatorios. Que trabajan desde lo público para que los sujetos con los que interactúan puedan tener cada vez mayor conocimiento y acceso a sus derechos, y que puedan ejercitarlos de la manera más plena posible en cada uno de los espacios que transitan en su vida cotidiana.

Un trabajo de algún modo inacabable porque justamente se trata de campos que se encuentran en permanente apertura y transformación, siempre en la búsqueda de ampliar sus horizontes y de seguir incluyendo, en la revisión crítica de sus propias exclusiones y negaciones.

Por ello este trabajo se plantea en ese sentido provisorio, como una cartografía realizada a tientas, caminando por los territorios que articulan prácticas y sentidos de la museología social con otros tantos sentidos sociales, con la intención de producir estos "mapas nocturnos" (Martín Barbero)

239 Por citar algunos ejemplos podemos nombrar las expresiones de Esteban Bullrich durante su gestión como Ministro de Educación de la Nación, o las de Patricia Bullrich desde su puesto de Ministra de Seguridad de la Nación, o en términos regionales los diversos discursos de odio expresados por Jair Bolsonaro, tanto durante su mandato como legislador así como en su actual posición de Presidente electo del Brasil. Los tres casos han tenido diversos discursos que podrían ser calificados como apología o incitaciones a acciones que son calificadas como crímenes, incluso algunos crímenes de lesa humanidad, pero que sin embargo han pasado por los medios y por la opinión pública, calificados solo como "declaraciones polémicas" para algunos sectores de la sociedad, y lo más grave, incluso han sido festejados por otros. 
desde la óptica del campo comunicación/educación, como perspectiva epistemológica crítica que articula interpretación y transformación desde una dimensión hermenéutica participativa (Fernández, 2014)

Sosteniendo el interés en respetar los sentidos de los sujetos de investigación y su "aquí y ahora" que los arraiga a los territorios en los que se localizan, produciendo desde un contextualismo radical, "sin garantías" (Hall, Grossberg, Restrepo), para la comprensión de un momento y un espacio singular de esta enorme trama cultural.

La que como emergente se expresa en esta red se sujetos identificados como referentes para la realización de las entrevistas, quienes forman parte de una comunidad política dispersa por el territorio nacional que se potencia a partir de sus lazos de interacción, en el modo en que Boaventura de Souza Santos (2010) enuncia como una "ecología de saberes", como un tipo de dimensión epistemológica basada en construcciones solidarias entre sujetos y grupos sociales diversos, en las que cada uno de los espacios colectivos que la conforman se movilizan de manera autónoma y por sus propias motivaciones, pero sabiendo que las acciones colectivas pueden transformar esas motivaciones en resultados prácticos que van más allá de las posibilidades y alcances que podrían alcanzarse de manera singular. En este sentido todas las prácticas de organización colectivas descriptas en el capítulo anterior dan cuenta de esta posibilidad, de cómo la producción colectiva en el marco de estas redes van fortaleciendo sus posiciones situadas y cómo les van permitiendo de algún modo ampliar sus rangos de actuación.

En su politicidad creciente estos sujetos sociales van generando núcleos de resistencia que se posicionan contra los múltiples avanzadas neoconservadoras y neocoloniales que se instalan cada vez con mayor presencia en gobiernos, instituciones y organizaciones de nuestro continente, y que por supuesto son a la vez expresión de voluntades colectivas que no pueden negarse, sino que deben ser reconocidas como primer paso para poder enfrentarlas y discutirlas desde los diversos espacios de intervención.

En este sentido, este trabajo de investigación también fue fortalecido y complejizado a partir de la participación en esos espacios colectivos, especialmente a partir del intercambio con los sujetos entrevistados, con estos trabajadores y trabajadoras de museos, en instancias de reflexión profunda a las que esta investigación pretende continuar aportando, y que tendrá como etapa posterior una nueva vuelta de diálogo e interlocución para compartir con ellos y ellas lo construido en esta cartografía realizada a tientas, para desde allí propiciar a nuevas búsquedas que puedan aportar a potenciar sus acciones y sus horizontes.

Desde una vocación de intervención política, esta investigación intentó aportar a la sistematización de aquellas rupturas significativas (Hall) que dan lugar a la identificación de dinámicas de transformación en el marco de procesos históricos mayores, en estos casos protagonizadas por 
sujetos que intervienen desde espacios museales. Sujetos que en el marco de este proceso reflexivo pueden visibilizarse no como sujetos individuales, inmersos en sus espacios, sino como integrantes nodales de una trama que se conforma como una comunidad política que los sostiene y les otorga mayor potencia para la producción de acciones de resistencia en sus propios espacios, donde no necesariamente son sujetos situados en posiciones de poder.

Al tratarse de un colectivo de sujetos que desde diversas disciplinas se posicionan desde epistemologías críticas, esto generalmente les lleva a antagonizar y disputar con diversos sentidos hegemónicos y a sostener una reflexividad continua sobre sus propia praxis.

En principio, a partir de lo sistematizado, este colectivo da cuenta de sostener una disputa sobre los sentidos y los modos de producción hegemónicos en los museos. Un imaginario institucionalizado socialmente, que los coloca como "templos", como espacios monumentales donde el saber está tallado en piedra y bronce, inmodificables e indiscutibles. Como espacios de saberes cristalizados, en los que el lugar para los sujetos de las comunidades es el de ir a aprender. Una construcción pedagógica más lineal y verticalista. Museos en los que muchas veces los saberes populares suelen estar representados como una fase anterior de la cultura desde una mirada evolucionista. Y si bien a esta altura ya son muy pocos los museos que se posicionan desde este imaginario, de todos modos sigue siendo una ideología que es hegemónica en el sentido común social. Por lo que aún cuando muchísimos museos han desarrollado otros tipos de perspectivas, y han discutido estos posicionamientos, el imaginario social sigue operando y produciendo demandas sobre todos los espacios observados, las que se manifiestan por ejemplo en los modos que diversos visitantes, y sobre todo docentes y estudiantes del sistema educativo, le siguen reclamando a las instituciones museales. Un imaginario que constituye una posición de resistencia retrógrada, que los sujetos que se posicionan desde perspectivas críticas deben atravesar en cada nuevo contacto. Que les obliga a realizar estrategias para interpelar a estos sujetos, para intentar en cada caso reconfigurar hacia otro tipo de relación en la que se puedan ubicar de manera más horizontal y donde los puedan reconocer como productores de otras lógicas para los museos.

En términos de disputar las posiciones hegemónicas, las personas que trabajan en estos espacios se han dedicado de algún modo a tratar de movilizar estructuras cristalizadas, sobre todo a partir de desnaturalizar posicionamientos y decisiones, de preguntarse los por qué de las cosas, a manifestar y explicitar sus propias perspectivas para los públicos y desde allí, a tocar lo que desde otros posicionamientos sería "intocable".

Todo esto, no por capricho, ni por un afán de generar caos en los espacios, sino desde un mirada que busca ampliar el acceso público a espacios culturales que culturalmente fueron creados para pocos, siendo exclusivos, y en los que si bien como ya dijimos se han desarrollado movimientos de apertura y transformación, aún requieren de mucho trabajo de dinamización. Desde los sentidos 
expresados en las entrevistas, dan cuenta de que para dar acceso a aquellos que aún no lo tienen, yendo más allá de la "mirada Bourdieu", logrando poner de relieve no solo las exclusiones de tipo social, sino en función también de cuestiones más subjetivas, donde muchos colectivos aún son invisibilizados. Es decir profundizar la comprensión de la accesibilidad más allá de un sentido físico, para llevarlo hacia la posibilidad de dar cuenta de las barreras en los modos y posibilidades de intervenir en el espacio, trabajando para que luego de logrado el acceso al predio, los sujetos de estos colectivos también puedan gozar de una experiencia plena dentro del espacio, sintiéndose reconocidos en su dignidad.

Desde ese mismo sentido, hay una preocupación por revisar las responsabilidades que los propios museos, como instituciones legitimadas socialmente, han tenido en la construcción de imaginarios sociales, en la configuración ideológica de identidades desde los marcos coloniales. Y a partir de identificar esos parámetros discursivos, avanzar hacia su deconstrucción con la participación de los propios sujetos involucrados. Propiciando reflexiones conjuntas, dando lugar a la diferencia, en interpelaciones subjetivas que transformen tanto a dichos sujetos como al museo y sus trabajadores y trabajadoras.

El ejercicio de apertura de los espacios, en términos de trabajo con la diferencia, también permite de algún modo descolonizar el modo de construcción de los saberes, abriendo el proceso de consulta no solo a especialistas científicos (como es usual) sino también a sujetos de la experiencia, aportando en ocasiones a que la producción científica pueda reconocer y complejizar sus producciones a partir de los aportes de los saberes de esos sujetos, e incluso habilitando en algunos casos a procesos de toma de decisiones y de gestión conjuntas. Algo que en la mayoría de los casos está en una etapa incipiente de desarrollo, pero que es visualizado como una preocupación, como un desafío con mucha presencia en sus horizontes de intervención. Y que en principio se expresa en la búsqueda de modos más horizontales y respetuosos de interacción, cuidando sobre todo de evitar crueldades con esos sujetos que han sido históricamente vulnerados y violentados.

Esa búsqueda de mayor horizontalidad también se deconstruye, según lo afirman en las entrevistas, hacia el interior de las comunidades de trabajadores y trabajadoras de los museos, con quienes también desde diversas estrategias de espacios de encuentros y organización colectiva están tratando de romper con relaciones jerárquicas cristalizadas que entorpecen la producción de otro tipo de dinámicas.

En todas estas preocupaciones anteriores también puede identificarse otro núcleo contra el que estos sujetos antagonizan, que tiene que ver con un modo de acceso a la cultura que excluye. Un modo que desde el pensamiento único sitúa a la cultura como un espacio uniforme, con bordes definidos. O la que desde esa "mirada Bourdieu" puede estamentarse según ciertos capitales económicos y simbólicos, para ubicar a los sujetos en diversos puntos de un campo con bienes al 
alcance de las posibilidades establecidas. O también contra aquella visión más mercantilizada de la cultura a la que solo se accede mediante el consumo, mediante un tipo de mandato de adquisición, de lo que "hay que tener", de lo que "hay que ver", de lo que "hay que saber".

Por el contrario, en las prácticas y experiencias relatadas por los entrevistados y entrevistadas hay otro tipo de búsqueda que da lugar a otro tipo de apropiación, en la que los suje tos desplazados por las miradas hegemónicas pueden ser incluidos y buscar que ellos mismo puedan sentirse parte, como sujetos dignos. Dándoles espacios para que sus saberes integren los relatos del museo, sin por eso desmerecer los conocimientos científicos, pero sí dando lugar a aquellos saberes que han sido históricamente negados por el conocimiento legitimado desde la cultura hegemónica. Un doble movimiento en el que se les habilita y a la vez se pueda presentar la crítica sobre esta idea de lo popular como "estado de naturaleza", para revalorizar aquello que aporta otras miradas interesantes, que suman diversidad al escenario considerado. Para romper de algún modo con la cartografía abismal que imposibilita la copresencia de los dos lados de la línea (de Sousa Santos). Reconociendo además que esos saberes populares (algunos incluso ancestrales) siguen siendo valorados porque históricamente les han aportado soluciones concretas para mejorar la calidad de vida. Soluciones prácticas que muchas veces se pueden conseguir a partir de elementos cotidianos, que están a mano, sin tener que recurrir a costosas tecnologías que por otro lado generan dependencia económica.

A la vez también es necesario aclarar que esta preocupación por la recuperación de saberes no está desprovista de conflictos, así como tampoco se los romantiza sabiendo que en el saber popular también residen poderosos núcleos retrógrados que atentan contra las posibilidades emancipatorias. Por eso, como se expresó también en los testimonios de los entrevistados y entrevistadas, escuchar al otro no significa que todo valga lo mismo, y en el marco de los posicionamientos asumidos, hay ciertos umbrales de sentido que ya no son admisibles, como por ejemplo aquellos referidos a avalar genocidios, o los que atenten contra la promoción de derechos que han sido conquistados de manera democrática. Se trata de que los museos sean espacios para la circulación de la palabra y la construcción de subjetividades que aporten a mejorar la calidad de vida de las personas, y donde el conflicto y la discusión son esperables y admisibles, donde pueden expresarse opiniones y se pude discutir en un marco institucional pensado para eso, pero donde no hay lugar para la intolerancia o la expresión de violencias. Lo que ubica a los museos como espacios mediadores, o como moderadores, que permitan superar prejuicios y barreras diversas, para propiciar encuentros, para posibilitar diálogos. La idea de que los museos pueden ser espacios seguros para discutir inseguridades (Bartolomé), que pueden ser espacios seguros para la interacción entre extraños (Hooper-Greenhill). 
En estos términos aparece una idea interesante que es la de que los museos a partir de sus actividades puedan convertirse en "caja de resonancia" de las expresiones de esas comunidades silenciadas o deslegitimadas. Es interesante porque se trata de una imagen que no propone hablar por el otro, sino que implica poner cuerpos, herramientas y al propio espacio a disposición, para que resuene, para que vibre con las voces de esos otros. Para que sus testimonios lleguen más allá. El museo así se transforma en un articulador de comunidades que puede poner en diálogo a unos sujetos sociales con otros sujetos sociales que tal vez de otro modo no se pondrían en contacto. El museo como un dispositivo mediador, facilitador de interacciones.

Esta mirada no debe confundirse con el ideal del consenso al modo liberal, no se trata de ese tipo de tolerancia en el que se permite la expresión de cada una de las identidades o las opiniones, como si a cada cual le correspondiese una fracción exactamente igual a la del otro, pero en la que no se permite la interacción, eximiendo al encuentro cultural de su carácter conflictivo. Por el contrario aquí se lo plantea reconociendo que existen posiciones de poder diversas y superpuestas, que cada colectivo, que cada sujeto ocupa, y que dicha participación implicará una disputa por la participación y la incidencia en la gestión y toma de decisiones dentro de esa comunidad.

Del mismo modo, en museos que se constituyen desde su ubicación como parte del espacio público, se transforman en ámbitos donde es posible construir (o reconstruir) otro tipo de memorias de manera colectiva: los museos como espacios sociales formativos desde lógicas comunales (Taborda, Kusch). Entendido no ya como instituciones monolíticas, sino como construcciones compuestas de múltiples subjetividades con posicionamientos y deseos que pueden estar en yuxtaposición de intereses, en tensión permanente, pero en definitiva, sosteniendo esas tensiones que les dan vitalidad, que les mantienen en movimiento.

Para esto también resulta central una actitud activa en cuanto al abandono de las recetas, en la búsqueda de modos propios. Desde el desarrollo de experimentos dentro de lo que podríamos considerar como "antideseños", o "antilenguajes" (Ford), un interés por desarmar lo hilos colonizadores del dispositivo. En el intento de provocar la deconstrucción decolonial a partir de la recuperación de las "praxis americanas" (Kusch), como gesto, como decisión cultural en términos propios. Recuperando así la posibilidad de participaciones de comunidades, de los sujetos populares, de los subalternos, de los desplazados, para construir prácticas genuinamente multiculturales que permita descolonizar también los gestos propios (Rivera Cusicanqui).

Esta es otra de las variables que resultan recurrentes en la sistematización realizada, la búsqueda por la reconstrucción de saberes populares y su dimensión creativa. En lo que denominamos como las "imaginaciones poéticas", una categoría construida como derivación del concepto de "imaginación museal" de Mario de Souza Chagas (2009), y que también podemos asociar 
a la máxima propuesta por el gran pensador americano Simón Rodríguez, cuando proponía el desafío dilemático de "o inventamos o erramos".

Esta proposición aún tal vez sin reconocer el pensamiento de Rodríguez se hace presente en muchos de estos museos, que deconstruyen también a partir de su discurso, que se deshacen de sus herencias coloniales a partir de crear lenguajes genuinos, con registros abiertos y amables, que dan lugar al diálogo, que aún siendo explícitos en su posicionamiento político de todos modos dejan lugar a la duda, abren espacio para otras posiciones, y a la vez aportan a una experiencia cognitiva y sensitiva singular, que interpelan desafíos en tiempo presente y que buscan conmover cada fibra del cuerpo y no solo el pensamiento. Y que a la vez invite a lo sujetos a imaginar otros mundos posibles, a provocar otras lecturas del espacio que habitan para poder reescribirlo (Freire).

Durante el encuentro de MINOM en Córdoba en 2017, Mario de Souza Chagas insistió con la necesidad desde la museología social de operar un desplazamiento desde los museos "necrófilos" hacia los museos "biófilos", lo que sintetizaba en una frase que repetía con insistencia en esos días y que también adoptamos como propia: "la museología que no sirve para la vida, no sirve para nada". Y aquí se hace viable otra articulación, la del desplazamiento propuesto desde comunicación/educación por Jorge Huergo en "La educación y la vida" (2015) donde propone correrse desde "la educación para la vida", para dejar entrar a "la vida en la educación", darle lugar al sentido vital de la experiencia formativa involucrando la integralidad de las dimensiones que componen nuestro estar en el mundo, como parte de una experiencia compartida, en el marco de colectivos sociales. Y en ese sentido la propuesta de articulación que propongo consiste en considerar a los museos como espacios sociales formativos inmersos dentro de una trama social que les da sentido y en la que una de sus misiones principales consiste en propiciar y defender el ejercicio de derechos, a través de la construcción colectiva de memorias situadas, para que aporten a mejorar ahora mismo la vida de esas personas involucradas.

Interpelaciones emancipadoras de los cuerpos y de las mentes. Que liberen y que no opriman. Que conmuevan, que produzcan interpelaciones subjetivas, que permitan mirar alrededor, a los y las que tenemos a lado, para conocernos y para reconocernos. Que den lugar al juego, a la risa, a la pregunta, pero también al enojo. Que provoquen recuerdos nostálgicos, emociones enraizadas en el pasado, pero también reflexiones críticas sobre lo que nos pasó y lo que nos pasa. Que construyan y reconstruyan memorias desde el aquí y ahora, que revitalicen las experiencias de los sujetos, que pongan en tensión las memorias hegemónicas, estereotipadas o estigmatizadas. Que desarticulen su carácter enfrascado e individual y las coloque en el marco de contextos sociales, que incluyan a las experiencias en marcos históricos mayores, que les otorguen otros nuevos sentidos. Que les permitan encontrar otro tipo de soluciones para sus problemáticas cotidianas y para sus problemas estructurales. Que les otorguen la posibilidad de encontrar otras causas y consecuencias, que puedan 
desnaturalizar eso que construyeron como el relato de las tragedias en sus destinos manifiestos y puedan encontrar otras respuestas, otras preguntas, otros rumbos posibles. Que puedan conocer y dar lugar al ejercicio pleno de sus derechos. Que desechen el odio como herramienta y puedan usar el amor como combustible. Que puedan convertir a las memorias en causas colectivas que le den forma a sus sueños y deseos, y que les aporten con urgencia a los requerimientos de la vida que fluye en tiempo presente. 


\section{BIBLIOGRAFÍA}

ALDEROQUI, Silvia. (2004) "Pasajes a la ciudad: el derecho a la herencia" en FRIGERIO, G., DIKER, G. (comps.) La transmisión en las sociedades, las instituciones y los sujetos. Un concepto de la educación en acción, Buenos Aires, Noveduc.

ALDEROQUI, Silvia, PEDERSOLI, Constanza (2011) La educación en los museos: de los objetos a los visitantes, Buenos Aires, Ed. Paidós.

ALEGRIA, Luis (2007) "La mesa de Santiago, una doble ruptura museológica" en IX Seminario sobre Patrimonio Cultural Museos en Obra, 21 y 22 de noviembre de 2007, Santiago de Chile, Dirección de Bibliotecas, Archivos y Museos.

ALONSO, Rodrigo (2012) "La feria de América y su legado" en Feria de América: vanguardia invisible, Mendoza, Fundación del Interior.

ARFUCH, Leonor (2002), El espacio biográfico. Dilemas de la subjetividad contemporánea, Buenos Aires, Fondo de Cultura Económica.

ARGUMEDO, Alcira (1996) Los silencios y las voces en América Latina. Notas sobre el pensamiento nacional y popular. Buenos Aires, Ed. del Pensamiento Nacional.

ARTIGUENAVE, Darío (2017) Construcción comunicacional de un espacio público educativo de memoria colectiva. Experiencia de intervención museográfica desde el campo comunicación/educación en el Museo Histórico Regional "Almirante Brown" de Bernal, Quilmes (julio 2014-diciembre 2015). Tesis de Maestría en Comunicación y Educación. La Plata, Facultad de Periodismo y Comunicación Social Universidad Nacional de La Plata. Disponible en http://hdl.handle.net/10915/60467

AZÓCAR, Miguel (2007) "A treinta y cinco años de la mesa redonda de Santiago" en en IX Seminario sobre Patrimonio Cultural Museos en Obra, 21 y 22 de noviembre de 2007, Santiago de Chile, Dirección de Bibliotecas, Archivos y Museos.

BADENES, Daniel., MANIAGO, Victoria (2012) "La república de Evita" en Revista Maíz, Núm. 1 noviembre 2012, La Plata, Facultad de Periodismo y Comunicación Social. Disponible en: http://www.revistamaiz.com.ar/2012/11/numero-n-1.html

BARTOLOMÉ, Olga (2014) El vínculo entre museo y escuela. Un territorio fértil para aprendizajes e identidades. Tesis de Maestría en Asesoriamiento y Gestión Pedagógica, Facultad de Filosofía y Humanidades. Córdoba, Universidad Nacional de Córdoba. 
BELINCHE, Marcelo, PANELLA, Claudio (comp.) (2010) Postales de la memoria: un relato fotográfico sobre la identidad de la región, La Plata, Editorial de la Universidad Nacional de La Plata. Disponible en: http://www.unlp.edu.ar/uploads/docs/postales de la memoria 2012.pdf

BENJAMIN, Walter (1989) Discursos Interrumpidos I, Buenos Aires, Taurus.

BICKEL, Ana (2006) "La sistematización participativa para descubrir los sentidos y aprender de nuestras experiencias" en Revista La Piragua N. 23 Sistematización de experiencias: caminos recorridos, nuevos horizontes. Mexico, CEAAL.

BOLIVAR BOTIA, Antonio (2002) ¿De nobis ipsis silemus?: Epistemología de la investigación biográfico-narrativa en educación. En Revista Electrónica de Investigación Educativa mayo, vol. 4, número 1, México, Universidad Autónoma de Baja California Ensenada. pp. 40-65.

BUENFIL BURGOS, Rosa Nidia (1993). Análisis de discurso y educación, DIE 26, México DF, Instituto Politécnico Nacional.

CAMARENA OCAMPO, Mario; MORALES LERSCH, Teresa; NECOCHEA GRACIA, Gerardo (1994) Reconstruyendo nuestro pasado: técnicas de historia oral. México DF, Consejo Nacional para la Cultura y las Artes. Disponible en http://bit.ly/historiaoral

CASALI, Carlos A. (2012) La Filosofía Biopolítica de Saúl Taborda. Universidad Nacional de Lanús, Ediciones de la UNLa.

CENDALES, Lola, TORRES, Alfonso (2006) "La sistematización como experiencia investigativa y formativa" en Revista La Piragua N. 23 Sistematización de experiencias: caminos recorridos, nuevos horizontes. Mexico, CEAAL.

CHAGAS, Mario de Souza (2006) Há uma gota de sangue em cada museu: a ótica museológica de Mário de Andrade, Chapecó SC, Argos Editora Universitária.

CHAGAS, Mario de Souza (2007a) "Museos, memorias y movimientos sociales" en IX Seminario sobre Patrimonio Cultural Museos en Obra, 21 y 22 de noviembre de 2007, Santiago de Chile, Dirección de Bibliotecas, Archivos y Museos.

CHAGAS, Mario de Souza (2007b) "La radiante aventura de los museos" en IX Seminario sobre Patrimonio Cultural Museos en Obra, 21 y 22 de noviembre de 2007, Santiago de Chile, Dirección de Bibliotecas, Archivos y Museos.

CHAGAS, Mario de Souz (2009) A imaginação museal: museu, memória e poder en Gustavo Barroso, Gilberto Freyre e Darcy Ribeiro. Brasilia, IBRAM Instituto Brasileiro de Museus, Ministerio de Cultura.

CLARKE, Guillermo (2012) "La República de los Niños. .Una creación que venció al tiempo" en PANELLA, C. (comp) La República de los Niños. Un aporte bonaerense a la Nueva Argentina, La Plata, Instituto Cultural de la Provincia de Buenos Aires.

DA PORTA, Eva (comp.), (2011) "Comunicación y educación. Debates actuales desde un campo estratégico", Córdoba, edición propia.

DANTAS, Marcello (2011). Conferencia La tecnología al servicio del arte en el montaje de exposiciones y museos en Jornadas de debate "Nuevas estrategias digitales en el diseño de exposiciones - Museos y Cultura Participativa". Buenos Aires, Fundación TyPA (Teoría y Práctica de las Artes). 
DE SAGASTIZABAL, Leandro, GIULIANI, Graciela (2013) "El trabajo editorial de Arturo Peña Lillo en la Colección La Siringa. El proyecto y sus lectores" publicado en Actas de las $3^{a}$ Jornadas de Intercambios y Reflexiones acerca de la Investigación en Bibliotecología, La Plata, 28-29 de noviembre de 2013. La Plata, Facultad de Humanidades y Ciencias de la Educación de la Universidad Nacional de La Plata.

DE SOUSA SANTOS, Boaventura (2010). "Para descolonizar Occidente Más allá del pensamiento abismal", Buenos Aires, Consejo Latinoamericano de Ciencias Sociales CLACSO Prometeo Libros.

DE VARINE, Hugues (1979) Los museos en el mundo. Barcelona, Salvat Editores.

DE VARINE, Hugues (2012) "Alrededor de la mesa redonda de Santiago" en NASCIMENTO JUNIOR, J., TRAMPE, A., SANTOS, P. (coord.) Mesa Redonda sobre la importancia y el desarrollo de los museos en el mundo contemporáneo: Mesa Redonda de Santiago de Chile 1972, Vol. 1, Brasilia, Instituto Brasileiro de Musesus, IBRAM, Programa Ibermuseos.

DELORY-MOMBERGER, Christine. (2009), Biografía y educación: figuras del individuo proyecto. 1ra ed. Buenos Aires, Editorial de la Facultad de Filosofía y Letras Universidad de Buenos Aires, Consejo Latinoamericano de Ciencias Sociales.

DÉRCOLI, Julián (2017) La Universidad Nacional y Popular de Buenos Aires, 1973: del conocimiento alienado al conocimiento para la liberación. Buenos Aires, Instituto de Estudios y Capacitación - Federación Nacional de Docentes Universitarios IEC - CONADU. Disponible en https://iec.conadu.org.ar/files/areas-de-trabajo/1519081158 2017-la-universidad-nacional-ypopular-de-buenos-aires.pdf

DEVOTO, Fernando, PAGANO, Nora (2009) Historia de la historiografía argentina, Buenos Aires, Sudamericana.

DOSSE, François . (2007), El arte de la biografía: entre la historia y la ficción, México D.F., Universidad Iberoamericana.

EDELSTEIN, Oscar (2011) "El pasado: entre la historia y los museos" en TABAKMAN, S. Objetos guardados, objetos mostrados. La visita escolar al museo, Buenos Aires, Biblos.

FACULTAD DE PERIODISMO Y COMUNICACIÓN SOCIAL (1997). "Documento curricular Plan 1997" La Plata, Ediciones de Periodismo y Comunicación Social.

FACULTAD DE PERIODISMO Y COMUNICACIÓN SOCIAL (2014). "Documento curricular Plan 2014", La Plata, Ediciones de Periodismo y Comunicación Social.

FERNÁNDEZ, M.B. (1997) "De la arquitectura escolar a la cartografía cultural: el significado del espacio educativo" en HUERGO, J. Comunicación/educación. Ámbitos, prácticas y perspectivas, La Plata, Ediciones de Periodismo y Comunicación Social, FPyCS- UNLP.

FERNÁNDEZ, María Belén, ARTIGUENAVE, Darío (2014) “Experiencias de inserción profesional de profesores en comunicación social en las instituciones educativas. Perfiles emergentes de intervención desde el campo comunicación/educación", en Giovine, R., Baldoni, M., Suasnábar, J. (2014) Revista Espacios en Blanco. I Encuentro Internacional de Educación: espacios de investigación y divulgación (1a ed.). Tandil, Universidad Nacional del Centro de la Provincia de Buenos Aires.

FERNÁNDEZ, María Belén, FELLI, María Susana (2012) "Narratividad como perspectiva metodológica para el análisis de experiencias profesionales del profesor en comunicación", en Actas de XIV Congreso REDCOMUniversidad Nacional de Quilmes, Junio 2012. 
FERNÁNDEZ, María Belén, SANGUINO, Silvia, ARTIGUENAVE, Darío (2013) "Debates, interrogantes y proyecciones del campo comunicación/educación" en En Revista Tram(p)as de la comunicación y la cultura. N 75, mayo-junio de 2013. Ediciones de Periodismo y Comunicación Social, La Plata. Pp 1930. Disponible en http://www.revistatrampas.com.ar/2013/12/debates-interrogantes-yproyecciones.html

FERNÁNDEZ, María Belén (2014) "Jorge Huergo y la institucionalidad del campo comunicación/educación" en Revista Question, Vol 1, No 42 (abril - junio de 2014). Disponible en http://perio.unlp.edu.ar/ojs/index.php/question/article/view/2178/1931

FERNÁNDEZ, Silvia (2012) "Políticas y diseño en la Feria de América" en Feria de América: vanguardia invisible, Mendoza, Fundación del Interior.

FORD, Anibal (1994a) "Culturas populares y (medio de) comunicación". En Navegaciones. Comunicación, cultura y crisis. Buenos Aires, Amorrortu.

FORD, Anibal (1994b) "Navegaciones. Culturas orales. Culturas electrónicas. Culturas narrativas" en Revista Diálogos de la Comunicación No 38 "Culturas y participación a Propósito de la Modernidad". Colombia, FELAFACS Federación Latinoamericana de Facultades de Comunicación Social. Disponible en http://dialogosfelafacs.net/wp-content/uploads/2015/38/38-revista-dialogos-culturas-oralescultura-electronicas.pdf

FREIRE, Paulo (1984) "Extensión o comunicación" 13a edición en español, Montevideo, SigloXXI.

FREIRE, Paulo (1991), La importancia del acto de leer y el proceso de liberación, Mexico, SigloXXI.

FREIRE, Paulo (1997) La educación como práctica de la libertad 45a edición, México, SigloXXI.

FREIRE, Paulo (2004) Pedagogía de la autonomía. Saberes necesarios para la práctica educativa. Sao Paulo, Paz e Terra.

FREIRE, Paulo (2005) Pedagogía del oprimido, 55a edición, México, SigloXXI.

FUENTES NAVARRO, Roberto (1998) Emergencia de un campo académico, México, ITESO Universidad de Guadalajara.

GALASSO, Norberto (1995) La larga lucha de los argentinos: y como la cuentan las diversas corrientes historiográficas, Buenos Aires, Colihue.

GALINDO CÁCERES, Jesús (1999) “Del objeto percibido al objeto construido. El saber sobre la práctica: sistemas y mundos posibles", en Estudios sobre las Culturas Contemporáneas, Época II, Vol. V. Núm. 9, Colima, Universidad de Colima México.

GARCÍA LINERA, Álbaro (2016) "Restauración conservadora y nuevas resistencias en Latinoamérica 27.05.16" conferencia dictada en Buenos Aires disponible en https://youtu.be/V-L3CSIVZQK

GHISO, Alfredo (1999) "De la práctica singular al diálogo con lo plural. Aproximaciones a otros tránsitos y sentidos de la sistematización en épocas de la globalización" en La Piragua Revista Latinoamericana de Educación y Política N. ${ }^{\circ} 16$, Mexico, CEAAL.

GHISO, Alfredo (2006) "Prácticas generadoras de saber. Reflexiones freireanas en torno a las claves de la sistematización" en La Piragua Revista Latinoamericana de Educación y Política N. ${ }^{\circ} 16$ Sistematización de prácticas en América Latina, CEAAL, México.

GONZÁLEZ MEZA, Yadur Nahel (2016) Diversidad cultural en los Museos Comunitarios de México. Tesis 
Programa de Doctorat en Gestió de la Cultura i el Patrimoni. Facultat de Geografia i Història. Universitat de Barcelona. Disponible en http://hdl.handle.net/10803/398655

GRAMSCI, Antonio (1977) Cultura y Literatura. Barcelona, Península.

GRANADOS FONT, Rosa (2005) “¿Qué se entiende por sistematizar? En Enfermería en Costa Rica, mayo 2005, vol 26.

GROSSBERG, Lawrence (2012) Estudios culturales en tiempo futuro: Cómo es el trabajo intelectual que requiere el mundo de hoy. Buenos Aires, Siglo XXI Editores.

GUBER, Rosana (2012) La etnografía. Método, campo y reflexividad. Buenos Aires, Siglo XXI Editores.

GUSDORF, Georges (1991), "Condiciones y límites de la autobiografía", en Revista Anthropos No 29, Madrid, p. 9-18.

HALL, Stuart (1984) "Notas sobre la desconstrucción de «lo popular»" en SAMUEL, R. (ed.). Historia popular y teoría socialista. Barcelona, Crítica. Disponible en https://es.scribd.com/document/258378355/HallStuart-Notas-Sobre-La-Deconstruccion-de-Lo-Popular

HALL, Stuart (1994) "Estudios Culturales: Dos Paradigmas" en Revista Causas y azares, N. 1, "Los lenguajes de a comunicación y de la cultura en (la) crisis". Buenos Aires. Consultado en Biblioteca Virtual Universal disponible en http://www.biblioteca.org.ar/libros/131827.pdf

HASSOUN, Jacques (1996) Los contrabandistas de la memoria, Buenos Aires, Ediciones de La Flor.

HLEAP BORRERO, José (1999), "Sistematizando experiencias educativas", en La Piragua Revista Latinoamericana de Educación y Política N. 16 Sistematización de prácticas en América Latina, México, CEAAL.

HOOPER-GREENHILL, Eilean (2007) "Education, Postmodernity and the Museum" en KNELL, S. J. et. al. How Museums Change and are Changed. Londres, Routledge.

HUANACUNI MAMANI, Fernando (2010) "Buen Vivir / Vivir Bien Filosofía, políticas, estrategias y experiencias regionales andinas" Lima Perú, Coordinadora Andina de Organizaciones Indígenas - CAOI.

HUERGO, Jorge (1992) "Buscando la identidad desde el 'mero estar'", en VV. AA., En torno a la Identidad Latinoamericana, FELAFACS, VII Encuentro Latinoamericano de Facultades de Comunicación, Acapulco, México.

HUERGO, Jorge (editor) (1997) Comunicación/educación. Ámbitos, prácticas y perspectivas, La Plata, Ediciones de Periodismo y Comunicación Social, FPyCS- UNLP.

HUERGO, Jorge, FERNÁNDEZ, María Belén (2000) "Cultura escolar, Cultura mediática / Intersecciones", Santa Fé de Bogotá, Edición de la Universidad Pedagógica Nacional.

HUERGO, Jorge (2003) Lo que articula lo educativo en las prácticas socioculturales. En Revista Nodos de comunicación/educación $N^{\circ}$ 2. Facultad de Periodismo y Comunicación Social UNLP, La Plata. Disponible en www.revistanodos.com.ar

HUERGO, Jorge (2004) Desafíos a la extensión desde la perspectiva cultural. En revista Dialoguemos Año 8 Nº 14, junio de 2004, Buenos Aires. pp. 9-13.

HUERGO, Jorge (2005). Hacia una genealogía de Comunicación/Educación. Rastreo de algunos anclajes políticoculturales, La Plata, Ediciones de Periodismo y Comunicación Social, FPyCS, UNLP.

HUERGO, Jorge, MORAWICKI, Kevin (2008) El sentido de la experiencia social, La Plata, DES-DGCyE. 
HUERGO, Jorge (2013). "Mapas y viajes por el campo comunicación/educación". En Revista Tram(p)as de la comunicación y la cultura. № 75, mayo-junio de 2013. Ediciones de Periodismo y Comunicación Social, La Plata. Pp 19-30. Disponible en http://www.revistatrampas.com.ar/2013/12/mapas-y-viajes-por-elcampo-de.html

HUERGO, Jorge (2015), La educación y la vida, La Plata, Ediciones de Periodismo y Comunicación Social (EPC) ebook disponible en http://perio.unlp.edu.ar/sites/default/files/la educacion y la vida ebook.pdf

JARA HOLLIDAY, Oscar (2006) La sistematización de experiencias y las corrientes innovadoras del pensamiento latinoamericano - una aproximación histórica. Publicado en La Piragua. Revista Latinoamericana de Educación y Política N. 23: Sistematización de experiencias: caminos recorridos, nuevos horizontes. Consejo de Educación Popular de América Latina y el Caribe (CEAAL) México.

JARA HOLLIDAY, Oscar (2011) "La evaluación y la sistematización" en Revista internacional sobre Investigación en educación global y para el desarrollo. Número Cero. Oct 2011. pags 110-112.

JARA HOLLIDAY, Oscar (2012) "Sistematización de experiencias: una propuesta enraizada en la historia latinoamericana" en La sistematización de experiencias, práctica y teoría para otros mundos posibles, San José, CEP Alforja - CEAAL - Interman OXMAN.

JAURETCHE, Arturo (2006) Política nacional y revisionismo histórico. Obras Completas, vol. 7, Buenos Aires, Corregidor.

JERIA, Verónica (2016) "Patagonia 1973: historias del Museo Etnográfico en la Universidad Nacional y Popular de Buenos Aires" en Revista Fragmentos del pasado. Revista de Arqueología. N. ${ }^{\circ}$ diciembre de 2016. Buenos Aires, AZARA Fundación de Historia Natural - Universidad Maimonides. pp 9-28. Disponible en http://www.fundacionazara.org.ar/img/revista-fragmentos-del-pasado/002/fragmentos-2016-00209-28.pdf

JORAJURIA, Roxana (2012) "Cuando industria, vanguardia y optimismo formaron parte de un programa nacional" en Feria de América: vanguardia invisible, Mendoza, Fundación del Interior.

KUSCH, Rodolfo (1976) Geocultura del Hombre Americano, Buenos Aires, F García Cambeiro.

KUSCH, Rodolfo (1978). Esbozo de una antropología filosófica americana, Buenos Aires, Castañeda.

KUSCH, Rodolfo (2007a) Obras completas - Tomo I, Rosario, Editorial Fundación Ross.

KUSCH, Rodolfo (2007b) Obras completas - Tomo II, Rosario, Editorial Fundación Ross.

KUSCH, Rodolfo (2007c) Obras completas - Tomo III, Rosario, Editorial Fundación Ross.

KUSCH, Rodolfo (2007d) Obras completas - Tomo IV, Rosario, Editorial Fundación Ross.

LARROSA, Jorge (2006) "Algunos apuntes sobre la experiencia y sus lenguajes", en Estudios Filosóficos Vol. 55, N. ${ }^{\circ} 160,2006$, pags 467-480.

LARROSA, Jorge y SKLIAR, Carlos (comp.) (2009) Experiencia y alteridad en educación, Rosario, Homo sapiens/Flacso.

LEIS ROMERO, Raúl (2006) "Sistematización de experiencias: el encuentro de la palabra y el acto" (editorial) en Revista La Piragua N. 23 Sistematización de experiencias: caminos recorridos, nuevos horizontes, México, CEAAL.

LEJEUNE, Philippe (1991), "El pacto autobiográfico", en Revista Anthropos No 29, Madrid, Antrophos Ediciones. p. 47-62. 
LEJEUNE, Philippe (1994), "La autobiografía de los que no escriben", en El pacto autobiográfico y otros estudios, Madrid, Megazul, p. 313-414.

LEY 20,654 Ley Orgánica de las Universidades Nacionales, marzo de 1974. Buenos Aires, Centro Nacional de Documentación e Información Educativa. Disponible en http://www.bnm.me.gov.ar/giga1/documentos/EL002644.pdf

LONGONI, René (2012) "Eva y la infancia. Ensayos arquitectónicos en la formación de futuras vanguardias durante los primeros gobiernos peronistas" en PANELLA, C. (comp) La República de los Niños. Un aporte bonaerense a la Nueva Argentina, La Plata, Instituto Cultural de la Provincia de Buenos Aires.

LORENTE, Jesus Pedro (2003) "La nueva museología ha muerto, jviva la museología crítica!" en ALMAZÁN TOMÁS, V., LORENTE, J (coord.) Museología crítica y arte contemporáneo, Zaragoza, Prensas Universitarias de Zaragoza.

LORENTE, Jesús Pedro (2006) "Nuevas tendencias en teoría museológica: a vueltas con la museología crítica" en Revista Museos.es N. 2, Madrid, Ministerio de Educación, Cultura y Deporte, disponible en http://es.calameo.com/read/0000753354330ecff53bf

MARRADI, Alberto, ARCHENTI, Nélida, PIOVANI, Juan Ignacio (2007) Metodología de las ciencias sociales. Buenos Aires, Emecé Editores.

MARTín BARBERO, Jesús (1991) De los medios a las mediaciones. Comunicación, cultura y hegemonía (2da edición) México, Ediciones G Gili.

MARTín BARBERO, Jesús (2004). Oficio de cartógrafo. Travesías latinoamericanas de la comunicación en la cultura, Buenos Aires, Fondo de Cultura Económica.

MARTín BARBERO, Jesús (2008). "De la experiencia al relato. Cartografías culturales y comunicativas en América Latina". En Revista Antrophos N²19. Barcelona, Antrophos Editorial.

MARTíNEZ, Darío (2015) Saberes, experiencias y subjetividades de la educación de jóvenes y adultos en la ciudad de La Plata. Un abordaje desde la perspectiva de comunicación/educación. Tesis de doctorado. La Plata, Facultad de Periodismo y Comunicación Social Universidad Nacional de La Plata. Disponible en http://hdl.handle.net/10915/49538

MAZZA, Carlos, BRUNO, Perla (2012) "Políticas de desarrollo territorial en áreas turísticas y del conurbano bonaerense durante el peronismo en la gobernación Mercante (Buenos Aires, Argentina)", en Historia Actual Online, Núm. 29, otoño 2012. pags 55-66.

MATA, María Cristina (1985), Nociones para pensar la comunicación y la cultura masiva, Buenos Aires, Centro de Comunicación educativa La Crujía.

MC LAREN, Peter (1995) La escuela como performance ritual. Hacia una economía política de los símbolos y gestos educativos, México, Siglo XXI.

MC LAREN, Peter (1998). Pedagogía, identidad y poder, Santa Fe, Homo Sapiens.

MÉNDEZ LUGO, Raúl (2001) Teoría y Método de la Nueva Museología en México, Tepic, UAN.

MÉNDEZ LUGO, Raúl (2008) Mapa Situacional de los Museos Comunitarios en México. México, UNESCO. Disponible en https://www.academia.edu/4580623/MAPA SITUACIONAL DE LOS MUSEOS COMUNITARIOS EN $\mathrm{M} \% \mathrm{C} 3 \% 89 \mathrm{XICO}$. UNESCO-M\%C3\%89XICO 
MORALES, Teresa; CAMARENA, Cuauhtémoc (2009) Manual para la creación y desarrollo de museos comunitarios. La Paz, Bolivia, Fundación Interamericana de Cultura y Desarrollo (ICDF). Disponible en http://bit.ly/manualmca

MOUFFE, Chantal (2007). En torno a lo político, Buenos Aires, Fondo de Cultura Económica.

NASCIMENTO JUNIOR, José (2012) "Memoria para hablar hoy" en NASCIMENTO JUNIOR, J., TRAMPE, A., SANTOS, P. (coord.) Mesa Redonda sobre la importancia y el desarrollo de los museos en el mundo contemporáneo: Mesa Redonda de Santiago de Chile 1972, Vol. 1, Brasilia, Instituto Brasileiro de Musesus, IBRAM, Programa Ibermuseos.

NASCIMENTO JUNIOR, José, TRAMPE, Alan, SANTOS, Paula (coord.) (2012a) Mesa Redonda sobre la importancia y el desarrollo de los museos en el mundo contemporáneo: Mesa Redonda de Santiago de Chile 1972, Vol. 1, Brasilia, Instituto Brasileiro de Musesus, IBRAM, Programa Ibermuseos. Disponible en http://www.ibermuseus.org/wp-content/uploads/2014/09/Publicacion Mesa Redonda VOL I.pdf

NASCIMENTO JUNIOR, José, TRAMPE, Alan, SANTOS, Paula (coord.) (2012b) Mesa Redonda sobre la importancia y el desarrollo de los museos en el mundo contemporáneo: Revista Museum 1973, Vol. 2, Brasilia, Instituto Brasileiro de Musesus, IBRAM, Programa Ibermuseos. Disponible en http://www.ibermuseus.org/wp-content/uploads/2014/09/Publicacion Mesa Redonda VOL II.pdf

PANELLA, Claudio (comp) (2012) La República de los Niños. Un aporte bonaerense a la Nueva Argentina, La Plata, Instituto Cultural de la Provincia de Buenos Aires.

PEREZ GOLLÁN, José Antonio; DUJOVNE, Marta (1995) "El museo etnográfico de la Facultad de Filosofía y Letras: Balance de una gestión" publicado en Revista Runa XXII, Vol. 1, núm, 1. Buenos Aires, Instituto de Ciencias Antropológicas, Facultad de Filosfía y Letras, Universidad de Buenos Aires. Disponible http://revistascientificas.filo.uba.ar/index.php/runa/article/view/1320/1270

PIÑA, Carlos (1999) "Tiempo y Memoria. Sobre los artificios del relato autobiográfico". En Proposiciones número 29, marzo de 1999, Santiago de Chile, Ediciones SUR.

PODGORNY, Irina (2009) "Recuerden que están muertos. Cuerpos embalsamados y museos ambulantes en la Buenos Aires del fin de Siglo" en Viajes, Buenos Aires, Teseo. Disponible en http://naturalis.fcnym.un|p.edu.ar/id/20111219009934

POLLAK, Michael (2006) Memoria, olvido, silencio. La producción social de identidades frente a situaciones límite, La Plata, Ediciones Al Margen.

PRIETO CASTILLO, Daniel (1987) Utopía y Comunicación en Simón Rodríguez, Quito, Editorial Belén CIESPAL. PRIETTO CASTILLO, Daniel (1999) La comunicación en la educación, Buenos Aires, Ediciones Ciccus-La Crujía. PUIGGRÓS, Rodolfo (1974). La Universidad del Pueblo. Buenos Aires, Crisis.

QUIROGA, Wustavo (2012) Feria de América: vanguardia invisible, Mendoza, Fundación del Interior.

RAMíREZ, Natalia (2016) "Museos comunitarios mexicanos: entre espejismos teóricos y autonomías inexploradas" en Archivo Churubusco, Año 1, número 1. México, Escuela Nacional de Conservación, Restauración y Museografía ENCRyM-INAH. disponible en https://archivochurubusco.encrym.edu.mx/n1letras3.html

RESTREPO, Eduardo (2012) Antropología y Estudios Culturales. Disputas y confluencias desde la perisferia. Buenos Aires, Siglo XXI Editores. 
RESTREPO, Eduardo, ROJAS, Axel (2010). Inflexión decolonial: fuentes, conceptos y cuestionamientos. Popayán, Instituto de Estudios Sociales y Culturales Pensar, Editorial Universidad de Cauca.

RESTREPO, Eduardo WALSH, Catherine, VICH, Victor (2010) "Práctica crítica y vocación política: pertinencia de Stuart Hall en los estudios culturales latinoamericanos" en HALL, S. Sin Garantías. Trayectorias y problemáticas en estudios culturales, Popayán, Envión editores.

RICOEUR, Paul (1985), Tiempo y narración, México, Siglo XXI.

RICOEUR, Paul (2005). Caminos de reconocimiento, Buenos Aires, Fondo de Cultura Económica.

RICOEUR, Paul (2006), Sí mismo como otro, Buenos Aires, Siglo XXI.

RINESI, Eduardo (2016) "Una defensa del republicalismo popular" en Revista Maíz 6, La Plata, Facultad de Periodismo y Comunicación Social UNLP, disponible en http://www.revistamaiz.com.ar/2016/06/unadefensa-del-republicanismo-popular.html

RIVERA CUSICANQUI, Silvia (2010) Ch'ixinakax utxiwa: Una reflexión sobre prácticas y discursos descolonizadores, Buenos Aires, Tinta Limón. disponible en http://tintalimon.com.ar/libro/CHIXINAKAXUTXIWA

RIVIĖRE Georges Henri (1985) "Definición evolutiva del ecomuseo" en Revista Museum N.º 148 (Vol XXXVII, nº 4, 1985) Imágenes del ecomuseo, París, UNESCO.

RODRÍGUEZ, Simón (2004). O inventamos o erramos. Biblioteca Básica de Autores Venezolanos, Caracas, Monte Avila Editores Latinoamericana.

SANTACANA MESTRE, Joan, HERNÁNDEZ CARDONA, Francesc (2006) Museología crítica, Gijón, Trea.

SANTOS, Paula Assunçao (2012) "La Mesa de Santiago para pensar el futuro" en NASCIMENTO JUNIOR, J., TRAMPE, A., SANTOS, P. (coord.) Mesa Redonda sobre la importancia y el desarrollo de los museos en el mundo contemporáneo: Mesa Redonda de Santiago de Chile 1972, Vol. 1, Brasilia, Instituto Brasileiro de Musesus, IBRAM, Programa Ibermuseos.

SERRAT ANTOLI, Nuria (2005) "Acciones didácticas y de difusión en museos y centros de interpretación" en SANTACANA MESTRE y SERRAT ANTOLI (coords.) Museografía didáctica, Barcelona, Ariel.

SOLANO, Fabiana (2016) "La fotografía de Tecnópolis, antes y después" nota publicada en Diario Registrado del 6 de octubre de 2016. Disponible en http://www.diarioregistrado.com/opinion/la-fotografia-detecnopolis--antes-y-despues a57f65d910c297bac2b680b97

SOTO, Moana Campos (2015). "Dos gabinetes de curiosidade aos museus comunitários: a construção de uma conceção museal à serviço da transformação social" en Cadernos de Sociomuseologia, n 4, abr 2015. Lisboa, Área da Museologia do Centro de Estudos Interdisciplinares em Educação e Desenvolvimento (CeiED) do Instituto de Educação da Universidade Lusófona de Humanidades e Tecnologias. Disponible en: http://revistas.ulusofona.pt/index.php/cadernosociomuseologia/article/view/4987

TABAKMAN, Silvia (coord) (2011) Objetos guardados, objetos mostrados. La visita escolar al museo. Buenos Aires, Ed. Biblos.

TABORDA, Saúl (1934), La crisis espiritual y el ideario argentino, Santa Fe, Instituto Social de la Universidad Nacional del Litoral. Disponible en http://www.fundacionosde.com.ar/pdf/pensadores/ideario argentino.pdf

TABORDA, Saúl (1936), El fenómeno político, Córdoba, Instituto de Filosofía de la Universidad Nacional de 


\section{Córdoba.}

TABORDA, Saúl (1936) “El fenómeno político" en AAVV Homenaje a Bergson, Córdoba, Instituto de Filosofía. TABORDA, Saúl (1988), La argentinidad preexistente, 1935-1941, Buenos Aires, Docencia-CINAE.

TABORDA, Saúl (2011) Investigaciones Pedagógicas reedición de la publicación original de 1951, 1ra edición, La Plata, Editorial Unipe. Disponible en

http://unipe.edu.ar/wp-content/uploads/2012/07/Investigaciones-Pedagogicas-de-Saul-Taborda.pdf

TAIANA, Jorge (1974) Nota de presentación del proyecto de Ley 20.654 dirigida al Honorable Congreso de la Nación. 14 de febrero de 1974. Buenos Aires, Centro Nacional de Documentación e Información Educativa. Disponible en http://www.bnm.me.gov.ar/giga1/documentos/EL002644.pdf

TAYLOR, Steve, BOGDAN, Robert (1994) Introducción a los métodos cualitativos de investigación, Barcelona, Paidós.

THOMPSON, Edward Palmer (1981) Miseria de la teoría, Barcelona, Editorial Crítica.

THOMPSON, Edward Palmer (1995) Costumbre en Común. Barcelona, Crítica.

THOMPSON, Edward Palmer (2002) "La formación de la clase obrera en Inglaterra”, en Obra Esencial. Barcelona, Crítica.

TORRES CARRILLO, Alfonso (2008) “La sistematización de experiencias: aporte de la educación popular para una nueva universidad" en Revista Diálogo de Saberes, Año 1 N. 2, Caracas, Universidad Bolivariana de Venezuela, Dirección de Investigación y Estudios Avanzados.

TRAMPE, Alan (2012) "Recuperando un tiempo perdido" en NASCIMENTO JUNIOR, J., TRAMPE, A., SANTOS, P. (coord.) Mesa Redonda sobre la importancia y el desarrollo de los museos en el mundo contemporáneo: Mesa Redonda de Santiago de Chile 1972, Vol. 1, Brasilia, Instituto Brasileiro de Musesus, IBRAM, Programa Ibermuseos.

VALDERRAMA, Carlos (editor) (2000), Comunicación-Educación. Coordenadas, abordajes y travesías, Bogotá, DIUC-Siglo del Hombre.

VVAA (1984) Declaración de QUÉBEC. Principios básicos de una Nueva Museología. Québec, Consejo Internacional de Museos ICOM. Disponible en

http://museosdesantafe.com.ar/wp-content/uploads/2014/08/DECLARACION-DE-QUEBEC.pdf

VVAA (1984) Declaratoria de Oaxtepec. Ecomuseos Territorio - Patrimonio - Comunidad. Oaxtepec, México. Disponible en http://www.ibermuseus.org/wp-content/uploads/2014/07/declaracao-de-oaxtepec.pdf VVAA (2006) Carta cultural iberoamericana, XVI Cumbre Iberoamericana de Jefes de Estado y de Gobierno, Montevideo, Uruguay, 4 y 5 de noviembre de 2006, Montevideo, Organización de Estados Iberoamericanos. Disponible en http://www.ibermuseus.org/wp-content/uploads/2014/07/cartacultural-ibero-americana.pdf

VVAA (2007) Declaración de la Ciudad de Salvador, I Encuentro Iberoamericano de Museos, Salvador de Bahía, Brasil, 26, 27 y 28 de junio de 2007, Salvador, Ibermuseos. Disponible en http://www.ibermuseus.org/ wp-content/uploads/2014/09/Declaracion-de-Salvador POR.ESP.pdf

VVAA (2007b) X Seminario sobre Patrimonio Cultural Museos en Obra, 21 y 22 de noviembre de 2007, Santiago de Chile, Dirección de Bibliotecas, Archivos y Museos. Disponible en http://www.dibam.cl/614/articles$\underline{5410 \text { archivo 01.pdf }}$ 
VVAA (2012) Declaración de Montevideo, VI Encuentro Iberoamericano de Museos: Museo ¿Territorio de Conflictos? Miradas contemporáneas a 40 años de la Mesa Redonda de Santiago, 22, 23 y 24 de octubre de 2012, Montevideo, Ibermuseos. Disponible en http://www.ibermuseus.org/wpcontent/uploads/2014/11/VI.EIM Declaracion Montevideo-2012-ESP.pdf

VVAA (2013) "Declaración de Caracas" en Revista Museos.ve (Revista Digital de los Museos Venezolanos), N. 22, Año 2, mayo de 2013, Caracas, Sistema Nacional de Museos. pp. 23-27. Disponible en https://issuu.com/museos.ve/docs/revista museosve-22

VVAA (2017) "Declaración de Córdoba" en el marco de la XXVIII Conferencia Internacional de MINON. Córdoba, Argentina. Disponible en http://www.minom-icom.net/files/minom 2017 - declaracion de cordoba - esp-port-fr-ing.pdf

WALSH, Catherine (editora) (2013). Pedagogías decoloniales. Prácticas insurgentes de resisitir, (re) existir y(re) vivir. Tomo I.Serie Pensamiento Decolonial. Quito, AbyaYala.

WILLIAMS, Raymond (2001) Marxismo y Literatura, Buenos Aires, Nueva Visión. 
